\title{
Meeting the Mental Health Needs of Student-Athletes: A Descriptive Study of Practitioners and their Perspectives
}

\author{
William C. Way III \\ West Virginia University, wcway@mix.wvu.edu
}

Follow this and additional works at: https://researchrepository.wvu.edu/etd

Part of the Kinesiology Commons

\section{Recommended Citation}

Way, William C. III, "Meeting the Mental Health Needs of Student-Athletes: A Descriptive Study of Practitioners and their Perspectives" (2021). Graduate Theses, Dissertations, and Problem Reports. 8018. https://researchrepository.wvu.edu/etd/8018

This Dissertation is protected by copyright and/or related rights. It has been brought to you by the The Research Repository @ WVU with permission from the rights-holder(s). You are free to use this Dissertation in any way that is permitted by the copyright and related rights legislation that applies to your use. For other uses you must obtain permission from the rights-holder(s) directly, unless additional rights are indicated by a Creative Commons license in the record and/ or on the work itself. This Dissertation has been accepted for inclusion in WVU Graduate Theses, Dissertations, and Problem Reports collection by an authorized administrator of The Research Repository @ WVU.

For more information, please contact researchrepository@mail.wvu.edu. 
Meeting the Mental Health Needs of Student-Athletes: A Descriptive Study of Practitioners and their Perspectives

$$
\text { William C. Way }
$$

Dissertation submitted

to the College of Physical Activity and Sport Sciences

at West Virginia University

in partial fulfillment of the requirements for the degree of

Doctorate of Philosophy in

Sport, Exercise, and Performance Psychology

Jack C. Watson II, Ph.D., Chair

Samuel Zizzi, Ed.D.

Monica Leppma, Ph.D.

Ashley Coker-Cranney, Ph.D.

Department of Sport Sciences

Morgantown, WV

2021

Keywords: Mental health, Practitioners, Student-athletes, Counseling, Psychological services

Copyright 2021 William Way 


\begin{abstract}
Meeting the Mental Health Needs of Student-Athletes: A Descriptive Study of Practitioners and their Perspectives

William C. Way
\end{abstract}

Efforts are being made to promote mental health awareness and destigmatize help-seeking behavior among student-athletes (e.g., Kern et al., 2017). The availability and visibility of practitioners with specialized training in sport psychology can facilitate these efforts (e.g., Flowers, 2007; Carr, 2007; McDuff et al., 2005). However, some student-athletes have observed that the clinical sport psychology (CSP) practitioners who are available to them are being stretched thin (Way et al., 2020). In the context of collegiate mental health more broadly, many campus counseling centers are struggling to meet the demand for clinical services (e.g., Kafka, 2019). Research on the experiences and perspectives of CSP practitioners in the collegiate setting has been scarce (cf. Schlimmer \& Chin, 2018), and has neglected the vantage point of practitioners who support student-athletes at institutions that do not have access to sport psychology services (cf. Petrie et al., 1995). As such, the first objective of this study was to expand upon the work of Hayden and colleagues (2013) to identify the population of clinical and applied sport psychology practitioners from all NCAA member institution websites (Power 5 conferences, all other DI, DII, and DIII). The second objective was to survey the experiences of these practitioners and counseling/psychological services staff at institutions that did not list CSP personnel. As a whole, practitioners reported that some generalized services (e.g., personal counseling available to all students, crisis intervention) were more in-demand among studentathletes than specialized sport-specific services. Sport psychology services were more common at P5 and other DI institutions, but also more likely to be stretched or exceeded by demand relative to similar services at DII and DIII institutions. At the risk of reducing service availability to a numerical tally of haves and have-nots, quantitative and qualitative data shed light on the ways in which practitioners experienced and were impacted by the structure, function, availability of, and institutional support for psychological services. In their open-ended responses, the most prevalent need that practitioners expressed was for more staffing (more staff, more diverse staff, and more multidisciplinary staff). Results invite athletics and institutional administration to consider the loads that are being shouldered by mental health and sport psychology staff at their institutions; the voice and support that is granted to these practitioners; and the value of robust mental health services/outreach for recruitment, retention, and risk management. 


\section{Acknowledgments}

I am filled with emotion as I look back on my time at WVU through to the completion of this project. What a formative chapter in my life this has been! This document already has so many pages that I feel no pressure to be stingy here with my gratitude.

First and foremost, I would like to thank my committee members. Your mentorship and guidance took root long before this project was even an idea, and will extend far beyond its completion.

Dr. Watson, from the moment I arrived on campus as an anxious candidate during interview weekend, I felt that I could be my authentic self with you. During our interview, you asked me about my strengths and weaknesses. Mustering the confidence to stand in my strengths was hard enough, until you reminded me about the penalty flag that would be discharged in the event of cliché "weaknesses." Perhaps caught off guard by the humor of the situation I blurted out (maybe in more detail than you were looking for!) that I can over-think things and get in my own way. You can now be the judge of the veracity of that response (: Through my time at WVU, your encouragement, support, and affirmation have helped me to stand more firmly in my strengths and to step back for a moment when my mind gets tangled. From essential readings and teaching observation, to research meetings, classes, career lunch, etc., you have taught me so much. In addition to disciplinary knowledge and professional practice wisdom that you have passed on, you have taught me (perhaps without meaning to) about hard work, balance, family, hula hooping, and the value of infectious laughter that echoes down the hall. I am so fortunate to have a mentor like you, and am beyond grateful for all that you have invested in me.

Dr. Zizzi, you have helped this project to morph and take shape since dissertation seminar. Throughout this journey you have challenged me to remember that, oftentimes, less is more... that it's okay to wander in the forest, so long as one can climb up above the trees thereafter. I have to admit that this document doesn't strike me as a "win" in the less-is-more column (!!), and it may be that I will always have to wander further than most before I can climb up, but your voice of wisdom and pragmatism will always encourage me to do so. I should add that your health and exercise psych course sits high on my list of favorites, and was incredibly impactful for me. You have helped me to see the importance of "staying in your lane," but also that an openness to peeking into other "lanes" can be incredibly instructive. You introduced me to program evaluation and stoked a systems-level curiosity within me. This energy and these ideas are cemented in the foundation of this project; and I have no doubt, in the foundation of my future career as a scholar-practitioner as well. Thank you.

Dr. Leppma, from your Theories and Techniques class during my first semester, through to supervision during internship, and now to dissertation, you have been with me through every leg of my journey at WVU. Whether it was discussing course content and case studies, or sorting through the myriad thoughts, emotions, and questions that have come up through it all, you have always been willing to carve out extra time to help. Throughout my studies and training, you 
have helped me to identify and clarify my approach to practice as a clinician in training - a philosophy that fits authentically for me as a person, and infuses my research too. I have so deeply valued your insight and mentorship.

Dr. Cranney, if I only had one word to describe you and your mentorship, it would be "brilliant." First, I say "brilliant" because you are one of the sharpest and most intelligent thinkers I have ever met. You have a way of seeing and conceptualizing things from different angles and with a level of sophistication that - on several occasions - has left me flabbergasted. I also say "brilliant" because there is an intensity, a brightness to the energy and curiosity that seems to fill all that you do. Through your encouragement, and through the example you set, you inspire me to reach - to consider a different perspective, to ask questions, to go out on a limb every so often, and to never set limits on what I do.

Outside of my committee, there are so many who I want to thank for their influence and support; so many who have made my time at WVU and this culminating project so meaningful.

Dr. Etzel, I am beyond fortunate to have "snuck in" prior to your retirement, and you have been like a second advisor to me. I arrived on campus a bit starstruck, and this was perhaps most palpable in your ethics class during my first semester. Here I was learning ethics from "the ethics guy," and I vividly recall choking on my nerves during what should have been a routine "what did you learn from the chapter" sort of presentation. It was awful. We talked about it in your office not long thereafter. "It was a bit tense," you said with a warm grin, and we both had a good laugh about it. From that point on, I felt freed up to take myself a little less seriously and to remember that any moment can become a learning opportunity so long as we are mindful enough to see it as such. I must add that any knowledge of counseling college student-athletes I have accumulated, I owe to you. You taught me to notice the culture of athletics and to use a holistic, developmental lens in my work with student-athletes. Finally, it seemed like your door was always open for a quick question, a consult, a good joke, a thought-provoking quote, and/or a really, really good cup of coffee ("a speedy cup of Seattle's Beast," as you would put it). Thank you so much for all of your wisdom, guidance, and support.

To all at the Carruth Center, my supervisors, and especially Layne, Missy, and T.Anne - I am grateful beyond words for the environment and the opportunities you offered me as a trainee. During a critical period in my professional development, I always had someone I could go to for help - from fumbling my way through Titanium for the first week (or month?!) and planning group sessions, to getting a second opinion on a risk assessment or processing transitions in my own life. I felt seen, held, affirmed, and encouraged, as well as challenged and extended. I emerged with a sense of growth, authentic confidence (or perhaps confidence in my authentic self), and inner certainty that "this is what I want to do with my life" unlike any I had known before. All of you, the work that you do, and the training you provide were in my heart during this study. 
To all my classmates in the program - past and present - it is a great joy and privilege to call you friends and colleagues. This program is so special because of the collaboration, support, and togetherness we have shared. To my cohort partners...

Bobby - My basecamp desk neighbor, there was never a dull moment! Perhaps spurred by some "unique" overheard choices in my headphones ("Bill, am I going crazy or are you listening to bird sounds?!"), you have introduced me to some great bands. I also have a newfound appreciation for Jeopardy from the mentorship of its greatest fan. Both of these things - music, and Jeopardy - have, to my surprise, been significant components of dissertating through quarantine. Finally, I think you are as close to a human database as one can get, and inspire me to consume more research. I sincerely hope that our collaboration will continue beyond our time in the program.

Kate - I don't think I could have survived multivariate without you! From all the classes we shared, to navigating internship, I always appreciated your insight and your sense of humor. I also recall you having the most beautiful, nutritious meals prepped for in between the myriad demands of the day. Even if I haven't quite nailed it yet, you challenged me to consider the importance of properly fueling the mind and body throughout a busy day (perhaps one spent dissertating!). I would also be remiss if I didn't add that I was blown away by your dissertation, and hope that I can stay current on the amazing things that you are going to do in the field.

Spencer - MY MAN. Our friendship through these last several years has been a true treasure, and our shared adventures in your beautiful home state made for a season of my life that I will never forget. From wide-eyed counseling tapes, to bonking on the ascent of Mud Pike, demolishing Kroger's supply of peanut butter, and the innumerable antics that we shared during your time with us at the Way Café, you helped this high-strung neurotic to remember that the fun/free child needs to get out to play every now and again. Your poised, mindful, and deliberate wisdom is an exceptional gift, and one that has helped me to great effect on more than one occasion. Your discerning eye and constructive feedback have been especially helpful and appreciated throughout this project. I feel so fortunate that our paths have converged and crossed, and I want to send my sincere gratitude your way.

To Jeri, Wesley, and Shannon - My experiences with LeadWELL and WellWVU were incredibly valuable. Your mentorship and supervision helped to cultivate the campus-ascommunity perspective that was foundational for this project. You also gave me space to think independently, creatively, and critically about student health and wellness. I have a new appreciation for the value of meeting and engaging students where they are; and my idea of what "outreach" is has been greatly enriched and expanded because of you. 
Last, and certainly not least, to my family...

Mom - Your strength has always inspired me, and as I have matured, I have come to see more and more clearly just how strong you really are. Likewise, as I have grown and matured, so too has our relationship. Watching this metamorphosis through my young adulthood has been one of my greatest joys. Through it all, your listening ear, support, and unconditional love have made all the difference in my life. I could never have done this without you.

Jason - Bro, your creativity and determination never cease to amaze me. All that you do, you do wholeheartedly, and I deeply admire this about you. I have tried to emulate your energy and passion in this project, and will continue striving to do so in my future work.

Grandpop - You delight in simplicity and beauty as an artist, and navigate obstacles with the pragmatic ingenuity of an engineer. I used to see these two ways of being as incompatible, but have come to realize how harmonious they are for you. I can see your influence and example rubbing off on me as I look back on the journey of this dissertation.

John and Donna - What a strange, tense place this world was during 2020. You have been saints to take me and Gabby in through this unexpected time of quarantine and "in between." I could not be more grateful for your support and provision. Who knows, once you are rid of us, perhaps the extra space at "Club Kendall" could become a Bed and Breakfast retreat for frazzled writers or dissertation hopefuls like me (;

Gabby - My love and my light, I could not imagine sharing this journey with anyone but you. From our breakfast breaks and plowing through websites, to long walks and deep talks, you have helped me through this project and this season in more ways than I can say. You have been my constant, and a voice of wisdom. With each passing day, I feel like I learn more and more about God's love through you. In each chapter of our life together I find myself awestruck by how much we continue to learn and grow - as individuals, as a couple, and as a team. This chapter has been no exception, and I cannot wait to see what unfolds when we find ourselves, "on the road again." 


\section{Table of Contents}

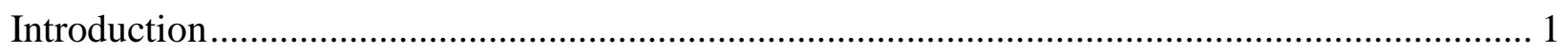

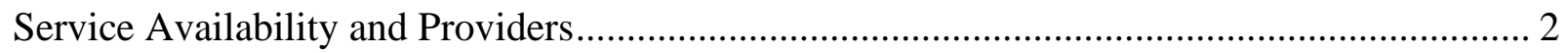

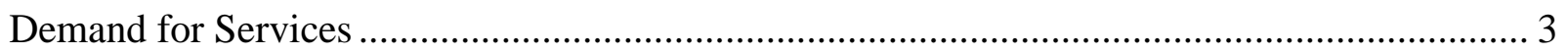

Practitioner Perspectives and Experiences ................................................................ 4

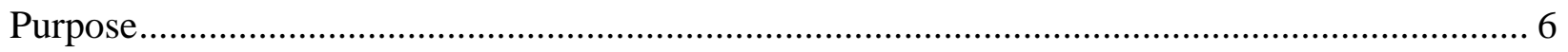

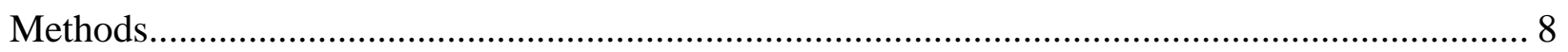

Website Review Procedures ......................................................................................... 8

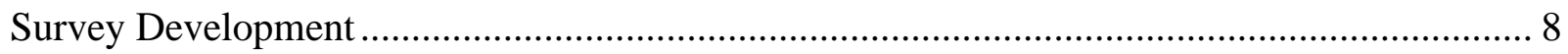

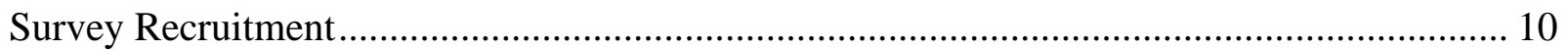

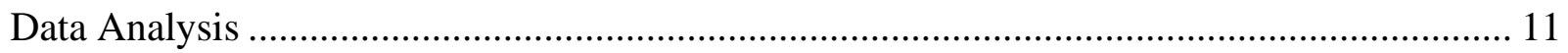

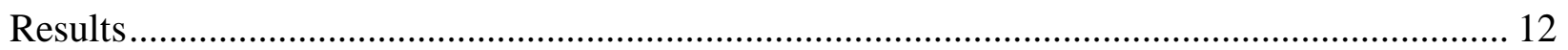

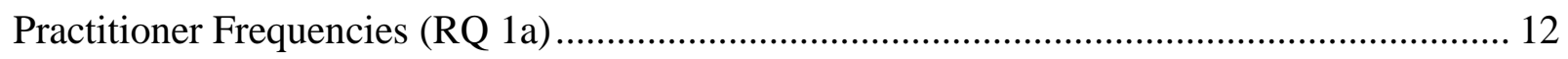

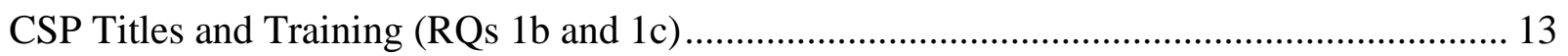

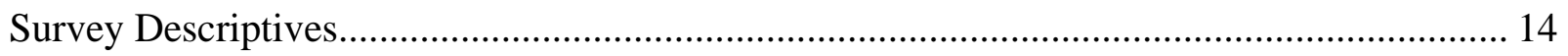

Perceived Demand for Services Among Student-Athletes (RQ 2a) ..................................... 15

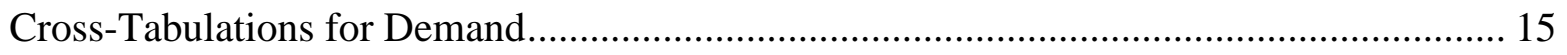

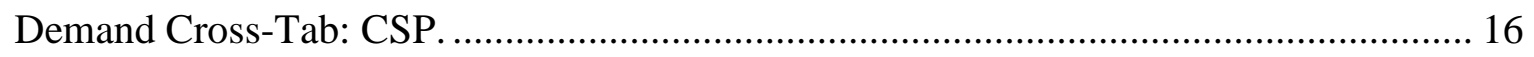

Demand Cross-Tab: Applied Sport Psychology..................................................... 17

Demand Cross-Tab: General Counseling. .................................................................. 17

Demand Cross-Tab: Mandated Counseling............................................................... 17

Demand Cross-Tab: Crisis Intervention. ............................................................... 18

Perceived Demand for Sport Psychology Services When Not Offered (RQ 2b)................... 18

Perceived Availability of Services for Students/Student-Athletes (RQ 2c).......................... 19

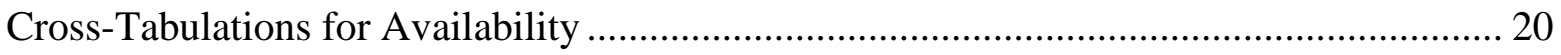

Availability Cross-Tab: CSP and Applied Sport Psychology....................................... 20

Availability Cross-Tab: General Counseling......................................................... 21

Availability Cross-tab: Psychiatry, Mandated Counseling, and Crisis Intervention........ 21

Practitioner Experiences at High and Low Service Availability (RQs 3b and 3c) ................. 22

Adding Qualitative Detail to Scaled Survey Items....................................................... 24

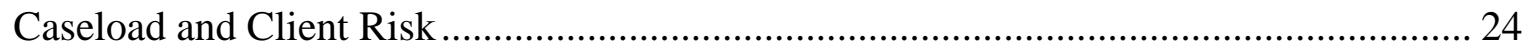

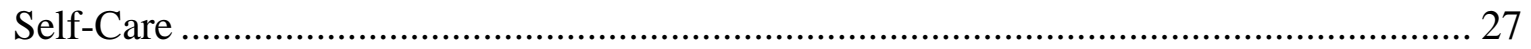




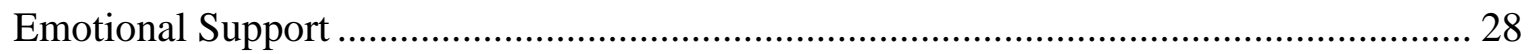

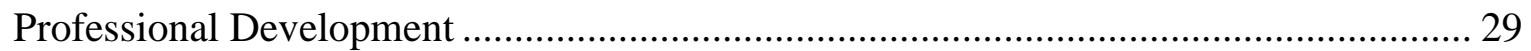

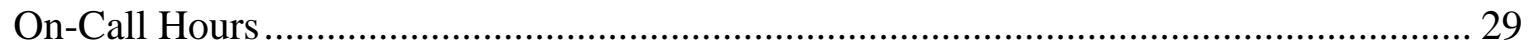

Additional Practitioner Perspectives (RQs 3a and 3c) .......................................................... 30

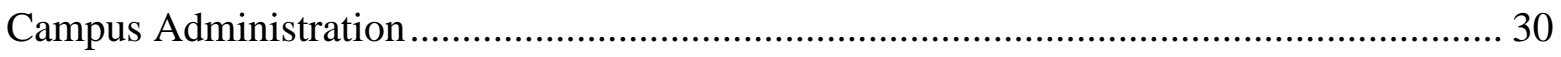

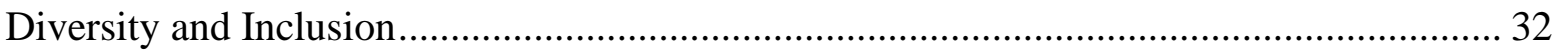

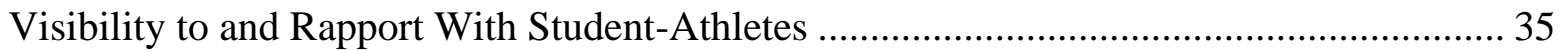

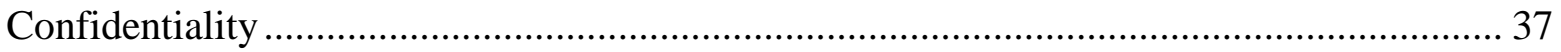

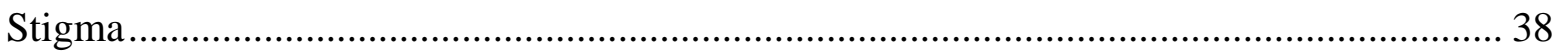

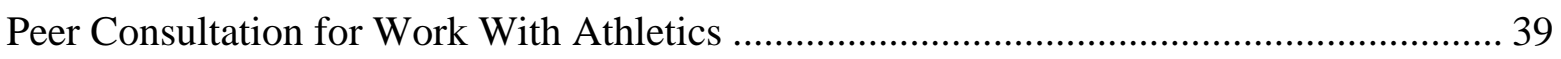

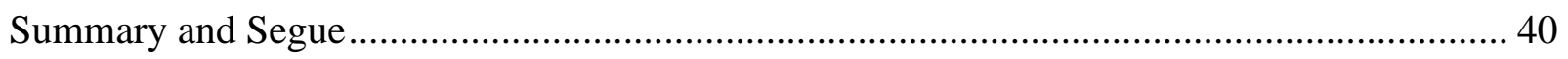

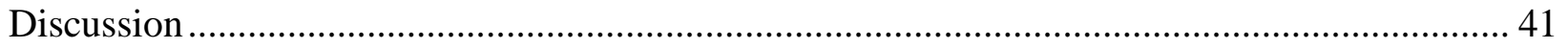

Objective 1: Identify and Describe the Population of Collegiate CSP Practitioners ................. 41

Website Review: Practical Implications........................................................................ 42

Objective 2: Describe Practitioner Perspectives on Service Availability .................................. 43

Demand for Unavailable Sport Psychology Services ........................................................... 44

Demand for Other Clinical Services Among Student-Athletes............................................ 45

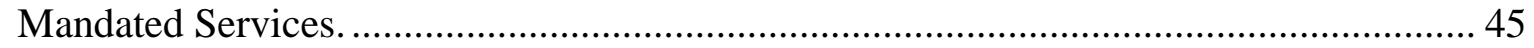

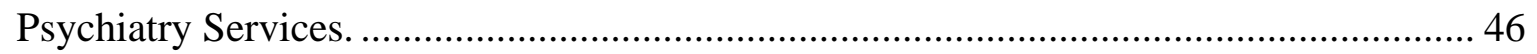

Crisis Intervention Services. .................................................................................. 46

Objective 3: Explore Practitioner Experiences ..................................................................... 47

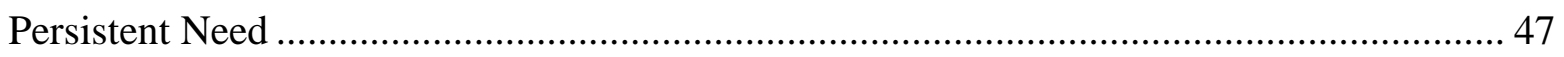

Practitioner Voice and Other Feedback Loops .................................................................. 48

Mental Health Promotion in Athletics ................................................................................... 49

Survey Data: Potential Limitations ................................................................................... 50

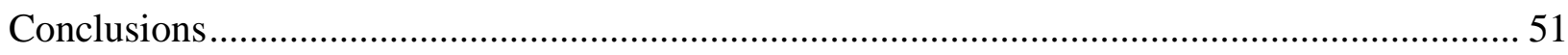

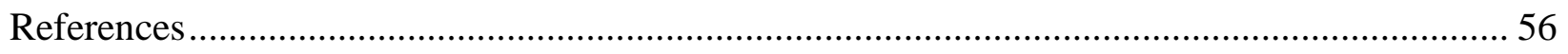

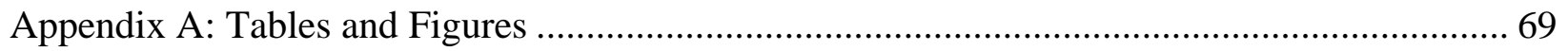

Table 1. Summary of sub-questions and planned analyses ....................................................... 69

Table 2. Sources that guided survey item development...................................................... 70

Table 3. Sport psychology practitioner presence cross-tabulated by NCAA division level ..... 71

Table 4. Cross-tabulation of demand for mental health services by division level and proportion of clinical hours with student-athletes. 
Table 5. Cross-tabulation of perceived mental health service availability for students/studentathletes by division level and proportion of clinical hours with student-athletes

Table 6. Independent sample t-tests comparing experiential statements across low and high perceived service availability groups ................................................................. 74

Table 7. Themes, sub-themes, and initial codes from inductive thematic analysis ................. 75

Figure 1. Frequencies of perceived demand for services among student-athletes ................. 81

Figure 2. Frequencies of perceived availability of services ......................................... 82

Appendix B: Text Version of Qualtrics Survey ............................................................... 83

Appendix C: Pre-Proposal Reflections and Philosophical Assumptions.................................. 88

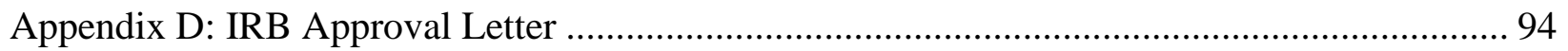

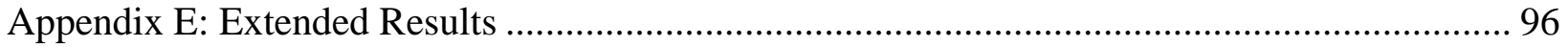

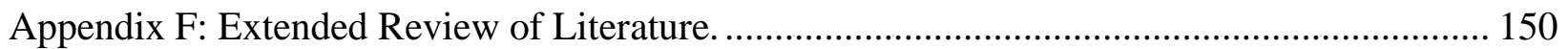




\section{Introduction}

At present, most institutions do not offer specialized services for the mental health and performance-related needs of student-athletes (Kornspan \& Duve, 2006; Hayden et al., 2013; Connole et al., 2014; Sudano \& Miles, 2017). Developing specialized services for athletics may not be practical or feasible when counseling and psychological services (CAPS) staff are already struggling to meet the needs of their campus communities. Many college counseling centers have not received additional resources during times of increased service utilization (Hodges, 2001; Eells et al., 2005), and are left to improvise amid heavy demands and unsustainable conditions (Much et al., 2010; Watkins et al., 2012; Schwartz, 2013). Kafka (2019) encapsulated these problematic conditions in his article title, Overburdened mental-health counselors look after students. But who looks after the counselors? The support needs of campus mental health practitioners may be in need of increased attention, and when a lone embedded practitioner is the only one providing for the mental health needs of an athletics department, the question of support needs could be equally significant.

At present, collegiate student-athletes appear to be utilizing mental health services more frequently than ever. Some documented rates of service use have included $<2 \%$ by Pierce (1969), $9 \%$ by Bergandi and Wittig (1984), an estimated $15 \%$ by Bennett (2007), and an estimated $25 \%$ by Johnson (2017). Whether spurring this trend or following from it, a growing body of research has explored student-athletes' preferences for sport psychology service providers (e.g., Lubker et al., 2012) and mental health services (e.g., López \& Levy, 2013), suggestions for increasing mental healthcare accessibility (NCAA, 2017), and satisfaction with service availability (Way et al., 2020). Researchers have also explored the availability of mental health services for student-athletes from the viewpoints of athletic trainers (Sudano \& Miles, 
2017) and administrators (Connole et al., 2014; Moore, 2016), as well as through analysis of counseling center and athletic department websites (Hayden et al., 2013). However, the perspectives of mental health practitioners who work with student-athletes have been largely absent from this growing body of research (Schlimmer \& Chin, 2018; Moreland et al., 2018).

The vantage point of these practitioners could be an untapped source of information regarding the mental health needs of student-athletes and the extent to which these needs are currently being met. Furthermore, researchers have been working to identify strategies for supporting student-athletes through their unique experiences and stressors, but a question remains as to whether CAPS and clinical sport psychology (CSP) providers are feeling in need of support themselves, and if so, in what ways. Before proposing steps to gather more information about practitioner perspectives, it is necessary to first quantify the current landscape of service availability for student-athletes, the level of demand for those services, and the experiences of service providers (see also Appendix F).

\section{Service Availability and Providers}

NCAA Bylaws 16.4.2 and 16.4.2.1 recently required Division I Power 5 conference (hereafter abbreviated P5) institutions and all other Division I, II, and III (DI, DII, DIII) institutions to ensure that their student-athletes have access to mental healthcare (Brutlag Hosick, 2019; see also https://web3.ncaa.org/lsdbi/). At this important juncture it is difficult to pinpoint the number and type of practitioners who provide mental health services to student-athletes (Gross et al., 2020); and in order to assess any growth in service availability that follows from these legislative changes, this would be an important time to collect baseline data about practitioner presence across NCAA institutions. Before looking ahead to the future of service availability, however, it may be prudent to first look back. 
In an early study of service availability, Bergandi and Wittig (1984) polled 53 college counseling center directors and found that $49 \%(n=26)$ offered some form of mental health services specifically for student-athletes. Their data did not detail what these services entailed. Since that time, surveys of service availability have sometimes lumped clinical and applied sport psychology services into one measured construct. Researchers have identified the presence of clinical and/or applied services at 23.4\% (Kornspan \& Duve, 2006) to 39.7\% (Connole et al., 2014) of institutions across divisional levels. Sport psychology services defined as clinical in nature have been identified in $20.5 \%$ of DI athletic training rooms (Sudano \& Miles, 2017) and $32.5 \%$ of DI FBS institution counseling centers (Hayden et al., 2013). Perceived service availability has typically been higher at DI institutions relative to DII and III institutions (Kornspan \& Duve, 2006; Connole et al., 2014; cf. Moore, 2016). When embedded services are made available, they tend to be staffed by one practitioner (e.g., LeViness et al., 2018) who could be working to serve a department with as many as 800 to 1,000 student-athletes (Flowers, 2007; Carr, 2007).

\section{Demand for Services}

One third of counseling center directors recently indicated that they had waitlists in effect for services at their clinic, with an average of 51 students waiting for services (range $=2-300$; LeViness et al., 2018). Researchers examining the demand for mental health services specifically among student-athletes have done so "with considerable variability" as to what this entails (Moreland et al., 2018, p. 64), and few have used clinical records to gauge rates of service use among this population. In what may be the most extensive records of student-athletes' mental health service use, the Penn State Center for Collegiate Mental Health (CCMH) studies have found that student-athletes comprised about $7 \%$ of campus counseling center clients over the last 
eight years (CCMH, 2012-2019). However, with the full and demanding schedules that studentathletes frequently balance, they may not be available to utilize the campus counseling center during its normal operating hours (Etzel et al., 2006). To provide for the unique needs of studentathletes, and when resources permit, some institutions create the specialized or embedded services outlined above. In these instances, the demand for CSP services can steadily increase in the years after these services are first offered (McDuff et al., 2005; Bennett, 2007; Flowers, 2007). In Chamberlain's (2007) experience, rates of service use had only plateaued because all available appointment times were filled. Offering an indirect clue as to what this might be like for a practitioner, a student-athlete shared with Way and colleagues (2020) that,

There [aren't] enough psychological services for athletes. I regularly go to [our sport psychologist] and most of the time she is booked two weeks in advance and she looks exhausted by the time in the day when I can see her because I've seen her schedule and the athletic department is running her thin. (p. 315)

\section{Practitioner Perspectives and Experiences}

To date there has only been one study to examine practitioners' experiences of providing mental health services to student-athletes (Schlimmer \& Chin, 2018). Apart from this, insight to the experiences of CSP practitioners must be gleaned from a few firsthand accounts (JCSP vol. 1, iss. 3; McDuff et al., 2005; Johnson, 2017), all of which have come from the DI context. This has neglected the experiences of mental health practitioners who work with DII and DIII studentathletes (cf. Rancourt et al., 2020), and the experiences of CAPS staff who support studentathletes at institutions that do not have access to CSP services (cf. Petrie et al., 1995). Consequently, including the perspectives of practitioners from all levels of athletic competition presents an important gap in the research. 
In the absence of broader data, experiential accounts from CSP personnel show some interesting similarities and differences to those of other practitioners in the milieu of college counseling. For example, CAPS and CSP personnel can both experience tension and role ambiguity with administrators (Chamberlain, 2007; Hack, 2007; Jodoin \& Ayers, 2013; Johnson, 2017). Likewise, just as there can be tugs on the confidentiality of student-athletes' mental health service use (Bennett, 2007; Chamberlain, 2007; Etzel \& Watson II, 2007; Hack, 2007; Loughran et al., 2014; Schlimmer \& Chin, 2018), maintaining client confidentiality can also be a challenge for CAPS staff working in small campus counseling centers (Vespia, 2007) or in the context of increasingly intrusive campus administrators (Grayson \& Meilman, 2013).

Confidentiality is especially important in light of student risk factors, campus tragedies, or high-profile cases. Clinical administrators have remarked on the increasing visibility and scrutiny of CAPS on college campuses, particularly with students who may be a danger to themselves or others (Watkins et al., 2012; Grayson \& Meilman, 2013). Speaking to an additional form of risk that can present for mental health practitioners who work in or with collegiate athletics, Zillmer and Gigli (2007) shared that student-athlete conduct (e.g., hazing, sexual misconduct, substance abuse) "can become a major problem not only for the athletic department but also for the university's image as a whole" (p. 220). As a result, they said, "sport psychologists may have a special entrée within this context of reducing the risk of negative publicity, while adding important life skills lessons to student-athletes" (p. 220; see also Bennett, 2007; Flowers, 2007).

It could be helpful to have broader data about practitioners' experiences of risk and risk management because of the stress it can impose. Recent research has focused on sport psychology practitioners' professional quality of life, coping strategies, and self-care (e.g., 
Cropley et al., 2016; Quartiroli et al., 2019a, 2019b), but less so on topics of practitioner mental health and use of personal counseling. Some twenty years ago, Andersen and colleagues (2000) suggested counseling and therapy for the personal/professional development of sport psychology practitioners as well as for the prevention of impairment. This suggestion could still carry some weight today, and for the broader population of collegiate mental health staff as well (Kafka, 2019). Despite the personal and professional benefits, little is known about the extent to which sport psychology practitioners engage in their own personal therapy.

In sum, CAPS staff face a variety of challenges, as do those working within the unique environment of athletics. Amid myriad stressors there are also many sources of enrichment, meaning, and enjoyment for CAPS and CSP practitioners (Kadambi et al., 2010; Chamberlain, 2007; Flowers, 2007; Wolanin, 2007; Zillmer \& Gigli, 2007). During an era in which more and more attention is being drawn to the mental health needs of student-athletes, and the availability of campus mental health services more broadly, the field could benefit from more inclusive data about the views and experiences of practitioners who work in this context.

\section{Purpose}

Three objectives (see Table 1) contribute to the overarching purpose of this study, which was to explore practitioner perspectives on the provision of mental health services to studentathletes in the broader context of collegiate mental health. At a historically relevant time point, the field lacks a broad picture to illustrate who is providing mental health services to studentathletes (Gross et al., 2020), and this is especially true in the context of DII and III athletics. Therefore, the first objective of this study was to expand upon the work of Hayden and colleagues (2013) to identify and describe the population of CSP personnel from all NCAA member institution websites. Within this objective, attention was devoted to the credentials and 
clinical titles held by these practitioners, as these can be pertinent factors for student-athletes' attitudes towards and intentions to engage in help-seeking behavior (Maniar et al., 2001; Lubker et al., 2012; López \& Levy, 2013; Woolway \& Harwood, 2015; Way et al., 2020).

The second objective of this study was to describe practitioner perceptions of the demand for mental health services among student-athletes at their institution, and the relative availability of those services. This objective was rooted in the observation that researchers have rarely examined demand and availability as distinct but related constructs (cf. Connole et al., 2014), and have under-utilized the firsthand experiences of service providers (Moreland et al., 2018; cf. Bergandi \& Wittig, 1984; Schlimmer \& Chin, 2018). Further, although scholars have attended to where CSP and other mental health services are available, few have detailed where they are not available and the need that might exist in their absence (cf. Rancourt et al., 2020). A subobjective aims to address these omissions in extant research.

Finally, in their provision of mental health services to student-athletes, some practitioners have commented on experiences of personal/professional support, relationships with athletics staff/administration, and other logistical aspects of service delivery (e.g., JCSP vol. 1, iss. 3; Schlimmer \& Chin, 2018). Similar experiences have also been voiced by practitioners serving the mental health needs of campus communities more broadly (e.g., Vespia, 2007; Jodoin \& Ayers, 2013). As such, the third objective of this study was to explore the pertinence of these topics for a broader sample of practitioners (see Table 2). In light of rising demands for clinical services, some have recently questioned the support that collegiate mental health staff are receiving (e.g., Kafka, 2019). From this observation, sub-objectives included exploring practitioner experiences at high versus low levels of service availability and what practitioners see as current needs to facilitate their work. 


\section{Methods}

\section{Website Review Procedures}

Building upon Hayden and colleagues (2013), CAPS and athletics websites were reviewed for all NCAA member institutions. As listed in April, 2020 (ncaa.org/directory/), this included 352 DI institutions (65 of which were sub-grouped as P5 conference institutions), 320 DII institutions, and 449 DIII institutions. Directories and sub-pages were analyzed for any sport psychology staff, as well as for any description of sport psychology or mental health services for student-athletes. The number of CAPS staff, CAPS trainees, CSP staff, CSP trainees, and applied staff/trainees were recorded in mutually exclusive categories. Educational degrees, licensures, and certifications were recorded for clinical/applied sport psychology personnel. Sport psychology staff/trainees were also coded as being listed on the CAPS website, the athletics website, or both. Email addresses were recorded for survey distribution. CSP staff/trainees were operationally defined as practitioners who held or were pursuing a mental health degree and had a clinical title that alluded to a role with student-athletes (clinicians listed on athletics websites were presumed to work with student-athletes in some capacity), were a member of the Association for Applied Sport Psychology (AASP) or a Certified Mental Performance Consultant (CMPC), listed a sport psychology degree or concentration (clinical or applied), or listed an interest in sport psychology or working with student-athletes in their online bio. Applied sport psychology practitioners were identified using the same criteria, but in the absence of a clinical degree or mental health credential.

\section{Survey Development}

The online survey for this project was developed using subjectivist epistemological assumptions (e.g., Romm, 2007; Lincoln et al., 2011; see Appendices B \& C). Recognizing the 
co-constructed nature of data that would be collected (Romm, 2013, 2014), the survey was written and re-written with an effort "to 'think' oneself into the perspective" of participants (Fielding, 1993, p. 157). In its final draft, the survey was conversational in tone, relatively concise, and transparent. The first section of the survey presented a series of statements based on experiences of campus mental health and sport psychology providers that have been documented in the academic literature (see Appendix B). Participants could agree/disagree with each statement based on their own experiences using a five-point Likert scale ("disagree," "slightly disagree," "slightly agree," “agree," and “can’t say from my experience”). The statements sought to gauge participants' experiences in a general sense (e.g., "My caseload is too large," "My institution promotes diversity and inclusion") and their experiences of providing services to student-athletes more specifically (e.g., "I could build rapport with student-athletes during my work with them").

The second section of the survey asked about the demand for various mental health services specifically among student-athletes at their institution. Participants were asked to rate the perceived demand prior to COVID-19 regardless of whether or not the services were offered (i.e., there could have been demand for a service that was not offered). A brief note was included to define non-clinical applied sport psychology services. Response options were "no demand," "low," "moderate," "high," and "not sure". Listed services included mental health counseling offered by a sport psychology specialist, mental health counseling offered by other clinical staff, applied sport psychology, mandated counseling (substance abuse/conduct), psychiatry, and crisis intervention. These services were selected for inclusion based on best practice recommendations (NCAA, 2016), emphases that campus clinics have placed on crisis intervention services (Kitzrow, 2009; Gallagher, 2012), the high demand for psychiatric services at present (LeViness 
et al., 2018), and the service delivery experiences of sport psychology practitioners working in collegiate athletics (e.g., JCSP vol. 1, iss. 3; Johnson, 2017). A single item was used to assess how practitioners thought COVID-19 impacted the demand for services among student-athletes.

Next, participants rated the perceived availability of each service for students and/or student-athletes. Participants were asked to respond with the perceived availability prior to COVID-19 and while considering both on campus resources and off campus referral networks (King Lyn, 2017a). A six-point scale was used for these items: "Availability exceeded demand," "Availability comfortably satisfied demand," "Demand was met but stretched available resources," "Demand exceeded available resources," "Service was not offered," and "Not sure." A single item was used to assess how practitioners thought COVID-19 impacted the availability of services for students and/or student-athletes. In the final portions of the survey, participants were invited to comment on what they were currently needing as a person/practitioner to facilitate their work. Demographic information was collected, and, consistent with the subjectivist epistemological approach to survey development (Romm, 2013), participants were invited to share their feedback or any points of clarification.

\section{Survey Recruitment}

Following IRB approval (Appendix D), all sport psychology providers (clinical and applied) identified during the website review were invited to participate in the survey. At institutions where clinical sport psychology services were not offered or could not be discerned, up to three mental health staff were invited to participate. In the event that CSP services were offered exclusively through athletics, up to three CAPS staff from the institution were also invited to participate. When CAPS had more than three practitioners, recruitment prioritized staff members other than directors. All recruitment correspondence took place via email. After an 
initial invitation was sent in late August, reminders were sent at 15, 28, and 42 days thereafter until the survey closed in mid-October. To incentivize participation, practitioners were invited to enter a random drawing for one of six Mastercard gift cards (one valued at $\$ 100$, five valued at $\$ 20$ each) and/or opt-in to receive a synopsis of results from the study.

\section{Data Analysis}

Research questions and analyses are summarized in Table 1. For the first objective of this study, frequencies of sport psychology personnel identified during the website review were reported in a cross-tabulated format by division level (P5, DI, DII, DIII). Clinical titles and credentials listed for CSP staff/trainees were descriptively summarized. For the second objective, the perceived demand for and availability of each service was cross-tabulated by NCAA division level as well as by the proportion of clinical hours that practitioners reported spending with student-athletes/athletics. Using the sub-sample of participants who indicated that sport psychology services were not offered at their institutions, perceived demand for those services was cross-tabulated by division level. For the final objective, data for each experiential statement were descriptively analyzed. To examine potential differences in practitioner experiences at higher and lower levels of perceived service availability, two sub-samples were created based on the number of services that practitioners indicated were stretched or exceeded by demand at their institutions. Independent-sample $t$-tests were used to compare high and low availability groups on their experiences of satisfaction with professional development, having reasonable on call expectations, having caseloads that were too large, engaging in enough self-care, feeling overstretched by client risk factors, and wanting more emotional support for their work as practitioners. As the independent variable of high versus low service availability was run on six dependent variables, a Bonferroni correction set alpha at .008. 
Qualitative data was analyzed using inductive thematic analysis (Braun \& Clarke, 2006). This was an iterative and recursive process that involved building familiarity with the data set as a whole, coding distinct meaning units within participant responses, and identifying themes across participants' responses (Braun \& Clarke, 2006). Brief notes and memos were recorded to serve as an audit trail during analysis (e.g., Tracy, 2010). Coding primarily took place at a semantic level, and memos documented inferences made about latent content that moved beyond the surface of participant responses. In striving to provide a credible and trustworthy account of the data, an effort was made to provide a thick and transparent report of participants' experiences (Tracy, 2010). Appendix E details qualitative data analysis in a theme-by-theme progression. However, in the results section that follows, qualitative data was integrated to add detail and specificity to the broader generality of quantitative data across this sample of participants.

\section{Results}

\section{Practitioner Frequencies (RQ 1a)}

Using the operational definitions outlined in the methods section, clinical sport psychology (CSP) staff were identified at 271 (24.2\%) institutions, CSP trainees were identified at $64(5.7 \%)$ institutions, and applied sport psychology staff/trainees (with non-clinical sport/performance psychology backgrounds) were identified at 49 (4.4\%) institutions. Only 20 institutions (1.8\%) listed both CSP and applied practitioners. In total, the website review identified 507 CSP staff, 85 CSP trainees, and 68 applied staff/trainees. Across divisions, the number of schools with any, one, two, three, four, or five or more practitioners in each category are presented in Table 3. All (100\%) P5 institutions had at least one CSP staff member listed, relative to $42 \%$ of DI institutions, $12 \%$ of DII institutions, and $11 \%$ of DIII institutions (see Table 3). Whereas no DIII institutions had more than two CSP staff, over half (55.4\%) of P5 
institutions had at least three. On a smaller scale, the listing of CSP trainees followed a similar trend as CSP staff when compared across divisions. Applied practitioners were listed at $1-2 \%$ of DII and DIII institutions and about $10 \%$ of DI and P5 institutions.

\section{CSP Titles and Training (RQs $1 b$ and 1c)}

Of all 592 CSP staff/trainees identified during the website review, $40 \%$ had clinical titles that referenced sport psychology or work with athletics (see extended results for additional detail on how titles were coded). Cross-tabulated by division, greater proportions of CSP staff/trainees had clinical titles that referenced sport psychology or athletics at P5 (48.2\%) and DI (40.8\%) institutions relative to DII (29.4\%) and DIII (20.7\%) institutions. Over half (56.6\%) of CSP practitioners identified during the website review held a doctoral degree, $23.7 \%$ listed a master's degree as their highest level of education, and 3.4\% held degrees in medicine (i.e., MD/DO). Trainees included both doctoral and master's students $(11.0 \%$ and $3.2 \%$ of all CSP practitioners, respectively). Terminal or current degrees were not listed for $2.2 \%$ of CSP practitioners. When biographical information was available online, CSP staff/trainees listed their highest degrees in a variety of disciplines, the most common of which were clinical (30.9\%) and counseling psychology (22.5\%), social work (10.1\%) and counseling/clinical mental health (8.9\%). CSP practitioners identified during the website review were cross-referenced in CMPC and AASP membership listings. Of all CSP staff/trainees, $13.7 \%$ held CMPC status and another $7.4 \%$ were current AASP members who were not certified. Across divisions, there were similar proportions of CSP practitioners with CMPC status at P5 (17.0\%), DI (14.5\%), and DII (13.7\%) institutions compared to DIII institutions $(2.4 \%)$. 


\section{Survey Descriptives}

From recruitment $(n=2,819), 495$ completed surveys were returned, along with another 20 partially completed surveys (> 30\% complete) for a total response rate of $18.3 \%$. Of all 515 respondents, $0.4 \%$ preferred to self-describe their gender identity, $1.0 \%$ identified as nonbinary, $27.6 \%$ identified as men, and $66.2 \%$ identified as women. Participants' racial/ethnic backgrounds included Native American (0.2\%), Native Hawaiian or Pacific Islander (0.2\%), Asian American/Asian (2.7\%), Hispanic or Latino/Latina/Latinx (3.7\%), biracial, multiracial, or multiethnic backgrounds (4.3\%), Black or African American (12.6\%), and White (70.3\%). Respondents included senior staff members (31.7\%), clinical staff members $(52.9 \%)$, and trainees (4.0\%). Another $11.3 \%$ of survey respondents described their role using other descriptors. On average, participants worked 36.5 hours/week (range $=3-70)$ and represented P5 $(n=74,15.3 \%)$, DI $(n=146,30.2 \%)$, DII $(n=96,19.9 \%)$, and DIII institutions $(n=167$, $34.6 \%)$. About half of the sample reported that they were affiliated with athletics as either trainees/employees of the institution $(n=210,42.7 \%)$ or external consultants $(n=44,8.9 \%)$. During a typical semester, participants spent about $30 \%$ of their clinical hours with studentathletes $(M=29.61$, Range $=0-100)$. The median proportion of clinical hours with studentathletes was $20 \%(\mathrm{IQR}=10-40)$. When asked about specialties or areas of expertise (openended), 350 participants responded. The most common specialties listed included trauma $(n=98$, $28.0 \%)$, sport/performance psychology and/or student-athletes $(n=84,24.0 \%)$, anxiety or mood disorders $(n=76,21.7 \%)$, specific modalities or theoretical approaches $(n=72,20.6 \%)$, disordered eating or body image $(n=47,13.4 \%)$, and alcohol or other drug counseling $(n=43$, $12.3 \%)$. Eighteen respondents $(5.1 \%)$ identified with a specialty in crisis counseling/suicidality and five $(1.4 \%)$ identified with a specialty in psychiatry. 


\section{Perceived Demand for Services Among Student-Athletes (RQ 2a)}

Participants were asked about the perceived demand for various mental health services among student-athletes prior to the COVID-19 pandemic. Respondents saw general mental health counseling as the most in-demand service among student-athletes (see Figure 1), and less than $1 \%$ of all respondents saw no demand for this service. Perceived demand was higher for CSP than for applied sport psychology, but practitioners appeared to be less certain about the demand for these services. One quarter indicated that they were unsure about the demand for CSP and one third felt unsure about the demand for applied services. Similar proportions of practitioners saw moderate-to-high demand for CSP (48.3\%) and psychiatry (46.7\%) services among student-athletes. Likewise, similar proportions of practitioners saw moderate-to-high demand for applied sport psychology (36.1\%) and mandated counseling (substance or conduct related, $35.7 \%$ ). Of note, $53.3 \%$ of respondents perceived a moderate to high demand for crisis intervention services among student-athletes. Participants were also asked about how they thought the COVID-19 pandemic impacted the overall demand for mental health services among student-athletes. Relative to perceived demand pre-pandemic, $35.3 \%$ of participants saw increased demand, $12.0 \%$ saw decreased demand, $18.0 \%$ saw no change, and $34.7 \%$ were unsure.

\section{Cross-Tabulations for Demand}

Perceived demand frequencies (i.e., the count of high, moderate, low, no demand, and not sure responses) were cross-tabulated by NCAA division and by the proportion of clinical hours that participants reported spending with student-athletes. For a more parsimonious display of cross-tabulations, P5 and DI status were combined into one categorical grouping, as were DII and DIII status. Three categories were developed for the proportion of clinical hours that 
practitioners spent with student-athletes/athletics based on the quartiles of data for the variable: practitioners who spent the least amount of time with student-athletes (defined as less than 10\% of clinical hours with student-athletes, corresponding with the first quartile), practitioners who spent a moderate amount of time with student-athletes (defined as $10 \%$ to $40 \%$ of clinical hours with student-athletes, corresponding with the IQR), and practitioners who spent the largest amount of time with student-athletes (defined as at least $41 \%$ of clinical hours with studentathletes, corresponding with the fourth quartile).

Demand Cross-Tab: CSP. Within the P5/DI grouping, the proportion of practitioners who saw a high demand for CSP services increased steadily as they spent more of their time with student-athletes (see dark gray highlighted cells, Table 4). Among participants who spent the least amount of time with student-athletes, $17.0 \%$ saw high demand for CSP services as compared to $34.8 \%$ of practitioners who spent a moderate amount of time with student-athletes, and $48.6 \%$ of practitioners who spent the most time with student-athletes. This increase was far less drastic in the DII/DIII grouping, and a lower proportion of practitioners saw high demand for CSP services (see light gray highlighted cells, Table 4). The proportion of P5/DI practitioners who were unsure about the demand for CSP services decreased in a relatively linear fashion moving from low to moderate to large amounts of time with student-athletes (see dark gray cells). On the contrary, the proportion of DII/DIII practitioners who were unsure about demand increased slightly among those who spent more time with student-athletes (see light gray cells). Finally, compared to the overall proportion for the sample (see purple cell), there was relatively little variation in the proportions of practitioners who saw moderate demand for CSP services across divisional groupings and time spent with student-athletes (lighter purple cells). 
Demand Cross-Tab: Applied Sport Psychology. Overall, a smaller proportion of practitioners saw high demand for applied sport psychology services, but demand was heightened in the P5/DI context relative to the DII/DIII context (see dark blue highlighted cells relative to light blue highlighted cells, Table 4). For instance, of participants who spent the least amount of time with student-athletes, $27.7 \%$ saw moderate-to-high demand in the P5/DI grouping relative to $18.5 \%$ in the DII/DIII grouping. Among those who spent the most time with student-athletes, 79.2\% saw moderate-to-high demand in the P5/DI grouping relative to $31.6 \%$ in the DII/DIII grouping. Across divisional groupings and the amount of time spent with studentathletes, shifts in the proportions of practitioners who were unsure about the demand for applied services followed a similar pattern as for CSP services (see dark blue cells relative to light blue cells).

Demand Cross-Tab: General Counseling. The proportions of practitioners who saw a high demand for general counseling services among student-athletes were relatively similar when comparing divisional groupings and appeared to increase as practitioners spent more of their clinical hours with student-athletes (see yellow relative to green relative to red highlighted cells, Table 4). Of those who spent the least time with student-athletes, high demand for general counseling was reported by $25.5 \%$ of P5/DI participants and $29.6 \%$ of DII/DIII participants. This increased to $41.7 \%$ of P5/DI participants and $47.4 \%$ of DII/DIII participants who spent the most time with student-athletes.

Demand Cross-Tab: Mandated Counseling. Within the DII/DIII grouping, the proportion of practitioners who saw moderate-to-high demand for mandated counseling increased steadily as they spent more of their time with student-athletes (see dark red highlighted cells, Table 4). Moderate-to-high demand for mandated counseling was reported by $25.9 \%$ of 
DII/DIII practitioners who spent the least time with student-athletes, $34.9 \%$ of DII/DIII practitioners who spent a moderate amount of time with student-athletes, and $44.7 \%$ of DII/DIII practitioners who spent the most time with student-athletes. There was a different pattern of responses in the P5/DI grouping. Specifically, the proportion of practitioners who saw moderateto-high demand for mandated counseling was lowest among those who spent the most time with student-athletes (see light red cells, Table 4).

Demand Cross-Tab: Crisis Intervention. As a final note, among practitioners who spent the most time with student-athletes, a greater proportion of those in the DII/DIII grouping (71.0\%) saw moderate-to-high demand for crisis intervention services relative to those in the P5/DI grouping (45.8\%; see dark orange relative to light orange highlighted cells, Table 4).

\section{Perceived Demand for Sport Psychology Services When Not Offered (RQ 2b)}

A total of 214 participants indicated that CSP services were not offered at their institution, about a third (32.2\%) of whom saw moderate to high demand for those services. A slightly greater proportion (40.2\%) saw no or low demand for CSP services, and another $27.6 \%$ felt unsure about demand. The demand for CSP services (again, when unavailable) was crosstabulated by division level. Nine participants from P5 institutions reported that CSP services were unavailable (recall that, per operational definitions used during the website review, all P5 institutions had at least one CSP practitioner), along with 48 DI participants, 53 DII participants, and 99 DIII participants (five who indicated that CSP services were unavailable did not report their institution's division level). Of these respondents, $22.2 \%$ of practitioners from P5 institutions perceived moderate-to-high demand for CSP services, as did $43.8 \%$ from DI institutions, 32.1\% from DII institutions, and 27.3\% from DIII institutions. 
Of 133 participants who indicated that applied sport psychology services were not available at their institutions, the majority were either unsure about the demand for these services $(37.6 \%)$ or saw no-to-low demand $(45.1 \%)$. Perceived demand for unavailable applied services was cross-tabulated by division. Four P5 participants indicated that applied services were unavailable, as did 27 DI participants, 35 DII participants, and 66 DIII participants (one participant who indicated that applied services were unavailable did not report their institution's division level). Of these respondents, slightly greater proportions saw moderate-to-high demand for applied sport psychology at P5 (25.0\%) and DI institutions (22.2\%) relative to DII (14.3\%) and DIII institutions (16.7\%).

\section{Perceived Availability of Services for Students/Student-Athletes (RQ 2c)}

Participants were asked about the perceived availability of various mental health services for students/student-athletes prior to the COVID-19 pandemic. As above, a relatively large proportion of respondents were unsure about the availability of CSP and applied services at their institution (see Figure 2). For students and/or student-athletes, general counseling was seen as the most stretched resource $(51 \%$ of respondents perceived it as stretched or exceeded by demand at their institutions). Other services that were particularly stretched included psychiatry and crisis intervention (perceived as stretched/exceeded by $39 \%$ and $36 \%$ of participants, respectively). Perhaps a reflection of its importance within the milieu of college counseling, only $11 \%$ of participants were unsure about the availability of crisis intervention services at their institution, and a fraction of a percent $(0.2 \%)$ reported that these services were not offered. A single item was used to gauge how participants saw the COVID-19 pandemic impacting the overall availability of mental health services for students/student-athletes. Responses were 
spread as follows: $25.3 \%$ of participants saw increased availability, $25.7 \%$ saw decreased availability, $37.7 \%$ saw no change, and $11.4 \%$ were unsure.

\section{Cross-Tabulations for Availability}

As with demand for services, the perceived availability of services was cross-tabulated by divisional grouping and the proportion of clinical hours that practitioners spent with studentathletes (see Table 5). To condense the data, the response options "availability exceeded demand" and "availability comfortably satisfied demand" were combined. The response options "demand was met but stretched available resources" and "demand exceeded available resources" were combined as well.

Availability Cross-Tab: CSP and Applied Sport Psychology. A contrast in the availability of CSP services emerged between divisional groupings. Proportionally, about twice as many practitioners saw CSP services as stretched or exceeded by demand in the P5/DI grouping relative to the DII/DIII grouping (see dark blue relative to light blue highlighted cells, Table 5). For instance, of those who spent the least time with student-athletes, $7.4 \%$ of DII/DIII practitioners saw CSP services as stretched or exceeded relative to $14.9 \%$ of P5/DI practitioners. Of those who spent the most time with student-athletes, $21.1 \%$ of DII/DIII practitioners saw CSP services as stretched or exceeded relative to $55.6 \%$ of P5/DI practitioners. However, it should be cautioned that these marked differences could have been influenced by proportions of practitioners who indicated that CSP services were not offered at their institutions, or who indicated that CSP services were available but that they were unsure of availability. When practitioners indicated that CSP services were offered and had a sense for the availability of those services, $65.8 \%$ of P5/DI practitioners indicated that CSP services were stretched or exceeded by demand relative to $53.5 \%$ of DII/DIII practitioners. 
Cross-tabulation reinforced website review data by indicating that applied sport psychology services were perceived as less available in the DII/DIII grouping relative to the P5/DI grouping (see light gray relative to gray highlighted cells, Table 5). Among those who spent the most time with student-athletes, for example, $18.4 \%$ of DII/DIII practitioners indicated that applied services were not offered at their institutions relative to only $4.2 \%$ of those in the P5/DI grouping. Likewise, among those who spent the least amount of time with studentathletes, $46.3 \%$ of DII/DIII practitioners indicated that applied services were not offered at their institutions relative to $27.7 \%$ of those in the P5/DI grouping.

Availability Cross-Tab: General Counseling. When comparing practitioners who spent low, moderate, and large amounts of time with student-athletes, larger proportions of practitioners in the DII/DIII grouping (about 9\% more) reported that demand for general counseling services was comfortably satisfied relative to those in the P5/DI grouping (see dark red highlighted cells relative to light red cells, Table 5). For instance, of those who spent the least amount of time with student-athletes, $46.3 \%$ of DII/DIII practitioners saw adequate availability of general counseling services at their institutions relative to $37.0 \%$ of P5/DI practitioners; and among those who spent the most time with student-athletes, $39.5 \%$ of DII/DIII practitioners saw adequate availability of general counseling relative to $30.6 \%$ of P5/DI practitioners.

\section{Availability Cross-tab: Psychiatry, Mandated Counseling, and Crisis Intervention.}

Across divisional grouping only (i.e., using the sum of P5/DI practitioners who spent low, moderate, and large proportions of time with student-athletes [dark green highlighted cells], and the sum of DII/DIII practitioners who spent low, moderate, and large proportions of time with student-athletes [light green highlighted cells]), a striking difference emerged in the availability of psychiatry services. Proportionally, more than four times as many practitioners $(20.9 \%$, see 
light green cells) in the DII/DIII grouping reported that psychiatry services were not available at their institutions as compared to practitioners in the P5/DI grouping (4.7\%, dark green cells). Again, across divisional grouping only, there also appeared to be a difference in the availability of mandated counseling. Proportionally, almost twice as many practitioners $(22.4 \%$, see light pink cells) in the DII/DIII grouping reported that mandated counseling was not available at their institutions as compared to practitioners in the P5/DI grouping (12.8\%, dark pink cells). Relative to these differences, there was more similarity in the perceived availability of crisis intervention services between divisional groupings. About half of practitioners in the P5/DI grouping (51.2\%, yellow cells) and DII/DIII grouping (54.9\%, pale yellow cells) reported that demand for crisis intervention services was comfortably satisfied. Of some concern, over one third of practitioners in the P5/DI (36.5\%) and DII/DIII (37.4\%) groupings reported that the availability of crisis intervention services was stretched or exceeded by demand.

\section{Practitioner Experiences at High and Low Service Availability (RQs 3b and 3c)}

Several survey items were developed based on aspects of practitioner experiences that have received attention in previous literature. Using these items, participants were asked about their satisfaction with professional development, their satisfaction with emotional support for stressors encountered in their clinical role, whether or not their on-call hours were reasonable, if they had caseloads that were too large, if they engaged in enough self-care, and if they felt overstretched by the number/severity of high-risk clients under their care. Most of these items were assessed on a 4-point scale (agree, slightly agree, slightly disagree, disagree), but items about oncall hours and stress associated with risk management included "not-applicable" response options for participants who did not have on-call hours or who did not encounter client risk factors. Practitioners were asked to consider their experiences prior to the COVID-19 pandemic. 
Overall, a large proportion of practitioners agreed/slightly agreed that they engaged in enough self-care to remain enthusiastic about their work (73.4\%), but an equally large proportion agreed/slightly agreed that they would have liked more time for their own professional development (74.6\%). Although most participants felt that their on-call hours were reasonable $(61.0 \%)$, or did not maintain on-call hours $(24.1 \%)$, many also felt that their caseload was too large (32.0\% slightly agreed and $30.5 \%$ agreed with the statement). Of some concern, $17.5 \%$ of practitioners agreed that they felt subjectively overstretched by the number/severity of high-risk clients under their care (another $31.1 \%$ slightly agreed while $3.0 \%$ did not encounter client risk factors). Perhaps linked to this experience, $64.1 \%$ of participants agreed/slightly agreed that they would have liked more emotional support for stressors that they encountered as practitioners.

A series of independent sample $t$-tests were conducted to explore if/how these aspects of practitioner experiences varied at higher versus lower levels of perceived service availability. For these $t$-tests, service availability was defined as the number of services for which practitioners reported that service availability was stretched or exceeded by demand. The low perceived availability group was comprised of 81 practitioners who marked the availability of four, five, or six services as "stretched" or "exceeded" by demand (recall that a total of six services were assessed on the survey). The high perceived availability group was comprised of 245 practitioners who marked one or zero services as "stretched" or "exceeded" by demand. As the high/low availability grouping variable was used for six tests, a Bonferroni correction set alpha at $p=.008$. Prior to running the $t$-tests, agree/disagree responses were re-coded as follows: disagree $=0$, slightly disagree $=1$, slightly agree $=2$, agree $=3$. "Not applicable" responses for the items pertaining to on-call hours and risk management were removed as missing data. 
Results of the independent sample $t$-tests are displayed in Table 6 . When practitioners perceived more strain on the availability of mental health and sport psychology services (i.e., the low availability group), they were significantly more likely to want additional time for professional development. They were also more likely to report that their caseload was too large, that they felt overstretched by the number/severity of high-risk clients under their care, and that they would have liked more emotional support for stressors encountered as a practitioner. Further, participants who saw more strain on service availability were significantly less likely to report adequate self-care and less likely to report that their on-call expectations were reasonable.

\section{Adding Qualitative Detail to Scaled Survey Items}

Participants' open-ended responses shed some additional light on these variables and their lived experience. Appendix E and Table 7 detail inductive data analysis more thoroughly. For reference, overarching categories were labeled as demand for mental health services, insights regarding clinical services and their delivery, equipping professionals, oversight and organizational dynamics, support at the intersection of person and professional, and opportunities and obstacles in the context of athletics (see Table 7). Here, snippets of these categories, their underlying sub-categories/initial codes, and participant responses will be integrated deductively to provide more nuanced detail than could be captured by the scaled survey response options.

Caseload and Client Risk. Although each dependent variable for the $t$-tests was examined in isolation, there could be compounding effects that result from a combination of the variables. For example, a handful of practitioners commented that demand was rising, client risk/acuity was rising, and service availability was simultaneously decreasing (which, by deduction, would impact caseload). One respondent indicated that their staffing had been cut in half over the duration of a few years despite heightened demand and a three-fold increase in 
student hospitalizations, adding that, “... administration did not respond to our concerns except to say 'everyone is doing more with less' and meanwhile we're preventing suicides on campus. It worries me that it will take a completed suicide before anyone pays attention." Another participant spoke to multiple variables from above by sharing of their experience in this way:

"With the increase in overall counseling demand across campus, including student-athletes, I have found myself experiencing more fatigue, amotivation, and difficulty engaging in as much self-care as I did prior to COVID-19. I have also seen an overwhelming increase in the risk/acuity of student-athletes' presenting issues."

The variable of clinician caseload could present an important junction at the intersection of demand, staffing/administrative oversight, and student experience. Some comments suggested that as caseload increases beyond a manageable point, the quality of treatment that students receive will decline. As one clinician shared, "We are understaffed and under-funded. This leads to greater demand and when we try to meet that demand it often times leads to poorer quality services. This leads to my own disappointment in not meeting student needs.” Another participant shared a similar sense of disappointment: "Student demand far exceeds our capacity causing our clinicians to experience fatigue, burn-out, decreased self-care and to feel that they are not offering the quality or quantity of services they would prefer to offer to students." Before proceeding, the issue of staffing deserves attention as it holds implications for caseload, client care, and clinician experience. Staffing was also, by far, the most prevalent topic that practitioners commented on in their open-ended responses. Across multiple responses, there was some solidarity on the issue: "We have been short staffed for years (as many college counseling centers are)," "Like every counseling center, we need more staff...," "As most 
college counseling centers encounter, we are understaffed," "We need more practitioners at all college campuses...". One clinician's reflections punctuated these remarks - and others similar to them - while also calling to mind other contextual factors at play:

"The counseling center systems are fatally flawed. They are underfunded at every institution, they are severely understaffed and dynamics around race are never supported enough. Since COVID, people are forced to take family leave to teach their children so the already understaffed staff has become even smaller. Staff is across universities burnt out and not supported enough but in addition, COVID and increasing racial tensions have further led to this."

In addition to meeting demand for services among the student body, staffing was also presented as an issue among those working with student-athletes/athletics (e.g., "As in most college counseling and athletic departments, we need more funding for more staff...," "I'm feeling the need to make copies of myself to be able to comfortably absorb the number of athletes coming on my case load"). One clinician offered a vivid glimpse into their experience of working to support student-athletes in a context that could benefit from increased staffing:

“...I was hired as a part-time Mental Health Counselor specialized in Sport Psychology for a DI University as the school was unaware if my specialized services would be needed or used enough for full-time work. My weeks were consistently booked out and many times I was working through my lunch or staying late just to catch up on my clinical notes. The plan was for me to go full-time due to the high demand of clinical and sport performance sessions (teams \& individuals), but when COVID hit the funding froze. Now this year the demand for services has increased significantly but my hours have remained the same as they noted there wasn't any funding for me. I'm also the only 
embedded counselor in athletics which makes it difficult to balance the team/individual needs but also my own sanity at times. Physically I need more time for sessions, mentally I need more time so I can breathe and actually eat my lunch..."

Self-Care. As alluded to in the response above, self-care can sometimes get swept aside when it is most needed - when clinicians/centers are stretched by demand. Other clinicians remarked on the need for intentionality in this regard. As put by one respondent, "I think selfcare and our own well-being is often left to the side, unless we are very intentional about it," and another, "We are stretched so thin managing this new semester...that we really have to work hard at self-care to prevent burn out." One participant offered a highly insightful reflection that called to mind a notion that personal responsibility can play a role in self-care ("As a person and practitioner, I need more rest and recuperation. I have to stop trying to do everything in my own strength and rely on support from others."), and others added contextual detail to illustrate more systemic influences. For example, one clinician shared that,

"College mental health really needs to come to terms with finding a balance between providing services to students and creating a healthy workplace environment for employees. It often feels that there is more value on providing more services to students at the expense of well-being of employees..."

Some found that administration spoke of but was not fully supportive of self-care (e.g., "My employer talks of self-care, but there really is little to no support of self-care.”), while others found administrators to be critical allies for self-care. As shared by one clinician, "Our director places a significant emphasis on work-life balance for our staff...This is definitely something that has been important in facilitating my work, even when things get busy." To be allies for self- 
care, administrators should consider how they frame it. One participant offered some detail in this regard, and shed light on a nuance that the scaled survey item may have failed to capture: "'Self-care' is a tricky answer to provide. Do I take time to pause and breathe in my free time away from work? Yes. Am I encouraged to take my paid time off? No. This is the messaging we need. Being told that we have to 'make do' with the scraps we get, while being underpaid and underfunded, isn't sustainable and we're seeing highly qualified staff leave because of this [in]consistent messaging. Practicing self-care in our free time does not suffice."

Emotional Support. Open-ended responses suggested that emotional support as a form of self-care can be important for practitioners in general (e.g., "It is simply difficult to manage the emotional toll of full-time service provision."), and especially so in the context of current events. An in-vivo code was developed from one practitioner's response in this regard: "campus mental health professionals are dealing with the same issues as everyone else during COVID-19 while supporting others struggles with the same issues/traumas." Comments from another practitioner underscored the rationale for emotional support regarding current events, as it can help to prevent impairment and bolster the ability to remain focused on clients' needs:

"I am needing increased spaces to process the challenges we are all facing - with colleagues and mentors - so that when I work with clients, I can gain some emotional distance from the impact of the current situation on me and focus on the client's needs."

Emotional support for stressors encountered as a clinician could be found amongst colleagues or in the confidential environment of personal therapy. One participant offered another, less direct alternative for emotional support in terms of structured breaks in the day or week to engage in 
non-clinical professional activities. This could include, as they put it, "built-in time to do noncounseling activities, such as teaching, to reduce burnout from dealing with emotional topics."

Professional Development. Research, continuing education, or self-study could also be included in a list of non-clinical activities to break up the emotional work of supporting students and student-athletes. The scaled survey item asked practitioners if they would have liked more time for professional development from the perspective of their pre-pandemic experiences; and in their open-ended comments, many participants shed light on how the need for professional development rapidly shifted as a result of COVID-19. For instance, one clinician shared, "We had NO training on providing virtual counseling services. We spent 5 months unsure of when, or if, we were returning to counseling. Our budget was frozen and we couldn't use this free time to take CEU courses to get more training on providing virtual services without paying out of pocket." (emphasis original) Funding was an issue raised in several responses that spoke to professional development (e.g., "My university provides continuing education financial support but this year, because of budget cuts, we will not have that option," "Cuts are being made to CEUs, which normally we would get a bit more coverage for. It sometimes feels like Counseling Services is on the chopping block when it comes to budgets."), as was the resource of time (e.g., "Additional professional development time would be beneficial. We are often stretched too thin and often have little time for [professional development] outside of summer term or non-work time.’)

On-Call Hours. On-call hours were a scarcely mentioned topic in participants' openended responses. Some clinicians commented that their center had recently purchased (or could benefit from purchasing) after-hours crisis support services to mitigate on-call demands. This may be especially helpful for single-staff centers. One clinician shared that, "As the only full- 
time therapist, on call staff for mental health emergencies, and director of my college counseling center I am needing another full-time therapist with me." They elaborated that, "Due to budget cuts and loss of funding, I have...part-time counselors and...interns who help but I am still required to do the duties mentioned above." Data also suggested that the definition of "on-call hours" may have shifted with the transition to work-from-home remote service delivery and calls to mind the importance of boundaries. For example, one participant expressed that, “...it appears that now our time is also less valuable, as we can be reached at all hours remotely...”.

\section{Additional Practitioner Perspectives (RQs 3a and 3c)}

In addition to the items used for the series of $t$-tests reviewed above, participants also responded to other items designed to gauge their experiences with institutional administration, campus climate, and athletics. Frequencies for these items are reviewed here to illustrate generalities across the sample. As above, participants' open-ended responses are integrated to add nuance and detail not afforded by the scaled survey items.

\section{Campus Administration}

Recalling the context of their work before COVID-19, participants responded to the item, “Campus administration had too much control over the way psychological services were provided at my institution." A relatively small proportion (3.5\%) felt as though they could not say from their experience, and $61.2 \%$ disagreed/slightly disagreed. One quarter of respondents slightly agreed and another $10.9 \%$ agreed. When administration surfaced in participants' openended comments, their remarks seemed polarized. Whereas some participants spoke to supportive, egalitarian climates in which they felt heard and appreciated by CAPS and campus administration, other practitioners commented that administrators at their institutions were detached, misinformed, insistent, and authoritarian. 
To illustrate these polar opposites, and practitioners' experiences of them, consider these two responses that spoke to the need for finding new, creative ways to meet the needs of students. First, one clinician shared of their experience in this way:

"I think an area where I would like to be able to grow (and where I think mental health practice needs to grow across the board) is in the area of innovative prevention approaches that go beyond psycho-educational programming. I have been supported by my director when I bring this up...Being that I work in a small center with a small staff, I am able to feel heard in terms of choosing the direction we take and how we want to administer our services. This has been really important to me..."

Whether for innovation or self-preservation, another participant also seemed to have new ideas for reaching and supporting students, but under more restrictive administrative oversight. This appeared to create a Catch-22 in terms of sparking change to manage the demand for services. "We...can barely keep up with the flow of students who need counseling services. There isn't time and financial support of branching out to make new resources available, even if the practitioners are interested. So, we have overbooked therapists with wait times for students, and the practitioners who see this problem aren't able to invest time and energy into creating potential solutions with resources that aren't based in a counselor's office. I think mainly administration sees it as losing money if we invest in more counselors or resources..." Building on this sentiment, some participants expressed a sense that clinical and/or institutional leadership valued numbers/students served above all else (e.g., "In my experience, many...counseling centers struggle with high expectations for "productivity,", "I feel the 
institution puts more emphasis on 'customer service' instead of actual clinical work.”). The effects of an over-emphasis on numbers could be compounded by a lack of opportunity for dialogue with administration. One participant shared of their experience in this way:

"As a practitioner with no access to dialogue with administrators, it can feel very limiting and draining to continue to be asked to do more for more students, with what feels like little regard for quality of care from the administrators. I would like to have more opportunities to share with administrators the challenges of providing competent psychological services and feel heard/supported.”

Some participants found that voicing their needs - ultimately in the service of students and their institution - were not met with much consideration. One respondent disclosed that, "My site does not offer peer consultation. I, and other professionals, have requested peer consultation, but there is concern amongst the administration team that we will lose clinical hours. Clinical hours are stretched thin. At the same time, we serve a very risky student population, and time set aside to consult as a team would be wonderful."

This dynamic could be underpinned by a lack of trust and understanding shared between practitioners and administrators, as suggested by comments like, "I would like less oversight and more trust in the work I do as a counselor," and "Admins who do not understand this work should not be dictating 'how much' or how 'busy' we are and watching over us."

\section{Diversity and Inclusion}

Two items asked participants about the extent to which they agreed that their institution as a whole promoted diversity and inclusion, and then about the extent to which they agreed that athletics at their institution was a diverse and inclusive space. Overall, $14.7 \%$ of respondents 
indicated that they could not speak to the cultural climate of athletics at their institution based on their experiences. Of the remaining participants, $4.4 \%$ disagreed that athletics was a diverse and inclusive space at their institution, and another $17.7 \%$ slightly disagreed. Across their institution as a whole, $6.0 \%$ of respondents disagreed that diversity and inclusion were promoted, and another $12.3 \%$ slightly disagreed. In their open-ended responses, several participants emphasized a critical need for intentional responses to issues of race and diversity.

In some instances, practitioners voiced a need to incorporate issues of diversity and social justice into the mission of the counseling center. As one clinician expressed, "I have needed spaces to work with colleagues to ensure the intentional incorporation of anti-racist values are at the forefront of our mission and work (diversity, equity, and inclusion committee and a white accountability group)." In other instances, practitioners observed that these mission and value statements were in place, but not being translated into action. How to best translate values into action is open for discussion, and from the vantage points shared by participants in this study, there are no easy answers - especially when it comes to supporting Black-identified students, staff, and faculty. One participant shared deeply of their experience in this regard:

"Recently, as a clinician of color I have been the most requested among my peers...Though this is humbling there isn't enough full disclosure conversations, seminars, or spaces to discuss what may have led to my heightened requests given the abhorrent racial events taken place summer 2020 or how these events have ignited a justified call to action from many BIPOC students addressing discriminatory practices on every PWI campus in America. Basically, though I am prepared because of my own personal experiences, I am not thoroughly prepared to adequately address the racial/discriminatory concerns through the 
counseling practice(s) and services via the pre-established operations of the counseling center. Because of these pre-set operations it appears as if we, the center, are waiting for the students to come to us; which has played out to be me being the one requested. I am humbled, but I recognize my limitations, and the parameters around college counseling centers. There needs to be more of 'me' and there needs to be an established climate that more readily addresses these concerns and provides sustainable support. Exactly what that looks like, I am still figuring that out myself."

To establish a climate in which support for issues of race, diversity, and social justice is more readily available and more sustainable, logistics were raised as important to consider. As mentioned in the response above, part of logistical planning entails diverse CAPS staffing. Another practitioner shared their experience in this regard:

"CAPS at my university is short-staffed in general and short-staffed in having Black identified therapists available to meet the needs of our Black students. I am the only Black identified therapist on campus. Our Black Student Union has asked for...more. However, funding is always an issue and the pandemic and other matters have complicated the issue even more."

Comprehensive logistical planning in support of diversity should be mindful of students' needs, as well as the needs of those who support them on campus. As one clinician shared, "There are many protocols in place for COVID-19 procedures, but nothing in order to prevent the ongoing perpetration of racial trauma. And that is for our students, student-athletes, staff, and faculty." Adding to this, and from the extended response that follows, there was a sense that developing logistics in support of diversity (and/or dismantling discriminatory logistics) can begin in or with 
CAPS, but could and should extend beyond CAPS to campus-wide counsels/committees - and perhaps to multi-campus initiatives as well:

"As a clinician of color, I too echo that same sentiments of many BIPOC students in society: 'where are the established places, spaces for me?'; 'where is the full preparation for my existence \& representation?'; \& 'where is the adequate response to my needs?'...Similar to how those with eating disorders on campus have entire counsels, committees, and staff monitoring their physical/mental/functional progress so too can teams be created and embedded to best monitor \&/or prepare around the impacts of racial (or particular intersectional) discriminatory practices that take place on college campus and even within college counseling centers...Additionally, this response from me is truly a general one and does not call any one particular college or center into question. I have listened and learned of many colleges in America facing similar call to actions from BIPOC students (and allies) and I always wonder who (or what) in the college counseling center is holistically prepared for them."

\section{Visibility to and Rapport With Student-Athletes}

When their clinical work included student-athletes, most participants (93.8\%) felt as though they could build rapport with this population. Just under one third (30.3\%) indicated that they spent time being visible to student-athletes and coaches by attending practices and/or competitions prior to the COVID-19 pandemic. In some instances, participants' open-ended comments mentioned that visibility and rapport were closely linked (e.g., "Outreach programs...[are] tailored to our athletes to help build rapport and facilitate a connection with the counseling staff."). To the extent that visibility could promote mental health service use among 
student-athletes, a few participants remarked that outreach could be a double-edged sword if heightened service use could not be accommodated. For instance, one clinician indicated that "we have a good working relationship with athletics that is growing, but increasing that relationships [sic] means more students seeking support and we don't have the staff to meet it."

Despite increased visibility and decreased stigma, some participants felt that they lacked support from athletics administration. Some felt that - in the words of one clinician - "The current approach seems more like band-aid and reactive rather than comprehensive and proactive in regards to the mental health care of athletes." As a result, a few participants expressed the need for more buy-in to mental health and sport psychology within the culture of athletics. In trying to secure buy-in, some practitioners saw a critical need to involve coaches/athletics staff in mental health prevention efforts. Speaking also about the "band-aid" approach to mental health referenced above, one practitioner shared this of their experience:

"I feel that the administration, coaches, athletic trainers view the counseling staff as 'fixers'. They feel they should just be able to walk a student-athlete over with no explanation of what they need or what the student's wish is...Mind you the coach, AT, administrator hasn't bothered to ask the student, 'How are you? What's wrong? How can I support you?' They appear to be afraid of talking about mental health with the student athletes. I have done numerous trainings with the coaching staff and athletic trainers about how to have these conversations with students. Year after year, the same thing always happens. I wish that they would talk with the student. When a student is just walked over and 'dumped' on us, they often feel betrayed and don't want to open up in session." 


\section{Confidentiality}

Contrary to observations that coaches or athletics staff were reluctant to engage with student-athletes' mental health, some participants expressed the opposite. When asked if athletics administration respected the confidentiality of student-athletes' mental health service use, most participants agreed (45.0\%) or slightly agree (26.9\%; another $10.4 \%$ indicated that they couldn't say from their experience). It would be helpful to get a more detailed sense of what facilitated respect for confidentiality when it was present, as confidentiality only surfaced in participants' open-ended comments when there were problems and/or boundaries were encroached. For instance, a few participants remarked with some expressivity that,

"Coaches/admin still believe they should be privy to details about student-athlete mental health conditions. Mental health providers end up 'in trouble' for 'withholding information' about a student's mental health status. It's frustrating that they only look through the liability lens when we're the ones taking on the risks."

In developing services for the athletics department, another participant reflected that, "I was unpleasantly surprised by the strength of athletic staff's initial expectation--expressed, seemingly from a position of unquestioned power--that I should just disregard the upholding of student confidentiality, in order to serve staff purpose(es)." With tremendous insight, they continued: "I was equally disturbed by my, almost, knee-jerk countertransferential desire (that, at present, I can only presume emanated from my own elite level intercollegiate athletic experiences) to comply with their expectation." While open communication may be clarifying expectations and boundaries (e.g., "To the staff's credit, they are showing flexibility in abiding by our conditions of confidentiality."), this individual continued to feel the effects of this dynamic, perhaps due to 
the vigilance required of attending to it (“...I am struggling to maintain my desire to work with the athletic department. I do not believe I would be struggling if I were able to work with directly with student-athletes, in the absence of an intermediary entity."). In addition to its impact on practitioners, concerns about confidentiality could also influence student-athletes' willingness to engage with mental health/sport psychology services. As expressed by one practitioner, "studentathletes continue to be concerned their coaches or peers will find out they are seeking services and this will be frowned up and they will be ridiculed. This has been shared by many athletes."

\section{Stigma}

Although concerns about confidentiality were not an issue for the majority of participants, stigma seemed to present a more widespread barrier. The majority of participants agreed $(23.9 \%)$ or slightly agreed $(48.6 \%)$ that student-athletes at their institution had stigmatized views of mental health. Some observed that the climate of athletics can be antimental health, and this could be a contributing factor (e.g., "student-athletics is a very different world....as though they’ve been bought and paid for to perform. Coaching styles can be very abusive and mentally destructive. The athletic culture is...strongly anti-mental health and providers need to tread lightly...”). In some cases, practitioners felt as though coaches had more stigmatized attitudes than their student-athletes. One practitioner shared that, "Some coaches are more stigmatized than students. We see athletes across almost all teams but coaches would be surprised that athletes don't feel safe telling them." Elaborating, this practitioner said, "We hear about stigma with athletes - and I'm sure it exists - but I think it is influenced by coaches' own stigma more than peers' or being an athlete." Perhaps a product of their outreach efforts, however, a small group of practitioners (3.4\%) disagreed with the statement that student-athletes at their institution held stigmatized views of mental health (13.9\% slightly disagreed and 10.2\% 
could not say from their experience). In their open-ended remarks, some participants commented that the stigma about mental health appeared to be decreasing among student-athletes, and in one instance, was attributed to the efforts of "strong student leaders within athletics."

\section{Peer Consultation for Work With Athletics}

Similar proportions of respondents agreed (15.7\%) and disagreed (18.9\%) that they would have liked more peer consultation for their work with student-athletes (note that another $34.1 \%$ slightly agreed and $27.1 \%$ slightly disagreed). Recall from website review data that many institutions employed one sport psychology provider. In a structural sense, this would make peer consultation difficult; as observed by one clinician: "As far as I am aware, I'm one of the only providers [among a large] staff... with a listed interest of working with student athletes. This leaves me with limited consultation opportunities...”. As an important point to consider, employing multiple sport psychology providers does not necessarily alleviate this barrier if organizational dynamics are not conducive to collaboration. One participant shared that, "At my (Div I) university, the sport psychologists are housed in a completely separate building/agency (sports medicine) than the counseling center (CC). This results in disconnect and lost opportunity for consultation between providers at $\mathrm{CC}$ and the sport psychologists when we do have student athletes seek services from CC. There is also limited encouragement of basic-level training of working with student athletes with CC staff (the norm is that clinicians just send them to the sports psychologists); however, student athletes usually seek us out because either they do not want to be seen in the sport psychologist's office, or they have not found treatment with them to be helpful thus far." 
Although some participants felt that more could be done to bridge the distance (physical, cultural) between CAPS and athletics, peer consultation to develop/enhance specialized services may not always be feasible or advisable. While the extended results (see Appendix E) afford more space to detail practitioner perspectives on the pros and cons of specialized services for student-athletes, the topic warrants a brief mention here as one practitioner called scope of practice to mind, and questioned the purview of college counseling to support a bridge to athletics:

"Our counseling services were at times challenged to build bridges with athletics with sometimes unreasonable requests on counseling staff to focus on studentathletes. At a small center, we are all generalists and unable to specialize on specific populations...I don't think it's really appropriate for our center to offer special treatment to student-athletes beyond what we provide to the general student population."

\section{Summary and Segue}

This section detailed results from multiple data sources ("archival" website content, quantitative and qualitative survey data) which, in combination, offer a broad descriptive snapshot of practitioners and their experiences of supporting college students and studentathletes. Clinical and applied sport psychology services were more widely available at P5/DI institutions relative to DII/DIII institutions and, despite better practitioner to student-athlete ratios (see Appendix E), were also more likely to be stretched or exceeded by demand. Relative to the demand for these specialized services, practitioners indicated that some generalized services (i.e., offered to the entire student body) were as in-demand if not more in-demand among student-athletes. Quantitative and qualitative data converged to illustrate various ways in 
which strained service availability could impact practitioners and the care that they provide to students and student-athletes. Several practitioners spoke to the influence that administrators had on the structure and function of CAPS and CSP services, and emphasized a need for more dialogue with administration. Diversity and inclusion surfaced as important needs as well, with emphasis on needs for more diverse staffing and more comprehensive resources for issues of discrimination and racial trauma. Finally, practitioners expressed various considerations, barriers, and facilitative factors that underpinned their work with student-athletes.

\section{Discussion}

\section{Objective 1: Identify and Describe the Population of Collegiate CSP Practitioners}

The first objective of this study was to identify and describe the population of CSP personnel from NCAA member institution websites. The operational definition used during the website review was intentionally broad to maximally capture practitioners who might identify with the CSP role. As less than half of CSP survey respondents self-identified a specialization in sport psychology/athletics, the definition used during the website review might be more accurate if reframed from "CSP practitioners" to "clinical practitioners with an interest/background in sport psychology". False positives for CSP presence may have arisen when individuals who met the CSP inclusion criteria were not providing CSP services in their current roles. False negatives arose from the website review as well. Seven practitioners who were coded as generalists during the website review self-reported a specialization in sport psychology on the survey.

These limitations in mind, the website review identified 592 CSP staff/trainees. Clinical and counseling psychology were the most common educational backgrounds. It was less common for CSP practitioners to list backgrounds in social work, clinical mental health counseling, psychiatry, and marriage/family therapy. However, the number of CSP practitioners 
with these backgrounds was similar in proportion to the presence of social workers, mental health counselors, psychiatrists, and marriage/family therapists in broader samples of collegiate mental health staffing (e.g., CCMH, 2019). With this slightly lopsided distribution of educational backgrounds, future research could explore the extent to which practitioners (both CSP and collegiate mental health providers, more broadly) have access to and benefit from interdisciplinary case consultation.

Overall, $14 \%$ of CSP providers held CMPC status, but only $2 \%$ of CSP providers at DIII institutions held this credential. To speculate about why these numbers were not higher, it could be that employers are not aware of or do not value the CMPC credential when deciding to hire or retain CSP personnel (Wilson et al., 2009). This could be especially true in the DIII context, where CSP providers tended to report more balanced roles and fewer clinical hours with studentathletes. Alternatively, and also plausible from the survey data, it could be that more collegiate CSP practitioners would like to pursue the CMPC credential, but lack the requisite time, support, mentorship, specific training, or access to athletics. Either way, educating stakeholders about the CMPC credential may be important moving forward. As administrative decision-makers selectively hire the practitioners who will be available to student-athletes, they are important gatekeepers for CSP service delivery (Lubker et al., 2012; Woolway \& Harwood, 2015).

\section{Website Review: Practical Implications}

From existing research, it is difficult to say what students and student-athletes look for on institutional websites related to CAPS and sport psychology services - or the extent to which they use these websites at all. That said, potential clients can form strong impressions about clinical services and providers from their websites (Liang \& Shepherd, 2020). Further, studentathletes sometimes prefer or seek out practitioners with certain titles and sport-related credentials 
(Maniar et al., 2001; Lubker et al., 2012; López \& Levy, 2013; Woolway \& Harwood, 2015;

Way et al., 2020). CAPS and athletics departments could use their websites to inform the campus community about the various credentials that their practitioners hold, the value and protection of certain titles or credentials, and the different treatment modalities that practitioners can offer (Lubker et al., 2012; Woolway \& Harwood, 2015, 2020). Institutions could ultimately use evidence-informed website design to highlight information that will be most relevant for students, student-athletes, and those who support them (e.g., coaches, parents, peers, faculty). In addition to promoting informed service consumption, this information could be a valuable recruiting tool (Bishop, 2010).

\section{Objective 2: Describe Practitioner Perspectives on Service Availability}

The second objective of this study was to describe practitioner perspectives on mental health service availability at their institution, and the perceived demand for services among student-athletes. In line with previous research (Kornspan \& Duve, 2006; Connole et al., 2014), CSP practitioners were more common at P5 and DI institutions than DII and DIII institutions. Although more common, practitioners were also more likely to report that CSP services were stretched or exceeded by demand at P5 and DI institutions. Practitioners have observed increased demand for CSP services in the years following their initial offering at an institution (McDuff et al., 2005; Bennett, 2007; Flowers, 2007; Chamberlain, 2007), and it could be that CSP service availability - and how that availability is communicated - is a precursor to and predictive factor for demand among student-athletes. Although further research is needed, survey data offered some support for this: practitioners were more likely to report no or low demand for CSP services when they were not offered. Extending this reasoning, the lower perceived demand for 
CSP services among DII and DIII practitioners could have been a function of lower service availability in those contexts.

Though plausible that the demand for services could follow from their availability (i.e., if you build it, they will come), the reverse is equally plausible. This would be to say that some growing level of demand could prompt the establishment and promotion of CSP services, which highlights the importance of needs assessment data. By this train of thought, it could not be assumed that a need for services does not exist if it has not been measured. Future research could explore how many institutions conduct some form of needs assessment related to their mental health/CSP services, who they share this data with, and what that communication does or does not achieve. To elaborate on the reasoning for this suggestion, relatively large proportions of practitioners felt unsure about the demand for clinical and applied sport psychology services. This uncertainty presents a scenario in which needs assessment data could be informative for practitioners; and moreover, for administrative gatekeepers as well (recall the comment, "I was hired as a part-time $[\mathrm{CSP}]$... as the school was unaware if my specialized services would be needed or used enough for full-time work...").

\section{Demand for Unavailable Sport Psychology Services}

Of participants who indicated that sport psychology services were not available at their institution, some saw moderate to high demand for them. In retrospect, it would have been informative to inquire about the perceived barriers to establishing sport psychology services at these institutions, but open-ended comments offered some tentative clues. Comments that directly mentioned barriers to developing sport psychology services included low buy-in to needs assessment data, funding issues (in amount or allocation), insufficient staffing, a lack of training in student-athlete issues (or finite time with which to pursue it independently), and a lack of 
access to athletics. Indirect barriers could have included broader challenges that practitioners were faced with, such as budget cuts, stretched clinical staffing, poor compensation, stress/low self-care, a need for more physical space, and staff at small centers being pulled into other institutional duties (e.g., COVID-19 response team). Among practitioners who saw moderate-tohigh demand for unavailable sport psychology services, it should be noted that some cautioned against developing these specialized services. To illustrate, one respondent articulated that "There is consistent pressure to provide specialized services or processes for athletes to engage in mental health support..." and "low awareness about how obliging this request sets unrealistic expectations in the athletics community that will no longer apply when [student-athletes] graduate." Instead, this practitioner advocated that "teaching students to find time for self-care and to appropriately navigate systems is the more appropriate technique, it is also more socially just."

\section{Demand for Other Clinical Services Among Student-Athletes.}

Developing specialized services for student-athletes may not be feasible when broader services are already stretched. Practitioners also reported that there may actually be stronger demand for some of these broader services among student-athletes. Conclusions drawn from this study concur with Hilliard and colleagues (2020) who emphasized the importance of multidisciplinary mental health and applied sport psychology staffing.

Mandated Services. Elliott and colleagues (2018) analyzed the inclusion of mandated counseling in DI and DII drug testing policies, but to this author's knowledge, researchers have not documented the number of student-athletes who are referred for mandated counseling at or across institutions. As some practitioners spoke of mandated counseling services as a menial chore ("[less investment in mandated service provision] would free up counselors to...pay more 
attention to developing their skills as psychotherapists"), future research could explore the frequency of referrals to mandated services, the approaches to and efficacy of these services for student-athletes, and practitioner experiences of providing them.

Psychiatry Services. Psychiatric services are in high demand on college campuses (LeViness et al., 2018), but may be less common at DII/DIII institutions relative to P5/DI institutions. At the risk of reducing service availability to numbers and "haves versus have nots," administrators and decision-makers should consider how service availability can impact practitioners, and ultimately, the students they support. As one participant disclosed, "My...institution is located in a small town with very limited psychiatric resources...I have felt extremely stressed when faced with students experiencing severe mental health-related crises, suicidal ideation, etc. because I have zero route for providing immediate psychopharmacological intervention. My administration encourages me to refer students off campus to doctors for treatment, but often students are unable to get in to see a physician for weeks."

Crisis Intervention Services. CAPS (Kitzrow, 2009; Watkins et al., 2012; Gallagher, 2012) and athletics departments (McDuff et al., 2005; NCAA, 2016; Currie et al., 2019; Gross et al., 2020) have been increasingly called upon to provide crisis prevention and intervention services. However, student-athletes (Way et al., 2020) and practitioners (Bennett, 2007; Flowers, 2007; McDuff, 2012) have commented that the culture of athletics can sometimes approach mental health as a reactive "knee-jerk" (Morse, 2013, p. 204) spurred by tragedy or crisis. Participants in the current study observed this too, and the tonal quality of their reflections ranged from exasperation and frustration (e.g., "It's frustrating that they only look through the liability lens when we're the ones taking on the risks") to a stark and sobering concern (e.g., "It 
worries me that it will take a completed suicide before anyone pays attention"). These comments underscore the importance of developmental outreach, consultation, and efforts to promote wellness while preventing crises (Brunner et al., 2017; Cramer et al., 2020). Practitioners in this study spoke to a need for "innovative prevention approaches" that resonated with the collaborative, systems-level approach espoused by Brunner and colleagues (2017, 2018). Some practitioners felt supported in their efforts to develop more robust outreach, others did not.

\section{Objective 3: Explore Practitioner Experiences}

The final objective was to explore practitioners' lived experiences. Throughout data analysis, an interconnectedness could be seen amongst clinical demand, service availability, administrative influence, current events, practitioner experiences, and quality of care. Clinical and institutional administration appeared to have tremendous influence, for better or worse, on the structure and function of CAPS/CSP services, on the appropriation of funding, on the lived practitioner experience, and ultimately on the quality of care that students and student-athletes received (see also Brunner et al., 2018; Keeling \& Heitzmann, 2003; Jodoin \& Ayers, 2013). To synthesize the volume of descriptive data outlined in the results section, discussion here will be limited to a few overarching issues. First, there is a question as to why longstanding needs in collegiate mental health persist at some institutions. Building on this first issue, practitioner voice and other potential feedback loops (e.g., clinical outcome data) in collegiate mental health were being undervalued at several institutions. Finally, results may hold implications for mental health promotion efforts within the unique context of collegiate athletics.

\section{Persistent Need}

Staffing was a critical need voiced by practitioners. Many practitioners need more staff, more diverse staff, and more multidisciplinary staff. It may be safe to say that these needs are not 
new (e.g., Harris \& Kranz, 1991; Vespia, 2007; Bonfiglio, 2016; King Lyn, 2017a, 2017b; Shelton, 2017) and persist amid recent data to suggest that some institutions are increasing their numbers of clinical staff (LeViness et al., 2019). The challenges of maneuvering administrative directives, addressing misconceptions about the scope of CAPS, and advocating for scarce resources were not novel findings either (Bishop, 2010, 2016; Much et al., 2010; Jodoin \& Ayers, 2013). Further still, other practitioner comments in this study ("being underpaid and underfunded, isn't sustainable;" "caseloads are way too big, just not sustainable;" "the idea of one clinician...for the whole of an athletic department does not seem to be a sustainable model') echoed - almost to the word - conclusions drawn by researchers nearly a decade ago ("many counseling centers appear to be in unsustainable positions," Watkins et al., 2012, p. 332).

Beyond this study, the question remains as to why these needs persist. Part of the answer may lie in Bishop's (2016) observation that the field of collegiate mental health lacks a "unified voice" (p. 16) that is both adequately representative and strong enough to advocate at the national level.

\section{Practitioner Voice and Other Feedback Loops}

In light of persistent needs, many practitioners and clinical administrators have gone to tremendous lengths to advocate on their behalf with institutional leadership. Needs assessment (also discussed above) and clinical outcome data have been cited as important tools for such advocacy (e.g., Mitchell et al., 2019). As such, it was surprising that some participants reported indifference from institutional administration in response to efforts like the "ongoing presentation of data to show the increasing need" or staffing requests from underrepresented student groups. Others have noticed that external experts/reviewers can sometimes have more say with institutional administration than clinical directors who conveyed the same information (Bishop, 2016), and there is evidence from this study to suggest that clinicians' expertise and 
input go undervalued and unheeded at some institutions. Future research could seek to clarify the administrative perspective in this dynamic.

More shocking were the unrealistic expectations imposed on some clinical staff (e.g., "oftentimes [CAPS] staff seems to be the conscience and caretaker of the University;" "the campus community - including senior administration - wants us to be everything, at all times, for students"), and simultaneously, the myriad ways in which they felt unappreciated and invalidated (e.g., "there are so many ways that I've felt undervalued in my institution;" "we are taking care of everyone and no one is taking care of us"). Not only were practitioner voices potentially neglected in some instances, but also the practitioners themselves. In both college counseling and sport psychology literature, there has been increased attention to topics like professional quality of life (e.g., Kuroiwa, 2019; Quartiroli et al., 2019a, 2019b), job satisfaction (e.g., Jodoin \& Ayers, 2017), and coping with the demands of practice (Cropley et al., 2016), yet practitioners' lived experiences, mental health, and emotional needs seem paradoxically taboo (cf. Kafka, 2019). Even clinician-oriented research networks (e.g., AUCCCD, CCMH) focus on the overarching structures, functions, and outcomes of CAPS services with little direct attention to the view from the ground and practitioners' lived experience. This is of some concern. David Onestak, the director of counseling services at James Madison University, once cautioned that, "If the healers are not well, who will do the healing?" (as quoted in Kafka, 2019, n.p.).

\section{Mental Health Promotion in Athletics}

Deeper exploration of practitioner experiences may also be warranted in the context of their work with student-athletes/athletics. The NCAA, several of its member institutions, student groups, and other organizations devote considerable effort to mental health awareness and stigma reduction. Some practitioners in this study suggested that mental health promotion for student- 
athletes may not be maximally effective without reducing stigma and promoting buy-in among coaches, staff, and administrators. To the extent that outreach and screening efforts aim to reduce stigma and promote service use, such efforts would be remiss without considering the infrastructure of services that are available for student-athletes who may be in need of them (Rancourt et al., 2020). As noted by Hack (2007), outreach can be too successful if practitioners subsequently receive more referrals than they can accommodate. Working to meet clinical demand amid stretched service availability, some participants indicated that they avoided conducting outreach with athletics for this very reason.

\section{Survey Data: Potential Limitations}

As with any survey, there are potential limitations to acknowledge. First, interpretation of these results must be sensitive to temporal context. The COVID-19 pandemic presented a highly dynamic and uncertain situation, and it could be that clinical demand, practitioner workload, institutional policies, and so forth changed drastically over the course of data collection. As a result, practitioners could have had different perspectives based on when they completed the survey. Second, with unsolicited requests for voluntary participation, a response bias could be present in the data. It may be that practitioners with a vested interest in student-athlete mental health were more likely to respond. It could also be possible that busier practitioners were less likely to respond. For these reasons, results may not generalize beyond this specific sample of participants. Third, applied practitioners were likely underrepresented by the website review methodology (e.g., many consult with athletics from academic departments, which were not analyzed), and thus under-recruited for participation. Moreover, the language of the survey was bent towards clinicians, and may have failed to represent the experiences of applied practitioners. 
Finally, the wording and design of the survey could have had other impacts on the data as well. Some practitioners indicated that they would have preferred more response options (e.g., a neutral response between agree/disagree). Also, the wording used for certain items was intentional and based on previous research, but not always neutral. In some instances, giving practitioners permission to voice their concerns (e.g., Agree/Disagree: "My caseload was too large.”) was prioritized over remaining in the role of detached external researcher (e.g., "On a scale of too small to too large, how would you rate the size of your caseload?"). However, participants were not blind to this framing. Whereas some commented that the slant of the items could have introduced bias, others expressed an appreciation for feeling like they had "a place to 'vent'". In hindsight, however, it may have been advantageous to use more neutral wording for the open-ended item. Asking practitioners what they needed to enhance their work may have dissuaded them from elaborating on contextual factors that were already facilitating their work. Although some participants commented that their needs were met, few offered additional detail about the circumstances that made this possible.

\section{Conclusions}

In light of these limitations, several key findings from this study build upon the existing literature. First, this study found that clinical and applied sport psychology services continue to be more common among DI institutions relative to the rest of the NCAA (see also Kornspan \& Duve, 2006; Connole et al., 2014). Adding more nuance to previous research in the DI context (e.g., Hayden et al., 2013; Sudano \& Miles, 2017), this study revealed a lopsided distribution when comparing P5 institutions - where CSP services were ubiquitous - and the rest of DI. Further, although CSP services were much more pervasive in the P5/DI context, two thirds of practitioners reported that those services were stretched or exceeded by demand. Data from this 
study also pointed to a demonstrable need for clinical and applied sport psychology services at several institutions that do not currently have access to them. That said, and from the vantage point of practitioners in this study, broader mental health services (i.e., counseling services open to the entire student body, mandated counseling, psychiatry, and crisis intervention) may be as in-demand or more in-demand among student-athletes than specialized clinical/applied sport psychology services.

Data from this study also shed light on practitioners' lived experiences of service delivery. Quantitative and qualitative data converged to illustrate that many practitioners in collegiate mental health/sport psychology are struggling to meet the demand for their services. As discussed above, this was not a novel finding, and it should be emphasized that practitioners are not impervious to the loads they shoulder. In several instances, practitioners' efforts came at great expense to themselves (e.g., stress, burnout, vulnerability to litigation) and their students (e.g., decreased access to and quality of care). When asked about what is needed to facilitate their work, practitioners pointed to a need for enhanced staffing (more staff, more multidisciplinary staff, and more diverse staff), more innovative outreach to allay clinical demand, a strengthened voice with institutional administrators, and bolstered attention to issues of diversity, equity, and inclusion. Data also signaled that practitioners could benefit from additional support for their self-care and professional development - and particularly so when clinical services are stretched by demand.

Taken together, these findings offer some future directions for the fields of sport psychology, collegiate mental health, and higher education administration. First, practitioners (CAPS and clinical/applied sport psychology), athletics departments, and their institutions are invited to further dialogue about the mental health needs of their student-athletes, the services 
that are or could be made available to them, and how those services are advertised. If specialized services are offered for student-athletes, they should be established in such a way that ongoing needs assessment ensures adequate service availability in terms of the type and amount of services that are most relevant for a given department at a given time. Without collaborative efforts that are shared with campus and community providers, it could be difficult for a lone embedded practitioner to safely and sustainably meet the needs of an entire athletics department. Furthermore, citing social justice principles and scope of practice amid resource constraints, practitioners in this study urged a degree of caution for institutions that have or plan to develop specialized mental health services for student-athletes. Care should be taken to avoid a scenario in which student-athletes have privileged access to services over other students in-need, or on the other hand, a scenario in which "student athletes are... sequestered from the services offered to the general student population," as one practitioner eloquently called to mind. To this latter point, institutional websites or sub-pages could be designed to educate student-athletes about the variety of campus and community services that are available to them, and promote their autonomous and informed decisions as consumers (see also extended results).

Second, and on a related note, clinical, institutional, and athletics administrators are encouraged to consider the value of a comprehensive approach to campus mental health (and sport psychology) that extends beyond the one-on-one delivery of clinical services. Hallmarks of such an approach include considerable consultation, collaboration, and outreach efforts in conjunction with ongoing needs assessment/program evaluation and clinical service delivery (e.g., Parcover et al., 2015; Brunner et al., 2017; 2018; Banks, 2020; Cramer et al., 2020). Comprehensive approaches to campus mental health can help to prevent mental challenges, promote early intervention as concerns arise (Brunner et al., 2017), provide more equitable care 
to underrepresented students (Banks, 2020), offset the number of students who present with crises or require intensive care (Parcover et al., 2015), and bolster a shared responsibility for campus mental health that extends beyond the counseling center (Cramer et al., 2020). All of these potential benefits align with needs that practitioners cited in the current study.

A third call to action that follows from this study is for stakeholders (e.g., clinical and institutional administration, human resources, professional groups/governing bodies) to ensure that campus mental health practitioners have sufficient and diverse staffing, reasonable caseloads, optimal self-care, regular opportunities for collaboration and/or professional development, and more ample emotional support for the work that they do. Data from this study would suggest that overburdened and under-supported mental health practitioners cannot sustainably serve their institutions or the students who attend them; are ill-equipped to reach vulnerable, at-risk, and marginalized members of the campus community; and may be unlikely to stay. Greater investment in campus mental health services, and the diverse practitioners who provide them, has the potential to yield returns at the institutional level. Such returns could include better recruitment and retention (Bishop, 2010), enhanced student wellness and crisis prevention (Cramer et al., 2020), and less negative publicity (Zillmer \& Gigli, 2007). From a professional practice standpoint, this could also allow campus counseling services to devote more time and energy to training the next generation of practitioners, and further still, to serve as representative role models for future generations of practitioners to-come (recall, for instance, one practitioner's comment that, "as a clinician of color...there needs to be more of 'me"').

Finally, and following from this third point, it may be incumbent upon the field and its myriad of multidisciplinary professional groups to contribute to a larger, louder, more unified, and more representative voice that can advocate on behalf campus mental health practitioners 
(Bishop, 2016). To be clear, there were several practitioners in this study who remarked on campus climates in which they felt supported, encouraged, appreciated, and invited to contribute their ideas and interests to develop innovative mental health programming (see also Kadambi et al., 2010). There were also practitioners who felt dismissed and neglected by their institutions, practitioners who felt vulnerable to crises that - if better equipped - they could help to prevent, and practitioners who felt this way amid repeated, evidence-based efforts to advocate for additional support. These practitioners appeared to be spoken over and spoken for. Moreover, this is not the first documented example in which campus mental health practitioners have felt as though the organizational odds were stacked against them (e.g., Bishop, 2010; Much et al., 2010; Jodoin \& Ayers, 2013; Kafka, 2019). As such, stronger advocacy is needed to create leverage for change, assist these professionals, and ultimately, to create more accessible and higher quality mental healthcare for students and student-athletes in higher education. 


\section{References}

Andersen, M. B., Van Raalte, J. L., \& Brewer, B. W. (2000). When sport psychology consultants and graduate students are impaired: Ethical and legal issues in training and supervision. Journal of Applied Sport Psychology, 12(2), 134-150. https://doi.org/10.1080/10413200008404219

Banks, B. M. (2020). Meet them where they are: An outreach model to address university counseling center disparities. Journal of College Student Psychotherapy, 34(3), 240-251. https://doi.org/10.1080/87568225.2019.1595805

Bennett, G. (2007). The role of a clinical sport psychologist in a division I athletics program. Journal of Clinical Sport Psychology, 1(3), 261-269. https://doi.org/10.1123/jcsp.1.3.261

Bergandi, T. A., \& Wittig, A. F. (1984). Availability of and attitudes toward counseling services for the college athlete. Journal of College Student Personnel, 25(6), 557-558.

Bishop, J. B. (2010). The counseling center: An undervalued resource in recruitment, retention, and risk management. Journal of College Student Psychotherapy, 24(4), 248-260. https://doi.org/10.1080/87568225.2010.509219

Bishop, J. B. (2016). What they never told me about being a counseling center director. Journal of College Student Psychotherapy, 30(4), 226-231. http://dx.doi.org/10.1080/87568225.2016.1219607

Bonfiglio, R. A. (2016). Anticipating the future of mental health needs on campus. New Directions for Student Services, 156, 97-104. https://doi.org/10.1002/ss.20195

Braun, V., \& Clarke, V. (2006). Using thematic analysis in psychology. Qualitative Research in Psychology, 3(2), 77-101. doi: 10.1191/1478088706qp063oa 
Brunner, J., Wallace, D., Keyes, L. N., \& Polychronis, P. D. (2017). The comprehensive counseling center model. Journal of College Student Psychotherapy, 31(4), 297-305. https://doi.org/10.1080/87568225.2017.1366167

Brunner, J., Wallace, D., Keyes, L. N., \& Polychronis, P. D. (2018). Comment on models of a counseling center and the importance of context. Journal of College Student Psychotherapy, 32(1), 4-9. https://doi.org/10.1080/87568225.2018.1428133

Brutlag Hosick, M. (January 24, 2019). Access to mental health services guaranteed by autonomy conferences. Obtained from http://www.ncaa.org/about/resources

Carr, C. M. (2007). A psychologist in the world of intercollegiate sports: Professional development issues. Journal of Clinical Sport Psychology, 1(3), 293-303. https://doi.org/10.1123/jcsp.1.3.293

Carter, L., \& Davila, C. (2017). Is it because I'm Black? Microaggressive experiences against Black professionals in sport and exercise psychology. Professional Psychology: Research and Practice, 48(5), 287-293. http://dx.doi.org/10.1037/pro0000145

Center for Collegiate Mental Health (2012, January). 2011 Annual Report (Publication No. STA 12-59). Retrieved from https://ccmh.psu.edu/publications/

Center for Collegiate Mental Health (2013, January). 2012 Annual Report (Publication No. STA 13-68). Retrieved from https://ccmh.psu.edu/publications/

Center for Collegiate Mental Health (2014, January). 2013 Annual Report (Publication No. STA 14-43). Retrieved from https://ccmh.psu.edu/publications/

Center for Collegiate Mental Health (2015, January). 2014 Annual Report (Publication No. STA 15-30). Retrieved from https://ccmh.psu.edu/publications/ 
Center for Collegiate Mental Health (2016, January). 2015 Annual Report (Publication No. STA 15-108). Retrieved from https://ccmh.psu.edu/publications/

Center for Collegiate Mental Health (2017, January). 2016 Annual Report (Publication No. STA 17-74). Retrieved from https://ccmh.psu.edu/publications/

Center for Collegiate Mental Health (2018, January). 2017 Annual Report (Publication No. STA 18-166). Retrieved from https://ccmh.psu.edu/publications/

Center for Collegiate Mental Health (2019, January). 2018 Annual Report (Publication No. STA 19-180). Retrieved from https://ccmh.psu.edu/publications/

Chamberlain, R. B. (2007). Sport psychology in a collegiate athletic department setting. Journal of Clinical Sport Psychology, 1(3), 281-292. https://doi.org/10.1123/jcsp.1.3.281

Connole, I. J., Shannon, V. R., Watson II, J. C., Wrisberg, C., Etzel E., \& Schimmel, C. (2014). NCAA athletic administrators' preferred characteristics for sport psychology positions: A consumer market analysis. The Sport Psychologist, 28(4), 406-417. http://dx.doi.org/10.1123/tsp.2013-0096

Cramer, R. J., Judah, M. R., Badger, N. L., Holley, A. M., Judd, S., Peterson, M., Hager, N., Vandecar-Burdin, T. \& Foss, J. J. (2020). Suicide on college campuses: A public health framework and case illustration. Journal of American college health. https://doi.org/10.1080/07448481.2020.1739053

Cropley, B., Baldock, L., Mellalieu, S. D., Neil, R., Wagstaff, C. R., \& Wadey, R. (2016). Coping with the demands of professional practice: Sport psychology consultants' perspectives. The Sport Psychologist, 30(3), 290-302. http://dx.doi.org/10.1123/tsp.20150125 
Currie, A., McDuff, D., Johnston, A., Hopley, P., Hitchcock, M. E., Reardon, C. L., \& Hainline, B. (2019). Management of mental health emergencies in elite athletes: A narrative review. British Journal of Sports Medicine, 53(12), 772-778. http://dx.doi.org/10.1136/bjsports-2019-100691

Eells, G. T., Seals, T., Rockett, J., \& Hayes, D. (2005). Enjoying the roller coaster ride: Directors' perspectives on fostering staff morale in university counseling centers. Journal of College Student Psychotherapy, 20(2), 17-28. https://doi.org/10.1300/J035v20n02_03

Elliott, K. P., Kellison, T. B., \& Cianfrone, B. A. (2018). NCAA drug testing policies and penalties: The role of team performance. Journal of Intercollegiate Sport, 11(1), 24-39. https://doi.org/10.1123/jis.2017-0036

Etzel, E. F., \& Watson II, J. C. (2007). Ethical challenges for psychological consultations in intercollegiate athletics. Journal of Clinical Sport Psychology, 1(3), 304-317. https://doi.org/10.1123/jcsp.1.3.304

Etzel, E. F., Watson II, J. C., Visek, A. J., \& Maniar, S. D. (2006). Understanding and promoting college student-athlete health: Essential issues for student affairs professionals. NASPA Journal, 43(3), 518-546. doi: 10.2202/0027-6014.1682

Fielding, N. (1993). Ethnography. In N. Gilbert (Ed.), Researching social life (pp. 154-171). London: Sage.

Flowers, R. (2007). Psychologist-sport psychologist liaison between counseling and psychological services and intercollegiate athletics. Journal of Clinical Sport Psychology, 1(3), 223-246. https://doi.org/10.1123/jcsp.1.3.223

Gallagher, R. P. (2012). National Survey of College Counseling 2012. Retrieved from http://dscholarship.pitt.edu/28175/1/NSCCD_Survey_2012.pdf 
Grayson, P., \& Meilman, P. (2013). Longevity speaks: Observations from long-serving counseling center directors. Journal of College Student Psychotherapy, 27(3), 185-199. https://doi.org/10.1080/87568225.2013.798219

Gross, K. D., Rubin, L. M., \& Weese, A. P. (2020). College athletes and suicide prevention: A collaborative autoethnography. Journal of Issues in Intercollegiate Athletics, Special Issue, 82-97.

Hack, B. (2007). The development and delivery of sport psychology services within a university sports medicine department. Journal of Clinical Sport Psychology, 1(3), 247-260. https://doi.org/10.1123/jcsp.1.3.247

Harris, S. A., \& Kranz, P. (1991). Small college counseling centers: Changing trends for a new decade, Journal of College Student Psychotherapy, 5(3), 81-89. https://doi.org/10.1300/J035v05n03_06

Hayden, E. W., Kornspan, A. S., Bruback, Z. T., Parent, M. C., \& Rodgers, M. (2013). The existence of sport psychology services among NCAA Division I FBS university athletic departments and counseling centers. The Sport Psychologist, 27(3), 296-304. https://doi.org/10.1123/tsp.27.3.296

Hayes, J. A., Youn, S. J., Castonguay, L. G., Locke, B. D., McAleavey, A. A., \& Nordberg, S. (2011). Rates and predictors of counseling center use among college students of color. Journal of College Counseling, 14(2), 105-116. https://doi.org/10.1002/j.21611882.2011.tb00266.x

Hilliard, R. C., Watson II, J. C., \& Zizzi, S. J. (2020). Stigma, attitudes, and intentions to seek mental health services in college student-athletes. Journal of American College Health. https://doi.org/10.1080/07448481.2020.1806851 
Hodges, S. (2001). University counseling centers at the twenty first century: Looking forward, looking back. Journal of College Counseling, 4(2), 161-173. https://doi.org/10.1002/j.2161-1882.2001.tb00196.x

Jodoin, E. C., \& Ayers, D. F. (2013). Professional norms versus managerialism in campus mental health centers: The experiences of eight clinicians. Journal of Student Affairs Research and Practice, 50(4), 432-449. https://doi.org/10.1515/jsarp-2013-0030

Jodoin, E. C., \& Ayers, D. F. (2017). Communication conflict styles, perception of ethical environment, and job satisfaction among college and university counselors. Journal of College Counseling, 20(2), 139-153. https://doi.org/10.1002/jocc.12066

Johnson, M. B. (2017). Becoming a sport psychologist employed by a university athletic department. Journal of Clinical Sport Psychology, 11(1), 53-66. https://doi.org/10.1123/ jcsp.2016-0001

Kadambi, M., Audet, C. T., \& Knish, S. (2010). Counseling higher education students: Counselors' positive experiences. Journal of College Student Psychotherapy, 24(3), 213232. https://doi.org/10.1080/87568225.2010.486296

Kafka, A. C. (2019, September). Overburdened mental-health counselors look after students. But who looks after the counselors? The Chronicle of Higher Education. Retrieved from https://www.chronicle.com/article/Overburdened-Mental-Health/247159

Keeling, R. P., \& Heitzmann, D. (2003). Financing health and counseling services. New Directions for Student Services, 103, 39-58. https://doi.org/10.1002/ss.98 
Kern, A., Heininger, W., Klueh, E., Salazar, S., Hansen, B., Meyer, T., \& Eisenberg, D. (2017). Athletes connected: Results from a pilot project to address knowledge and attitudes about mental health among college student-athletes. Journal of Clinical Sport Psychology, 11(4), 324-336. https://doi.org/10.1123/JCSP.2016-0028

King Lyn, M. M. (2017a). Professional issues in college counseling center staffing. In S. J. Hodges, K. Shelton, \& M. M. King Lyn (Eds.), The college and university counseling manual: Integrating essential services across the campus (pp. 89-107). Springer.

King Lyn, M. M. (2017b). Essential services in college counseling. In S. J. Hodges, K. Shelton, \& M. M. King Lyn (Eds.), The college and university counseling manual: Integrating essential services across the campus (pp. 41-64). Springer.

Kitzrow, M. A. (2009). The mental health needs of today’s college students: Challenges and recommandations. NASPA Journal, 46(4), 646-660. doi: 10.2202/1949-6605.5037

Kornspan, A. S., \& Duve, M. A. (2006). A niche and a need: A summary of the need for sport psychology consultants in collegiate sports. Annals of American Psychotherapy, 9(1), 1925.

Kuroiwa, J. Y. (2019). A first step: Analyzing the professional quality of life of U.S. college mental health counselors (Publication No. 2868) [Doctoral dissertation, University of Texas at El Paso]. Open Access Theses \& Dissertations.

LeViness, P., Bershad, C., Gorman, K., Braun, L., Murray, T. (2018). The Association for University and College Counseling Center Directors annual survey 2018. Obtained from https://www.aucced.org/director-surveys-public 
LeViness, P., Gorman, K., Braun, L., Koenig, L., \& Bershad, C. (2019). The Association for University and College Counseling Center Directors annual survey: 2019. Obtained from https://www.aucced.org/director-surveys-public

Lewis, K. R., \& Shah, P. P. (2019). Black students' narratives of diversity and inclusion initiatives and the campus racial climate: An interest-convergence analysis. Journal of Diversity in Higher Education. https://doi.org/10.1037/dhe0000147

Liang, Y. S., \& Shepherd, M. A. (2020). A multicultural content analysis of mental health private practices' websites and intake forms. Professional Psychology: Research and Practice, 51(4), 325- 334. https://doi.org/10.1037/pro0000305

Lincoln, Y. S., Lynham, S. A., \& Guba, E. G. (2011). Paradigmatic controversies, contradictions, and emerging confluences, revisited. In N.K. Denzin \& Y. S. Lincoln (Eds.), The Sage handbook of qualitative research (4th ed., pp. 97-128). London: Sage.

López, R. L., \& Levy, J. J. (2013). Student athletes' perceived barriers to and preferences for seeking counseling. Journal of College Counseling, 16(1), 19-31. https://doi.org/10.1002/j.2161-1882.2013.00024.X

Loughran, M., Etzel, E. F., \& Hankes, D. (2014). Ethical issues in work with collegiate studentathletes. In E. F. Etzel \& J. C. Watson II (Eds.), Ethical issues in sport, exercise, and performance psychology (pp. 37-48). Morgantown, WV: FiT Publishing.

Lubker, J. R., Visek, A. J., Watson, J. C., \& Singpurwalla, D. (2012). Athletes' preferred characteristics and qualifications of sport psychology practitioners: A consumer market analysis. Journal of Applied Sport Psychology, 24(4), 465-480. doi: $10.1080 / 10413200.2012 .694968$ 
Maniar, S. D., Curry, L. A., Sommers-Flanagan, J., \& Walsh, J. A. (2001). Student-athlete preferences in seeking help when confronted with sport performance problems. The Sport Psychologist, 15(2), 205-223. https://doi.org/10.1123/tsp.15.2.205

McCarver, Z., Anderson, S., Vosloo, J., \& Harenberg, S. (2019). Diversity characteristics and experiences of discrimination in Certified Mental Performance Consultants. The Sport Psychologist, 33(3), 228-231. https://doi.org/10.1123/tsp.2018-0126

McDuff, D. R. (2012). Sports psychiatry: Strategies for life balance and peak performance. Arlington, VA: American Psychiatric Association.

McDuff, D. R., Morse, E. D., \& White, R. K. (2005). Professional and collegiate team assistance programs: Services and utilization patterns. Clinics in Sports Medicine, 24(4), 943-958. https://doi.org/10.1016/j.csm.2005.02.001

Mitchell, S. L., Oakley, D. R., \& Dunkle, J. H. (2019). White paper: A multidimensional understanding of effective university and college counseling center organizational structures. Journal of College Student Psychotherapy, 33(2), 89-106. https://doi.org/10.1080/87568225.2019.1578941

Moore, M. (2016). Do psychosocial services make the starting lineup? Providing services to student-athletes. Journal of Amateur Sport, 2(2), 50-74. https://doi.org/10.17161/jas.v0i0.5046

Moreland, J. J., Coxe, K. A., \& Yang, J. (2018). Collegiate athletes' mental health services utilization: A systematic review of conceptualizations, operationalizations, facilitators, and barriers. Journal of Sport and Health Science, 7(1), 58-69.

https://doi.org/10.1016/j.jshs.2017.04.009 
Morse, E. D. (2013). Sports psychiatrists working in college athletic departments. In D. A. Baron, C. L. Reardon, \& S. H. Baron (Eds.), Clinical sports psychiatry: An international perspective (pp. 203-214). John Wiley \& Sons.

Much, K., Wagener, A. M., \& Hellenbrand, M. (2010). Practicing in the 21 st century college counseling center. Journal of College Student Psychotherapy, 24(1), 32-38. https://doi.org/10.1080/87568220903400138

National Collegiate Athletic Association (2016). Interassociation consensus document: Mental health best practices. Indianapolis, IN: National Collegiate Athletic Association.

National Collegiate Athletic Association (2017). NCAA study of student-athlete social environments (2012-2016). Retrieved from http://www.ncaa.org/about/resources/ research/ncaa-social-environments-study

Parcover, J., Mays, S., \& McCarthy, A. (2015). Implementing a public health approach to addressing mental health needs in a university setting: Lessons and challenges. Journal of College Student Psychotherapy, 29, 197-210. doi: 10.1080/87568225.2015.1045781

Petrie, T. A., Diehl, N. S., \& Watkins Jr., E. W. (1995). Sport psychology: An emerging domain in the counseling psychology profession. The Counseling Psychologist, 23(3), 535-545. https://doi.org/10.1177/0011000095233010

Pierce, R. A. (1969). Athletes in psychotherapy: How many, how come? Journal of the American College Health Association, 17(3), 244-249.

Quartiroli, A., Etzel, E. F., Knight, S. M., \& Zakrajsek, R. A. (2019a). The multifaceted meaning of sport psychology professional quality of life. Journal of Clinical Sport Psychology, 13(4), 645-667. https://doi.org/10.1123/jcsp.2017-0048 
Quartiroli, A., Etzel, E. F., Knight, S. M., \& Zakrajsek, R. A. (2019b). Self-care as key to others' care: The perspectives of globally situated experienced senior-level sport psychology practitioners. Journal of Applied Sport Psychology, 31(2), 147-167. https://doi.org/10.1080/10413200.2018.1460420

Rancourt, D., Brauer, A., Palermo, M., Choquette, E. M., \& Stanley, C. (2020). Response to Tomalski et al. (2019): Recommendations for adapting a comprehensive athlete mental health screening program for broad dissemination. Journal of Sport Psychology in Action, 11(1), 57-67. https://doi.org/10.1080/21520704.2020.1722770

Romm, N. (2007). Issues of accountability in survey, ethnographic and action research. In A. Rwomire \& F. B. Nyamnjoh (Eds.), Challenges and responsibilities of social research in Africa: Ethical issues (pp. 51-74). Addis Ababa, Ethiopia: OSSREA.

Romm, N. R. (2013). Employing questionnaires in terms of a constructivist epistemological stance: Reconsidering researchers' involvement in the unfolding of social life. International Journal of Qualitative Methods, 12(1), 652-669. https://doi.org/10.1177/160940691301200136

Romm, N. R. (2014). Active and accountable social inquiry: Implications and examples. Participatory Educational Research, 1(2), 13-20. https://doi.org/10.17275/per.14.07.1.2

Schlimmer, E., \& Chin, J. W. (2018). Addressing psychiatric disorders among student-athletes: Challenges facing mental health professionals in NCAA Division I athletics. The International Journal of Sport and Society, 10(1), 49-66. http://doi.org/10.18848/21527857/CGP/v10i01/49-66

Schwartz, V. (2013). College mental health at the cutting edge? Journal of College Student Psychotherapy, 27(2), 96-98. https://doi.org/10.1080/87568225.2013.766094 
Shelton, K. (2017). Multicultural counseling competency and diversity issues. In S. J. Hodges, K. Shelton, \& M. M. King Lyn (Eds.), The college and university counseling manual: Integrating essential services across the campus (pp. 13-40). Springer.

Sudano, L. E., \& Miles, C. M. (2017). Mental health services in NCAA Division I athletics: A survey of head ATCs. Sports Health: A Multidisciplinary Approach, 9(3), 262-267. https://doi.org/10.1177/1941738116679127

Tracy, S. J. (2010). Qualitative quality: Eight “big-tent” criteria for excellent qualitative research. Qualitative Inquiry, 16(10), 837-851. https://doi.org/10.1177/1077800410383121

Vespia, K. M. (2007). A national survey of small college counseling centers: Successes, issues, and challenges. Journal of College Student Psychotherapy, 22(1), 17-40. https://doi.org/10.1300/J035v22n01_03

Watkins, D. C., Hunt, J. B., \& Eisenberg, D. (2012). Increased demand for mental health services on college campuses: Perspectives from administrators. Qualitative Social Work, 11(3), 319-337. https://doi.org/10.1177/1473325011401468

Way, W. C., Coker-Cranney, A. M., \& Watson II, J. C. (2020). "So many mental health issues go unsaid": Implications for best practice guidelines from student-athletes' perspectives about service availability. Journal of Clinical Sport Psychology, 14(3), 305-324. https://doi.org/10.1123/jcsp.2019-0051

Wilson, K. A., Gilbert, J. N., Gilbert, W. D., \& Sailor, S. R. (2009). College athletic directors' perceptions of sport psychology consulting. The Sport Psychologist, 23(3), 405-424. https://doi.org/10.1123/tsp.23.3.405 
Wolanin, A. T. (2007). Clinical sport psychology services based in a doctoral training clinic. Journal of Clinical Sport Psychology, 1(3), 270-280. https://doi.org/10.1123/jcsp.1.3.270

Woolway, T., \& Harwood, C. (2015). Do titles matter in sport psychology? Performer attitudes toward professional titles and the effect of a brief intervention. The Sport Psychologist, 29(2), 171-182. https://doi.org/10.1123/tsp.2014-0050

Woolway, T., \& Harwood, C. G. (2020). Consultant characteristics in sport psychology service provision: A critical review and future research directions. International Journal of Sport and Exercise Psychology, 18(1), 46-63. https://doi.org/10.1080/1612197X.2018.1462230

Yu, A. B., Nguyen, T., \& Petrie, T. (2016). The Jeremy Lin effect: Being an Asian sport psychology consultant in a Black and White world. Journal of Clinical Sport Psychology, 10(4), 289-308. https://doi.org/10.1123/jcsp.2016-0006

Zillmer, E. A., \& Gigli, R. W. (2007). Clinical sport psychology in intercollegiate athletics. Journal of Clinical Sport Psychology, 1(3), 210-222. https://doi.org/10.1123/jcsp.1.3.210 


\section{Appendix A: Tables and Figures}

Table 1. Summary of sub-questions and planned analyses.

Objective 1. Identify and describe the population of CSP personnel from NCAA member institution websites.

Sub-Question

Planned Analysis

1a How many mental health practitioners identify with Frequencies cross-tabulated by a clinical interest in sport psychology/student- division level athletes relative to applied practitioners without clinical training?

1b How many of these clinical practitioners have titles Deductive content analysis, referencing sport psychology or athletics? cross-tabulated frequencies

1c What credentials (education, licensures, $\quad$ Frequencies cross-tabulated by certifications) do CSP practitioners list? division level

Objective 2. Describe practitioner perspectives of mental health service availability at their institution, and the perceived demand for services among student-athletes.

\section{Sub-Question}

2a How do practitioners rate the demand for sport psychology and broader mental health services among student-athletes at their institution?

$2 \mathrm{~b}$ What is the perceived demand for sport psychology services (clinical and applied) among practitioners at institutions that do not currently offer them?

2c Relative to perceived demand, how do practitioners rate the availability of sport psychology and broader mental health services at their institution?

\section{Planned Analysis}

Frequencies cross-tabulated by division and proportion of clinical hours with athletics Frequencies cross-tabulated by division

Frequencies cross-tabulated by division and proportion of clinical hours with athletics

Objective 3. Explore the extent to which practitioners endorse common challenges and supports that have been identified in the literature.

\section{Sub-Question}

3a To what extent do practitioners endorse (i.e., agree/ disagree with based on their experience) common challenges and supports that have been identified in existing literature (see Table 2)?

$3 b$ Do practitioners tend to report different experiences of certain challenges/supports at higher vs. lower levels of perceived service availability?

3c What are participants currently needing as a person/practitioner to facilitate their work.
Planned Analysis

Frequencies: Descriptively summarized with deductive use of qualitative data T-test with high and low availability sub-samples (defined by number of services stretched/exceeded) Inductive thematic analysis (See also Appendix E) 
Table 2. Sources that guided survey item development.

Broad experiences
Campus administration had too much control over the way
psychological services were provided at my institution.

Jodoin \& Ayers, 2013; Keeling \& Heitzmann, 2003; Hack, 2007; Johnson, 2017

My institution as a whole promoted diversity and inclusion.

Hayes et al., 2011; Shelton, 2017;

Lewis \& Shah, 2019; Liang \&

Shepherd, 2020

I would have liked more time for my own professional

Bartholomew et al., 2017; Carr, development (continuing education, reading, conducting research, etc.). 2007; Johnson, 2017; Quartiroli et

I engaged in enough self-care to remain enthusiastic about al., 2019 my work.

Chamberlain, 2007; Jodoin \& Ayers, 2013; Moreland et al., 2018; Quartiroli et al., 2019

My caseload was too large. Vespia, 2007; Hack, 2007; Connole et al., 2014

My on-call obligations were reasonable. Bennett, 2007; Hack, 2007; Chamberlain, 2007

Subjectively, I felt overstretched by the number/severity of high-risk clients under my care.

Benton et al., 2003; Vespia, 2007;

Grayson \& Meilman, 2013; Watkins et al., 2012; Bennett, 2007; Flowers, 2007; Zillmer \&

Gigli, 2007

I would have liked more emotional support for stressors that I encountered as a practitioner.

Kadambi et al., 2010; Kafka, 2019; Ren et al., 2017

\begin{tabular}{l} 
Experiences with athletics/student-athletes \\
\hline I would have liked more peer consultation for my work \\
with student-athletes. \\
\hline I spent time being visible to student-athletes and coaches by \\
attending practices, competitions, etc.
\end{tabular}

Petrie et al., 1995; Carr, 2007; Rancourt et al., 2020

Chamberlain, 2007; Flowers, 2007; Carr, 2007; Wolanin, 2007; McDuff et al., 2005; Gross et al., 2020

Student-athletes at my institution had stigmatized views of mental health services. López \& Levy, 2013; Kaier et al., Athletics at my institution was a diverse and culturally inclusive space. 2015; Moore, 2017 Flowers, 2007; Yu et al., 2016; Carter \& Davila, 2017; McCarver et al., 2019

Athletics staff/administration at my institution respected the confidentiality of student-athletes' mental health service Bennett, 2007; Chamberlain, 2007; Etzel \& Watson II, 2007; use. Hack, 2007; Loughran el al., 2014; Schlimmer \& Chin, 2018

I could build rapport with student-athletes during my work Schlimmer \& Chin, 2018 with them.

Note: Plain font citations denote a sport psychology context, italicized denote college counseling literature, and bolded denote practitioner experiences in other mental health specialties. 
Table 3. Sport psychology practitioner presence cross-tabulated by NCAA division level.

\begin{tabular}{|c|c|c|c|c|c|c|c|c|c|c|c|c|c|c|}
\hline \multirow{2}{*}{$\begin{array}{c}\text { Staff } \\
\text { Category }\end{array}$} & \multirow[b]{2}{*}{ Div } & \multirow{2}{*}{$\begin{array}{c}\text { Total } \\
\text { Schools }\end{array}$} & \multirow{2}{*}{$\begin{array}{c}\text { Any } \\
\text { Staff }\end{array}$} & \multicolumn{3}{|c|}{1} & \multicolumn{2}{|l|}{2} & \multicolumn{2}{|l|}{$\mathbf{3}$} & \multirow{2}{*}{$\begin{array}{c}4 \\
\text { Staff }\end{array}$} & \multicolumn{3}{|c|}{$5+$} \\
\hline & & & & $\%$ & Staff & $\%$ & Staff & $\%$ & Staff & $\%$ & & $\%$ & Staff & $\%$ \\
\hline \multirow{4}{*}{$\begin{array}{c}\text { CSP } \\
\text { Staff }\end{array}$} & P5 & 65 & 65 & $100 \%$ & 13 & $20 \%$ & 16 & $25 \%$ & 14 & $22 \%$ & 10 & $15 \%$ & 12 & $18 \%$ \\
\hline & I & 287 & 121 & $42 \%$ & 68 & $24 \%$ & 30 & $10 \%$ & 14 & $5 \%$ & 6 & $2 \%$ & 3 & $1 \%$ \\
\hline & II & 320 & 37 & $12 \%$ & 34 & $11 \%$ & 2 & $1 \%$ & 1 & $0.3 \%$ & 0 & $0 \%$ & 0 & $0 \%$ \\
\hline & III & 449 & 48 & $11 \%$ & 39 & $9 \%$ & 9 & $2 \%$ & 0 & $0 \%$ & 0 & $0 \%$ & 0 & $0 \%$ \\
\hline \multirow{4}{*}{$\begin{array}{c}\text { CSP } \\
\text { Trainee }\end{array}$} & P5 & 65 & 13 & $20 \%$ & 8 & $12 \%$ & 4 & $6 \%$ & 1 & $2 \%$ & 0 & $0 \%$ & 0 & $0 \%$ \\
\hline & I & 287 & 24 & $8 \%$ & 18 & $6 \%$ & 5 & $2 \%$ & 1 & $0.3 \%$ & 0 & $0 \%$ & 0 & $0 \%$ \\
\hline & II & 320 & 6 & $2 \%$ & 4 & $1 \%$ & 1 & $0.3 \%$ & 0 & $0.3 \%$ & 1 & $0.3 \%$ & 0 & $0 \%$ \\
\hline & III & 449 & 21 & $5 \%$ & 18 & $4 \%$ & 2 & $0.4 \%$ & 1 & $0.2 \%$ & 0 & $0 \%$ & 0 & $0 \%$ \\
\hline \multirow{4}{*}{ Applied } & P5 & 65 & 7 & $11 \%$ & 5 & $8 \%$ & 2 & $3 \%$ & 0 & $0 \%$ & 0 & $0 \%$ & 0 & $0 \%$ \\
\hline & I & 287 & 29 & $10 \%$ & 25 & $9 \%$ & 0 & $0 \%$ & 0 & $0 \%$ & 1 & $0.3 \%$ & 3 & $1 \%$ \\
\hline & II & 320 & 7 & $2 \%$ & 7 & $2 \%$ & 0 & $0 \%$ & 0 & $0 \%$ & 0 & $0 \%$ & 0 & $0 \%$ \\
\hline & III & 449 & 6 & $1 \%$ & 5 & $1 \%$ & 1 & $0.2 \%$ & 0 & $0 \%$ & 0 & $0 \%$ & 0 & $0 \%$ \\
\hline
\end{tabular}

Note: Staff categories are clinical sport psychology staff, clinical sport psychology trainees, and applied sport psychology staff/trainees. Columns represent the number of institutions within each division that have any, one, two, three, four, or five or more practitioners in each category. The total number of schools in each division were carried across as the denominators to calculate percentages. 
Table 4. Cross-tabulation of demand for mental health services by division level and proportion of clinical hours with student-athletes.

\begin{tabular}{|c|c|c|c|c|c|c|c|c|c|c|c|c|c|c|c|}
\hline \multirow{3}{*}{\multicolumn{2}{|c|}{$\begin{array}{r}\% \text { Clinical hrs w/SAs } \\
\text { NCAA Division } \\
N \text { in Category }\end{array}$}} & \multicolumn{4}{|c|}{$\begin{array}{c}<\mathbf{1 0 \%} \\
\text { (Least time with SAs) }\end{array}$} & \multicolumn{4}{|c|}{$\begin{array}{c}10 \%-40 \% \\
\text { (Mod. time with SAs) }\end{array}$} & \multicolumn{4}{|c|}{$\begin{array}{c}\geq 41 \% \\
\text { (Most time with SAs) }\end{array}$} & \multirow[b]{2}{*}{ Sum } & \multirow[b]{4}{*}{$\begin{array}{c}\% \text { of } \\
\text { Category }\end{array}$} \\
\hline & & \multicolumn{2}{|c|}{ P5 \& D1 } & \multicolumn{2}{|c|}{ D2 \& D3 } & \multicolumn{2}{|c|}{ P5 \& D1 } & \multicolumn{2}{|c|}{ D2 \& D3 } & \multicolumn{2}{|c|}{ P5 \& D1 } & \multicolumn{2}{|c|}{ D2 \& D3 } & & \\
\hline & & & 47 & & 54 & & 93 & & 167 & & 72 & & 38 & 471 & \\
\hline & & $n$ & $\begin{array}{l}\% \text { of } \\
\text { Col. }\end{array}$ & $n$ & $\begin{array}{l}\% \text { of } \\
\text { Col. }\end{array}$ & $n$ & $\begin{array}{l}\% \text { of } \\
\text { Col. }\end{array}$ & $n$ & $\begin{array}{l}\% \text { of } \\
\text { Col. }\end{array}$ & $n$ & $\begin{array}{l}\% \text { of } \\
\text { Col. }\end{array}$ & $n$ & $\begin{array}{l}\% \text { of } \\
\text { Col. }\end{array}$ & $\begin{array}{l}\text { Row } \\
\text { Sum }\end{array}$ & \\
\hline & High & 8 & $17.0 \%$ & 5 & $9.3 \%$ & 32 & $234.8 \%$ & 21 & $12.7 \%$ & 35 & $48.6 \%$ & 6 & $15.8 \%$ & 107 & $22.8 \%$ \\
\hline & Moderate & 11 & $23.4 \%$ & 12 & $22.2 \%$ & 28 & $830.4 \%$ & 37 & $22.3 \%$ & 23 & $31.9 \%$ & 12 & $31.6 \%$ & 123 & $26.2 \%$ \\
\hline \multirow[t]{3}{*}{ CSP } & Low & 4 & $8.5 \%$ & 17 & $31.5 \%$ & 11 & $1 \quad 12.0 \%$ & 37 & $22.3 \%$ & 7 & $9.7 \%$ & 6 & $15.8 \%$ & 82 & $17.5 \%$ \\
\hline & No demand & 4 & $8.5 \%$ & 8 & $14.8 \%$ & 1 & $1.1 \%$ & 23 & $13.9 \%$ & 3 & $4.2 \%$ & 4 & $10.5 \%$ & 43 & $9.2 \%$ \\
\hline & Not sure & 20 & $42.6 \%$ & 12 & $22.2 \%$ & 20 & $0 \quad 21.7 \%$ & 48 & $28.9 \%$ & 4 & $5.6 \%$ & 10 & $26.3 \%$ & 114 & $24.3 \%$ \\
\hline General & High & 12 & $25.5 \%$ & 16 & $29.6 \%$ & 34 & $437.0 \%$ & 55 & $33.1 \%$ & 30 & $41.7 \%$ & 18 & $47.4 \%$ & 165 & $35.2 \%$ \\
\hline Mental & Moderate & 16 & $34.0 \%$ & 21 & $38.9 \%$ & 42 & $245.7 \%$ & 85 & $51.2 \%$ & 19 & $26.4 \%$ & 15 & $39.5 \%$ & 198 & $42.2 \%$ \\
\hline Health & Low & 13 & $27.7 \%$ & 13 & $24.1 \%$ & 13 & $314.1 \%$ & 17 & $10.2 \%$ & 15 & $20.8 \%$ & 2 & $5.3 \%$ & 73 & $15.6 \%$ \\
\hline \multirow[t]{3}{*}{ Coun. } & No demand & 0 & $0.0 \%$ & 1 & $1.9 \%$ & 1 & $1.1 \%$ & 0 & $0.0 \%$ & 2 & $2.8 \%$ & 0 & $0.0 \%$ & 4 & $0.9 \%$ \\
\hline & Not sure & 6 & $12.8 \%$ & 3 & $5.6 \%$ & 2 & $2.2 \%$ & 9 & $5.4 \%$ & 6 & $8.3 \%$ & 3 & $7.9 \%$ & 29 & $6.2 \%$ \\
\hline & High & 2 & $4.3 \%$ & 2 & $3.7 \%$ & 17 & $18.5 \%$ & 7 & $4.2 \%$ & 19 & $26.4 \%$ & 3 & $7.9 \%$ & 50 & $10.7 \%$ \\
\hline Applied & Moderate & 11 & $23.4 \%$ & 8 & $14.8 \%$ & 25 & $27.2 \%$ & 34 & $20.5 \%$ & 38 & $52.8 \%$ & 9 & $23.7 \%$ & 125 & $26.7 \%$ \\
\hline Sport & Low & 5 & $10.6 \%$ & 13 & $24.1 \%$ & 19 & $920.7 \%$ & 45 & $27.1 \%$ & 10 & $13.9 \%$ & 12 & $31.6 \%$ & 104 & $22.2 \%$ \\
\hline \multirow[t]{2}{*}{ Psych } & No demand & 8 & $17.0 \%$ & 14 & $25.9 \%$ & 6 & $6.5 \%$ & 18 & $10.8 \%$ & 0 & $0.0 \%$ & 2 & $5.3 \%$ & 48 & $10.2 \%$ \\
\hline & Not sure & 21 & $44.7 \%$ & 17 & $31.5 \%$ & 25 & $27.2 \%$ & 62 & $37.3 \%$ & 5 & $6.9 \%$ & 12 & $31.6 \%$ & 142 & $30.3 \%$ \\
\hline Mandated & High & 7 & $14.9 \%$ & 4 & $7.4 \%$ & 12 & $213.0 \%$ & 12 & $7.2 \%$ & 7 & $9.7 \%$ & 4 & $10.5 \%$ & 46 & $9.8 \%$ \\
\hline Coun. & Moderate & 13 & $27.7 \%$ & 10 & $18.5 \%$ & 33 & $335.9 \%$ & 46 & $27.7 \%$ & 11 & $15.3 \%$ & 13 & $34.2 \%$ & 126 & $26.9 \%$ \\
\hline (AOD or & Low & 10 & $21.3 \%$ & 26 & $48.1 \%$ & 28 & $830.4 \%$ & 67 & $40.4 \%$ & 40 & $55.6 \%$ & 14 & $36.8 \%$ & 185 & $39.4 \%$ \\
\hline \multirow[t]{4}{*}{ Conduct) } & No demand & 5 & $10.6 \%$ & 9 & $16.7 \%$ & 3 & $3.3 \%$ & 19 & $11.4 \%$ & 9 & $12.5 \%$ & 5 & $13.2 \%$ & 50 & $10.7 \%$ \\
\hline & Not sure & 12 & $25.5 \%$ & 5 & $9.3 \%$ & 16 & $6 \quad 17.4 \%$ & 22 & $13.3 \%$ & 5 & $6.9 \%$ & 2 & $5.3 \%$ & 62 & $13.2 \%$ \\
\hline & High & 9 & $19.6 \%$ & 9 & $16.7 \%$ & 14 & $4 \quad 15.2 \%$ & 20 & $12.0 \%$ & 15 & $20.8 \%$ & 4 & $10.5 \%$ & 71 & $15.2 \%$ \\
\hline & Moderate & 8 & $17.4 \%$ & 12 & $22.2 \%$ & 33 & $335.9 \%$ & 57 & $34.3 \%$ & 26 & $36.1 \%$ & 18 & $47.4 \%$ & 154 & $32.9 \%$ \\
\hline \multirow[t]{4}{*}{ Psychiatry } & Low & 10 & $21.7 \%$ & 21 & $38.9 \%$ & 22 & $223.9 \%$ & 51 & $30.7 \%$ & 25 & $34.7 \%$ & 11 & $28.9 \%$ & 140 & $29.9 \%$ \\
\hline & No demand & 0 & $0.0 \%$ & 5 & $9.3 \%$ & 3 & $3.3 \%$ & 5 & $3.0 \%$ & 1 & $1.4 \%$ & 2 & $5.3 \%$ & 16 & $3.4 \%$ \\
\hline & Not sure & 19 & $41.3 \%$ & 7 & $13.0 \%$ & 20 & $0 \quad 21.7 \%$ & 33 & $19.9 \%$ & 5 & $6.9 \%$ & 3 & $7.9 \%$ & 87 & $18.6 \%$ \\
\hline & High & 7 & $14.9 \%$ & 9 & $16.7 \%$ & 17 & $7 \quad 18.5 \%$ & 21 & $12.6 \%$ & 5 & $6.9 \%$ & 7 & $18.4 \%$ & 66 & $14.0 \%$ \\
\hline Crisis & Moderate & 12 & $25.5 \%$ & 20 & $37.0 \%$ & 43 & $346.7 \%$ & 70 & $41.9 \%$ & 28 & $38.9 \%$ & 20 & $52.6 \%$ & 193 & $41.1 \%$ \\
\hline \multirow[t]{3}{*}{ Interv. } & Low & 18 & $38.3 \%$ & 21 & $38.9 \%$ & 26 & $628.3 \%$ & 60 & $35.9 \%$ & 35 & $48.6 \%$ & 9 & $23.7 \%$ & 169 & $36.0 \%$ \\
\hline & No demand & 1 & $2.1 \%$ & 2 & $3.7 \%$ & 0 & $0.0 \%$ & 3 & $1.8 \%$ & 0 & $0.0 \%$ & 0 & $0.0 \%$ & 6 & $1.3 \%$ \\
\hline & Not sure & 9 & $19.1 \%$ & 2 & $3.7 \%$ & 6 & $6.5 \%$ & 13 & $7.8 \%$ & 4 & $5.6 \%$ & 2 & $5.3 \%$ & 36 & $7.7 \%$ \\
\hline
\end{tabular}

Note: Item sums do not equal 471 for all categories due to missing data. Highlighted cells are discussed in-text. 
Table 5. Cross-tabulation of perceived mental health service availability for students/student-athletes by division level and proportion of clinical hours with student-athletes.

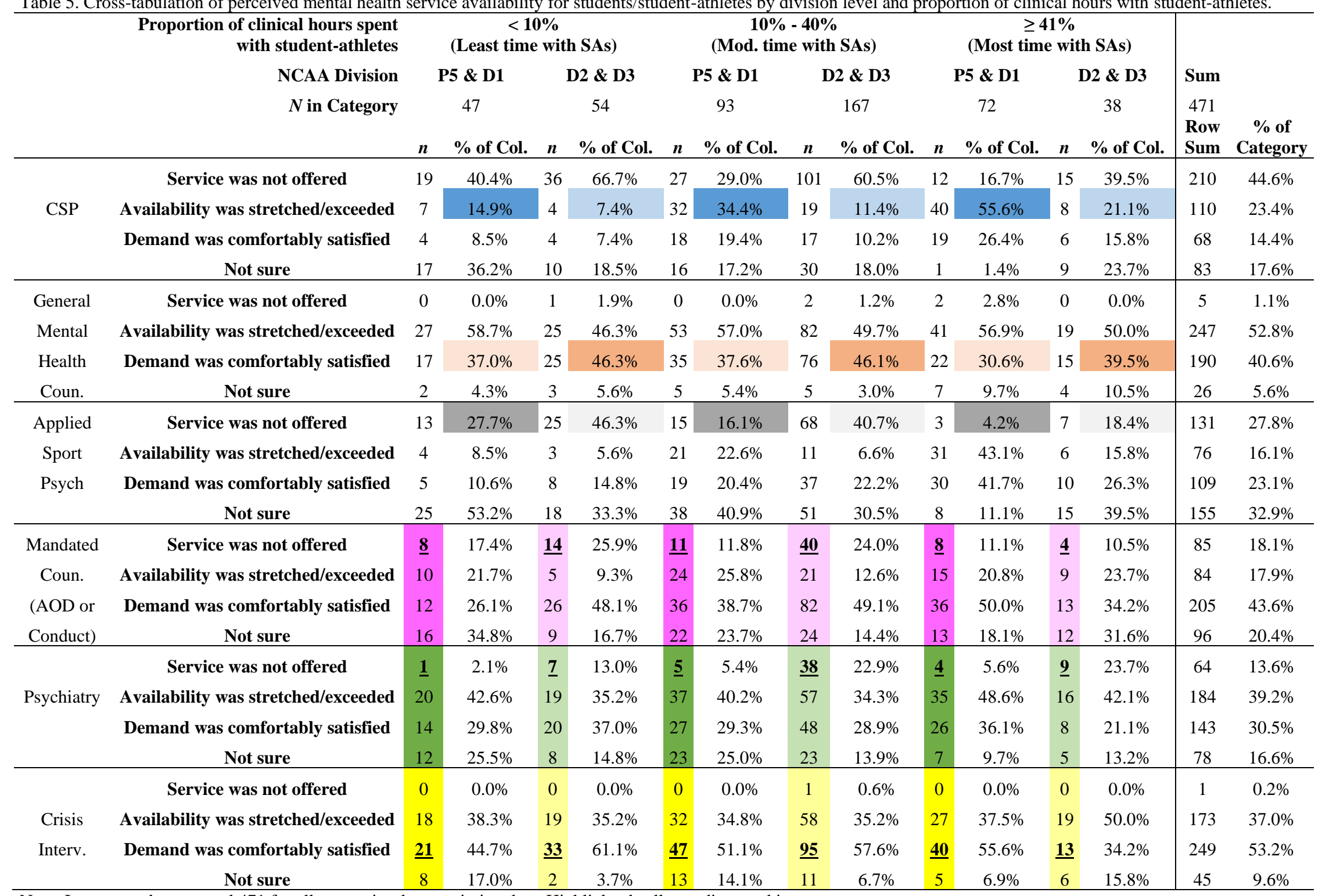

Note: Item sums do not equal 471 for all categories due to missing data. Highlighted cells are discussed in text. 
Table 6. Independent sample $t$-tests comparing experiential statements across low and high perceived service availability groups.

\begin{tabular}{|c|c|c|c|c|c|c|c|c|c|c|}
\hline & \multicolumn{2}{|c|}{ Low Availability } & \multicolumn{2}{|c|}{ High Availability } & \multicolumn{2}{|c|}{ Levene's } & \multirow[b]{2}{*}{$t$} & \multirow[b]{2}{*}{ Df } & \multirow[b]{2}{*}{$p$} & \multirow[b]{2}{*}{$d$} \\
\hline & $M$ & $S D$ & $M$ & $S D$ & $F$ & $p$ & & & & \\
\hline More prof. development & 2.30 & 0.87 & 1.83 & 1.11 & 7.76 & $<.05$ & 3.87 & 172 & .001 & 0.44 \\
\hline Enough self-care & 1.69 & 1.01 & 2.20 & 0.84 & 6.99 & .01 & -4.07 & 119 & .001 & -0.57 \\
\hline Caseload was too large & 2.20 & 0.90 & 1.47 & 1.01 & 7.31 & .01 & 6.08 & 152 & .001 & 0.73 \\
\hline On-call hrs reasonable & 2.11 & 0.93 & 2.49 & 0.86 & 0.15 & .7 & -3.02 & 251 & .003 & -0.43 \\
\hline Overstretched by risk & 1.86 & 0.98 & 1.18 & 0.95 & .001 & .9 & 5.51 & 313 & .001 & 0.71 \\
\hline More emotional support & 1.94 & 0.97 & 1.55 & 1.06 & 6.75 & .01 & 3.09 & 148 & .002 & 0.38 \\
\hline
\end{tabular}

Note: All tests were significant with a Bonferroni correction setting alpha at .008. For context, agree/disagree responses were re-coded as follows: disagree $=0$, slightly disagree $=1$, slightly agree $=2$, agree $=3$. The low availability group included practitioners who listed four, five, or six services (out of six total services) as stretched or exceeded by demand. The high availability group listed one or zero services as stretched or exceeded by demand. 
Table 7. Themes, sub-themes, and initial codes from inductive thematic analysis.

\begin{tabular}{|c|c|}
\hline Theme: The Demand for Mental Health Services & $n$ \\
\hline \multicolumn{2}{|l|}{ COVID-19 } \\
\hline Anticipate/prep for demand that COVID-19 could create & 10 \\
\hline Context - Uncertainty about demand/the semester ahead & 10 \\
\hline Context - COVID-19 increases demand for mental health services & 6 \\
\hline Context - Fluctuation in demand for services since COVID-19 & 1 \\
\hline \multicolumn{2}{|l|}{ Demand for Remote Services } \\
\hline Context - Remote services are less sought after & 24 \\
\hline Context - "Mixed response" to remote services & 3 \\
\hline Context - Remote services are less accessible for some & 7 \\
\hline Context - Remote services are more accessible for some & 7 \\
\hline \multicolumn{2}{|l|}{ Broadly } \\
\hline Context - "Demand keeps growing" & 10 \\
\hline Context - In general, demand for services is high & 7 \\
\hline Context - Demand is currently lower than expected & 1 \\
\hline Context - Less service use, higher severity & 1 \\
\hline Context - Different rates of service use across demographics & 1 \\
\hline More diverse staffing could alleviate barriers to service use & 2 \\
\hline \multicolumn{2}{|l|}{ From Athletics } \\
\hline Context - Recent increase in student-athlete mental health service use & 4 \\
\hline Context - Encouraged by rate of service use among student-athletes & 1 \\
\hline Context - High demand for sport psychology, but it’s not offered & 1 \\
\hline Context - Proportionally, less student-athletes use services but with higher acuity & 1 \\
\hline Context - In general, demand for services is low among student-athletes & 2 \\
\hline \multicolumn{2}{|l|}{ Observations About What Some Clients Are Facing } \\
\hline Context - Emotional impacts of current events on students/student-athletes & 15 \\
\hline Context - COVID-19 impacts clients’ self-care & 5 \\
\hline Context - Mixed message: students are on campus, but CAPS is remote & 1 \\
\hline
\end{tabular}

Note: Coding reflects responses to the inquiry about what participants were needing as people/practitioners to facilitate their work. Codes were assigned to both contextual observations that were shared (prefaced with "Context - ...") and more explicitly stated needs. 
Table 7 cont. Themes, sub-themes, and initial codes from inductive thematic analysis.

\begin{tabular}{|c|c|}
\hline Theme: Insights Regarding Clinical Services and their Delivery & $n$ \\
\hline \multicolumn{2}{|l|}{ What Some Centers Are Needing } \\
\hline Intentional response to issues of race/diversity & 13 \\
\hline BIPOC staffing helps; broader, more proactive, and sustained dialogue is needed & 1 \\
\hline After hours crisis intervention services & 1 \\
\hline Better response to cases of sexual assault & 1 \\
\hline More accessible psychiatric resources & 5 \\
\hline Better communication with off-campus resources & 1 \\
\hline More integrative care/collaboration with campus constituents & 2 \\
\hline Innovative approaches to prevention & 1 \\
\hline Catch 22 prevents change & 3 \\
\hline How to provide information about services/promote engagement & 3 \\
\hline Promote understanding of CAPS policies and counseling & 2 \\
\hline \multicolumn{2}{|l|}{ How Some Centers Are Adjusting } \\
\hline Context - Less visibility to students/groups while remote & 7 \\
\hline Context - Increased emphasis on outreach at present & 7 \\
\hline Context - Outreach can be a double-edged sword & 2 \\
\hline Context - Campus mental health services were/are outsourced & 6 \\
\hline Context - Ancillary services added to offset demand & 2 \\
\hline Context - Developing a walk-in clinic has been a win-win for CAPS and for students & 1 \\
\hline Context - CAPS provides group services but students don't like group work & 1 \\
\hline \multicolumn{2}{|l|}{ Adjustments That Some Practitioners Are Maneuvering } \\
\hline Remote work "is not an equivalent substitute for in-person contact" & 9 \\
\hline Context - Difficulty of remote work & 8 \\
\hline Context - Gratitude to continue work remotely & 3 \\
\hline Context - Opportunities for "some good work" while remote & 1 \\
\hline Context - Dynamic situation makes scheduling/consistency difficult & 2 \\
\hline Context - Maneuvering new protocols and procedures & 5 \\
\hline Context - Difficulty of case management when schools closed & 1 \\
\hline Maneuvering In-person services that now "feel more sterile" & 2 \\
\hline Context - COVID-19 impacts treatment related to loneliness & 1 \\
\hline
\end{tabular}

Note: Coding reflects responses to the inquiry about what participants were needing as people/practitioners to facilitate their work. Codes were assigned to both contextual observations that were shared (prefaced with "Context - ...") and more explicitly stated needs. 
Table 7 cont. Themes, sub-themes, and initial codes from inductive thematic analysis.

\begin{tabular}{|c|c|}
\hline Theme: Equipping Professionals & $n$ \\
\hline \multicolumn{2}{|l|}{ Preparing for/Supporting Remote Work } \\
\hline Portability of licensure & 15 \\
\hline Training for remote work/platforms & 15 \\
\hline Context - Received training for remote work & 1 \\
\hline Reliable technology for remote work (wifi, access to software, etc.) & 10 \\
\hline \multicolumn{2}{|l|}{ Professional Development } \\
\hline Consultation/Supervision & 11 \\
\hline Consultation with sport psychology mentors & 3 \\
\hline More connection with others in the field & 3 \\
\hline Context - Demands on senior staff preclude supervision & 1 \\
\hline Context - As a lone provider, opportunities for consultation are limited & 1 \\
\hline Continuing education/Professional development & 12 \\
\hline Training to improve cultural competency & 3 \\
\hline Context - Budget cuts remove support for continuing education & 4 \\
\hline Involvement in professional organizations & 1 \\
\hline \multicolumn{2}{|l|}{ Human and Financial Resources } \\
\hline Increased staffing & 64 \\
\hline Increased BIPOC staffing & 2 \\
\hline More diverse staff & 1 \\
\hline Context - Student advocacy for BIPOC has gone unanswered & 1 \\
\hline Stronger leadership from clinical administration & 4 \\
\hline Context - COVID-19 impacts training program/trainee services & 2 \\
\hline More financial resources & 10 \\
\hline Context - Furlough or funding issues despite demand & 17 \\
\hline Context - "It feels as though the mantra is "do more with less"" & 2 \\
\hline Context - COVID-19 exacerbates preexisting financial strain & 1 \\
\hline Context - Conditional support from executive administration & 1 \\
\hline \multicolumn{2}{|l|}{ Logistics } \\
\hline Comprehensive services and protocols to support BIPOC students, staff, faculty & 2 \\
\hline More attention to safety in institutional response to COVID-19 & 10 \\
\hline More efficient distribution of information & 3 \\
\hline More information amid uncertainty & 3 \\
\hline More physical space & 2 \\
\hline Locating all support services together would enhance delivery & 1 \\
\hline
\end{tabular}

Note: Coding reflects responses to the inquiry about what participants were needing as people/practitioners to facilitate their work. Codes were assigned to both contextual observations that were shared (prefaced with "Context - ...") and more explicitly stated needs. 
Table 7 cont. Themes, sub-themes, and initial codes from inductive thematic analysis.

\section{Theme: Oversight and Organizational Dynamics}

Esteem, broadly

"There are so many ways that I've felt undervalued in my institution"

More awareness/recognition of "unseen" efforts

Better compensation

Context - Needs satisfied

Dialogue

Address discrepancies in staff/administration viewpoints

More voice with administration

Context - Unanswered advocacy

\section{Oversight Eventually Impacts Students}

Context - Treatment quality suffers with too few staff

Context - Too few staff translates to wait times for students seeking services 3

Context - Referring out creates "issues of affordability/access" 2

Context - Limited services means limited support for retention/graduation 1

Context - Furloughs decrease service availability, students will be referred out

Note: Coding reflects responses to the inquiry about what participants were needing as people/practitioners to facilitate their work. Codes were assigned to both contextual observations that were shared (prefaced with "Context - ...") and more explicitly stated needs. 
Table 7 cont. Themes, sub-themes, and initial codes from inductive thematic analysis.

\section{Theme: Support at the Intersection of Person and Professional}

Connectedness with Colleagues

Collegial support/collaboration

Context - High collegial support has been appreciated

\section{Self-Care}

Support for self-care

Support Re: "dealing with the same issues as every one else"

Context - COVID-19 impacts practitioner self-care

Context - Insight of self in system

Sabbaticals

\section{Support in the Structure of the Workday}

More time for administrative tasks, case management, prep, etc. 8

More flexibility with scheduling $\quad 5$

$\begin{array}{lr}\text { Context - Multiple roles } & 6\end{array}$

$\begin{array}{lr}\text { Fewer "hats" to wear } & 6\end{array}$

Smaller caseload $\quad 4$

Attention to severity of caseload based on clinician identity $\quad 1$

More self-care at work $\quad 3$

Context - Self-care is "intentionally integrated" by director $\quad 1$

Time for non-clinical professional activities to decrease emotional fatigue $\quad 1$

\section{Support for the Remote Workday}

Support for the balance of family life and remote work $\quad 5$

Enhanced home workspace for remote work 3

Adjusted caseload due to difficulty of remote work 3

Compassion/understanding amid adjustments 3

Note: Coding reflects responses to the inquiry about what participants were needing as people/practitioners to facilitate their work. Codes were assigned to both contextual observations that were shared (prefaced with "Context - ...") and more explicitly stated needs. 
Table 7 cont. Themes, sub-themes, and initial codes from inductive thematic analysis.

\begin{tabular}{|c|c|}
\hline Theme: Opportunities and Obstacles in the Context of Athletics & $n$ \\
\hline \multicolumn{2}{|l|}{ The mental health climate in athletics } \\
\hline More buy-in to mental health and sport psychology within athletics & 6 \\
\hline Normalize mental health for student-athletes & 3 \\
\hline Context - CAPS/Sport Psych as a band-aid in culture of athletics & 6 \\
\hline Context - Increased emphasis on mental health follows from student-athlete suicide & 1 \\
\hline Context - Coaches hold more stigma than athletes & 2 \\
\hline Context - Culture of athletics can be "anti mental health" & 1 \\
\hline Context - Stigma in athletics is decreasing & 2 \\
\hline Context - Have buy in from athletics & 1 \\
\hline \multicolumn{2}{|l|}{ Navigating organizational dynamics in athletics } \\
\hline Respect for confidentiality in athletics & 6 \\
\hline Context - Student-athlete concerns about confidentiality & 2 \\
\hline Context - Power dynamics/Who is the client & 1 \\
\hline Involvement of coaches/athletics staff in mental health prevention efforts & 5 \\
\hline Broader acknowledgment of "how strange and stressful these times are" from athletics & 1 \\
\hline Clarify issues regarding medication with sports med & 1 \\
\hline Clarity about distinction between mental health and psychological skills training & 1 \\
\hline \multicolumn{2}{|l|}{ Constructing a bridge between CAPS and athletics } \\
\hline Enhanced access and collaboration between athletics and CAPS & 16 \\
\hline Training for CAPS staff to support student-athletes & 10 \\
\hline Need time in schedule for athletics & 2 \\
\hline Context - Outreach to athletics & 6 \\
\hline Context - Athletic trainers are "valuable support and liaisons" & 4 \\
\hline Context - Staff/member sought or received training for work with athletics & 2 \\
\hline Context - With limited resources, can't give preferential treatment to athletics & 1 \\
\hline Context - Good working relationship with athletics & 1 \\
\hline \multicolumn{2}{|l|}{ Pros and cons of services embedded within athletics } \\
\hline Context - "Sequestered from the services offered to the general student population" & 5 \\
\hline Context - Sequestered student-athletes seek CAPS at times & 1 \\
\hline Training student-athletes to navigate existing systems is better than catered services & 1 \\
\hline Context - Embedded or sport psychology services facilitated student-athlete service use & 3 \\
\hline More resources for student-athletes, given unique stressors & 2 \\
\hline
\end{tabular}

Note: Coding reflects responses to the inquiry about what participants were needing as people/practitioners to facilitate their work. Codes were assigned to both contextual observations that were shared (prefaced with "Context - ...") and more explicitly stated needs. 


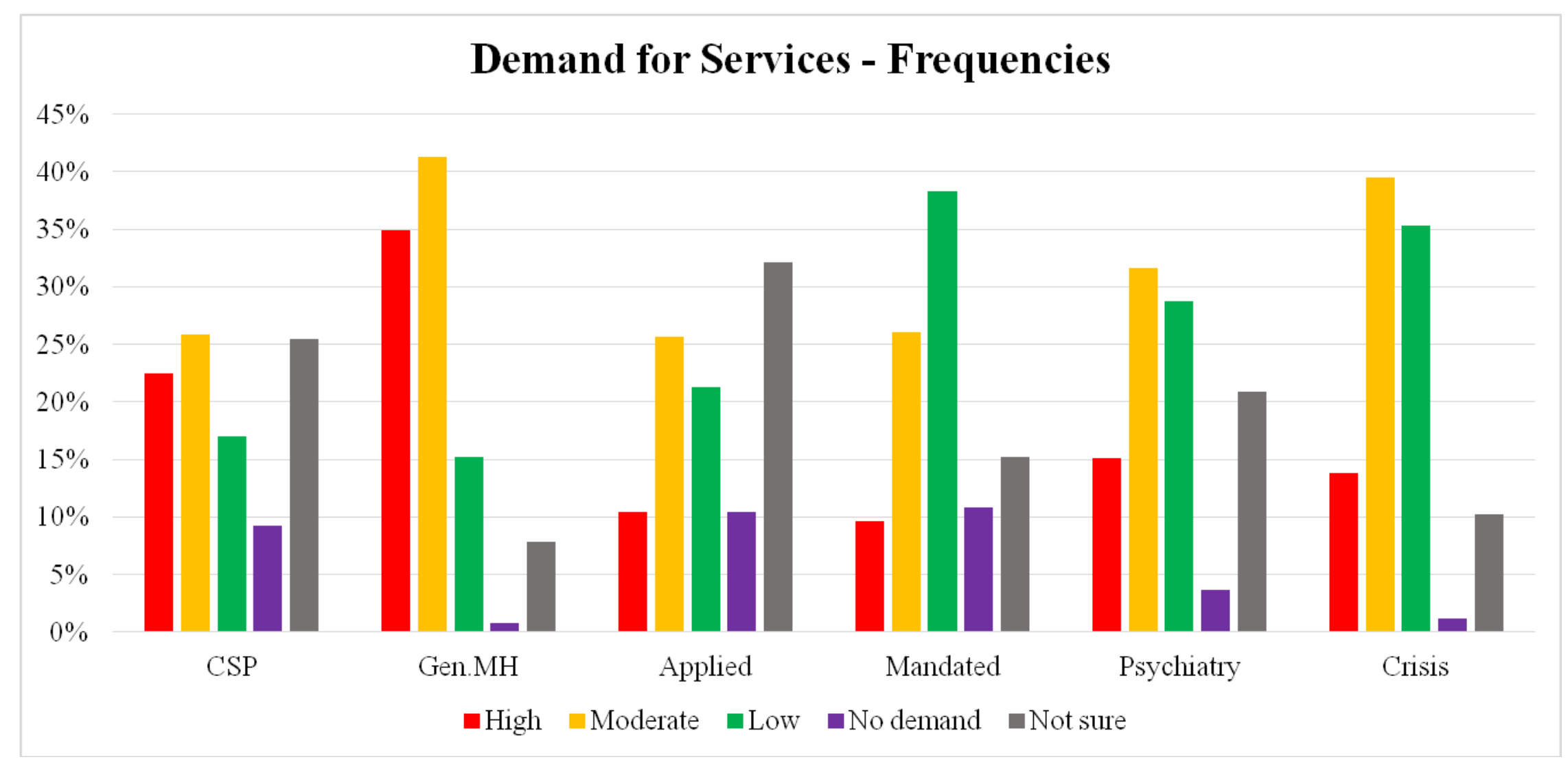

Figure 1. Frequencies of perceived demand for services among student-athletes. Services include mental health counseling from a sport psychology specialist (CSP), counseling from all other clinical staff (Gen.MH), applied sport psychology, mandated counseling (substance abuse/conduct), psychiatry, and crisis intervention. 


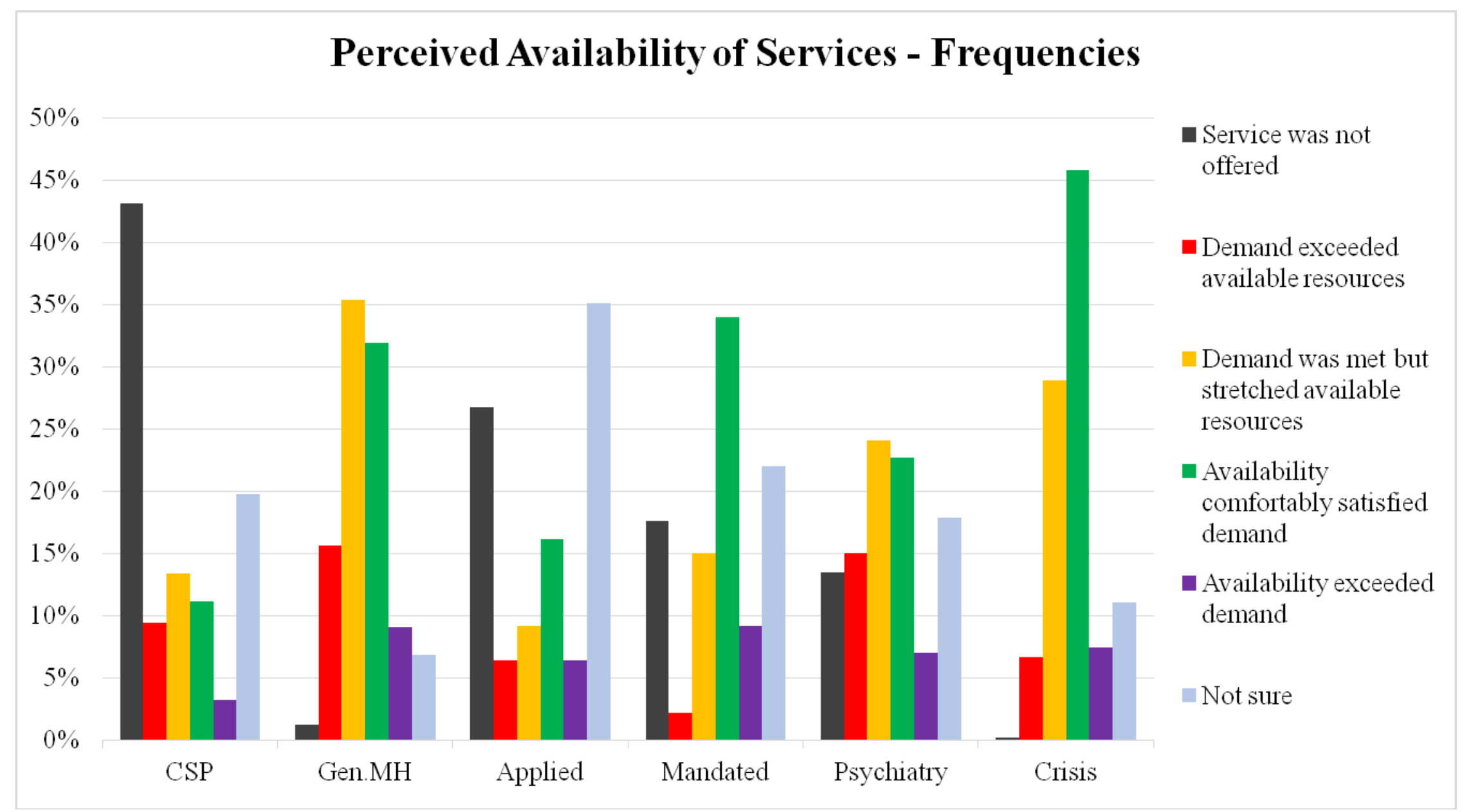

Figure 2. Frequencies of perceived availability of services (for students and/or student-athletes). Services include mental health counseling from a sport psychology specialist (CSP), counseling from all other clinical staff (Gen.MH), applied sport psychology, mandated counseling (substance abuse/conduct), psychiatry, and crisis intervention. 


\section{Appendix B: Text Version of Qualtrics Survey}

-- WELCOME SCREEN --

\section{Practitioner Perspectives and Data for Dialogue}

We're eager to hear from you. Before we get stared, let us reiterate the goals of this project and how we intend to protect your data.

Insert informed consent here...

Do you consent to participate in this survey? Yes / No

-- PAGE BREAK 1 --

\section{Section 1 of 4}

Thinking back to what things were like before COVID-19, how would you describe your experiences as a service provider? Let us know how much you agree or disagree with each statement based on your experience.

Campus administration had too much control over the way psychological services were provided at my institution.

Agree, Agree slightly, Disagree slightly, Disagree, Can't say from my experience

My institution as a whole promoted diversity and inclusion.

Agree, Agree slightly, Disagree slightly, Disagree

I would have liked more time for my own professional development (continuing education, reading, conducting research, etc.).

Agree, Agree slightly, Disagree slightly, Disagree

I engaged in enough self-care to remain enthusiastic about my work.

Agree, Agree slightly, Disagree slightly, Disagree

My caseload was too large.

Agree, Agree slightly, Disagree slightly, Disagree

My on-call obligations were reasonable.

Agree, Agree slightly, Disagree slightly, Disagree, I did not have on-call hours

Subjectively, I felt overstretched by the number/severity of high-risk clients under my care. Agree, Agree slightly, Disagree slightly, Disagree, I did not encounter instances of risk management

I would have liked more emotional support for stressors that I encountered as a practitioner.

Agree, Agree slightly, Disagree slightly, Disagree 
-- PAGE BREAK 2 --

\section{Section 2 of 4}

Thanks for sharing your perspectives. In this section, we'd like to hear about your experiences with varsity student-athletes as a population with multiple intersecting identities. Whether you work with student-athletes directly or indirectly, every day or very rarely, your input is valid and valued. As in the previous section, let us know how much you agree or disagree with each statement based on your experiences before COVID-19.

I could build rapport with student-athletes during my work with them.

Agree, Agree slightly, Disagree slightly, Disagree, I had never worked with a studentathlete

Athletics at my institution was a diverse and culturally inclusive space.

Agree, Agree slightly, Disagree slightly, Disagree, Can't say from my experience

Student-athletes at my institution had stigmatized views of mental health services.

Agree, Agree slightly, Disagree slightly, Disagree, Can't say from my experience

I would have liked more peer consultation for my work with student-athletes.

Agree, Agree slightly, Disagree slightly, Disagree, I had never worked with a studentathlete

I spent time being visible to student-athletes and coaches by attending practices, competitions, etc.

Agree, Agree slightly, Disagree slightly, Disagree

Athletics staff/administration at my institution respected the confidentiality of student-athletes' mental health service use.

Agree, Agree slightly, Disagree slightly, Disagree, Can’t say from my experience

\section{Demand for Services}

Before COVID-19, how would you have rated the demand for the following services (listed below) among student-athletes at your institution? Please rate the level of demand that you perceived whether or not the service was offered.

Note: with performance consultation we are referring to individual or group work focused on mental skills for sport performance (e.g., arousal regulation, mental imagery, team communication, etc.) with little or no focus on broader mental health issues. 
Whether or not they were offered, how would you rate the demand for these services among student-athletes at your institution?

Presented in grid format; response options include... No demand, Low, Moderate, High, Not sure

Mental health counseling offered by a sport psychology specialist

Mental health counseling offered by other clinical staff

Performance consultation

Mandated counseling (substance abuse/conduct)

Psychiatry

Crisis intervention

Other

As you see it, has COVID-19 impacted the demand for mental health services among studentathletes at your institution?

Increased demand

Decreased demand

No impact on demand

Couldn't say from my experience

\section{Availability of Services}

Including off-campus referral networks, how available were the following services for students and/or student-athletes at your institution?

Presented in grid format; response options include... Availability exceeded demand, Availability comfortably satisfied demand, Demand was met but stretched available resources, Demand exceeded available resources, Service was not offered, Not sure

Mental health counseling offered by a sport psychology specialist

Mental health counseling offered by other clinical staff

Performance consultation

Mandated counseling (substance abuse/conduct)

Psychiatry

Crisis intervention

Other

As you see it, has COVID-19 impacted the availability of mental health services for students and/or student-athletes at your institution?

Increased availability

Decreased availability

No impact on availability

Couldn't say from my experience

-- PAGE BREAK 3 -- 


\section{Section 3 of 4}

We appreciate your time and input! To this point, we've asked about your experiences and perspectives prior to COVID-19 and the many challenges that have arisen over the last several months. Before our last few questions, we'd like to offer you some space to share about what you are currently needing as a person/practitioner to facilitate your work. This prompt is intentionally broad so that you can share freely about what feels significant for you. Please share your thoughts and any examples that come to mind in the space below.

\section{-- PAGE BREAK 4 --}

\section{Section 4 of 4}

Thank you so much for your contribution to this project! In this final section of the survey, please tell us a little about you. Data from this section is for aggregate descriptive purposes only, and will not be analyzed/reported in any way that could reasonably lead to your identification.

What NCAA division level does your athletic department primarily compete within?

Div. I, Power 5 conference (ACC, Big Ten, Big 12, SEC, PAC-12)

Div. I

Div. II

Div. III

Are you affiliated with or a liaison to your institution's athletics department as a clinical and/or applied practitioner?

Yes, as a trainee or employee of the institution

Yes, as an external consultant

No

How would you describe your role as a clinician and/or applied practitioner on campus?

Practicum trainee

Master's intern

Doctoral intern

Post-graduate fellow or resident

Clinical staff member

Senior staff member

Other or additional descriptor

How many hours do you work during a typical week in your role as a practitioner on campus?

Over the course of a semester, what percentage (roughly) of your work involves direct or indirect service provision to athletics/student-athletes?

Response will be a slider bar ranging from 0 to 100 
What specialization(s) or areas of expertise do you identify with?

How would you describe your race/ethnicity? Please select all that apply.

American Indian or Alaskan Native

Asian American/Asian

Black or African American

Hispanic or Latino/Latina/Latinx

Middle Eastern or North African

Native Hawaiian or Pacific Islander

White

Other or additional descriptor

Prefer not to answer

How would you describe your gender? Please select all that apply.

Woman

Man

Nonbinary

Prefer to self describe

Prefer not to answer

In our experience, surveys tend to feel like a one-way street. In an effort to make amends, the space below is for you. If there is anything that you would like to voice regarding this survey additional thoughts or clarification, feedback, concerns, etc. - we invite you to share in the space below.

We are so appreciative for your participation, and once data collection is finished, would like to share the results with you. After clicking on the red arrow (below) to complete this survey, you will see a link to a separate form where you can enter your contact information to receive a synopsis of the results. You can also enter to win a raffled MasterCard gift card. Your contact information will remain confidential and will not be connected your survey responses in any way. Thanks for considering. 


\section{Appendix C: Pre-Proposal Reflections and Philosophical Assumptions}

In February of 2020 I was finishing what I thought/hoped was a nearly done dissertation proposal document. For better or worse my thoughts wandered ahead to the day of the proposal. Daydreaming about the conclusion of the presentation, I braced myself for questions. Some imaginary figure belted out, "So tell me, Bill, in this mixed methods research that you are proposing, how does this constructivist view of your qualitative data gel with the quantitative data that you hope to collect and analyze?"

"Well," I stammered, "I mean... (insert one of those 3 second pauses that feels like an eternity here) it's really- I guess I have a constructivist view of the quantitative data as well."

I envisioned puzzled/concerned looks radiating from my imaginary audience.

"I guess?"

In retrospect, I find it interesting that I had not called into question the philosophical stance I was adopting for my dissertation until that moment. During my master's thesis, I had an appendix devoted to outlining various ontological and epistemological research philosophies before explaining the concoction of post-positivist and constructivist assumptions that underpinned my study. As part of a qualitative research methods course in the spring of 2018, I wrote brief reflections to detail how my assumptions had scooted further into the constructivist camp. Though I had certainly put thought into the rationales for my dissertation topic, I had not engaged with the philosophical assumptions that were guiding my approach. Perhaps this was because I have been envisioning my dissertation as a quantitatively oriented mixed-method study that is a first step for qualitative follow-up in the future.

The idea of a philosophical stance for quantitative research was never one that had been entertained in my education, and I don't recall ever hearing the words "positivism" or "postpositivism" until I first dipped my toes into qualitative methods. As such, I was recently struck by Mertens' (2010) reflective observation:

I find it mildly amusing that the need for critical self-reflection and knowledge of self-as-instrument is most often expressed as an issue for researchers who use qualitative methods... Who the researcher is and what their belief system is has implications no matter which paradigm a researcher calls home. (p.16)

That there could be a philosophy underpinning quantitative research was intriguing enough, until I nearly choked on my coffee while reading the title to Romm's (2013) article Employing Questionnaires in terms of a Constructivist Epistemological Stance: Reconsidering Researchers ' Involvement in the Unfolding of Social Life. Now, wrestling with the idea that there could be an approach to quantitative survey research outside of positivism's realist ontology and objectivist/dualist epistemology (e.g., Guba \& Lincoln, 1994), I have begun thinking through my assumptions and aims more explicitly. 
The purposes of this research (... any my reasons, goals, and values)

In its simplest sense, the impetus for this project stems from a lack of research on the perspectives of mental health practitioners who work with collegiate student-athletes. My personal interest in the topic follows from my hopes of working with this population (and college students more broadly) in a campus counseling center. To acknowledge a source of bias, I have some concerns - for lack of a better word - about the demands faced by sport psychology and other on-campus mental health practitioners. As a result, I am curious about their experiences. If some degree of concern should turn out to be warranted based on participant perspectives, a hoped-for outcome of this project is to shed light on the issues as practitioners see them so as to kindle broader discussion. This is the cleanest and most concise rendition of this that I could muster. Perhaps space will be afforded to let this unravel more in the future.

$\underline{\text { Assumptions guiding this research }}$

"If researchers do not acknowledge (or know) the philosophical assumptions that underlie their works, this does not mean that they have no philosophical assumptions. It merely means that they are operating with unexamined assumptions."

(Mertens, 2010, p. 9)

In this study my assumptions will be guided by a relativist ontology, with the premise that multiple socially constructed realities exist as opposed to any one single, absolute, and universal reality (Guba \& Lincoln, 1994; Hatch, 2002). Guided by the framework of constructivist theory, relativism assumes the presence of "multiple, apprehendable, and sometimes conflicting social realities that are the products of human intellects, but that may change as their constructors become more informed and sophisticated" (Guba \& Lincoln, 1994, p. 111). Guided by a constructivist paradigm, I will draw from a subjectivist epistemology. Subjectivism assumes that multiple realities can be approximated through the interaction of researcher and participant, and from a co-construction of knowledge that occurs therein (Denzin \& Lincoln, 2005; Lincoln, Lynham, \& Guba, 2011). I say approximated because I recognize that there may be "extensive slippage" (Lincoln et al., 2011, p. 125) between how research participants experience the world, how they describe or represent their reality, my interpretation of the data they share, and my ability to convey what I have learned in a research report. For me, the interaction of researcher and participant exemplifies John Dewey's concept of "experience" (as explained by Beista, 2010). In conducting research, I assume that I inevitably exert some influence on the people or environment that I am studying (e.g., a stimulus created by assessment or interview), thereby creating some change and new, reactive conditions. Further, I say co-construction above because, as Lincoln and colleagues (2011) put it, "we are shaped by our lived experiences, and these will always come out in the knowledge we generate as researchers and in the data generated by our subjects" (p. 104).

Due to this interactive nature of research, I believe there is a degree of reflexive self-study that is required in my methods and of me to recognize the role that I play as a research instrument (Lincoln et al., 2011). My own beliefs could potentially cause me to interpret participants' voices in way that was different from what they intended, so in my effort to respect and honor their voices, I will need to utilize methods such as member checking and creating an open, egalitarian 
space to discuss/refine findings with participants. Within a constructivist framework, my methods will also be guided by the hermeneutic and dialectical processes of eliciting others' experiences/realities, interpreting these data, comparing and contrasting data from across participants, and working to generate "one or a few constructions on which there is substantial consensus" (Lincoln et al., 2011, p. 104). My aim is to engage in a research process marked by rich-rigor, sincerity, and credibility (Tracy, 2010).

$\underline{\text { So, why numbers? }}$

With such little research in this area, why not start with a qualitative approach to seek an indepth understanding of the perspectives/experiences of a few? In this study, I do not hope to paint by numbers but with numbers. I am not seeking numbers to predict or explain, but instead to paint a broad descriptive landscape in the hope that it will invite commentary and dialogue that dives deeper into the messiness, complexity, and nuance that could not be captured with such broad strokes. This may be naïve of me, however. My thought is that numbers might catch the attention of others in order to start this dialogue, while the words, stories, and meanings found therein could be what sustain it. Ultimately, my hope is that this mixed methods approach will allow for input from a larger and wider range of practitioners than would be feasible with qualitative methods alone; and that, to the extent that numbers can be one way of portraying myriad realities and lived experiences, such numbers might strike a chord with and stimulate further discussion among a variety of audiences within and beyond this study (Creswell, Shope, Plano Clark, \& Green, 2006; Wright, 2014).

\section{Caveats of a constructed survey}

As Wright (2014) called to mind, "there is no reason why a reflexive and relational approach cannot be used with quantitative techniques," and "there is no reason why counting must be associated with a particular epistemology or a particular ontology" (p. 5). With my constructivist bend, I do not assume that the survey developed for this project can objectively capture any singular experience of college counseling, but, to borrow from Wright (2014), "a rendering of it that produces certain realities and invites certain consequences" (p. 6). In pondering the potential for producing realities and inviting consequences, Romm's (2007) writing has sunk in for me:

Forms of research such as surveys, with questions designed by researchers, give too much control to researchers in the interaction between them and respondents. This means that reality normally becomes constructed from the perspective of the interests of researchers. Heterogeneous experiences of reality can become suffocated through the very way in which surveys are set up and results created. (Romm, 2007, p. 55)

By focusing on practitioner perspectives of student-athletes as a sub-population, this study may stymie practitioner perspectives on college students more broadly or on other sub-populations of students who are equally deserving of services that cater to their unique needs. Though it seems an unavoidable limitation given the constraints of this project, it does not sit well with me that data collection will - in a way - privilege student-athletes over other student groups. Further, Wright (2014) observed that, among many researchers, "statistics are seen as statistics, with little 
attention paid to the power associated with the production of categories" (p. 2). As such, an equally uncomfortable realization is that categorically dichotomizing "student-athletes" and "all other students" in the study will overemphasize the athlete identity and simultaneously dismiss the student and myriad other identities that these young adults may have. This could also be the case in dichotomizing "sport psychology practitioners" and "all other clinical staff".

Since my survey is focused (mainly) on practitioners' experiences of providing mental health services to student-athletes, it could potentially deter the input practitioners who work with student-athletes on rare occasions, see student-athletes as a privileged population, or who see the mental health needs of other student sub-groups as more pressing. As an additional consideration, I am not a person of influence in the field of mental health (the vast majority of my participants will have no idea who I am or what I am about), and will be reaching out to some very busy people. With my lack of social capital, I could foresee the length of my survey as another potential barrier to participation.

\section{$\underline{\text { To make amends }}$}

Romm $(2013,2014)$ indicated that data collection can be impacted by the quality of communication between researchers and participants, as well as by the way in which participants interact with a questionnaire. As such, the survey for this project was written and re-written with the thought that it would constitute an interactive exchange between me as a researcher and practitioners as participants. I hoped that this exchange would be relevant for a range of practitioners, open to their comments, conversational in tone, and relatively concise.

While thinking these elements through, I tried to empathize with my future participants (in some instances, by taking the survey myself... which yielded more pronounced reactions than I anticipated). Romm and her colleagues have "considered it important to take into account how the research endeavour might be seen by participants and how this...might feel for them" (Romm, 2014, p. 19). Fielding (1993) phrased this as trying "to 'think' oneself into the perspective" of participants (p. 157). From these suggestions, however, I tried to imagine participants' experience of my survey with the aforementioned caveats and considerations in mind. How might I minimize the impact of these caveats and/or make amends?

First, the recruitment correspondence (forthcoming) will need to have some transparency about my aims. Correspondence should also include an acknowledgement that the project's focus on the mental health needs of student-athletes does not preclude comments on the mental health needs of other student sub-populations or the needs of the student body as a whole. If participants choose to engage with them, several opportunities for open-ended comments have been built into the survey. I have tried to frame these prompts in such a way as to call to mind the shortcomings and limitations of the closed, Likert-type scales that precede them.

For one example, the survey asks about various aspects of practitioner experiences that seemed to me to be pertinent trends in available literature. Practitioners may or may not have had similar experiences, and further, their experiences may or may not have much impact on them and their clinical practice. Initially, the thought was to ask participants about whether they experienced this or that (e.g., do participants agree or disagree that their caseload is too large) and about the 
significance of this experience for them (e.g., to what extent do participants see the size of their caseload as having an impact on them and their clinical practice). While this approach struck me as affording participants the opportunity to weight their responses (as suggested by Martí, 2016), I also felt that it made for a bulky and tedious section of the survey. Instead, participants are asked to agree or disagree with a list of phrases based on their experience and elaborate on which has the most impact on them (or what impacts were not captured by the survey) in an open-ended prompt. (This open-ended prompt was later dropped to focus instead on current needs.)

\section{Towards an additional remedy}

As a result of the constructed nature of my survey, and the ways in which it may produce certain realities at the expense of others, I hope to reach out to participants with a synopsis of the findings from this study - both quantitative and qualitative. In this exchange, I want invite dialogue about the results (e.g., do they "fit" and "feel right"?) as well as deeper discussion about the topics of the study (or topics missed by the study). For those who wish to engage (which may be "data" as well), this will be an invitation to prolonged engagement with the project; and for practical purposes, will likely extend beyond the timeline of my dissertation. Although soliciting the input and feedback of participants is an encouraged practice in producing credible qualitative research (e.g., Tracy, 2010), this appears to be a less common - if not unusual - practice among those engaged in quantitative or mixed methods survey research. My motivations for doing so are grounded in some recent reading and self-reflection.

With an awareness of the constructed nature of questionnaires, Romm (2007) suggested that ethical and accountable researchers "need to develop a way of interacting with participants and of writing up results (for audiences) that is less controlling than that associated with traditional survey research" (p. 55). From his participatory research in Botswana, Acquah (2007; cited in Romm, 2013) called to mind that this interaction is important because survey results may or may not resonate with participants' experiences of the phenomenon under investigation. When discrepancies arise, researchers who are willing to step aside from a sense of authority can create opportunities for discussion, compromise, and insights to new ways of interpreting or using the data. Citing Acquah (2007) and others, Romm (2013) framed their work as "constructivistoriented in the sense that they treat, and implore others to treat, any research 'results' as being constructed and hence as open to reconstruction" (p. 659).

By maintaining an openness to this construction and reconstruction, and an accountability for the product(s) of this research, I hope to adopt what Romm (e.g., 2013, 2014) has called a trusting constructivist approach. Through ongoing dialogue, Romm (2014) said that "researchers can earn the trust of research participants and wider audiences by signalling that they are willing to engage in discussion around their research practices, including around the implications of any 'results/interpretations' that are presented" (p. 18). From this sentiment, I do not want this project to end with publication. Though beyond the scope of dissertation requirements (I think?), my hope is that follow-up dialogue with participants will also include their input on what (if anything) needs to be done with the results (Romm, 2014). Based on their experiences and needs, what (again, if anything) needs to change? Who might assist in creating that change? How might the results of this research be used in stimulating their engagement? This process, Romm (2014) 
said, would be "different from taking a stance of relinquishing responsibility for whether anyone may notice reports that become produced" (p. 19). 


\section{Appendix D: IRB Approval Letter}

\section{WestVirginiaUniversity.}

OFFICE OF HUMAN RESEARCH PROTECTIONS

aes Chetma sidge fase Morgarbown. WW abse

\section{Flex Model Approval}

$08 / 14 / 2020$

To: Jack Watson

From: WVU Human Research Protection Program

Protocol Type: NHSR / Flex

Approval Date: 08/14/2020

Submission Type: Initial

Expiration Date: 08/13/2025

Funding: N/A

WVU Protocol \#: 2008078957

Protocol Title: Practitioner Perspectives in Collegiate Mental Health and Sport Psychology

The West Virginia University Institutional Review Board has determined that your submission of protocol 2008078957 qualifies for approval under the WVU Flexibility Review Model.

- FLEX: The review of the above referenced protocol was conducted in accordance with the ethical principles of the Belmont Report. The protocol meets the criteria for approval Flex Model Review because the project does not have federal funding, is considered to be minimal risk, and falls within the guidelines of the WVU Flex Model as of this approval date.

The following documents were reviewed and approved for use as part of this submission. Only the documents listed below may be used in the research. Please access and print the files in the Notes \& Attachments section of your approved protocol.

- Survey_Finaldoc

- Survey_Final_Contact info.doc

- IRB_Follow up interview guide.doc

- Informed consent.pdf

- Informed consent_Follow Up Interviews.pdf

- Recruitment Emails_Final.doc 
WVU IRB approval of protocol 2008078957 will expire on 08/13/2025.

If the study is to continue beyond the expiration date, a renewal application should be submitted no later than four (4) weeks prior to the expiration date. It is your responsibility to submit your protocol to the WVU IRB for review.

Once you begin your project, the following apply:

1. Unanticipated, serious adverse events and or side effect(s) encountered at WVU or an affiliate site that are related to the research must be reported to the WVU IRB within five (5) days using the Notify IRB action in WvU+ke.

2. Any Unanticipated Problem or UPRTSO or other research related eveat resulting in new or increased risk of harm to study subjects, occurring at WVU or an affiliate site, mast be reported to the WVU IRB within five (5) days using the Notify IRB action in WVU+kc.

3. All research persounel performing tasks related to the research must complete and remain curreat for the required training as applicable to the protocol referenced above.

4. Only Flex Consent Forms with the WVU+ke watermark may be used to consent participants.

5. The IRB must be notified if there is an increase in risk to participants or if federal funding is awarded to conduct research under this protocol. These modifications must be submitted as an amendment in WVU+kc.

The WVU Human Research Protection Program will be glad to provide assistance to you throughout the research process. Please feel free to contact $w$ by phone at 304.293 .7073 or by email at $\underline{\mathrm{IRB} Q \text { mail.wutu.edu. }}$

Sincerely,

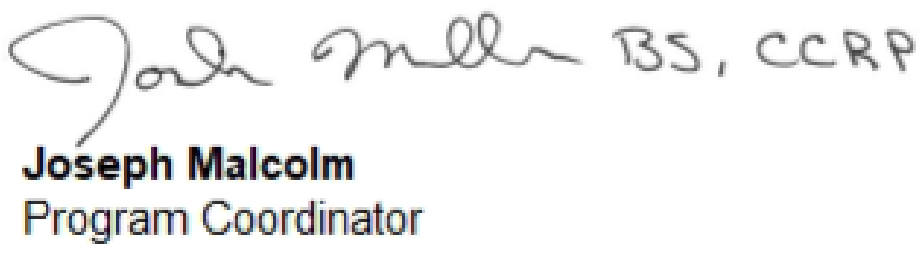




\section{Appendix E: Extended Results}

\section{Website Review}

CAPS presence by division level. In total, all 1,121 NCAA institution websites were reviewed, including 65 Division 1 Power 5 conference institutions (P5), all other 287 Division I institutions (DI), 320 Division II institutions (DII), and 449 Division III institutions (DIII). Of all NCAA institution websites, $1.16 \%$ did not list any counseling psychological services (CAPS), $0.80 \%$ listed off-campus affiliate clinics, and $0.62 \%$ listed on-campus affiliate clinics (i.e., an oncampus clinic staffed by an external organization or group practice as opposed to employees of the institution). Examined by division level, all P5 institutions had CAPS. One DI institution $(0.35 \%)$ listed an on-campus affiliate clinic, and all others had CAPS. Among DII institutions, seven $(2.19 \%)$ did not list any psychological services, and five (1.56\%) listed off-campus affiliate clinics. Six DIII institutions (1.34\%) did not list any psychological services, another six listed on-campus affiliate clinics, and four $(0.89 \%)$ listed off-campus affiliate clinics.

CAPS Practitioner frequencies across all institutions. Mental health staff were not listed online and could not be tallied at 58 institutions (5.17\%). Likewise, mental health trainees were alluded to (by way of a training director on staff, a sub-page devoted to practicum/ internship applications, etc.) but could not be tallied on CAPS websites at 177 institutions (15.80\%). Acknowledging these limitations, the website review identified 7,832 total mental health staff members $(M=7.37, S D=8.00$, range $=1-60)$ and 1,695 mental health trainees $(M$ $=1.80, S D=3.14$, range $=0-27)$. Of all institutions, $98(8.74 \%)$ only had one mental health practitioner listed for on-campus CAPS.

Integrating institutional enrollment data. To supplement website review data, institutional enrollment data was collected from the National Center for Education Statistics (NCES, 
https://nces.ed.gov/globallocator/). At the time of data collection, the most recent institutional data available from the NCES was from the 2019 Fall semester (which was one semester prior to the website review). For each NCAA institution, total institutional enrollment (undergraduate and graduate) was recorded from the NCES database. The ratio of mental health staff to students was calculated by dividing total institutional enrollment (from the NCES) by the number of mental health staff/trainees identified during the website review. Quotients were rounded to the nearest whole number. Mental health staff to student ratios could be calculated for 1,047 or 93.4\% of all NCAA institutions. After removing four outliers (with practitioner to student ratios over 1:6,000), counseling centers that were reviewed had, on average, one staff/trainee for every 1,113 students $(S D=783.20, \operatorname{Min}=70, \operatorname{Max}=5,653)$. There was a relatively linear increase in the number of students per mental health practitioner as institutional enrollment size increased. Using similar enrollment categories as the AUCCCD survey (LeViness et al., 2019), mental health staff to student ratios can be seen in Table Ext1 below.

Table Ext1. Student to mental health practitioner ratio by institutional enrollment.

\begin{tabular}{lcccc}
\hline $\begin{array}{l}\text { Institutional } \\
\text { Enrollment }\end{array}$ & $\begin{array}{c}\text { Number of } \\
\text { Institutions }\end{array}$ & $\begin{array}{c}\text { Mean } \\
\text { Ratio }\end{array}$ & $\begin{array}{c}\text { Minimum } \\
\text { Ratio }\end{array}$ & $\begin{array}{c}\text { Maximum } \\
\text { Ratio }\end{array}$ \\
\hline$<1,501$ & 143 & $1: 600$ & $1: 70$ & $1: 1495$ \\
$1,501-2,500$ & 185 & $1: 739$ & $1: 97$ & $1: 2496$ \\
$2,501-5,000$ & 223 & $1: 998$ & $1: 132$ & $1: 4574$ \\
$5,001-7,500$ & 109 & $1: 1367$ & $1: 231$ & $1: 5653$ \\
$7,501-10,000$ & 79 & $1: 1367$ & $1: 324$ & $1: 4517$ \\
$10,001-15,000$ & 103 & $1: 1381$ & $1: 349$ & $1: 3547$ \\
$15,001-20,000$ & 57 & $1: 1653$ & $1: 414$ & $1: 5272$ \\
$20,001-35,000$ & 92 & $1: 1507$ & $1: 511$ & $1: 4220$ \\
$>35,000$ & 52 & $1: 1612$ & $1: 681$ & $1: 4505$ \\
\hline
\end{tabular}

Sport Psychology Practitioner frequencies across all institutions. Three institutions did not list athletics staff or services, so the presence or absence of sport psychology services could not be accounted for in these instances. Of the remaining 1,118 NCAA institutions, 320 
$(28.6 \%)$ listed any sport psychology staff or trainees. One additional institution described sport psychology services, but did not list any staff who provided them (correspondence with this institution yielded no data). Clinical Sport Psychology (CSP) staff could be identified at 271 (24.2\%) institutions, CSP trainees could be identified at $64(5.7 \%)$ institutions, and applied staff/trainees could be identified at $49(4.4 \%)$ institutions. Only 20 institutions (1.8\%) listed both CSP staff and applied practitioners. At the time of the website review, 53 institutions were listed as HBCUs (this number has since changed). Among HBCUs, only four (7.6\%) listed any CSP staff. No applied staff or CSP trainees were listed at HBCUs. When comparing public $(n=480)$ and private $(n=641)$ institutions, $17.0 \%$ of private institutions listed any CSP staff relative to $33.8 \%$ of public institutions. CSP trainees were listed at similar proportions of private (5.3\%) and public $(6.3 \%)$ institutions. Applied staff were listed at $2.8 \%$ of private institutions and $6.5 \%$ of public institutions.

The website review identified a total of 507 CSP staff and 85 CSP trainees. Tallies of CSP trainees were not possible for two institutions (where CSP training programs were referenced without any list or count of past/present trainees). On average, institutions that listed any CSP practitioners had one or two $(M=1.87, S D=1.35$, range $=1-10)$. Likewise, when any were listed, institutions tended to have one CSP trainee $(M=1.33, S D=0.64$, range $=1-4)$. Of institutions that listed CSP trainees, 20 (23.53\%) did not have CSP staff concurrently listed. Of those 20, four were DI institutions, four were DII institutions, and twelve were DIII institutions. The website review identified 68 applied practitioners, and this tally reflects both staff and trainees. Institutions with applied practitioners listed, on average, one staff member or trainee in this area $(M=1.39, S D=1.13$, range $=1-6)$. Relying on athletics websites to identify applied practitioners may underestimate their true presence across the NCAA. 
Practitioner frequencies cross-tabulated by division. To examine the distribution of sport psychology practitioners across division levels, see Table 1 (Appendix A). All P5 institutions had at least one CSP staff member listed. However, at all other DI institutions, CSP staff were listed at $42 \%$ of institutions. About $11-12 \%$ of DII and DIII institutions listed CSP staff, and when they did, few listed more than one. Whereas no DIII institutions had more than two CSP staff, over half (55.4\%) of P5 institutions had at least three. Though on a smaller scale, the listing of CSP trainees followed a similar trend as CSP staff when compared across divisions. Applied practitioners were listed at $1-2 \%$ of DII and DIII institutions and about $10 \%$ of DI and P5 institutions.

Integrating student-athlete enrollment data. As with institutional enrollment, studentathlete enrollment data was also collected to supplement the website review. Using the U.S. Department of Education Equity in Athletics Data Analysis website (EADA, https://ope.ed.gov/ athletics/\#/institution/search), the number of unduplicated student-athletes (i.e., a multisport athlete was only counted once) enrolled at each NCAA institution was recorded. At the time of the website review, the most recent EADA data available for student-athlete enrollment was from the 2018 - 2019 academic year (which was the year prior to the website review). The number of unduplicated student-athletes enrolled was available for 1,084 (96.7\%) of NCAA institutions. The average number of student-athletes enrolled per institution was 385.9 (Min = 37, $\operatorname{Max}=1,183$ ). On average, there were more student-athletes enrolled at institutions within the P5 conferences $(M=581.6, \operatorname{Min}=353, \operatorname{Max}=1,054)$ than at DI $(M=394.9$, Min $=57$, Max $=1,065), \mathrm{DII}(M=340.9, \operatorname{Min}=93, \operatorname{Max}=1,183)$, and DIII $(M=383.12, \operatorname{Min}=37, \operatorname{Max}=827)$ institutions, the latter of which all had relatively similar numbers. 
Sport psychology staff to student-athlete ratios were examined as a crude measure of service availability - when offered - for those student-athletes who may be inclined to use them. There were 315 institutions for which student-athlete enrollment data was available and any sport psychology practitioners listed (CSP staff/trainees and/or mental skills staff/trainees). The ratio of sport psychology practitioners to student-athletes was calculated by dividing the total number of unduplicated student-athletes by the total number of sport psychology practitioners (i.e., the sum of CSP staff, CSP trainees, and mental skills staff/trainees). Quotients were rounded to the nearest whole number. When CSP and/or mental skills services were offered, the average ratio of sport psychology practitioners to student-athletes was 1:296 and ranged from 1:51 to 1:1,183. Examined across division levels, there were lower (i.e., "better") ratios of sport psychology practitioners to student-athletes among institutions within the $\mathrm{P} 5$ conferences $(M=$ $1: 226$, range $=1: 66-1: 721)$ and the rest of DI $(M=1: 282$, range $=1: 55-1: 756)$ relative to DII $(M=1: 346$, range $=1: 51-1: 1,183)$ and DIII institutions $(M=1: 363$, range $=1: 108-1: 741)$.

Location of practitioner listing. During the website review, CSP practitioners were identified in a number of locations. Almost half (48\%) were listed on CAPS websites. Just over one third (36\%) were listed in athletic department directories and/or other sub-pages of athletics websites (e.g., on pages devoted to sports medicine or sport psychology, within student-athlete handbooks). Another 15\% were listed on the institution's CAPS website as well as the athletics directory or some other sub-page of the athletics website. When cross-tabulated by division level, however, these proportions shifted. At P5 institutions, two thirds of CSP practitioners were listed on athletics or both athletics and CAPS websites, relative to $52 \%$ at all other DI institutions, $35 \%$ at DII institutions, and $18 \%$ at DIII institutions. 
CSP staff/trainee titles. Of all 592 CSP staff and trainees identified, 40\% had clinical titles that referenced sport psychology or work with athletics. Cross-tabulated by division, CSP staff and trainees appeared to be more likely to have clinical titles that referenced sport psychology at P5 (48.2\%) and DI (40.8\%) institutions relative to DII (29.4\%) and DIII (20.7\%) institutions. Overall, CSP practitioners/trainees who were listed on athletics websites (65\%) or both CAPS and athletics websites $(68 \%)$ appeared to be more likely to hold clinical titles that referenced athletics relative to practitioners who were listed on CAPS websites alone (12\%). There were a wide variety of titles used by CSP practitioners, perhaps indicative of the numerous educational backgrounds and approaches to the work of clinical sport psychology.

To condense categorically, practitioners' titles were inductively coded. Multiple codes were applied to some titles. Of all practitioners that were coded as having titles that referenced sport psychology or clinical work with athletes, 51\% had titles that specifically included "sport psychology," or some derivative thereof (e.g., Director of Sport Psychology, Sport Psychologist, Sport Psychology Consultant). Used in a similar way, "performance" appeared in 14\% of coded titles (e.g., Coordinator of Mental Performance, Mental Health and Performance Clinician). Athletic counseling was referenced or included in 5\% of coded titles, and another $3 \%$ referenced other athletic/sport-based titles (e.g., Sport Psychiatry, Athletic Neuropsychologist, Sports Psychotherapist). About $9 \%$ of coded titles specifically mentioned student-athletes or services for them (e.g., Director of Student-Athlete Mental Health; Counseling Clinician, Student-Athlete Services Coordinator; Student-Athlete Dedicated Counselor).

While the titles above suggest roles as liaisons to athletics or as embedded practitioners, only $2 \%$ of coded titles specifically denoted roles as embedded practitioners, and $10 \%$ denoted roles as liaisons. Without specifically saying so, another $9 \%$ of coded titles made some other 
reference to teams or athletics departments, which could imply consultative or embedded roles (e.g., Mental Health Counselor, Athletics; Resident in Psychology (Athletics); Team Psychiatrist; Contract Psychologist - Department of Athletics). Finally, 5\% of coded titles included aspects of athletics administration (e.g., Associate Athletic Director/Athletic Counselor, Assistant Athletic Director for Mental Health Services) and 2\% referenced current or past sport psychology certifications (e.g., CMPC, CC-AASP, AASP-Certified Sports Psychologist).

CSP Educational Backgrounds. Among the 592 CSP practitioners identified, educational degrees were not listed for $2.2 \%$. More than half $(56.6 \%)$ of CSP practitioners held a doctoral degree, and another $10.98 \%$ were doctoral students (including those with candidacy). Just less than a quarter (23.7\%) of CSP practitioners listed a master's degree as their highest level of education, and another 3.2\% were master's students. Finally, $3.4 \%$ of CSP practitioners held medical degrees.

Perhaps worth noting, and as displayed in the figure below, there appeared to be shifts in the proportions of highest educational degrees held by CSP practitioners across divisions. Moving from P5 and DI institutions to DII and DIII institutions, proportionally fewer CSP practitioners held doctoral or medical degrees, and proportionally more practitioners were graduate students. While this trend could be coincidental, it could also be plausible that smaller institutions/athletics departments (physically and financially) rely more heavily on trainees to provide CSP services - perhaps, at times, without the oversight of CSP staff. Recall from above that, of institutions with CSP trainees but no CSP staff, $80 \%$ were DII and DIII institutions.

CSP practitioners earned their highest degrees in a variety of disciplines, the most common of which were clinical (30.9\%) and counseling psychology (22.5\%), followed by social work $(10.1 \%)$ and counseling/clinical mental health (8.9\%). In mutually exclusive categories, 


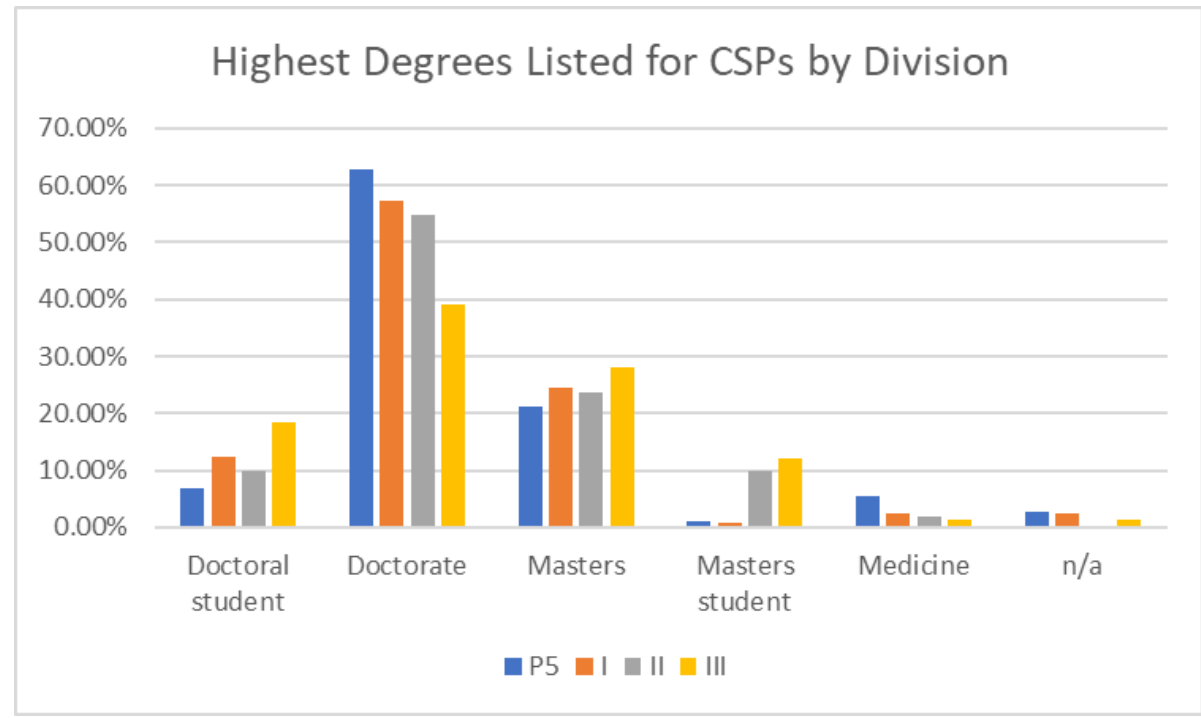

$6.6 \%$ of practitioners listed their highest degree as clinical in nature with a concentration in sport psychology, and 3.4\% listed their highest degree as an applied or non-clinical study of sport psychology (recall that, per inclusion criteria, these practitioners held a secondary degree that was clinical in nature). Less common educational backgrounds for CSP practitioners included psychiatry (i.e., medicine/nursing, 3.6\%), counselor education and supervision $(2.0 \%)$, other mental health disciplines (e.g., marriage and family therapy, school psychology; $2.4 \%$ ), and other applied disciplines (e.g., applied psychology, education; 1.9\%). Note that educational background could not be found for $7.8 \%$ of CSP practitioners identified.

Secondary degrees and secondary degree topics were available for about $77 \%$ and $71 \%$ of CSP practitioners, respectively. Most listed bachelor's (27.0\%) or master's (48.1\%) degrees, though some $(1.5 \%)$ identified other doctorates or specialized certificates earned. In mutually exclusive categories, one quarter of CSP practitioners listed a secondary degree in mental health (counseling, clinical psychology, social work, or other) and $18.4 \%$ listed a secondary degree in psychology (general or other). Secondary degrees also included mental health degrees with concentrations in athletic counseling/sport psychology (6.9\%), non-clinical sport and exercise psychology degrees $(8.1 \%)$, and other topics within the exercise and sport sciences $(2.0 \%)$. The 
remaining $10.6 \%$ of secondary degrees listed included a wide range of topics across the arts and humanities, sciences, financial/managerial studies, and health/human services not already listed.

CSP certifications and licensures. CSP practitioners identified during the website review were cross-referenced in CMPC and AASP membership listings. Overall, 13.7\% of CSP practitioners held CMPC status. An additional 7.4\% were current AASP members. A small number of practitioners identified with CC-AASP status (AASP's certification credential prior to the exam-based CMPC credential) but were not listed in the CMPC or AASP member directories at the time of data collection. Across divisions, there were similar proportions of CSP practitioners with CMPC status at P5 (17.0\%), DI (14.5\%), and DII (13.7\%) institutions compared to DIII institutions $(2.4 \%)$.

Licensures/certifications could not be identified for $21.0 \%$ of CSP practitioners. When listed, the population of CSP practitioners identified during the website review held a wide variety of licensures, certifications, and other credentials (note that some listed more than one, so categories are not mutually exclusive). Almost half (45.6\%) were licensed psychologists, $15.7 \%$ were licensed professional or mental health counselors, and $10.5 \%$ were licensed social workers. Though less common, $3.4 \%$ listed medical or psychiatric credentials and $1.2 \%$ were licensed as marriage and family therapists. Sub-specialties or other certifications that were listed included substance abuse or addictions (3.4\%), bio- or neurofeedback (1.0\%), EMDR or other trauma certificates $(0.7 \%)$, and others. A small number of practitioners $(0.8 \%)$ listed sport-based certifications apart from the CMPC credential. Examples included the Certificate of Sport Social Work offered from the Alliance of Social Workers in Sports, or the Certificate of Additional Training in Sports Psychiatry through the International Society for Sports Psychiatry. Some 
sport-based certifications were ambiguous or were not tied to a specific credentialing group or governing body.

Descriptions of sport psychology services. For institutions that had any sport psychology practitioners/trainees listed, coding was used to document the presence of any description of those services. Using generous inclusion criteria (see methods), just over one third ( $n=111,34.7 \%)$ of institutions that listed sport psychology practitioners offered a description of their services (Note that one institution described services without listing any practitioners). These descriptions were usually located on the institution's athletics website, though seven institutions described sport psychology services on a sub-section of their CAPS website. An additional five institutions (1.6\%) that listed sport psychology practitioners did not describe sport psychology services, but instead offered a description of CAPS services on their athletics websites. When cross-tabulated by division, the proportion of institutions that listed sport psychology practitioners and described sport psychology services shifted. While three quarters $(n$ $=49,75.4 \%$ ) of P5 institutions offered a description of sport psychology services, descriptions were offered by less than one third $(n=45,31.3 \%)$ of all other DI institutions, less than one fifth of DII institutions $(n=8,17.0 \%)$, and even fewer DIII institutions $(n=9,14.1 \%)$.

When present, there was wide variation in the description of sport psychology services. Of the 111 descriptions analyzed, about half (51.4\%) included a statement about the confidentiality of services. About half $(51.4 \%)$ of the descriptions provided both contact information and office location for service providers. One third of descriptions provided contact information only, $3.6 \%$ provided office location only, and $11.7 \%$ provided neither. Of the 61 total office locations provided, $19(17.1 \%)$ were in CAPS or an academic building and 28 (25.2\%) were within athletics buildings/facilities. Another 13 listings (11.7\%) included office 
locations in both CAPS and athletics, and one final listing included offices in athletics facilities and an off-campus location. Anecdotally, there were varying degrees of specificity with location. Some websites indicated that services were offered in a certain building, while others listed the floor/room number of the office(s), and in some cases, step by step directions to maneuver the building and locate the office.

Initiating service use. When sport psychology services were described, just over three quarters $(n=86,77.5 \%)$ of the descriptions included directions for how to initiate sport psychology services. For reference, $92.2 \%(n=1,033)$ of CAPS websites included directions for how students could initiate psychological services. As was the case on CAPS websites, invitations to use sport psychology services varied in depth, ranging from a brief statement (e.g., “call for an appointment") to a screen capture video demonstrating step-by-step instructions for using the institution's online scheduling portal. In all likelihood, the tone and content of these invitations varied with the different philosophies and organizational structure of services. In some instances, student-athletes (the presumed readers) were addressed directly and their autonomy as service users was encouraged - for example, "Our approach to serving studentathletes provides you the opportunity to choose an 'in-house' athletic department psychologist or a campus or community provider that best fits your needs." In other instances, student-athletes' service use was framed within the system of a team-based approach to care, sometimes with less emphasis on their autonomy as service users. As outlined at one institution, student-athletes interested in using sport psychology/mental health services "should, ideally, consult the athletic trainer for their sport. Alternative referral pathways include direct contact with a team physician or [lists other administrator]...[The] team physician and the psychologist will decide best management plan for that student athlete (could involve additional referral)." Among invitations 
to utilize sport psychology services, some websites explicitly stated that sport psychology services were free for student-athletes.

What to expect from service use. About one quarter $(n=27,24.3 \%)$ of sport psychology descriptions provided information about what to expect from services. In many of these instances, but not all, website content had a specific "what to expect" heading. This information often included some description of the intake process, such as, "the first session typically lasts about an hour and includes time for completing initial paperwork and discussing current concerns, relevant history, and goals for counseling." At some institutions, websites specified that student-athletes should arrive prior to their appointment time to complete paperwork. Many descriptions of what to expect included the interpersonal climate that service users could anticipate (e.g., "Counseling provides...an accepting environment," "staff are culturally responsive;" "our philosophy is strengths-based, positive, and holistic"); and therein, some placed emphasis on a collaborative approach to service delivery (e.g., "Counseling...is a goalbased collaborative process, involving a non-judgmental, supportive counselor;" "studentathletes are encouraged to provide feedback to sport psychology and work collaboratively to make sure that individual services are meeting their needs").

In transitioning to follow-up care, some websites included information about what to expect regarding the duration of sport psychology services, and a few conveyed that the process may look different from one person to the next (e.g., "While some athletes get what they need through the brief consultation alone, many schedule follow up sessions," "For some people [counseling] takes a small amount of time, in some cases as little as one or two sessions; for others, the process may last longer."). Several websites provided information about the scheduling of follow-up sessions (e.g., 30 - 50mins, weekly/bi-weekly, flexibility of scheduling). 
In rare instances, some websites detailed the blend of traditional office-based sessions and brief consultations that student-athletes could expect if utilizing performance-based services. One institution's website put it this way:

"Performance psychology sessions may look different than a traditional personal counseling session. For example, sessions may range from short discussions in passing while at practice to a full 50-minute session in the staff psychologist's office. Additionally, when compared to traditional personal counseling, performance psychology sessions tend to be more instruction based and solutionfocused."

An interesting contrast was observed while reviewing descriptions of clinical services (on CAPS websites and open to the entire student body) and descriptions of sport psychology services (clinical and/or applied and housed in CAPS and/or athletics). While many descriptions of clinical services came with a clearly articulated scope of practice and session limits (if any), this was far less common among sport psychology descriptions. No descriptions of sport psychology services included session limits. Further, some descriptions of clinical services included information about the role of the client (often framed as "how to get the most out of counseling," etc.), this was also rare among descriptions of what to expect from sport psychology services. A noteworthy exception to this trend was found at one institution:

"For our work with you to be successful, it is essential that you (a) stay actively involved and invested in all aspects of the intervention plan, (b) always follow through on homework assignments given, (c) provide honest and timely feedback to your sport psychology consultant regarding your performances and the changes 
you are making in your life, and (d) be willing to share openly about yourself, your performances, and your goals."

Stigma reduction efforts. About one third $(n=35,31.5 \%)$ of sport psychology descriptions contained a statement or other resources aimed at reducing the stigma of mental health service use. The 35 websites that described sport psychology services and contained statements and/or videos aimed at reducing the stigma of mental health were inductively coded (see the Table Ext2 below). Common components of stigma reduction efforts included acknowledgment of the unique demands that student-athletes encounter (e.g., "In addition to challenges all college students face, student-athletes also face added pressures of time management, travel, visibility, performance demands, and injury.") and the normalization of performance-related issues ("Yet even the best performers in the world may face doubt, fear, distraction, failure, or other setbacks...”) or mental health concerns (e.g., "30\% of studentathletes have experienced overwhelming anxiety"). Another trend was labeled as, "putting faces to the issues," as the content of several websites included student-athlete stories or public service announcement videos about mental health and/or mental health services (e.g., "Meet [names student-athlete and lists performance accolades]...one of 40 million Americans with an anxiety disorder..."). The content of some websites spoke to a collective commitment that studentathletes can embrace to support each other, eradicate the stigma of mental health, and make supportive referrals to services when needed. As put in one student-athlete handbook, for instance, "You play a central role in normalizing help seeking and assisting fellow studentathletes who may need help, and who could benefit from accessing mental health resources." Related to these efforts, some websites encouraged help-seeking by listing the benefits of service use, displaying rates of service use among student-athletes at the institution, and by highlighting 
the preventative benefits of using services sooner rather than later. Website content also drew attention to the difficulty of help-seeking; and reframed seeking supportive services as a sign of strength, not weakness. As expressed on one website, "Many student-athletes are often reluctant to seek help because of the stigma... We want student athletes to know that mental health is just as important to attend to as physical health and...seeking help for our difficulty is a sign of strength."

Table Ext2. Coding of stigma reduction efforts.

\section{Putting Faces to the Issues}

Brought in high profile athlete to speak about $\mathrm{MH}$

High profile athlete quotes

Identifiable athlete stories of $\mathrm{MH}$ and seeking help

Student-athlete PSA/Videos

\section{Count

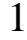 \\ 1 \\ 4 \\ 12}

\section{In This Together}

Shared commitment to acknowledge $\mathrm{MH} /$ end stigma

How to make referral/support others

3

3

It's Okay to Not be Okay

Acknowledge unique demands of Sport

11

Normalize stress/concerns

Normalize with statistics/figures

Address the Meaning of Service Use

Seeking Help is Strength, Not Weakness

Acknowledge difficulty of seeking help

Acknowledge difficulty of vulnerability

Promoting Service Use

Benefits of services

Encourage service use

Info about services

Service use as prophylaxis

Statistic about rates of help-seeking at institution

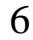

6

6

4

1

5

1

1

3

2

\section{Quantitative Survey Data}

Using the Qualtrics mailing list functionality, recruitment correspondence for survey participation was emailed to 2,725 total practitioners (another 40 invitations bounced back as undeliverable). Separate recruitment letters were drafted for CAPS, CSP, and mental skills 
practitioners (Dillman et al., 2014). A total of 495 completed surveys were returned, along with another 20 partially completed surveys (defined as > 30\% complete) for a total response rate of 18.9\%. Using practitioner categories established during the website review, response rates for full survey completion were higher among CSP practitioners $(n=122,25.5 \%)$ than mental skills consultants $(n=8,15.7 \%)$ and generalist mental practitioners $(n=334,15.6 \%)$. In addition to mailing list email blasts, recruitment efforts also included correspondence that was sent on an individual basis to 94 practitioners. These individuals were contacted individually for a variety of reasons: personal connection, direct messaging portals were made available in lieu of email addresses, or because practitioners were external consultants (which required more specifically tailored language/details than afforded by large email distribution letters). Contributing to the overall response rate above, 28 (29.8\%) of these individuals participated.

Demographics. Of all 515 respondents, $0.4 \%$ preferred to self-describe their gender identity, $1.0 \%$ identified as nonbinary, $27.6 \%$ identified as men, and $66.2 \%$ identified as women (4.85\% preferred not to answer or left the item blank). Participants represented a variety of racial/ethnic backgrounds, including Native American (0.2\%), Native Hawaiian or Pacific Islander (0.2\%), Asian American/Asian (2.7\%), Hispanic or Latino/Latina/Latinx (3.7\%), biracial, multiracial, or multiethnic backgrounds (4.3\%), Black or African American (12.6\%), and White (70.3\%, another 5.6\% preferred not to answer or left the item blank). Respondents included $157(31.7 \%)$ senior staff members, $262(52.9 \%)$ clinical staff members, and $20(4.0 \%)$ trainees ranging from master's level to post-graduate fellows/residents. Another $11.3 \%$ of respondents described their role using other descriptors (e.g., Mental Training Specialist, Outreach Coordinator, Psychiatric Provider, Professor/Counselor). 
On average, participants worked 36.5 hours/week (range $=3-70$ ). Participants who reported their institution's NCAA divisional affiliation spanned P5 institutions $(n=74,15.3 \%)$, all other DI institutions ( $n=146,30.2 \%)$, DII institutions ( $n=96,19.9 \%)$, and DIII institutions $(n=167,34.6 \%)$. Of those who responded to the item about athletics affiliation, about half $(n=$ $238,48.4 \%$ ) indicated that they were not affiliated with their athletics department in their clinical role. The other half indicated that they were affiliated as trainees/employees of the institution $(n$ $=210,42.7 \%)$ or as external consultants $(n=44,8.9 \%)$.

When asked about specialties or areas of expertise (open-ended), 350 participants responded. The most common specialties listed included trauma $(n=98,28.0 \%)$, sport/performance psychology and/or student-athletes $(n=84,24.0 \%)$, anxiety or mood disorders $(n=76,21.7 \%)$, specific modalities or theoretical approaches $(n=72,20.6 \%)$, disordered eating or body image $(n=47,13.4 \%)$, and alcohol or other drug counseling $(n=43$, $12.3 \%)$. Eighteen respondents $(5.1 \%)$ identified with a specialty in crisis counseling/suicidality and five $(1.4 \%)$ identified with a specialty in psychiatry. Of 144 practitioners who met CSP inclusion criteria during the website review, only $47.9 \%$ self-identified with a specialty in sport psychology, athletics, etc. Of the nine applied practitioners who responded, eight (88.9\%) selfidentified with a specialization in sport psychology. Of all 84 participants who self-identified with a specialization in sport psychology, athletics, etc., seven (8.3\%) were not identified as CSP or Applied practitioners during the website review.

Proportion of clinical hours with student-athletes. Over the duration of a semester, the proportion of clinical hours that practitioners spent with athletics/student-athletes was positively skewed. On average, participants spent about $30 \%$ of their clinical hours with student-athletes $(M$ $=29.61, S D=28.40$, Range $=0-100)$. The median proportion of clinical hours with student- 
athletes was $20 \%(\mathrm{IQR}=10-40)$. As expected, there was wide variability in the proportion of clinical hours spent with student-athletes when examined across practitioner categories.

Categorically, CSP and applied practitioners (as defined during the website review) were combined into a sport psychology category ("SP" in the graph below), and were sub-grouped based on whether or not they self-identified with a specialization related to sport psychology. Practitioners who were identified as generalists during the website review ("Not SP" in the graph below) were also sub-grouped based on whether or not they self-identified with a specialization related to sport psychology. As seen in the graph below, the spread of clinical hours spent with athletics was very similar when comparing sport psychology personnel who did (Median $=51$, $\mathrm{IQR}=20-90)$ and did not $($ Median $=45, \mathrm{IQR}=15-88.5)$ self-identify with a sport psychology specialization on the survey. Those who were identified as generalists during the website review but self-identified with a specialization in sport psychology on the survey spent more of their clinical hours with athletics (Median $=30, \mathrm{IQR}=8-60)$ than did generalists who did not selfidentify with a specialization in sport psychology $($ Median $=14, \mathrm{IQR}=8.75-25)$.

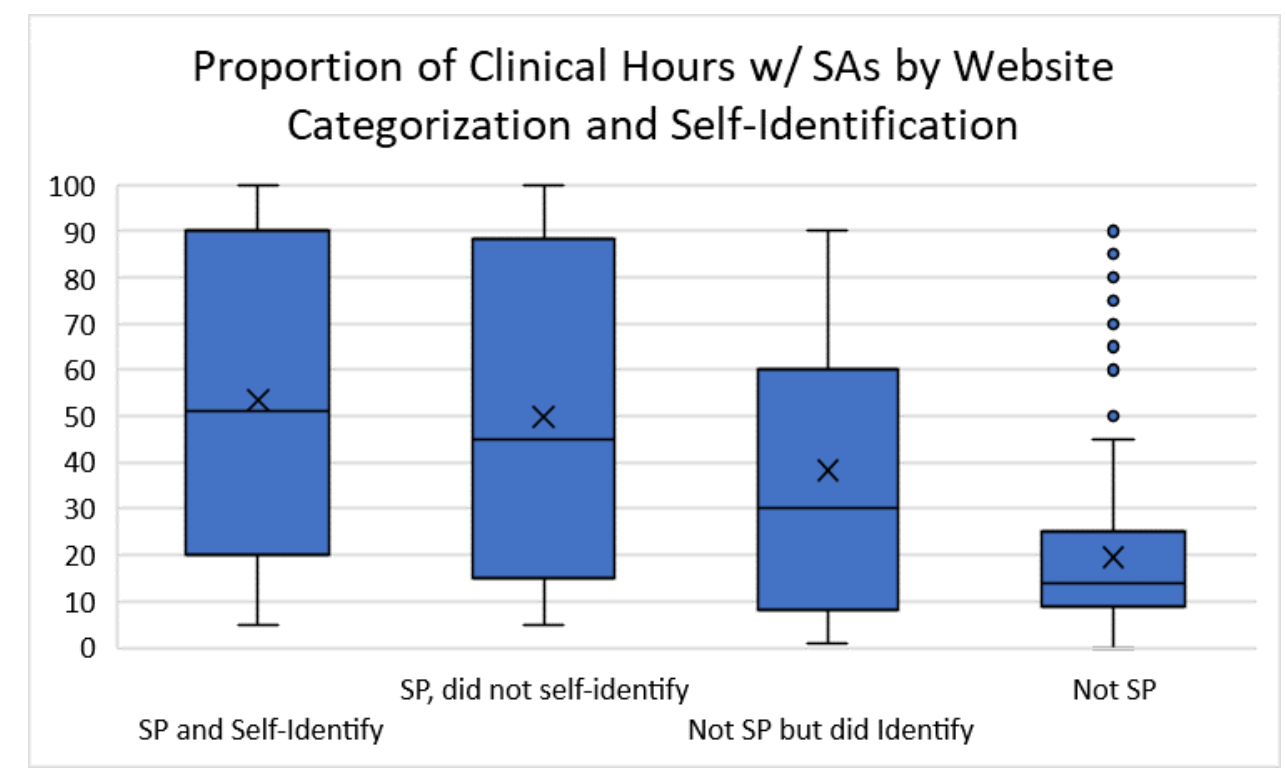


Proportion of clinical hours with athletics by division. In general, and as displayed in the graph below, generalist mental health practitioners (as defined by the website review) spent increasing amounts of time with student-athletes moving from P5 and DI institutions to DII and DIII institutions; which could have been a function of the relative scarcity of CSP practitioners in the DII/DIII context. Conversely, CSP practitioners (again, as defined by the website review) spent smaller proportions of their clinical hours with athletics moving from P5 to DI, DII, and DIII institutions. This suggests that CSP practitioners in DIII contexts may have more balanced roles that entail service delivery to broader populations in the campus community. In the P5 context, CSP practitioners spent - on average - two thirds of their clinical hours with athletics, and $44.2 \%(n=19)$ spent $90 \%$ or more of their clinical hours with student-athletes.

Proportionally, fewer CSP practitioners in the DI $(n=10,17.2 \%)$ and DII $(n=2,18.2 \%)$ context spent $90 \%$ or more of their clinical hours with student-athletes. No CSP practitioners in the DIII context spent over $80 \%$ of their clinical hours with student-athletes.

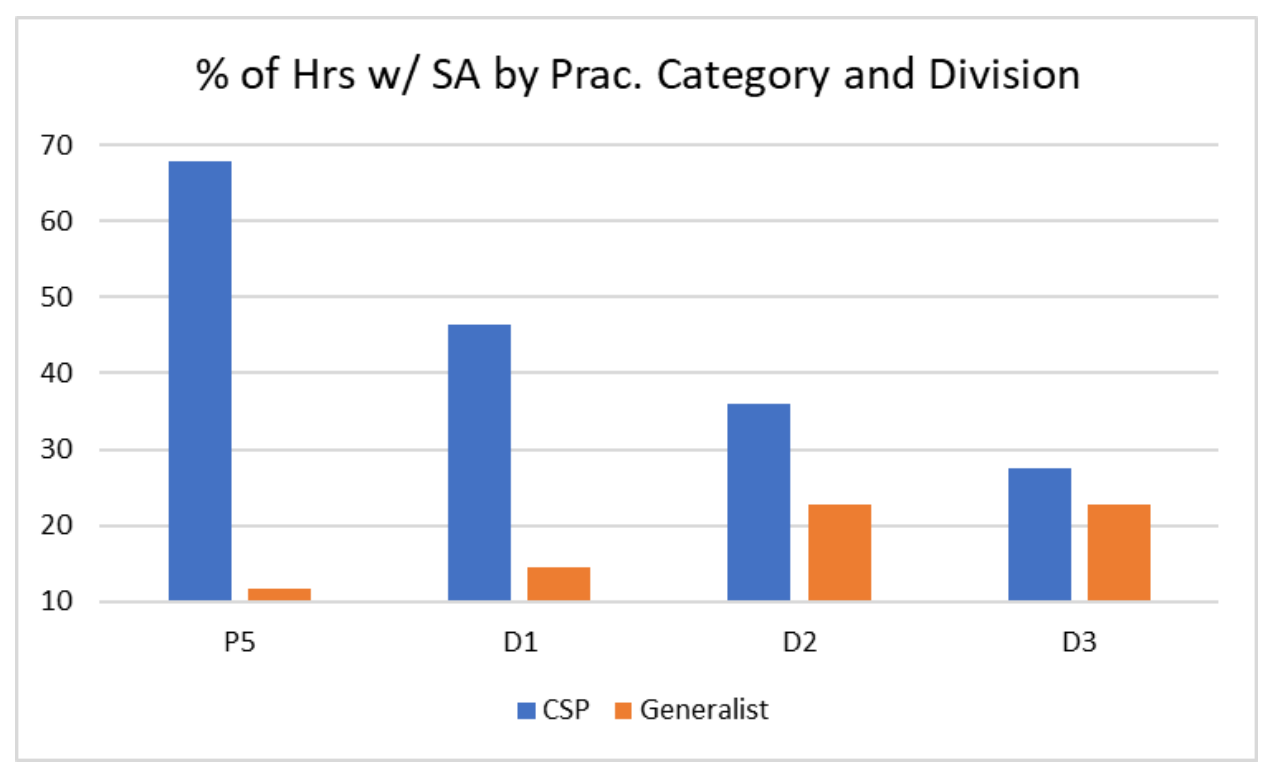

Cross-tabulating demand and availability. To further explore practitioner perceptions of sport psychology service availability, their responses were cross-tabulated by perceived 
demand among student-athletes. This was done with the thought, for instance, that participants who saw CSP service availability as comfortably satisfying demand means something different in the context of low versus high perceived demand. As expected, the proportion of practitioners who rated CSP service availability as stretched or exceeded by demand increased with demand (see the graph below). That said, $10.6 \%$ of respondents who saw low demand for CSP services indicated that availability was stretched or exceeded by that low demand. Within the sample, this would represent the lowest CSP service availability when offered at all. On the other hand, the highest CSP service availability was represented by participants who saw high demand for CSP services and who also indicated that availability of those services exceeded or comfortably satisfied demand. This was the case for $17.0 \%$ of respondents. Also of note, there appeared to be an inverse relationship between CSP service availability and perceived demand for CSP. When CSP services were not offered, the overwhelming majority of participants saw no demand for those services. Conversely, proportionally fewer participants indicated that CSP services were not offered when moving from low to moderate demand and from moderate to high demand.

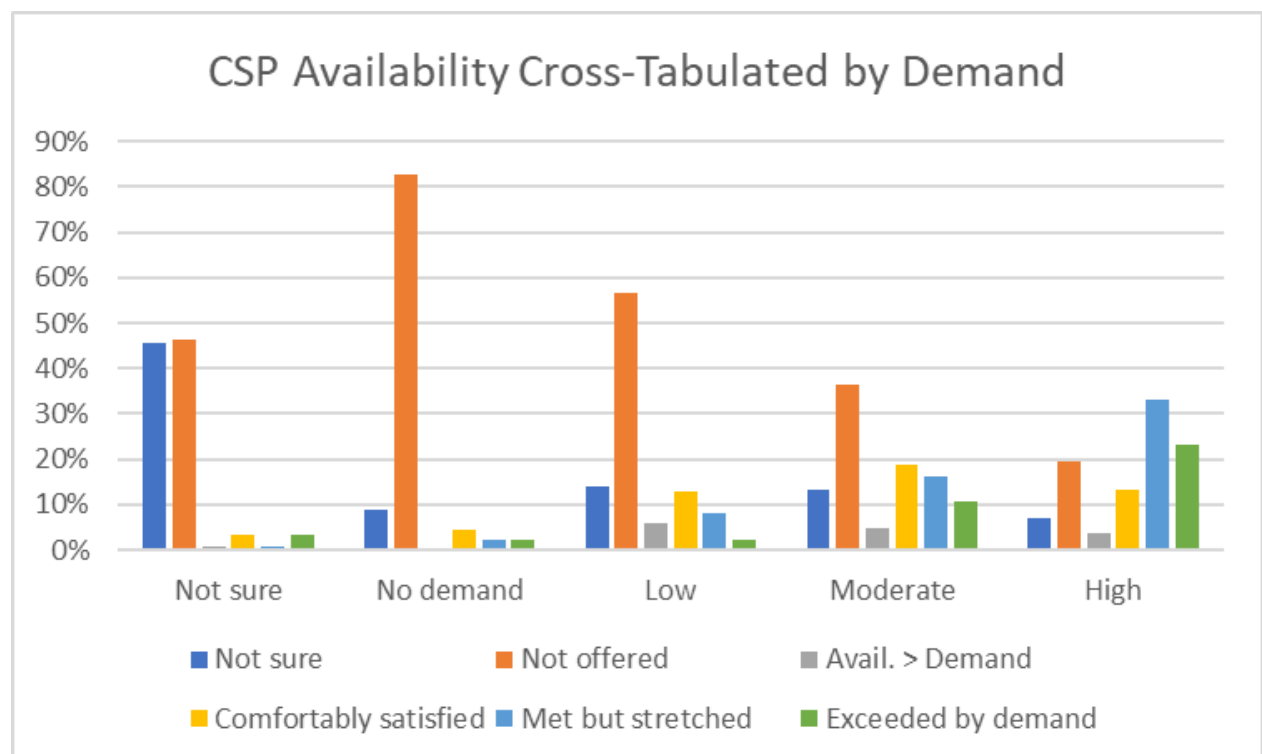


In a similar way, the perceived availability of performance consultation services was cross-tabulated by perceived demand. Showing some similar trends (see the graph below), the proportion of practitioners who saw the availability of performance consultation services as stretched or exceeded by demand increased with perceived demand. Of those who saw low demand for performance consultation services, $13.2 \%$ saw availability as stretched or exceeded by that low demand. As above, this would represent the lowest availability of performance consultation services when offered. Of practitioners who saw high demand for performance consultation services among student-athletes, $36.5 \%$ indicated that availability exceeded or comfortably satisfied demand. This would represent the highest availability of performance consultation services within the sample. As was the case for CSP services, there also appeared to be an inverse relationship between service availability and demand.

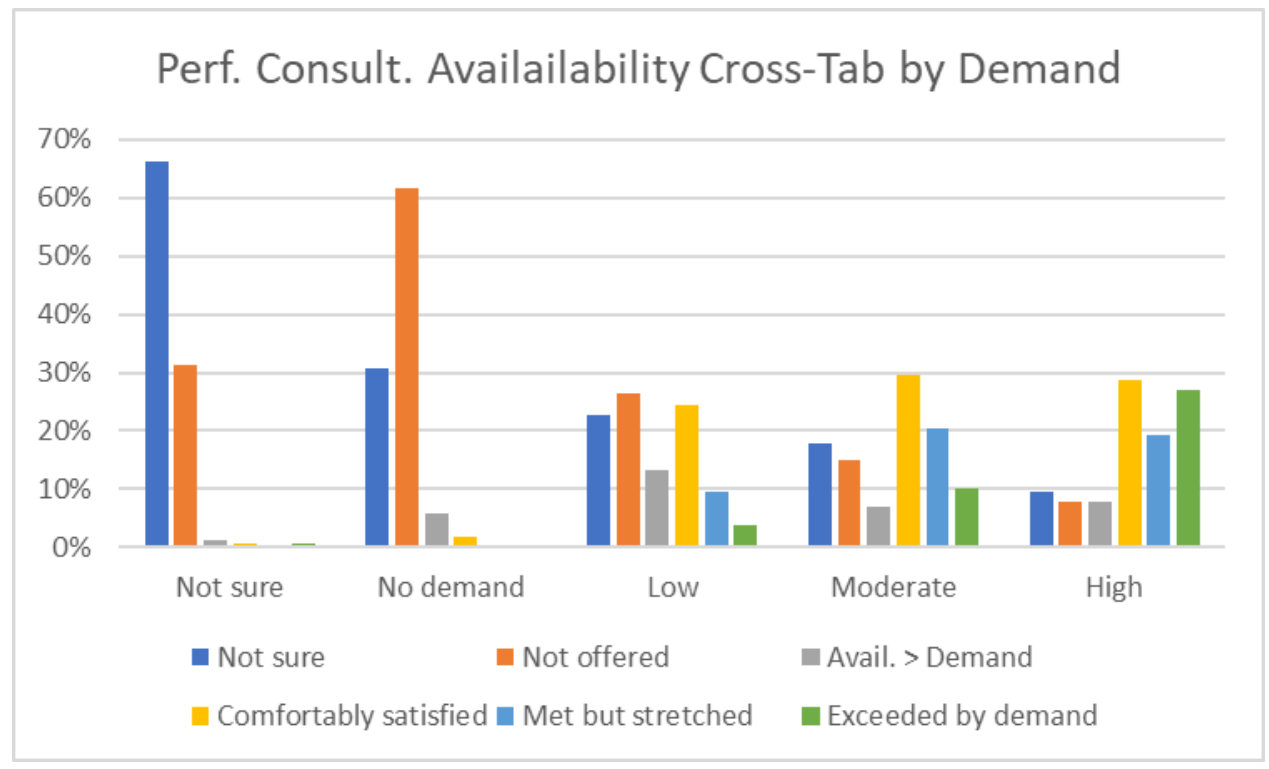

Practitioner experiences at high and low service availability. Recall from the methods section that a series of independent samples $t$-tests would be run to explore practitioner experiences at high versus low levels of perceived service availability. For the purpose of these tests, service availability was defined as the number of services for which practitioners reported 
that service availability was stretched or exceeded by demand. With six surveyed services, aggregate availability could range from zero to six. The low perceived availability group was comprised of 81 practitioners who marked the availability of four, five, or six services as "stretched" or "exceeded" by demand. The high perceived availability group was comprised of 245 practitioners who marked one or zero services as "stretched" or "exceeded" by demand. As the high/low grouping variable was used for six tests, a Bonferroni correction set alpha at $p=$ .008 . For context, agree/disagree responses were re-coded as follows: disagree $=0$, slightly disagree $=1$, slightly agree $=3$, agree $=4$.

More Professional Development. Among all respondents, $74.6 \%$ agreed or slightly agreed that they would have liked more time for professional development prior to COVID-19. When comparing the low availability $(n=81)$ and high availability $(n=245)$ groups, Levene's test revealed unequal variance $(F=7.76, p<.05)$ between them. The low availability group $(M=$ $2.30, S D=0.87$ ) agreed more with statement "I would have liked more time for my own professional development (prior to COVID-19)" as compared to the high availability group $(M=$ $1.83, S D=1.11)$. Equal variances not assumed, this was a significant difference with a small to moderate effect size $(t(172)=3.87, p<.001, d=.44)$.

Enough self-care. Most participants (73.4\%) agreed/slightly agreed that they engaged in enough self-care to remain enthusiastic about their work prior to COVID-19. Overall, about $8 \%$ of respondents disagreed with this statement. Levene's test revealed unequal variance $(F=6.99$, $p=.01)$ between the low availability $(n=81)$ and high availability $(n=245)$ groups on this variable. The low availability group $(M=1.69, S D=1.01)$ expressed less agreement with the statement, "I engaged in enough self-care to remain enthusiastic about my work (prior to COVID-19)" as compared to the high availability group $(M=2.20, S D=0.84)$. Equal variances 
not assumed, this was a significant difference with a moderate effect size $(t(119)=-4.07, p<$ $.001, d=-.57)$.

Caseload was too large. As a whole, just under two thirds of participants $(62.5 \%)$ agreed/slightly agreed that their caseload was too large before the COVID-19 pandemic began. Levene's test revealed unequal variance $(F=7.31, p=.01)$ between the low availability $(n=81)$ and high availability $(n=245)$ groups for this item. The low availability group $(M=2.20, S D=$ 0.90) agreed more with the statement that their caseload was too large prior to COVID-19 as compared to the high availability group $(M=1.47, S D=1.01)$. Equal variances not assumed, this was a significant difference with a moderate to large effect size $(t(152)=6.08, p<.001, d=.73)$.

On-call hours were reasonable. Reflecting on their work prior to COVID-19, 61.0\% agreed/slightly agreed that their on-call hours were reasonable. About one quarter $(24.1 \%)$ of participants indicated that they did not have on-call hours. For this item, the response option, "I did not have on-call hours" could not be converted to ordinal or interval data, and was thus treated as missing data. Levene's test revealed equal variance $(F=.15, p=.7)$ between the low availability $(n=66)$ and high availability $(n=187)$ groups. The low availability group $(M=$ 2.11, $S D=0.93$ ) expressed less agreement with the statement that their on-call obligations were reasonable prior to COVID-19 as compared to the high availability group $(M=2.49, S D=0.86)$. Equal variances assumed, this was a significant difference with a small effect size $(t(251)=-$ $3.02, p=.003, d=-.43)$.

Subjectively overstretched by client risk factors. As with the item above, the response option, "I did not encounter instances of risk management" could not be converted to ordinal or interval data, and was thus treated as missing data. That said, only $3 \%$ of respondents indicated that they had not encountered instances of risk management in their work before COVID-19. 
Responses to this item were more evenly spread (17.5\% of all participants agreed with the statement while $21.6 \%$ disagreed $)$, and Levene's test revealed equal variance $(F=.001, p=.9)$ between the low availability $(n=80)$ and high availability $(n=235)$ groups. When responding to the statement, "subjectively, I felt overstretched by the number/severity of high-risk clients under my care (prior to COVID-19)," the low availability group $(M=1.86, S D=0.98)$ agreed more than did the high availability group $(M=1.18, S D=0.95)$. Equal variances assumed, this was a significant difference with a moderate to large effect size $(t(313)=5.51, p<.001, d=.71)$.

More emotional support. As a whole, just over one quarter (28.2\%) of participants indicated that they would have liked more emotional support for stressors encountered as practitioners. Another one third (35.9\%) slightly agreed. When comparing the low availability (n $=81)$ and high availability $(n=245)$ groups, Levene's test revealed unequal variance $(F=6.75$, $p=.01)$ between them. The low availability group $(M=1.94, S D=0.97)$ agreed more with the statement that they would have liked more emotional support for stressors encountered as a practitioner (prior to COVID-19) as compared to the high availability group $(M=1.55, S D=$ 1.06). Equal variances not assumed, this was a significant difference with a small effect size $(t(148)=3.09, p=.002, d=.38)$.

The way in which the high and low service availability groups were operationally defined could have potentially influenced the results of the $t$-tests. For example, the high availability group was defined as those who indicated that no more than one of six services was stretched or exceeded by demand. Having few services stretched by demand could be qualitatively different than having the availability to comfortably satisfy demand for multiple services. Although $t$-tests were not re-run, redefining the high availability group as practitioners who listed four, five, or six services as exceeding or comfortably satisfying demand did not appear to substantially alter 
group descriptives for wanting more professional development $\left(M_{\text {new }}=1.83, S D_{\text {new }}=1.15\right.$ vs. $M$ $=1.83, S D=1.11)$, engaging in enough self-care $\left(M_{\text {new }}=2.17, S D_{\text {new }}=0.88\right.$ vs. $M=2.20, S D=$ $0.84)$, having a caseload that was too large $\left(M_{\text {new }}=1.47, S D_{\text {new }}=0.99\right.$ vs. $\left.M=1.47, S D=1.01\right)$, having reasonable on-call hours $\left(M_{n e w}=2.53, S D_{n e w}=0.77\right.$ vs. $\left.M=2.49, S D=0.86\right)$, feeling overstretched by client risk factors $\left(M_{\text {new }}=1.16, S D_{\text {new }}=0.94\right.$ vs. $\left.M=1.18, S D=0.95\right)$, and wanting more emotional support for stressors encountered in their professional role $\left(M_{\text {new }}=1.46\right.$, $S D_{\text {new }}=1.06$ vs. $\left.M=1.55, S D=1.06\right)$.

Additional experiences. Participants also responded to other experiential items designed to gauge their experiences with institutional administration, climate, and athletics. Recalling the context of their work before COVID-19, participants responded to the item, "Campus administration had too much control over the way psychological services were provided at my institution." A relatively small proportion (3.5\%) felt as though they could not say from their experience. About $11 \%$ agreed with the statement, while $61.2 \%$ disagreed/slightly disagreed.

Two items asked participants about the extent to which they agreed that their institution as a whole promoted diversity and inclusion, and then about the extent to which they agreed that athletics at their institution was a diverse and inclusive space. Overall, 14.7\% of respondents indicated that they couldn't speak to the cultural climate of athletics at their institution based on their experience. Of the remaining participants, $4.4 \%$ disagreed that athletics was diverse and inclusive space at their institution, and another $17.7 \%$ slightly disagreed. Across their institution as a whole, $6.0 \%$ disagreed that diversity/inclusion were promoted, and another $12.3 \%$ slightly disagreed.

When their clinical work included student-athletes, most participants (93.8\%) felt as though they could build rapport with this population. Fairly similar proportions of respondents 
agreed $(15.7 \%)$ and disagreed $(18.9 \%)$ that they would have liked more peer consultation for their work with student-athletes. Just under one third (30.3\%) indicated that they spent time being visible to student-athletes and coaches by attending practices and/or competitions prior to the COVID-19 pandemic. Perhaps a function of these outreach efforts, a small group of practitioners $(3.4 \%)$ disagreed with the statement that student-athletes at their institution held stigmatized views of mental health (13.9\% slightly disagreed and $10.2 \%$ could not say from their experience). Finally, for the most part, participants tended to agree (45.0\%) or slightly agree $(26.9 \%)$ that athletics administration respected the confidentiality of student-athletes' mental health service use $(10.4 \%$ indicated that they couldn't say from their experience.

\section{Qualitative Survey Data}

In an open-ended item, respondents ( $n=333,65.5 \%$ response rate) shared about what they currently needed as people/practitioners to facilitate their work. Using practitioner categories generated during the website review, it did not appear that one group of practitioners was more or less likely to respond to the open-ended item. Just over one quarter of respondents were CSP practitioners (26.5\%, 30.6\% of non-responders were CSP practitioners), $71.7 \%$ were generalist mental health practitioners (67.7\% of non-responders were generalists), and $1.8 \%$ were mental skills consultants (1.6\% of non-responders were mental skills consultants). Further, those who did and did not respond to the open-ended item were not different in terms of perceived service availability at their institutions. Using the high/low service availability coding scheme that was employed above (for the series of independent sample $t$-tests), there were similar proportions of practitioners in the low perceived availability group when comparing responders $(17.1 \%)$ and non-responders $(13.1 \%)$. Among the open-ended responses that were received, the average word count shared was 61.4 words (Range $1-623$ ). Inductive thematic analysis 
generated the following categories: demand for mental health services, insights regarding clinical services and their delivery, equipping professionals, oversight and organizational dynamics, support at the intersection of person and professional, and opportunities and obstacles in the context of athletics. All sub-categories and initial codes are documented in Table 7.

\section{The Demand for Mental Health Services}

Adding nuance to scaled survey items about the perceived demand for mental health services among student-athletes, practitioners' open-ended responses spoke to the demand for mental health services among the broader student body as well. Their responses also offered a glimpse into the ways in which the demand for services has been impacted by COVID-19 and the transition to remote telehealth service delivery.

Demand and COVID-19. Observations regarding the demand for mental health surfaced in various ways across participants' responses. Several responses revolved around demand in the context of the COVID-19 pandemic (see Table 7). A few practitioners had already seen heightened demand in light of the pandemic, and others expressed uncertainty about how demand would look in the semester ahead. For some, this uncertainty prompted a call for counseling centers and their institutions to anticipate and prepare for the impact that COVID-19 could have on the demand for mental health services. As one participant put it,

"When we work with natural disasters, we understand that the demand often comes when the disaster is over; we are still navigating the COVID-19 pandemic so while I have not had the time/experience to see how much it will increase...I project that the demand for service will increase the longer this goes on as well as when we finally "come out the other side" so an increase in the services available may be key to addressing this." 
Another participant invited faculty and staff (broadly speaking) into preparation efforts:

"The emotional and psychological impact of Covid 19 will take years to unravel. Hopefully faculty and staff will be able to first realize and name the impact it has had on them. While that is occurring they can prepare processes and insight to confidently reach out to students."

Demand for remote services. As a result of the COVID-19 pandemic, many colleges and universities have shifted to provide mental health services remotely. In some ways this shift has made mental health services more accessible for students, and less accessible in other ways. Telehealth services were cited as alleviating the barriers of physical distance to the counseling center (e.g., for students with a long commute or attending in an online format) and the risk of Coronavirus transmission that could occur during office-based services. However, students' lack of access to private locations and/or reliable technology were cited as barriers to telehealth service use. Several practitioners indicated that remote services appeared to be less sought after relative to in-person services. Some suggested reasons for this included utilization of community services while home, less comfort using telemedicine, "Zoom fatigue," perceptions "that virtual counseling will not be as good as in-person counseling," and "a lack of communication and a fear about liability" that occurred as students left campus amid shutdowns.

Demand - Broadly and within athletics. Practitioners also remarked on general trends in the demands for their services. Responses that detailed the demand for mental health services among student-athletes mirrored responses that commented on trends within the student body at large. Some saw demand as high and/or growing. Responses about a low demand for services were less common; but a few practitioners elaborated that, although rates of service use were lower, students and student-athletes were presenting with higher levels of acuity. Pointing to 
disparities that can exist in rates of mental health service use, one clinician observed that, "I think white female student-athletes use counseling services. Students of color and male students are significantly less likely to come see us." Others added that more diverse staffing could help to reduce these disparities.

Shedding light on other factors that could be influencing the demand for mental health services, some participants shared about how current events have impacted students. Recent emotions that were cited included uncertainty, confusion, anxiety, depression, safety concerns (contracting/spreading the COVID-19), and loneliness. One practitioner called to mind the extensive reach of these emotions: "All of our students are struggling with grief and loss in some form." A handful of responses drew attention to the salience of grief for student-athletes with the cancellation of competitive sport seasons. One practitioner offered an alternative point of view:

"When the decision was made that spring season would be canceled, and students would return home, our department (housed in the athletics) observed a decrease in clinical and performance services. We identified the cause of service decline was related to the student-athletes primary stressor being removed (sport)."

In addition to introducing new mental health challenges, some practitioners commented on how current events have exacerbated pre-existing stressors. As put by one clinician, "COVID-related anxiety seemed to affect those who were already struggling with mental health challenges. It seemed like it was one more straw on their back, so to speak."

\section{Insights Regarding Clinical Services and their Delivery}

In responding to the demand for services, practitioners also offered a glimpse into how they saw the structure, delivery, and needs of clinical mental health services on their campuses. 
As outlined in Table 7, participants shared about how they - and their centers - were navigating recent adjustments, and what was needed moving forward.

Adjustments that some practitioners are maneuvering. To add context for some of the support needs that practitioners highlighted (to be reviewed below), several commented on the difficulty of transitioning to remote work. This included, for instance, ironing out new protocols and procedures. One clinician shared that, before getting phone lines connected to remote telehealth software, students initiating services had "to go through our after hours service and then wait to get a call back. It is an awkward process and often it is a few calls before we connect." Other challenges that were cited in the transition to remote services included a sense of isolation, heightened fatigue, and a more deliberate attention to taking breaks. One clinician summarized their experience this way:

"It is easy to stay still at your computer all day. I have learned to schedule breaks, walks and moments to...breathe fresh air. [Working remotely] requires an increase in meetings to connect to co-workers...It requires over communication. It requires creativity. It requires being more aware of burnout symptoms and self care."

Contributing to an in-vivo code that captured the sentiment of several other responses, one practitioner said that, "for assessment and psychotherapy, [telehealth] is not an equivalent substitute for in-person contact." Other responses also conveyed a sense that remote services and videoconferencing had a quality that was subjectively different from in-person contact; and participants found this to be true of collegial interactions as well: "All of our clinical work has moved online, so what I'm missing the most is the chance to foster team-building and closeness among my staff. It's possible via Zoom, but it's just not the same." 
How some centers are adjusting. Drawing attention to another way in which remote services have not been "an equivalent substitute," several practitioners commented on the difficulty of maintaining the counseling center's visibility with certain groups on campus (e.g., "We do not have any student athletics for this semester at our institution so our mental health team would not be able to be accessible by visibility to student athletes.”). Some centers attempted to compensate for this with an increased emphasis on outreach. For other centers, however, an increased emphasis on outreach was more about ameliorating demand and reaching more students with few (or fewer) staff. One participant shared this response: "I am the only clinician at my college - and honestly I've been handling the demand by offering...open forum groups which allows me to see a larger number of students at once." Another indicated that “30\% of our student body has utilized our services (pre COVID)," and that without increased funding, "We are adopting a stepped-care model to provide more workshops on building coping skills to try to meet the demand for mental health without increasing our staff." When demand exceeded available resources, some participants shared that their institutions outsourced (or were planning to outsource) mental health services. Some expressed their concerns with this approach. As put by one clinician, "Outsourcing mental health services to companies who can 'save money' is not a solution to providing therapy on-campus by clinicians who have relationships with students and direct contact with other staff/faculty on campus.” Another felt that their institution had "remained willfully blind to the research surrounding the negative impact [outsourcing] will have on services for students, PARTICULARLY vulnerable students (emphasis original)."

What some centers are needing. The topics of demand, outreach, and preventative services provide a nice segue into comments from practitioners about what was needed within 
their counseling centers specifically in terms of services and service delivery (issues of staffing and other resources, for instance, will be reviewed below). Participants commented on servicerelated needs that included "innovative prevention approaches that go beyond psychoeducational programming," more integrative care/collaboration with other campus constituents, more widely available psychiatric resources, after-hours crisis care, and better responses to cases of sexual assault. The code "Catch 22 prevents change" was applied to a select few responses that illustrated a critical barrier to developing solutions for service-related needs. A key quotation from which this code was inspired came from one clinician, who shared that,

"We...can barely keep up with the flow of students who need counseling services. There isn't time and financial support of branching out to make new resources available, even if the practitioners are interested. So, we have overbooked therapists with wait times for students, and the practitioners who see this problem aren't able to invest time and energy into creating potential solutions with resources that aren't based in a counselor's office."

This barrier to proactive and preventative care also surfaced in the context of services embedded within athletics, and was expressed in this way: "There is only one of me and roughly 500 student-athletes...The expectation is to provide clinical care, which pulls me away from more preventative treatments such as workshops, education, training, and full team interventions."

A critical need that was cited for college counseling was that of intentional responses to issues of race and diversity. Just as COVID-19 and its impacts can be seen across several categories of this qualitative data set, so too do issues of diversity and responding to deeply entrenched systemic racism. The main objective in this section is to highlight needs at the level of the campus counseling center. For example, some practitioners spoke to clinical leadership 
that was reluctant (at best, and resistant at worst) to engage in conversations of social justice and supporting students of color on campus. In some instances, practitioners voiced a need to incorporate issues of diversity and social justice into the mission of the counseling center. As one clinician expressed, "I have needed spaces to work with colleagues to ensure the intentional incorporation of anti-racist values are at the forefront of our mission and work (diversity, equity, and inclusion committee and a white accountability group).” In other instances, practitioners observed that these mission and value statements were in place, but not being translated into action (e.g., "I work at a college that holds the values of diversity, inclusion, and social justice, and those are the named values of the counseling center as well. There needs to be more work done, however, to implement those values."). How to best translate values into action is open for discussion; and from the vantage points shared by participants in this study, there are no easy answers - especially when it comes to supporting Black-identified students, staff, and faculty. To punctuate this section, space will now be afforded for the extended response of one participant who shared deeply of their experience in this regard:

"Recently, as a clinician of color I have been the most requested among my peers...Though this is humbling there isn't enough full disclosure conversations, seminars, or spaces to discuss what may have lead to my heightened requests given the abhorrent racial events taken place summer 2020 or how these events have ignited a justified call to action from many BIPOC students addressing discriminatory practices on every PWI campus in America. Basically, though I am prepared because of my own personal experiences, I am not thoroughly prepared to adequately address the racial/discriminatory concerns through the counseling practice(s) and services via the pre-established operations of the 
counseling center. Because of these pre-set operations it appears as if we, the center, are waiting for the students to come to us; which has played out to be me being the one requested. I am humbled, but I recognize my limitations, and the parameters around college counseling centers. There needs to be more of 'me' and there needs to be an established climate that more readily addresses these concerns and provides sustainable support. Exactly what that looks like, I am still figuring that out myself."

\section{Equipping professionals}

As touched on in this extended response and in others throughout the section above, changes to the structures, protocols, and delivery of clinical services require that professionals are adequately equipped. Equipping professionals was another main theme across participants' open-ended responses, and as delineated in Table 7, included the "equipment" of human/ financial resources, logistics, professional development, and preparation for remote work.

Preparing for/supporting remote work. Amid the abrupt transition to remote telehealth services, several practitioners were limited in what they could provide to students due to the lack of licensure portability across state lines. The need for federal legislation in this area was heightened as a result of the COVID-19, but was not entirely new to practitioners working with student-athletes (e.g., "National licensing is needed. It is impossible to continue mental health work when an athlete travels out of state or moves home during school breaks."). Access to reliable technology (wireless internet, access to university systems, etc.) was highlighted as an area of need by some practitioners - and at times, for their clients as well. Finally, training for telehealth service delivery was another frequently mentioned need amongst practitioners. In particular, several voiced that they would like ideas for interactive programming, group work, 
and among those working with athletics, team sessions that were conducted via remote platforms. To illustrate, one practitioner shared that, "My colleagues and I have been looking for a way to keep athletes engaged via Zoom." "This has not been an issue in individual sessions," they clarified, "but, during team workshops, we have been exploring websites such as Kahoot to increase involvement."

Professional development. Beyond telehealth training, practitioners also remarked on a need for training to improve cultural competency, and for continuing education/professional development in a broader sense as well. In a time of tight institutional budgets, one practitioner's comment summarized a trend that appeared to be true for other participants as well: "Cuts are being made to CEUs, which normally we would get a bit more coverage for." Further, financial support for continuing education would not go far without the additional resource of time. As put by one clinician, "Additional professional development time would be beneficial. We are often stretched too thin and often have little time for PD outside of summer term or non-work time."

A stated need for consultation/supervision was relatively common as well, and for those working with student-athletes, extended to include mentorship in sport psychology. For instance, one practitioner indicated that they would have liked, "support for consultation time both with on-campus mental health providers, in addition to broader sport psychology key mentors/ colleagues." Pertaining to the need for consultation and supervision, a contextual comment from one practitioner called to mind a potential barrier: "University administration has put unreasonable demands and expectations on our wellness center director, which makes it almost impossible for them to offer adequate supervision to staff here as they are constantly...expected to put their time and energy elsewhere." Though it was only applied to this one response, the 
code, "Context - Demands on senior staff preclude supervision" was applied to make note of this barrier to supervision.

Human and financial resources. Inadequate access to supervision/consultation could hinder the growth of young professionals entering the field of collegiate mental health; and the need for increased staffing was - by and large - the most frequently cited need among participants in this study. Taking an analytic leap beyond the semantic content of responses about staffing may provide some additional support for the code just mentioned above (i.e., “Context - Demands on senior staff preclude supervision”). Specifically, while different practitioners made comments like, "We need more clinicians," "We are understaffed," "We need more practitioners at all college campuses," and "I'm feeling the need to make copies of myself to be able to comfortably absorb the number of athletes coming on my case load;" others qualified their responses with language like an "increased staffing of well-trained providers," "a well-trained triage specialist," "reassurance from my department that we will be able to hire more full-time licensed mental health providers," and "more licensed professionals on staff to decrease the clinician to student ratio" (all emphases added). These qualifiers could be coincidental; or, though unspoken, they could also convey a concern about the capacity of shortstaffed college counseling centers to provide training, mentorship, and supervision towards licensure and/or enhanced clinical skills.

That said, some practitioners explicitly mentioned the critical role of supervised trainees in allaying the demand for services, and further, how COVID-19 impacted training programs at their centers. For instance, one clinician remarked that, "we...have been unable to offer positions to internship or practicum students, while in a normal academic year we would have at least 1 or 2 who could help relieve some of the pressure on full-time counselors." Whether prompted by 
COVID-19 or not, participants also commented on furloughs and funding issues at their centers despite high and/or rising levels of clinical demand. In the milieu of athletics, one practitioner shared of their experience in this way:

"Last year I was hired as a part-time mental health counselor specialized in sport psychology...as the school was unaware if my specialized services would be needed or used enough for full-time work. My weeks were consistently booked out and many times I was working through my lunch or staying late just to catch up on my clinical notes. The plan was for me to go full-time due to the high demand of clinical and sport performance sessions (teams \& individuals), but when COVID hit the funding froze. Now this year the demand for services has increased significantly but my hours have remained the same as they noted there wasn't any funding for me."

In an alarming and longer-term scenario, another clinician shared that their staffing had been cut in half over the past several years "due to budget cuts and a freeze on hiring, while demand for services has increased." "Further," they added, "the acuity of clients in crisis has vastly increased. We had a $300 \%$ increase in hospitalizations [over the span of one year], and administration did not respond to our concerns except to say 'everyone is doing more with less'...It worries me that it will take a completed suicide before anyone pays attention."

As suggested earlier, diversity was another area of critical need in the staffing of college counseling centers. The observation by one clinician of color that "there needs to be more of 'me"' (see above) was not an isolated utterance. In another instance, it appeared that the call of 
one campus community for more representation among counseling center staff went unattended. One clinician expressed that,

"CAPS at my university is short-staffed in general and short-staffed in having Black identified therapists available to meet the needs of our Black students. I am the only black identified therapist on campus. Our Black Student Union has asked for 2 more. However, funding is always an issue and the pandemic and other matters have complicated the issue even more."

Speculating as to what these undisclosed "other matters" might entail, one could be led to wonder about the organizational culture and institutional logistics in which this individual's experience was situated.

Logistics. Institutional logistics was the final thematic component of the "equipping professionals" category, and gave further voice to the need for structures and protocols to support diversity within the campus community. From participants' remarks, students need logistics that support diversity, as do all those who work to support students. As one clinician shared, "There are many protocols in place for COVID-19 procedures, but nothing in order to prevent the ongoing perpetration of racial trauma. And that is for our students, student-athletes, staff, and faculty." Adding to this, and from the extended response that follows, this author interpreted a sense that developing logistics in support of diversity (and/or dismantling discriminatory logistics) could begin in or with CAPS, but necessarily extend beyond CAPS with campus-wide counsels/committees - and perhaps to multi-campus initiatives as well:

"As a clinician of color, I too echo that same sentiments of many BIPOC students in society: 'where are the established places, spaces for me?'; 'where is the full preparation for my existence \& representation?'; \& 'where is the adequate 
response to my needs?'... Similar to how those with Eating Disorders on campus have entire counsels, committees, and staff monitoring their physical/mental/ functional progress so too can teams be created and embedded to best monitor \&/or prepare around the impacts of racial (or particular intersectional) discriminatory practices that take place on college campus and even within college counseling centers...Additionally, this response from me is truly a general one and does not call any one particular college or center into question. I have listened and learned of many colleges in America facing similar call to actions from BIPOC students (and allies) and I always wonder who (or what) in the college counseling center is holistically prepared for them."

Another area of logistics in need of attention was raised in several comments about how practitioners were being equipped for in-person service delivery during the COVID-19 pandemic (e.g., "We need safer...protocols to conduct in-person sessions."). Some commented on a need for protocols or personal protective equipment, and others commented on logistics in terms of physical space. For example, one participant indicated that "our individual offices have no windows, [and our] whole office has only one hallway window, so no opportunity for more ventilation." Further still, a few practitioners voiced that logistics needed to be developed to communicate more information amid uncertain times, and to do so more efficiently.

\section{Oversight and Organizational Dynamics}

Communication was a key component of the next thematic category across participants' responses, which was labeled as "oversight and organizational dynamics." As can be seen in Table 7, communication was of pivotal importance for dialogue between practitioners and their clinical and/or institutional administration. Likewise, several responses portrayed the esteem in 
which practitioners were held in their campus community, and how their "value" was communicated to them by administration. Sketching out the products of this communication, several contextual comments were also included in the category to illustrate ways in which administrative oversight trickled down to impact the student-as-service-user.

Dialogue. Though dialogue certainly connotes communication, there was also a sense among participant responses that dialogue conveyed value or mattering in the sense that practitioners did or did not have opportunities to enter into communication with administration, and did or did not have much say when their voices were heard. The initial codes of "More voice with administration" and "Context - Unanswered advocacy" were developed and applied in an effort to capture these experiences. Contributing to the code of "More voice with administration," one clinician disclosed that,

"As a practitioner with no access to dialogue with administrators, it can feel very limiting and draining to continue to be asked to do more for more students, with what feels like little regard for quality of care from the administrators. I would like to have more opportunities to share with administrators the challenges of providing competent psychological services and feel heard/supported."

Another practitioner shared that their voice and clinical judgment were overpowered by institutional administration that catered instead to parents' wishes: "My institution also sends students to our counseling services for preferential treatment because of parent demands instead of leaving it up to the mental health professional to determine level of care for students." As a polar opposite to these responses, one practitioner had this to say of their experiences in a "small center with a small staff": 
"I am able to feel heard in terms of choosing the direction we take and how we want to administer our services. This has been really important to me because if there is something I am struggling with or disagree with, I feel confident that my director will be responsive and work with me to improve my concerns."

Similar to the response that referenced a $300 \%$ increase in hospitalizations (above), another practitioner shared about how their requests for case consultation have gone unanswered, contributing to the code of "Context - Unanswered advocacy":

"My site does not offer peer consultation. I, and other professionals, have requested peer consultation, but there is concern amongst the administration team that we will lose clinical hours. Clinical hours are stretched thin. At the same time, we serve a very risky student population, and time set aside to consult as a team would be wonderful.

Some practitioners advocated on behalf of specialized services for student-athletes, with similar results. One participant commented that,

"Our institution provides mental health services to athletes only via our Counseling Center in the same way it is offered to all enrolled students. Despite ongoing presentation of data to show the increasing need for [the] student athlete population, the Athletics Department has not yet moved forward with many ideas to implement, such as having a counselor from [our] center work specifically with student athletes one day per week, because they 'don't have the money'."

As implied by this participant's use of quotation marks in their response, and as alluded to in other responses in this section, several comments conveyed a need to address discrepancies that existed between the viewpoints of clinical staff and administration (be it clinical 
administration or institutional administration). Oftentimes, these discrepancies arose in regards to the use of time and/or financial resources. Discrepancies also surfaced around the scope and quality of clinical care offered through the counseling center. As put by one clinician, "Some higher up administration and other campus officials do not understand the scope of work that our counseling services office does," and another, "I would like less oversight and more trust in the work I do as a counselor. I feel the institution puts more emphasis on 'customer service' instead of actual clinical work." A few practitioners disclosed their frustration with the decision-making power of administrators who lacked this understanding (e.g., "Admins who do not understand this work should not be dictating 'how much' or how 'busy' we are and watching over us.”). One participant's response seemed to highlight each of these components, while also calling to mind ethical discrepancies and conveying the overall weight of unrealistic administrative expectations: "The rest of the campus community (including senior administration) wants us to be everything, at all times, for students. They want us to offer weekly counseling to those who want it, they expect us to be available at all times to meet with students on a walk-in basis, they want us to outreach to the campus and students, they expect us to evaluate students who are experiencing acute symptoms (mania, psychosis), they want us to 'deal with' students who are displaying appropriate emotions, they want us to have no wait time for students to be seen, they don't respect out legal and ethical responsibilities pertaining to confidentiality and client privilege, they want us to serve on campus-wide committees and to be the voice for student mental health."

Esteem, broadly. Amid expectations of being everything at all times for the campus community, the participant above punctuated their comment by adding that administration and 
the campus community at large "get angry at us when we cannot meet these conflicting demands and expectations, and then we are accused of not caring enough about students, and our office is talked about poorly." During data analysis, this comment impressed the author with a sense that - despite working towards (and sometimes meeting) unrealistic expectations - some practitioners in collegiate mental health were not valued or appreciated. Other responses that were similar in tone and language seemed concur with this clinician's experience:

"I'm a doctoral level practitioner and am exhausted by the notion that we (my colleagues and I) often feel undervalued by our institution. Professors with Phds are given much latitude and we are required to clock in daily and are treated like freshmen in HS...There are so many ways that I've felt undervalued in my institution. I can say with absolute confidence that my colleagues and I give SO much to our work and the students we support. We perform with a high degree of professionalism, care and concern. We are all grossly underpaid for our work. Feeling appreciated by my institution and being paid accordingly would be a GREAT place to start.” (emphases original)

At the risk of over generalizing, there were also several instances in which participants commented that their needs were well looked after at their institutions. This could be seen in responses like, "I am very supported in my work," "I think my needs are met by my institutionas they always have been," and,

"Working in a UCC, which is by far the most supportive and pleasant work setting I have worked in, has created space for what I need simply based on the seasonal nature of the academic calendar, with built in breaks and reprieves that I can count on to recharge. I am a Master's level clinician and other than some 
elitism and exclusion I feel, I feel very supported and happy in this location. Far more than when I worked in community mental health for example."

The sentiment of support also extended into the realm of athletics (e.g., "Current resources are adequate to meet the requests for counseling and sport psychology requests by student-athletes and coaches.").

Oversight eventually impacts students. Though relatively brief in comparison to other reflections shared by participants, a handful of contextual comments shed light on the ways in which administrative oversight trickled down to impact the student experience. As administrative expectations and resource allocation can impact the workload of practitioners in collegiate mental health, some participants saw unwieldy caseloads as diminishing the quality of care that they could provide. This can be an emotionally cumbersome experience, as shared by one clinician who said, "We are understaffed and under funded. This leads to greater demand and when we try to meet that demand it often times leads to poorer quality services. This leads to my own disappointment in not meeting student needs." Similar to the code of "Catch 22 prevents change" that was discussed above, a few responses to a sequential chain of events that began with administrative oversight and ended with a low accessibility of support for students who were struggling. Specifically, if centers are ill equipped to meet clinical demand, students will be placed on waitlists to receive services. If waitlists grow too large and/or presenting concerns are severe, students will be referred out to services in the community. In some instances, and as one participant put it, "referring creates its own issues of affordability/access." If and when campuses and their communities care cannot collectively meet this demand, another participant observed that the situation ultimately "limits what is available to students at our institution and likely has an impact on students' ability to complete their degree." 


\section{Support at the Intersection of Person and Professional}

As participants worked to meet the mental health needs of students and student-athletes in their campus communities, they also reflected on ways in which they themselves were in need of support. Table 7 delineates the different aspects of support that practitioners spoke to, including connectedness with colleagues, self-care, support in the structure of the workday, and in recent times, support for the remote workday.

Connectedness with colleagues. Building on responses that detailed the difficulty of remote work and the notion that online/remote connection was "not an equivalent substitute for in-person contact" (above), several participants voiced a need for collegial support and collaboration. Some phrased this as needing "to feel more connected with my colleagues," “greater peer support from colleagues," and "intentional spaces to...community build regarding stressors and identities." Speaking to a connectedness that was both supportive and collaborative, one clinician shared that, "I am needing intentional virtual spaces created to build connection among colleagues as a practitioner... and to boost morale," add that they have also "felt the need to connect with coworkers via online chat throughout the workday to answer questions, check in with one another, and chat for fun to keep connected."

Self-care. For many, this collegial connectedness comprised a social component of selfcare. A need for self-care was emphasized in the context of the pandemic. An in-vivo code was developed from one practitioner's response in this regard: "campus mental health professionals are dealing with the same issues as everyone else during COVID-19 while supporting others struggles with the same issues/traumas." With a flavor of the collegial connectedness mentioned above, one clinician phrased the need for support Re: "dealing with the same issues as everyone else" in this way: 
"I wish that our center spent more time checking in with clinicians to see how we are doing personally during the pandemic...Once...we all adjusted to our 'new normal,' I felt like there hasn't been much space to make sure staff are doing ok." Comments from another practitioner underscored an important rationale for this self-care, as it can help to prevent impairment and bolster the ability to remain focused on clients' needs:

"I am needing increased spaces to process the challenges we are all facing - with colleagues and mentors - so that when I work with clients, I can gain some emotional distance from the impact of the current situation on me and focus on the client's needs."

Self-care also surfaced in responses that referenced needs for more sleep, exercise, and "recuperation," as well as in responses that spoke of self-care in more general terms (e.g., "I think self-care and our own well-being is often left to the side, unless we are very intentional about it.").

Though qualitatively different from these aspects of self-care, a sparse but subjectively rich code labeled "Context - Insight of self in system" was also grouped into this thematic category. This code was applied to instances in which participants had clearly done the reflective work to notice how they were responding to the systems and interpersonal processes that surrounded them. The code was grouped in here because it seems more likely that participants could generate these insights having had at least some space for self-care and self-reflection. To provide one example, a participant shared about their efforts to develop services for their institution's athletics department. This individual recalled feeling, "unpleasantly surprised by the strength of athletic staff's initial expectation--expressed, seemingly from a position of unquestioned power--that I should just disregard the upholding of student confidentiality, in 
order to serve staff purpose(es)." Expanding on their personal insight, they shared, "I was equally disturbed by my, almost, knee-jerk countertransferential desire (that, at present, I can only presume emanated from my own elite level intercollegiate athletic experiences) to comply with their expectation." From this insight, the practitioner could further identify how the dynamic was impacting their current motivation to continue working with athletics.

Support in the structure of the workday. Participants remarked on aspects of self-care that could be afforded by shifts in the structure of their workday. This included more time for administrative tasks, case management, prep work, and similarly, more flexibility with scheduling. Some practitioners commented on multiple roles that they (or their colleagues) were called to fill. Additional time in the workday could potentially come from opportunities to "wear fewer hats," so to speak. One practitioner spoke to a need for "fewer hats" in this way: "As a clinician, outreach coordinator and supervisor, I wear a lot of different hats...while I like the variety, at times, it is too much to take on and feels overwhelming and I get conflicting direction from my director." Other aspects of self-care that could be afforded in the structure of the workday were mentioned by practitioners who shared that, "Physically I need more time for sessions, mentally I need more time so I can breathe and actually eat my lunch," and "Having time off mid-day to exercise would be a HUGE bonus. The recognition that we, as therapists, hold SO much for others" (emphases original).

Support for the Remote Workday. With the recent shift to telehealth services, some comments from participants spoke to support needed for the remote workday. In a qualitatively different sense from being "equipped" for remote work (discussed above), support needs here occurred at the intersection of personal and professional matters. This included support for the balance of family life and remote work (e.g., "I need support managing the academic needs of 
my children while I try to do my counseling work."), an adequate home workspace (e.g., "private working space at home," "Not having a proper home office space - physical discomfort from sitting at make-shift desk for hours a day”), and compassion/understanding from others (students, administrators, etc.) amid the many adjustments being made (e.g., "Since moving to remote, need more understanding and flexibility," "Compassion as our work platform is changing constantly").

\section{Opportunities and Obstacles in the Context of Athletics}

A goal of this study was to develop a broad description of the experiences of mental health practitioners working on college campuses. Within the context of this broader landscape, analysis also attended to issues and experiences of service delivery (mental health as well as clinical/applied sport psychology) with student-athletes. To this end, participants' open-ended responses appear to coalesce around the following themes: the mental health climate in athletics, navigating organizational dynamics in athletics, constructing a bridge between CAPS and athletics, and the pros/cons of services embedded within athletics (see Table 7).

The mental health climate in athletics. There were mixed views as practitioners described their vantage points on the climate of mental health in athletics. Some commented that the stigma of mental health appeared to be decreasing among student-athletes at their institutions, and in one instance, was attributed to the efforts of "strong student leaders within athletics." Others shared their observations that the climate of athletics can be anti-mental health (e.g., "student-athletics is a very different world...as though they've been bought and paid for to perform. Coaching styles can be very abusive and mentally destructive. The athletic culture is...strongly anti-mental health and providers need to tread lightly...”). In some cases, practitioners felt as though coaches had more stigmatized attitudes than their student-athletes. 
One practitioner shared that, "Some coaches are more stigmatized than students. We see athletes across almost all teams but coaches would be surprised that athletes don't feel safe telling them." Elaborating, this practitioner said, "We hear about stigma with athletes - and I'm sure it exists but I think it is influenced by coaches' own stigma more than peers' or being an athlete." In light of this stigma, and in the absence of support from athletics administration, some felt that - in the words of one clinician - "The current approach seems more like band-aid and reactive rather than comprehensive and proactive in regards to the mental health care of athletes." Another practitioner expressed their concern with this approach:

"Despite increased reaching out and psychoeducation regarding mental health impact of isolation and missing out on competitive seasons, $\mathrm{AD}$ and coaches have reached out on a very limited basis. My fear is that they will only reach out once a student-athlete experiences a crisis when my services could potentially help prevent the crises."

Sadly, this was the case in one clinician's experience, who saw that cuts in mental health services for student-athletes were only partially restored in the aftermath of a completed suicide within the athletics department. From these observations and experiences, a few participants expressed the need for more buy-in to mental health and sport psychology within the culture of athletics. One participant reflected that,

"There are times where mental health services are talked about by administrators or other faculty members, but little is done to connect student-athletes with those services. In my work I have noticed there is this tendency to talk about the services offered without actually doing much in terms of making sure those services are being accessed." 
Navigating organizational dynamics in athletics. In trying to secure buy-in and navigate the organizational dynamics of athletics, some practitioners saw a critical need to involve coaches/athletics staff in mental health prevention efforts. Speaking also to the "bandaid" approach to mental health that was referenced above, one practitioner shared this of their experience:

"I feel that the administration, coaches, athletic trainers view the counseling staff as "fixers". They feel they should just be able to walk a student-athlete over with no explanation of what they need or what the student's wish is...Mind you the coach, AT, administrator hasn't bothered to ask the student, "How are you? What's wrong? How can I support you?" They appear to be afraid of talking about mental health with the student athletes. I have done numerous training with the coaching staff and athletic trainers about how to have these conversations with students. Year after year, the same thing always happens. I wish that they would talk with the student. When a student is just walked over and "dumped" on us, they often feel betrayed and don't want to open up in session."

In their interactions with coaches and athletics staff/administration, some practitioners felt pressed to share confidential details of student-athletes' service use. Recall, for instance, the comment shared in the "insight of self in system" above. Another practitioner felt similarly, describing their experience as follows: "Coaches/admin still believe they should be privy to details about student-athlete mental health conditions. Mental health providers end up 'in trouble' for 'withholding information' about a student's mental health status. It's frustrating that they only look through the liability lens when we're the ones taking on the risks." 
Constructing a bridge between CAPS and athletics. Participants remarked on different structures and approaches to providing mental health services for student-athletes. Oftentimes, mental health and/or sport psychology services were housed in the campus counseling center, or delivered within athletics by staff who served in a rotating or consulting role with the department from CAPS. In these instances, participants conveyed a sense that more could be done to bridge the distance (physical, cultural) between the two entities in order to strengthen the visibility and accessibility of CAPS. As phrased by one clinician, "I believe that there should be a purposeful intervention in bridging Athletics and the university counseling center together." Part of this bridging, participants said, entailed gaining more access to the world of athletics (e.g., "As a sport psychologist practicing at the counseling center, there is always a struggle to increase visibility and decrease stigma of MH counseling with student-athletes," "It would...be helpful to have more face-time with our athletes and coaches to understand the needs that may or may not be being met.") and more bidirectional collaboration between the two entities (e.g., "It would be useful to have more collaboration between the Athletics Department and the Counseling Center, so that we are working together to meet the counseling and mental health programming needs of our student athletes.").

Offering additional detail as to what access and collaboration looked like, some clinical staff sought additional training in sport psychology or student-athlete mental health. This training enabled different forms of outreach to athletics, such as informal "let's talk" drop-in hours located within athletic training facilities, or "in-services for coaches and mental health awareness presentations to teams." For practitioners who may want to pursue this outreach, one participant offered an example by sharing about their approach in detail: 
"My experience working with student-athletes was from a community development and engagement perspective. My roles consisted of creating events and programs, data intake, providing new resources, partnership building. For example, creating a monthly event would be dedicating a month to a mental health awareness topic, such as eating disorder awareness month. I would table this event a couple of times to discuss with athletes about mental health issues, and I would provide an activity to do with them. My role was to look [after] and offer services to student-athletes as a group rather than an individual."

In other responses, partnership building was mentioned with specific reference to the relationships that practitioners developed with athletic training staff. As put by one practitioner, "Trainers are valuable support and liaison between therapy and athletes. I hope not underrated," and another, "I have worked intentionally to foster a relationship with the athletics department (and particularly the athletic trainers).”

There were also several practitioners who cited a need for or expressed an interest in training to better support the mental health and performance-related needs of student-athletes. Finding time in busy clinical schedules for this training or outreach to athletics was mentioned as a barrier. In light of time and other resources, one practitioner's thoughtful comment called scope of practice to mind, and questioned if it is in the purview of the college counseling to create specialized services for athletics:

“Our counseling services were at times challenged to build bridges with athletics with sometimes unreasonable requests on counseling staff to focus on studentathletes. At a small center, we are all generalists and unable to specialize on specific populations or clinical concerns. Better relationships and more training 
on sports psychology might be helpful, however, our focus is really clinical mental health, and I don't think it's really appropriate for our center to offer special treatment to student-athletes beyond what we provide to the general student population. That being said, I think there are clinical concerns that are potentially impacting student-athletes disproportionately...However, with limited resources, it is difficult to work on programs to target those concerns."

Pros and cons of services embedded within athletics. When resources permit, and are allocated, some athletics departments will create in-house mental health/sport psychology services for their student-athletes. Here too there are potential benefits and potential pitfalls. A potential benefit cited by practitioners in this was the convenience of service use for studentathletes. Others cautioned that highly specialized and embedded services run the risk of sequestering student-athletes from the rest of the campus community and its services.

Contributing to an in-vivo code for this concept, one clinician shared that,

"Student athletes are discouraged at times from seeking services from the community or even campus-provided mental health services....It would help me as a practitioner to have more access to student athletes, who can be essentially sequestered from the services offered to the general student population. This separation is understandable at times and not always detrimental, but must be considered carefully..."

Another practitioner said it this way, "We do serve student athletes [in CAPS], but athletics have hired their own counselor and the culture that exists currently is that the expectation is for those students to work with that counselor." Thus it seemed that the culture, staff, and/or expectations of the athletics milieu were largely responsible for sequestering student-athletes from services. 
As an interesting juxtaposition, however, there may also be times when well-intentioned CAPS clinicians are the ones doing the "sequestering." This may be more likely to occur when staff do not feel adequately trained to support student-athletes, as one practitioner observed, "There is... limited encouragement of basic-level training of working with student athletes with CC staff (the norm is that clinicians just send them to the sports psychologists)..." 


\section{Appendix F: Extended Review of Literature.}

\section{Historical landscape of collegiate mental health}

Historical records suggest that the first practitioners to address matters of mental health on college campuses were psychiatrists (King Lyn, 2017). The broader, more holistic discipline of college counseling began to emerge in the early 1900s, and particularly so as some began to recognize that institutions of higher learning could do more to assist their students with the personal and academic issues that were brought with them to campus (Williamson, 1939). In this time, counseling typically revolved around issues of personal adjustment (e.g., homesickness), developmental transitions, academic or career related concerns, and preventative outreach (Hodges, 2017; Schwartz \& Kay, 2009). There was, however, some debate over who should provide these services (e.g., faculty, clerical staff) and what degree or training background they should possess (Hodges, 2017). This debate withstanding, many colleges agreed upon an in loco parentis philosophy that the institution should function "in the place of parents" (Hodges, 2017). Following from this philosophy, students were often prohibited from living off campus and tight regulations were imposed on campus, such as curfews (Hodges, 2017).

After World War II, the GI Bill encouraged veterans to attend college and many did (Hodges, 2017). As the first influx of students outside the traditional age range of 18 to 22 years old, many veterans challenged the control of in loco parentis after arriving to campus with spouses and children of their own (Hodges, 2017). These years also saw marked expansion of "guidance services" for vocational and academic support, which was foundational for the growth of college counseling (Hodges, 2017). Campuses were also becoming increasingly diverse because of the Civil Rights and Women's movements (Hodges, 2017). Along with these demographic changes, organizational changes were taking place on campuses as well. Many of 
the administrative duties once assumed by faculty were shifting to the purview of student affairs staff, and counseling too diverged to become a separate and more specialized service - now provided by practitioners with graduate training in psychology (Hodges, 2017). Some saw the increased professionalization of student affairs as tugging the counselor's role to be less studentcentered and more institutionally centered (Grayson \& Meilman, 2013).

As these developments were unfolding within institutions of higher education, psychology as a field was also expanding and changing through the 1960s, 70s, and 80s. For instance, Carl Rogers (1961) challenged previous theoretical approaches to counseling by promoting unconditional positive regard, empathy, and genuineness as necessary and sufficient conditions for effective psychotherapy. This era also saw increased development and use of personality and mental health assessment, a stronger emphasis on credentialing, and the introduction of new professional backgrounds into the landscape of college counseling (e.g., social work, marriage and family therapy, psychiatric nursing; Hodges, 2017; King Lyn, 2017).

This diversification in staffing would be useful, as the 1980s saw an increased demand for mental health services on college campuses (Harris \& Kranz, 1991). As waitlists for services first started appearing, smaller campuses with fewer practitioners realized a need for team-based care and referring students in need to off-campus resources (Harris \& Kranz, 1991). This trend has continued to present day, as more and more licensed clinical social workers are being employed as case managers to oversee the continuity of care for students with a high need for support and/or referral to off campus resources (King Lyn, 2017). It was recently found that about one quarter $(24.5 \%)$ of institutions employ one or more case managers (LeViness, Bershad, Gorman, Braun, \& Murray, 2018). 
Another increasing need has been for psychiatric services and the use of psychotropic medications to assist students experiencing mental health challenges (King Lyn, 2017). At present, estimates suggest that about $46.6 \%$ of college mental health clinics offer any psychiatric services (LeViness et al., 2018). However, among those institutions that do offer psychiatric services to students, about $57 \%$ of counseling center directors endorsed a need for more weekly hours devoted to providing this service (LeViness et al., 2018).

Along with the increasing demand for mental health services among college students from the late 1980's to present day, an increased severity and persistence of mental illness among college students has been observed as well (e.g., Beamish, 2005). This shift has challenged practitioners "to rethink their developmental models and their methods of service delivery" (Beamish, 2005, p. 138). College counseling center directors have subsequently described their most essential services as moving away from personal and career counseling and more towards crisis intervention and consultative services with other campus constituents (Kitzrow, 2009; Gallagher, 2012). Short-term and crisis-oriented models of care may also be necessary since many college counseling centers have not received additional resources during times of increased service utilization (Hodges, 2001; Eells, Seals, Rockett, \& Hayes, 2005). At the time of their review, Much, Wagener, and Hellenbrand (2010) indicated that many college counseling centers across the country reported having less than sufficient resources.

Adaptations to these challenges have included imposing session limits or adopting briefer treatment models, introducing fee-for-service models or billing student insurance, and providing off-campus referrals in the absence of adequate resources to meet student needs (Benton, Robertson, Tseng, Newton, \& Benton, 2003; Beamish, 2005). Offices of disability services have also been developed (or called upon when already established) to support students with severe 
psychopathology (Beamish, 2005). The preventative and developmental roots of college counseling have not been completely eradicated, however. Other recent goals for college counseling centers have included providing easily accessible services and a continuity of care, delivering comprehensive educational outreach campaigns, identifying and assisting students who may be at risk for mental health concerns, and promoting a campus culture that destigmatizes help-seeking behavior (Douce \& Keeling, 2014; Mowbray et al., 2006).

\section{College counseling in present-day}

At the time of this review, the 2017-2018 Association for University and College Counseling Center Directors Annual Survey (LeViness, Bershad, Gorman, Braun, \& Murray, 2018) provides the most recent and most comprehensive contextual information about college counseling centers. LeViness and colleagues (2018) drew upon data from 571 institutions of higher learning, with student bodies ranging from under 1,500 to over 45,000 students. Across these school sizes, the mean number of full-time equivalency mental health staff was $8.66(S D=$ 8.13); with ranges in staffing from one half-time practitioner to as many as 40 full-time equivalency staff members.

While the smallest 4-year public colleges/universities $(<1,500$ students $)$ generally had only one to two full-time professional staff members $(M=1.86)$, the largest 4-year public institutions (> 45,000 students) generally had about 32 to 33 full-time professional staff members $(M=32.79)$. Mental health providers on college campuses also included supervised trainees. Within their sample of institutions, LeViness and colleagues (2018) found that supervised trainees filled, on average, 2.25 full-time equivalency positions $(S D=2.68$, range $=0-12$ fulltime equivalency positions). According to LeViness and colleagues (2018), full time staff spent about $64 \%$ of their time providing direct clinical services and $21 \%$ of their time engaging in 
indirect services (including training, supervision, consultation, and outreach). An additional 13\% of staff members' time was devoted to administrative tasks (meetings, committee work, and professional development). Finally, on average, about $2 \%$ of staff members' time was devoted to other tasks like teaching or research.

In an effort to ensure that adequate clinical care is being provided to students in light of the other administrative tasks and preventative initiatives that practitioners engage in, accrediting bodies have made recommendations for the ideal practitioner to student ratio. The International Accreditation of Counseling Services, for instance, has put forth the aspirational ratio of one fulltime professional staff member (excluding supervised trainees) for every 1,000 to 1,500 students (IACS, 2019). Some research has been conducted to examine student to staff ratios. For example, Jodoin and Ayers (2017) recently found that mental health practitioners on small college campuses reported higher levels of job satisfaction relative to practitioners on medium and large campuses. They reasoned that this may have been due to differences in student to staff ratios, and that the lower ratios commonly seen on smaller campuses may have been associated with fewer resource constraints, and ultimately, lower stress levels (Jodoin \& Ayers, 2017). Adding an additional point to consider in this line of inquiry, Elreda (2014) found that student to staff ratios were not associated with treatment effectiveness (defined as change in CCAPS distress index from intake to termination or final CCAPS administration) at 37 university counseling centers. With the wide range of student to staff ratios present in his sample (range $=488: 1$ to $3,364: 1$ ), it would have been informative to have data on practitioners' stress levels as they attempted to provide effective services in these varying campus contexts.

Available literature has also pointed to other challenges faced by practitioners in the current landscape of collegiate mental health. First, some authors have drawn attention to the 
lack of funding that gets apportioned to research on mental health issues among college students (Schwartz \& Kay, 2009). Second, other authors have suggested that when resources are stretched thin, university counseling centers may be inclined to devote their energy to clinical service provision at the expense of other services like consultation, outreach, and preventative personal growth initiatives (Kitzrow, 2009; Much et al., 2010). Funneling energy into the provision of extensive clinical services may be due, in part, to pressure that is exerted on counseling centers to demonstrate their worth to university administrators and advocate for continued financial support in the face of economic downturns (Keeling \& Heitzmann, 2003). This pressure could be linked to a perception among faculty and staff that universities need to assume more responsibility for students who enter higher education with preexisting mental health challenges (McAllister et al., 2014; c.f. Schwartz, 2013). One final challenge that exists because of resource constraints includes referring students to off campus mental health services when campus counseling centers lack the resources or expertise to meet students' needs (Stone, Vespia, \& Kanz, 2000). Here too, a pressure might exist to provide on-campus care for those students who would struggle to obtain mental health services in the community (Benton et al., 2003). Schwartz and Kay (2009) indicated that college counseling centers may feel compelled to provide longterm care for students who have limited health insurance and present with more severe concerns.

Trends in service use among college students. Examining changes in clinical data at one university counseling center, Stukenberg, Dacey, and Nagy (2006) compared data from three cohorts of students: 1964-1967, 1998-2001, and 2001-2004. Whereas $4.9 \%$ of the student body presented for mental health services in the '64-'67 cohort, $10.4 \%$ presented in the '98-'01 and $9.4 \%$ in the '01-'04 cohorts. The authors also noted a significant increase in the number of graduate students presenting for services, with 4.9\% utilizing services in the '64-'67 cohort, 
$16.7 \%$ in the '98-'01 cohort, and $14.2 \%$ in the '01-'04 cohort. Though presenting concerns could not be compiled, Stukenberg and colleagues found that $19.8 \%$ of students used more than eight sessions in '64-'67 relative to $40.1 \%$ in '98-'01 and $36.6 \%$ in '01-'04. Stukenberg and colleagues (2006) suggested that one factor that could have contributed to this trend was the clinic's movement away from a brief treatment model over the duration of data collection. This was an interesting shift as many campus clinics are currently moving towards brief treatment approaches (Benton et al., 2003; Beamish, 2005). Over time, however, clinicians appeared to be more uncertain about whether they had helped a student throughout the course of counseling in recent years. Uncertainty about helpfulness was endorsed by $14.9 \%$ of clinicians working with students in the '64-'67 cohort compared to $31.0 \%$ and $39.5 \%$ of clinicians working with students in '98'01 and '01-'04 cohorts, respectively.

Using a somewhat similar approach, Benton and colleagues (2003) examined archived clinical data from 13,257 students who presented for mental health services over a thirteen year period (1988/1989 to 2000/2001). The number of students presenting for services remained consistent over this time period $(M=1,020$; range $=921$ to 1,078$)$, and there was a slight increase in the percentage of male students who sought mental health services over the final four years of data collection (32.5\% to $38.9 \%$ ). The authors also indicated that students of color who utilized mental health services were "slightly overrepresented" compared to the proportion of students of color among the entire student body (p. 67). Throughout the thirteen-year data set, the percentage of service users who were students of color ranged from $11.8 \%$ to $14.7 \%$.

Benton and colleagues' (2003) primary objective was to examine trends over time in the primary concerns that students addressed in therapy. Their measure was an internally developed Case Descriptor List, which clinicians completed at the time that a student terminated their 
course of counseling to indicate the presence (yes/no) of issues addressed therein. This was completed in a select-all-that-apply format, so one student could have been documented as seeking services for "relationship issues," "depression," and "physical problems," for one example (p. 68). Temporally, three time periods were averaged and compared: 1988-1992, 19921996, and 1996-2001. Across these three cut-points, Benton and colleagues found statistically significant and generally linear increases in the number of students seeking services for academic skills, developmental issues, depression, grief, medication management, and broad situational concerns. Several other concerns were flagged as significantly more prevalent in the second and third time periods relative to the first, including relationship issues, stress/anxiety, family issues, physical problems, personality disorders, suicidal ideation, and sexual assault. On average, the most prevalent concerns in the third period were stress/anxiety $(62.9 \%)$, situational concerns $(58.2 \%)$, and relationship issues $(56.2 \%)$.

Anecdotally, Benton and colleagues (2003) noted that amid the increased prevalence of more severe mental health concerns (e.g., suicidality), their center had not received additional staffing. The authors indicated that adapting to this trend led their counseling center staff to spend less time in one-on-one counseling with students and more time consulting with hospitals or doctors, external referral sources, families, and other academic units on campus. They also added that documentation began demanding more attention than in previous years. Though Benton and colleagues' (2003) report provided insight into the landscape of collegiate mental health at the turn of the $21^{\text {st }}$ century, it has not been without criticism. Sharkin (2004) urged caution in the interpretation of Benton and colleagues' (2003) results, pointing out that the study assessed categorical shifts without adequately addressing the severity of concerns within in those categories. For instance, Sharkin (2004) argued that, 
Benton et al. did not differentiate degrees of suicidal ideation (e.g., high vs. low) or even between suicidal ideation and suicidal behavior. Survey data appear to show that many students experience suicidal ideation, but relatively few actually attempt or commit suicide... (p. 314)

Using a more widely adopted clinical rating form, Pérez-Rojas and colleagues (2017)

made a recent addition to the literature on common presenting concerns among college students as assessed by clinicians. More specifically, data from the Clinician Index of Client Concerns was compiled to examine students' presenting concerns (all presenting concerns per student and top presenting concern per student) as documented by practitioners. Pérez-Rojas and colleagues analyzed a data set compiled from 84 college counseling centers, 1,383 practitioners, and 53,194 students who presented for mental health services. The authors also examined presenting concerns and suicidality across student demographic groups (e.g., race/ethnicity, sexual orientation, student-athlete status, etc.).

Across all student demographic groups, the top five most common presenting concerns noted by clinicians were anxiety, depression, stress, family-related issues, and academic performance. Nonparametric analyses revealed that all student demographic groups showed a significant level of concordance (i.e., similarity) with these top five presenting concerns. For instance, the top five most common concerns for student-athletes were anxiety, stress, depression, family-related issues, and academic performance. Though statistically similar in rank-order to overall presenting concerns, a slight deviation was found for transgender clients, for whom gender identity was the most common presenting concern, followed by depression, anxiety, stress, and identity development. Across all student demographic groups, clinicians documented suicidality as the top concern for $8.4 \%$ of students who presented for services. The 
prevalence of suicidality as a top concern appeared to be slightly higher among some student demographic groups, such as transgender students (top concern for 17.9\%), students who were questioning their sexual identity (17.3\%), bisexual students (14.6\%), and American Indian or Alaskan Native students (12.0\%). From their data and analyses, Pérez-Rojas and colleagues (2017) suggested that college counseling centers could tailor professional development staff trainings to include best practices for treating anxiety, depression, stress, family-related issues, and academic performance among students. Given that the prevalence of these concerns tends to be relatively similar across student demographic groups, the authors also encouraged clinicians to consider group counseling or educational outreach programming to address these concerns.

\section{Rates of mental health concerns among student-athletes}

Relative to the non-athlete student body, collegiate student-athletes can face demands that may make them "at risk" for experiencing distress (Pinkerton, Hinz, \& Barrow, 1989). In addition to academic pressures and developmental tasks commonly shared with their non-athlete peers, student-athletes face demanding training and competition schedules, pressures related to dealing with the media and being a recognizable figure on campus, and potential exposure to overtraining or injury (Hill, Burch-Ragan, \& Yates, 2001; Etzel, Watson, Visek, \& Maniar, 2006; Martin \& Andersen, 2014). Additionally, some students can develop identities that are hinged exclusively on their role as athletes (Petitpas \& Tinsley, 2014), leading to a condition that Marcia (1966) referred to as identity foreclosure. As put by Howard-Hamilton and Sina (2001), "this is a problem because students should be making tangible steps toward a future that focuses on all of their strengths, not just their athleticism" (p. 37). Complicating matters, a "common stereotype is that athletes are somehow immune to the mental health concerns that may affect the general population" (Esfandiari, Broshek, \& Freeman, 2011, p. 611), leaving many athletes to 
wonder if reaching out for help could paint them as "weak" and jeopardize their playing time or status on the team (Bauman, 2016).

Although degrees of severity will vary, many student-athletes experience mental or emotional difficulty over the course of their collegiate career. For example, $62.5 \%(n=407)$ of student-athletes at one large Division I institution indicated that their athletic performance suffered as a result of mental or emotional difficulties within the last four weeks (Kern et al., 2017). Within a sample of athletes at a Division II institution, $46.6 \%$ endorsed at least mild symptoms of depression over the course of a season (McGuire, Ingram, Sachs, \& Tierney, 2017). Further still, a recent survey found that $98.4 \%(n=125)$ of head athletic trainers at Division I universities had observed depression among student-athletes who were under their care (Sudano \& Miles, 2017). Though not exhaustive, the following sections will provide an overview of the literature on common mental health challenges experienced by student-athletes.

Depression. Rates of depression (or at least reported cases) may be on the rise among student-athletes. In the late 1960's, Carmen, Zerman, and Blaine (1968) observed that only about $1.75 \%$ of Harvard student-athletes sought psychological support services on campus for depression over the span of five years. Of course, this number does not account for studentathletes who experienced depression but did not seek services for it on campus. More recently, McGuire and colleagues (2017) found that $10.75 \%(n=10)$ of fall sport athletes at a Division II institution were flagged for moderate or severe symptoms of depression across six bi-weekly administrations of the PHQ-9. However, this finding excluded six student-athletes who were currently seeking treatment for depression (counseling and/or medication). Also using the PHQ9, Kroshus (2017) found that about 7\% of 621 student-athletes at four colleges (level of NCAA competition was not specified) reported at least moderate symptoms of depression. 
Several studies have examined depressive symptomology among student-athletes using the Center for Epidemiologic Studies Depression Scale (CES-D; Radloff, 1977). Administering the CES-D to 257 Division I student-athletes during pre-season meetings, Yang, Peek-Asa, Corlette, Cheng, Foster, and Albright (2007) found that $21 \%$ of their sample endorsed at least mild symptomology. Ten athletes (3.9\%) reported a history of diagnosed depression, and eight athletes $(3.1 \%)$ reported severe symptoms during the past week. Freshman, females, and those experiencing pain appeared to be at an increased risk for symptoms. Within another sample of Division I athletes ( $n=465)$, Wolanin, Hong, Marks, Panchoo, and Gross (2016) found that $23.7 \%$ endorsed at least mild symptomology and $6.3 \%$ reported moderate to severe symptoms. More than twice as many females $(n=75,28.5 \%)$ reported mild symptoms as compared to males $(n=35,17.6 \%)$, but there was no difference between genders for moderate to severe symptoms. Cox, Ross-Stewart, and Foltz (2017) also assessed depressive symptoms among 950 Division I student-athletes using the CES-D. Within their sample, $33.2 \%$ reported at least mild symptomology (CES-D score $\geq 16$ ) and $8.7 \%$ endorsed severe symptoms (CES-D score $\geq 30$ ). Female student-athletes $(M=14.46)$ demonstrated higher symptomology than males $(M=12.10$; $t(947)=-3.30, p=0.00)$, freshman and sophomore student-athletes $(M=14.36)$ demonstrated more symptoms that juniors and seniors $\left(M=12.74 ; F(1,932)=6.67, p=0.01, \eta^{2}=0.01\right)$, inseason athletes $(M=14.10)$ demonstrated more symptoms than athletes in the off-season $(M=$ 13.14; $\left.F(1,932)=3.98, p=.05, \eta^{2}=0.004\right)$, and athletes who had sustained an injury in the last six months $(M=14.49)$ demonstrated more symptoms than those who had not $(M=13.07 ; t$ $(784)=2.01, p=0.05)$.

Research directly comparing rates of depression among student-athletes to the broader population of college students has produced mixed results. At the group-level, Storch, Storch, 
Killiany, and Roberti (2005) found no difference between student-athletes and non-athletes.

Storch and colleagues did, however, find a significant gender by athlete status interaction effect in which female student-athletes endorsed more depressive symptomology than male athletes, male non-athletes, and female non-athletes. Gorczynski, Coyle, and Gibson (2017) recently found similar results. These authors conducted a meta-analysis of five articles that drew from samples in the US, Iran, Germany, and Switzerland. Their analysis revealed that student-athletes (and elite U-21 athletes) were about as likely to report depressive symptoms compared to the general population, but male athletes were $52 \%$ less likely to endorse depressive symptomology than female athletes. On the contrary, Armstrong and Oomen-Early (2009) observed that studentathletes demonstrated significantly lower depressive symptomology than their non-athlete peers. Athletes in their sample reported higher self-esteem and a stronger sense of social connectedness, suggesting that these may be protective factors for this population relative to their non-athlete peers (Armstrong \& Oomen-Early, 2009). Likewise, Proctor and Boan-Lenzo (2010) found lower levels of depression among Division I baseball players (15.6\%) relative to their non-athlete peers $(29.4 \%)$. Proctor and Boan-Lenzo found that task-focused coping was negatively correlated with depression, and that emotion-focused coping was positively correlated with depression; but athletes and non-athletes were not found to differ in their tendency to use these coping styles.

The growing body of literature on rates of depression among student-athletes needs to be examined with a few caveats in mind. First, Roberts, Faull, and Todd (2017) recently argued that despite increased media attention to high-profile athletes' experiences with mental health concerns like depression, "there remains a consensus that the true prevalence is under-reported" (p. 2). A recent study by Gross, Wolanin, Pess, and Hong (2017) offered some preliminary 
support for these claims. Gross and colleagues administered the CES-D and Marlowe-Crowne Social Desirability Scale Short Form-C to 244 Division I and Division III student-athletes. Although their analyses cannot prove that depressive symptoms were being under-reported, Gross and colleagues found that those student-athletes who engaged in socially desirable response styles endorsed significantly fewer symptoms than student-athletes who did not engage in socially desirable responding. Female student-athletes were also significantly less likely to engage in socially desirable responding when compared to male student-athletes. Again, although these findings were merely correlational, they may be worth keeping in mind while interpreting research findings (such as those reviewed above) that suggest substantially higher rates of depression among female student-athletes. However, other authors have pointed to the unique stressors that female student-athletes face - such as lower perceived social support, body image expectations, weight-related pressures from coaches, and revealing uniforms - and how these could contribute to a higher incidence of depression (McGuire et al., 2017).

As pointed out by several authors, a second caveat to consider while synthesizing research on depression among student-athletes is that several symptoms of depression can mimic symptoms of burnout in both the general population (Bianchi, Schonfeld, \& Laurent, 2015) and athletic populations (Bär \& Markser, 2013; Schuch, 2015). None of the studies reviewed above assessed for both depression and overtraining syndrome or burnout, so it is unclear about how many cases of burnout (if any) yielded false positives for depression. Recent research that assessed for both depression and athletic burnout among elite junior athletes in Germany suggested that the two conditions are linked but do not fully explain each other (Frank, Nixdorf, \& Beckmann, 2017). 
One final caveat to consider in this line of research is that several studies (Armstrong \& Oomen-Early, 2009; Cox et al., 2017; Proctor \& Boan-Lenzo, 2010; Wolanin et al., 2016; Yang et al., 2007), and even some of the most recent publications (Frank et al., 2017; Gross et al., 2017; Li, Moreland, Peek-Asa, \& Yang, 2017) used the CES-D to assess for depressive symptomology. This instrument was originally developed by Radloff (1977), and 27 years later, was revised (CESD-R) by Eaton, Smith, Ybarra, Muntaner, and Tien (2004). At the time of their revisions, Eaton and colleagues (2004) indicated that the CES-D was not aligned with DSM-III criteria for major depressive disorder and was, "even more out of date with the current DSM-IV definition" (p. 365). This problem is concerning as the field now operates with the DSM-5 and research is still being conducted with the original form of the instrument. Further, the original CES-D does not assess for suicidal ideation. Ultimately, the CESD-R would seem to be a more comprehensive screening tool as compared to the original CES-D, but of the studies reviewed above, none provided a rationale or their use of the CES-D over the CESD-R.

Anxiety. Comorbid depression and anxiety can be quite common (Cameron, 2007). Within a sample of Division I athletes who reported symptoms of either depression or anxiety at the beginning of their competitive season, $48.5 \%(n=158)$ endorsed symptoms of both (Li et al., 2017). However, relative to the body of research examining rates of depression among studentathletes, and the body of research on performance anxiety among student-athletes, there have been few studies to assess rates of clinically significant anxiety (Esfandiari, Broshek, \& Freeman, 2011). This is surprising as anxiety tends to be one of the most common presenting concerns among student-athletes who seek mental health services (Pérez-Rojas et al., 2017). Among those studies that are available, Sudano and Miles (2017) recently found that $97.6 \%$ of surveyed athletic trainers indicated that they had observed symptoms of anxiety among the 
Division I student-athletes under their care. Storch and colleagues (2005) surveyed 105 Division I student-athletes and found that $37.3 \%(n=19)$ of female student-athletes and $22.2 \%(n=12)$ of male student-athletes endorsed clinically significant symptoms of social anxiety. In their sample, female student-athletes were found to have significantly higher social anxiety scores than male student-athletes, male non-athletes, and female non-athletes. Within a larger Division I sample, Li and colleagues (2017) did not find a significant difference between the percentage of male (27.9\%) and female (26.5\%) student-athletes who reported symptoms of anxiety. Using a prospective design, and after controlling for 12-month history of injury, BMI, race, age, and university attended, Li and colleagues observed that student-athletes who endorsed symptoms of anxiety at the beginning of their season were significantly more likely to sustain an athletic injury than those who did not report anxiety (Li et al., 2017). Ultimately, clinically significant anxiety appears to be an important but understudied aspect of student-athletes' mental health.

There is some evidence to suggest that anxiety disorders may be a risk factor for the development of substance use disorders (Back \& Brady, 2008). Providing one example, Buckman, Yusko, Farris, White, and Pandina (2011) surveyed male student-athletes who endorsed past year marijuana use and found that those who reported using marijuana during their competitive season reported higher levels of anxiety and more negative mood than those who only used marijuana during the off-season. However, this may not be the case with alcohol use. In their review, for example, Martens, Kilmer, and Beck (2009) concluded that student-athletes rarely endorse emotional coping motives for alcohol consumption.

Substance use. It has been suggested that alcohol use can be seen as "a normative experience" during the college years (Esfandiari et al., 2011), and that there may be a prevalent "cultural myth that campus life is about alcohol abuse and drug use" (Hainline, Bell, \& Wilfert, 
2014, p. 40). A survey administered by the NCAA sampled 21,000 student-athletes and found that about $80 \%$ endorsed past year alcohol use (Rexroat \& Hollomon, 2014). Relative to data gathered in 2005, this more recent iteration of the survey revealed that rates of excessive drinking had fallen for both male (63\% to $44 \%)$ and female (41\% to $33 \%)$ student-athletes (Rexroat \& Hollomon, 2014). Around the same time of the NCAA's baseline survey, Storch and colleagues (2005) found that rates of clinically significant alcohol use were quite similar across male $(5.6 \%)$ and female (5.9\%) Division I student-athletes. Comparing athletes and non-athletes, Nelson and Wechsler (2001) demonstrated that student-athletes endorsed more negative consequences related to alcohol use (e.g., got in trouble with law enforcement, required medical treatment for excessive alcohol) than their peers who did not participate in athletics. Yusko, Buckman, White, and Pandina (2008) indicated that male student-athletes endorsed more episodes of heavy drinking in the past year (39.5 days) and a higher number of drinks during their heaviest drinking episodes (13.2 drinks) relative to male students (26.8 days and 11.3 drinks, respectively). Yusko and colleagues did not find statistically significant differences for these variables when comparing female students and student-athletes in their sample.

Broadly, alcohol and other drug use appears to be more prevalent among Division III student-athletes than Division I and II student-athletes (Rexroat \& Hollomon, 2014). This may be due to the more comprehensive monitoring and enforcement that is implemented in Division I and II athletic departments (Esfandiari et al., 2011). Excluding alcohol, student-athletes appear to engage in less recreational drug use than their non-athlete peers (Rexroat \& Hollomon, 2014). For example, Buckman and colleagues (2011) found that male (37\%) and female (25\%) studentathletes were less likely to endorse past year marijuana use relative to their non-athlete peers ( $50 \%$ and $48 \%$, respectively). These rates of marijuana usage among student-athletes appear to 
be greater than among Selby, Weinstein, and Bird's (1990) sample of 267 student-athletes some 20 years earlier. Selby and colleagues reported that $22 \%$ of males and $14 \%$ of females reported using marijuana once per month or more during their competitive season, and were more likely to report weekly use during the off-season. Selby and colleagues also found that $13 \%$ of males and $8 \%$ of females endorsed in-season cocaine use. These rates rose to $17 \%$ and $10 \%$, respectively, during the off-season. Examining student-athletes' use of other substances, Rextroat and Hollomon (2014) reported that about $6 \%$ of student-athletes used nonprescription pain medication, $9 \%$ used ADHD medication without a prescription, and about $25 \%$ of male student-athletes (relative to only $2 \%$ of female student-athletes) used spit tobacco during the last year. Within their sample of 392 student-athletes and 504 students, Yusko and colleagues (2008) found that $17.8 \%$ of male student-athletes and $3.2 \%$ of female student-athletes endorsed lifetime use (i.e., had used these substances at least once in their life) of banned performance enhancing substance. Male and female student-athletes demonstrated statistically significant higher rates of performance enhancing substance use relative their non-athlete peers, as $7.8 \%$ of male students and $0.3 \%$ of female students endorsed lifetime use of performance enhancing substances. Yusko and colleagues found similar rates of lifetime weight-loss product use (e.g., ephedra) when comparing male (12.1\%) and female (12.7\%) student-athletes. Significantly fewer female student-athletes endorsed lifetime weight loss product use when compared to female non-athletes ( $25.9 \%$ of whom reported lifetime use). While the use of weight loss products does not necessarily signal disordered eating, this is not an uncommon concern for mental health practitioners working with student-athletes.

Disordered eating. While working as a counseling psychologist in the Brigham Young University athletics department, Chamberlain (2007) anecdotally reported that disordered eating 
was among the most common clinical concerns presented by athletes who sought his services. Likewise, when Sudano and Miles (2017) surveyed head ATCs at Division I institutions, 92.1\% $(n=117)$ indicated that they had encountered disordered eating among athletes under their care. In their recent review of the eating disorder literature, Joy, Kussman, and Nattiv (2016) concluded that male and female athletes are more likely to develop an eating disorder than nonathletes. Among collegiate student-athletes, Selby and colleagues (1990) found that a history of bulimia was endorsed by $2 \%$ of women and $1 \%$ of males. Four percent of females in their sample acknowledged a history of anorexia relative to $1 \%$ of males. These authors also found that $33 \%$ of female student-athletes endorsed weight and eating behaviors as a source of stress relative to 5-6\% of male student-athletes. Using a much larger sample, Johnson, Powers, and Dick (1999) surveyed 1,445 Division I student-athletes. Applying DSM-IV criteria, it was found that no athletes met the full criteria for anorexia nervosa, but $2.85 \%$ of female student-athletes identified clinically significant symptomology (no male student-athletes endorsed clinically significant symptoms of anorexia nervosa). Among female student-athletes that Johnson and colleagues surveyed, $1.1 \%$ met the full diagnostic criteria for bulimia nervosa and $9.2 \%$ endorsed clinically significant bulimic symptoms. No male student-athletes met the criteria for bulimia nervosa, and only $0.01 \%$ endorsed clinically significant bulimic symptoms. More recently, but also using DSM-IV criteria, it has been found that $2 \%$ of female student-athletes met the diagnostic criteria for an eating disorder relative to $1.1 \%$ of male student-athletes (Greenleaf, Petrie, Carter, \& Reel, 2009; Chatterton \& Petrie, 2013). Among these samples, $25.5 \%$ of female student-athletes endorsed clinically significant disordered eating symptoms as compared to $16 \%$ of male studentathletes (Greenleaf et al., 2009; Chatterton \& Petrie, 2013). 
Summary of Mental Health Research. The aim of this section was to provide a quick overview of common mental health concerns among student-athletes. Relative to their nonathlete peers, student-athletes tend to engage in higher levels of problematic alcohol use, may be more at risk for developing disordered eating behaviors, and appear to experience relatively similar rates of depression and anxiety. With these rates of clinically significant mental health symptoms, and an observation that student-athletes may have more negative attitudes towards counseling than their non-athlete peers (Watson, 2005), recent resources and initiatives have aimed to increase mental health literacy and destigmatize help-seeking behavior among this population (e.g., Chow, Gabana, \& Swanbrow Becker, 2019).

\section{Recent developments in mental health promotion for student-athletes}

Whether following from or spurring research on the mental health of collegiate studentathletes, the NCAA has emphasized mental health promotion for student-athletes in recent decades. About five years ago, the NCAA unveiled Mind, Body and Sport, its first substantial publication focused solely on the mental health concerns of student-athletes (Brown, Hainline, Kroshus, \& Wilfert, 2014). In the introduction of Mind, Body and Sport, Brian Hainline, the NCAA's Chief Medical Officer, reported that after listening to hundreds of student-athletes' perspectives on the health and safety challenges of collegiate sport, "almost to a person, the No. 1 response is student-athlete mental health and wellness" (n.p.). He continued to mention that although the NCAA has held student-athlete health and safety at the core of its institutional mission for the last century, "only recently have we begun to fully understand the mental health component of being a student-athlete" (n.p.).

Additional resources developed by the NCAA in support of student-athlete mental health have included a resource manual geared towards coaches and a broad range of student-athlete 
support staff (Managing Student-Athletes'Mental Health Issues; Thompson \& Sherman, n.d.) as well as a revamped website that - at present - includes various fact sheets, videos, and an interactive educational module all geared towards recognizing and supporting the mental health of student-athletes (see ncaa.org/sport-science-institute/mental-health). Stemming from the collaborative efforts of an interdisciplinary task force (Neal et al., 2013), the NCAA (2016) has also promoted a set of best-practice recommendations for supporting student-athlete mental health. In broad terms, these recommendations encourage (but do not require) the availability of clinically licensed mental health practitioners for student-athletes, institutional protocols to recognize and refer student-athletes who may be experiencing mental health difficulties, the implementation of pre-participation mental health screening, and efforts to create an environment that is supportive of student-athletes' resilience and well-being (NCAA, 2016). In its most recent motion to support student-athlete mental health, legislation will now require institutions within the Division I autonomy conferences (i.e., "Power 5") to ensure that their student-athletes have access to mental healthcare, educational resources about mental health, and information about the mental health services available at the institution as well as the ways in which studentathletes can access them (Brutlag Hosick, 2019). To date, some researchers have assessed student-athletes' access to mental health and applied sport psychology services by examining the availability of these services across institutions and division levels.

\section{Mental health service availability for student-athletes}

In an early study of service availability, Bergandi and Wittig (1984) polled 53 college counseling center directors and found that $49 \%(n=26)$ indicated that their campus offered some form of mental health services specifically for student-athletes. Several years later, Kornspan and Duve (2006) distributed 1,032 surveys to athletic directors at Division I, II, and III institutions to 
assess the current and anticipated future employment of sport psychology consultants. In their study, "sport psychology consultant" could have included a practitioner who provided performance enhancement and/or mental health services. Kornspan and Duve received 286 responses for $27.7 \%$ response rate. A total of 67 athletic directors $(23.4 \%)$ indicated that they currently utilized sport psychology services. Services were available at $48 \%$ of Division I institutions (where 46 of 95 athletic directors mentioned service use), $11 \%$ of Division II institutions (where 8 of 72 athletic directors mentioned service use), and $11 \%$ of Division III institutions (where 13 of 118 athletic directors mentioned service use).

Service providers ranged from graduate students and volunteers, to full-time practitioners employed by the university or athletic department. Of these providers, 13 were certified consultants (at the time, through AAASP) and 47 held some form of mental health licensure (16 counselors, 28 psychologists, and 3 social workers). Among the 45 athletic directors who reported the number of sport psychology consultants that they employed, $64 \%$ employed one consultant, $22 \%$ employed two consultants, $11 \%$ employed three consultants, and only $2 \%$ employed four or more consultants. Although budgetary concerns were the most frequently cited barrier to hiring a sport psychology practitioner (or additional ones), many athletic directors perceived a need for one. Whereas $74 \%$ of Division I athletic directors saw a legitimate need for a sport psychology consultant, only $38 \%$ of Division II athletic directors and $35 \%$ of Division III athletic directors felt the same way. Though not mentioned by Kornspan and Duve (2006), it would have been interesting to note if the reasons given in support of hiring sport psychology personnel differed across participants' division level.

As was the case in Kornspan and Duve's (2006) sample of athletic directors, Connole, Shannon, Watson II, Wrisberg, Etzel, and Schimmel (2014) concluded that concerns about 
funding continue to be a barrier for athletic administrators over and above poor attitudes about sport psychology services. Connole and colleagues surveyed 478 athletic directors and other athletic administrators about the availability of sport psychology services (defined as performance-based and/or clinical in nature) at their NCAA Division I, II, and III institutions. Of their respondents, 39.7\% indicated that sport psychology services were available at their institutions, $52.3 \%$ indicated that sport psychology services were not available, and an additional $7.9 \%$ were unsure about the availability of services.

Of those athletic administrators who did not have a sport psychologist or sport psychology consultant on staff, $23(8.1 \%)$ indicated that they were actively planning to create a position for one within the next five years. In terms of most preferred qualifications, athletic administrators sought professionals who could provide both mental health and performance enhancement services (endorsed by $43.8 \%$ of administrators) as opposed to just mental health (endorsed by $13.6 \%$ ) or just performance enhancement (endorsed by $11.5 \%$ ). With any of these profiles, $31.1 \%$ of administrators indicated that they would choose not to hire for the position. Like Kornspan and Duve (2006), Connole and colleagues (2014) also found that sport psychology services were more readily available at Division I institutions (63.5\%) relative to Division II (23.5\%) or Division III (22.8\%) institutions. Regardless of service availability at their institutions, just over one third of athletic administrators (34.6\%) said they would need more than one sport psychology professional to adequately meet the needs of their student-athletes. It may have been insightful to have additional information about what those perceived needs were.

Although athletic directors are key stakeholders in terms of hiring sport psychology professionals, and thus warrant study, there has been limited research to examine studentathletes' perceptions of service availability. In one study to fill this gap, Cox and colleagues 
(2017) found that most (88.4\%) Division I student-athletes agreed that mental health services were "easily available" at their institution. Moore (2016) took a more comprehensive approach by examining the perceived availability of psychosocial services among student-athletes relative to athletic directors. Within a sample of 132 athletic directors and 349 student athletes, Moore found that psychosocial services were perceived to be less available than athletic or academic services. Further, student-athletes perceived psychosocial services to be less available $(M=4.23)$ than did athletic directors $(M=5.40$; measured on an 8-point Likert scale).

In contrast to research cited above, which suggested that mental health services are more widely available at Division I institutions, Moore (2016) found that athletic directors' perceptions of availability were not in line with this trend. Using ambiguous "composite scores," there was a significant difference in perceived availability of psychosocial services across athletic directors at different divisional levels $\left(F_{(2,129)}=6.08, p=0.003, \mathrm{\eta}_{\mathrm{F}}^{2}=0.09\right)$. Division III athletic directors perceived psychosocial services to be more readily available $(M=27.93)$ than did Division I athletic directors $(M=22.79 ; p=0.002)$. Perceptions among Division II athletic directors were not significantly different from either. There was also a significant difference in the perceived availability of psychosocial services across student-athletes at different divisional levels $\left(F_{(2,346)}=11.23, p<0.001, \mathrm{\eta}^{2}=0.06\right)$. In contrast to the finding among athletic directors, Division I $(M=12.75)$ and II $(M=11.19)$ student-athletes perceived psychosocial services to be more available than did Division III student-athletes $(M=8.49, p<0.001$ and $p=0.006$ respectively).

Using a different approach to assess the availability of sport psychology services, Hayden, Kornspan, Bruback, Parent, and Rodgers (2013) analyzed the content of athletic department and counseling center websites for 120 NCAA Division I FBS institutions. Just over 
one quarter $(28.3 \%)$ of athletic department websites mentioned the presence of a sport psychology provider, as did about one third of counseling center websites (clinical or performance-based services in either setting). Though the presence of these services were listed, $58 \%$ of athletic department websites and $85.9 \%$ of counseling center websites did not provide any description of their performance enhancement and/or mental health services for studentathletes. Most athletic departments $(67.6 \%)$ and counseling centers $(56.4 \%)$ identified as only having one sport psychology provider. Six athletic departments (17.6\%) and 12 counseling centers $(30.7 \%)$ had two sport psychology providers. There were relatively similar proportions of athletic departments and counseling centers that had three (11.7\% and $10.3 \%$, respectively) or four (2.9\% and 2.6\%, respectively) sport psychology providers. Hayden and colleagues (2013) did not clarify if their content analysis of websites was mutually exclusive (i.e., if one practitioner was mentioned on both the athletic department and counseling center website, was this coded any differently than if there were two providers but each was only mentioned on one website), but their study used a novel approach to gauge service availability.

By sampling a different population to gauge the availability of mental health services, Sudano and Miles (2017) recently found that $20.5 \%$ of head athletic trainers at Division I universities indicated that there was a mental health clinician present in their athletic training room. Of their 127 participants, almost half $(n=59,46 \%)$ agreed that access to a mental health provider on-site would enhance the care that they could provide for their student-athletes. Responding in a select all that apply format, $72.4 \%$ of participants said that mental health clinicians were available through the college counseling center and $18 \%$ said there was a mental health clinician embedded within the athletics department. Among the 25 head athletic trainers who provided information about the number of mental health clinicians available for student- 
athletes, most indicated that one clinician $(n=15,60 \%)$ was available, about one quarter of respondents $(n=6)$ said two clinicians were available, and about 14\% $(n=4)$ reported that three or more clinicians were available. Of note, head athletic trainers at two institutions reported that student-athletes did not have the option of seeking mental health services at all.

\section{Location of mental health services}

As suggested by the research reviewed above, there can be myriad locations for the provision of sport psychology services. In a handful of firsthand accounts and program evaluation projects that have been published in the literature, practitioners have offered some insights on service delivery in each of these locations. For instance, McDuff, Morse, and White (2005) noted that housing their Team Assistance Program (and in particular, the services of a sport psychiatrist) in the athletic training room was initially borne from the observation of high no-show rates and low rates of retention when student-athletes were referred to or otherwise utilized the campus counseling center. The authors indicated that "the training room is a good environment for brief interactions about lifestyle concerns and performance," and that "more indepth discussions often follow" from these initial points of contact (p. 953). In conjunction with opportunities for direct service provision, McDuff and colleagues also commented that housing services in the athletic training room facilitated the development of collaborative relationships and case consultation with sports medicine staff.

Describing the provision of sport psychology services from within a collegiate sports medicine department, Bennett (2007) also gave a nod to the convenience of in-house services for student-athletes. Adding to the convenience of location, Bennett said that student-athletes could schedule appointments for services or present on a walk-in basis. Though housed within sports medicine, Bennett clarified that he was technically a member of the institution's counseling 
center. This affiliation, he said, allowed for convenient referral to on-campus psychiatric services and provided back-up coverage when he was unavailable for student-athletes.

Practitioners have offered additional insight to the pros and cons of providing services to student-athletes through the university counseling center. As Bennett (2007) saw it, providing services to student-athletes in the counseling center presented challenges such as scheduling difficulties due to athletes' time demands, athletes' reluctance to visit the counseling center, worries about confidentiality, and "difficulties being seen on a regular basis because of the large demands on the resources of such centers" (p. 267). In light of these challenges, Flowers (2007) commented on some benefits that followed from his decision to relocate his office from within athletics to the university counseling center:

I relinquished my office in ICA [Intercollegiate Athletics] in favor of the confidentiality and additional psychological support available in my CAPS [Counseling and Psychological Services] office. This move also invited studentathletes and coaches into CAPS and began a process to demystify and destigmatize campus psychological services for student-athletes and ICA personnel. (p. 228)

Whether for institutional or environmental reasons, not all athletic departments will have the resources to accommodate student-athletes with conveniently located in-house services (Moreland, Coxe, \& Yang, 2018). University counseling centers may be equally stretched financially - if not more so (e.g., Much et al., 2010). An alternative method of service delivery that could be more economically efficient is through a doctoral training clinic (Wolanin, 2007), in which students who are completing practicum or internship placements offer their services for student-athletes. Using this arrangement, Wolanin (2007) commented that the separation "both 
physical and organizational" between the clinic and athletics necessitates scheduling time for meetings to discuss service provision (p. 279). Despite, or perhaps following from this distance, Wolanin (2007) found that creating a sport psychology space on the athletics website "has improved the accessibility of our services" (p. 279). This observation contributes to the practical significance of the approach that Hayden and colleagues (2013) used when examining the availability of sport psychology services through listings on university websites.

\section{Staffing mental health services for student-athletes}

As discussed above, staffing of sport psychology positions typically ranges from zero to four practitioners across institutions. Although staff to student ratios have been examined in the college counseling literature (e.g., Elreda, 2014) and director surveys (e.g., LeViness et al., 2018), sport psychology practitioner to student-athlete ratios have not received similar attention. This ratio would seem an important area of inquiry, given Hack's (2007) observation that outreach and relationship building can be too successful if practitioners receive more referrals than they can accommodate. In the published accounts that are available, practitioners could be responsible for delivering services to as many as 1,000 student-athletes on 36 teams, as did Carr (2007), recalling his time working in a major Division I athletic department. Elsewhere he oversaw services for 400 student-athletes on 18 teams (Carr, 2007). Around the same time period at other institutions, Chamberlain (2007) made sport psychology services available to 550 student-athletes on 20 teams, and Flowers (2007) serviced 800 student-athletes on 26 teams - in addition to 121 coaches, staff, and administrators.

These ratios could be buoyed by service provision through doctoral training clinics, such as the one described by Wolanin (2007), whose clinic serviced 400 student-athletes on 16 teams. Here, each graduate student enrolled in practicum or internship at the clinic committed to 20 
hours of service delivery per week (Wolanin, 2007). Other practitioners have also commented on the role that pre- and post-doctoral interns play in clinical service provision to student-athletes (Bennett, 2007; Flowers, 2007). In fact, as Flowers (2007) anticipated growth in the demand for comprehensive sport psychology services, he recommended that his institution create both a fulltime position and expanded opportunities and resources for more supervised trainees.

Offering other considerations for future staffing, some have made deliberate efforts to establish an interdisciplinary team-based approach to providing care for student-athletes (e.g., McDuff et al., 2005; Sudano, Collins, \& Miles, 2017). In addition to diversity in the expertise of staff members, their cultural diversity is important as well. Flowers (2007) pointed out that promoting cultural diversity and cultural competency among student-athletes, coaches, support staff, and administration is foundational for cultivating a safe, healthy environment for all: "Developing and promoting a more culturally diverse athletic department creates a more inviting environment and provides resources for academic, athletic, and personal assistance that culturally diverse student-athlete populations both require and deserve" (p. 241). As researchers cited above have analyzed the availability of sport psychology services for student-athletes in a numeric fashion (Kornspan \& Duve, 2006; Connole et al., 2014; Hayden et al., 2013), none commented on the demographics of practitioners in these positions. This may be a gap for future research to address.

\section{Barriers and facilitators to student-athlete service use}

Once the location for sport psychology services is defined and staffed, the question remains as to whether or not student-athletes in need will reach out to utilize the services. Rates of service utilization will be the focus of the next section, but it may be helpful to first draw some brief attention to factors that can facilitate or detract from the likelihood that student- 
athletes engage in service use. A big barrier for help-seeking behavior among student-athletes is the stigma that is attached to mental health (e.g., Gulliver, Griffiths, \& Christensen, 2012; López \& Levy, 2013; Kaier, DeMarni Cromer, Johnson, Strunk, \& Davis, 2015; Moore, 2017) and the generally lower attitudes of and expectations for counseling among this group (Watson, 2005).

Given the significance of this barrier, many have recently devoted attention to programming that aims to decrease stigma, provide mental health education, and encourage service use (e.g., Kern et al., 2017; Chow, Gabana, \& Swanbrow Becker, 2019).

Though stigma remains a formidable barrier, there is also reason to believe that attitudes may be improving, albeit slowly. When Leffingwell, Wiechman, Smith, \& Christensen (2001) asked student-athletes at their institution about the reason(s) for which they had not used sport psychology services, the authors indicated that, "No respondents chose reasons associated with a stigma about consulting with a sport psychologist" (from a list of nine response options, p. 535). Instead, the most commonly cited reasons included "Things were going well for me" (endorsed by $15 \%$ of student-athletes), "I did not have the time" (endorsed by $13 \%$ ), "I did not feel I needed to improve my skills" (endorsed by 7\%), and "Felt I could learn the skills without help" (endorsed by $7 \%)$.

Six years after the report from Leffingwell and colleagues (2001), some practitioners working within collegiate athletics anecdotally reported that stigma appeared to be decreasing among their student-athletes over the previous decade (Carr, 2007; Flowers, 2007). Adding some more recent data to this idea, Barnard (2016) sampled 127 college students (77 were studentathletes) and found that student-athletes demonstrated lower levels of devaluing/discriminating against someone with a mental illness relative to their non-athlete peers. Moreover, Barnard (2016) found no differences between athletes and non-athletes in terms of attitudes toward 
seeking psychological support. Beyond stigma, other barriers can dissuade student-athletes from utilizing mental health services, such as being a recognizable figure on campus, a general lack of services (Watson, 2003), time demands (Etzel et al., 2006), and difficulty connecting interpersonally with clinicians who do not understand the culture of athletics (Hack, 2007).

In efforts to minimize the aforementioned barriers, educational outreach and relationship building can be helpful. In their outreach, practitioners may need to deliberately educate studentathletes about the location of available services. Johnson (2017) indicated that doing so is "vital" (p. 63). Indeed, the proportions of student-athletes who did not know about available mental health services can vary across samples (e.g., 22\% in Leffingwell et al., 2001; 26\% in Cox et al., 2017; about 9\% in Way et al., in press). Practitioners can also promote effective relationships with student-athletes by providing education about what sport psychology practitioners do and do not do, as well as about the realistic outcomes that can follow from service use (Wolanin, 2007; Zillmer \& Gigli, 2007). Likewise, should practitioners have personal athletic experience, some modest self-disclosure can be helpful for developing credibility (Flowers, 2007).

Apart from connecting with student-athletes, developing collaborative relationships across a collegiate athletics department can be beneficial for promoting mental health services and service use (Wolanin, 2007). Collaborative relationships could include those with coaches and administrators (Bennett, 2007), compliance officers and student affairs staff (Zillmer \& Gigli, 2007; Flowers, 2007), athletic trainers (Chamberlain, 2007), and other sports medicine personnel. For instance, Zillmer and Gigli (2007) saw sports medicine as "the milieu in which most clinical aspects of sport psychology emerge" and an important social hub within the athletic department. Supporting this notion, McDuff et al. (2005) documented that, after self-referrals, 
athletic trainers and physicians were the second most common referral source for student-athletes who used mental health services at their institution.

\section{Rates of mental health service use among student-athletes}

Perhaps influenced by the barriers to service use outlined in the previous section, not all students or student-athletes will reach out for help when they could reasonably benefit from it. Reports have suggested that only about a quarter of college students with concerns about their mental health seek supportive services (Haines et al., 2008; Miller et al., 2016), and further, that about $10 \%$ of student-athletes who screen positive for anxiety or depression will utilize mental health services (Eisenberg, 2014). This said, and from a historical perspective, rates of mental health service use among student-athletes appear to be rising, mirroring the trend seen in the broader college counseling literature.

In a recent review of mental health service use among collegiate student-athletes, Moreland, Coxe, and Yang (2018) examined 21 articles published between 2005 and 2016. The authors commented that, within the articles they reviewed, student-athletes' utilization of mental health services was conceptualized "with considerable variability" (p. 64). This, they said, complicated their ability to compare results from one study to the next. It could be argued that mental health service use implies measurement of overt help seeking behavior, but many of the studies reviewed by Moreland and colleagues conceptualized "mental health service use" as intentions to use services, comfort seeking services, referral for services or willingness to refer, and encouraging service use. There was also a wide range of professionals who provided these services, ranging from licensed mental health providers and sport psychology consultants to athletic trainers, dieticians, and sports medicine clinicians. 
It does not appear as though any of the articles reviewed by Moreland and colleagues used overt behavioral measurement (e.g., records of service use). Of the three studies that assessed self-reported sport psychology use, Moreland and colleagues' review did not comment on the frequencies therein. In one of these studies, Martin (2005) found that 15\% $(n=122)$ of 793 high school and collegiate athletes had utilized sport psychology consulting services at least once. Next, among 464 Division I and II student-athletes, Lubker, Visek, Watson, and Singpurwalla (2012) found that $37 \%$ endorsed previous work with a sport psychology practitioner. Finally, in a large sample of 2,440 Division I athletes, Wrisberg, Simpson, Loberg, Withycombe, and Reed (2009) found that 650 (26.6\%) had utilized the services of a sport psychology consultant, of whom 192 were currently utilizing sport psychology services on campus at the time of the study. Descriptive statistics about the demographics of athletes who had used services were not provided in these three studies.

In the limited body of research that has examined mental health service use by collegiate student-athletes via clinical records, one of the first was conducted by Carmen, Zerman, and Blaine (1968). Examining clinical records at Harvard University over the span of five years, these authors found that 106 student-athletes utilized services within that timeframe. This constituted $7 \%$ of the student-athlete population. Over the same five years, $8.5 \%$ of the broader student body utilized psychological support services. No tests were run to examine the statistical significance of service use among student-athletes relative to their peers. Of those studentathletes who utilized services, most (66\%) used 5 sessions or fewer, and only $13 \%$ of studentathletes reapplied to continue services in subsequent academic years relative to $36 \%$ of nonathletes. Less than half (41\%) of student-athletes who presented at the counseling center were self-referred. Carmen and colleagues noted that referrals to the counseling center made by 
"school authorities" were $10 \%$ greater for student-athletes relative to non-athletes. The authors took this to mean that student-athletes were more reluctant to seek services, and in turn, needed to be referred to counseling more frequently. Around the same time, Pierce (1969) found different results at the University of Rochester. He used a longitudinal design to follow 2,075 male students over four years $(1963$ - 1967). Over that time, Pierce found a significant difference between athletes and non-athletes $\left(\chi^{2}=13.14, p<0.01\right)$ as $6.25 \%$ of non-athletes utilized mental health services relative to only $1.59 \%$ of athletes.

Some 15 years later, Bergandi and Wittig (1984) polled college counseling center directors and athletic directors about student-athlete utilization of mental health services during the 1982-83 academic year. From their data, the authors estimated that about $9 \%$ of studentathletes utilized mental health services at their respective institutions during that time span. Combined, $42 \%$ of counseling center directors and athletic directors thought that more studentathletes were seeking mental health services relative to the 1981-82 academic year. Most respondents (39\%) estimated that female student-athletes sought services more frequently than male student-athletes, or thought that male and female student-athletes used services at equal rates $(35 \%)$. About one quarter $(26 \%)$ of participants believed that male student-athletes used services more frequently than females. Relative to these estimated rates of service use, Selby, Weinstein, and Bird (1990) directly surveyed student-athletes $(n=267)$ at a "major private university" during the 1985 academic year and found that $5 \%$ of women and $1 \%$ of men reported using psychological services during the last two academic quarters.

At the turn of the millennium, Leffingwell, Wiechman, Smith, Smoll, and Christensen (2001) provided some data about service use within the University of Washington athletic department. Services were delivered by full-time staff and graduate student trainees in a clinical 
psychology program, and included approximately 300-400 hours of direct work with athletes and teams annually. Based on their records, Leffingwell and colleagues indicted that $43 \%$ of studentathletes who sought sport psychology services did so for purely performance-related reasons and $42 \%$ sought services for personal/clinical concerns. An additional $15 \%$ of student-athletes who sought services did so for a performance-related concern that was later found to be underpinned by a more clinically related issue. Common presenting concerns that they saw included depression, anxiety, anger, substance abuse, eating concerns, and life skill development.

After Leffingwell and colleagues documented their program development, so too did McDuff, Morse, and White (2005) who assembled an interdisciplinary team of mental healthcare providers within a Division I athletic program. Over a three-year span, McDuff and colleagues reported that 69 student-athletes met with the sport psychiatrist. Utilization of the sport psychiatrist's services increased from $1.7 \%$ of student-athletes during the first three months of availability, to $13.1 \%$ in the first full year of availability, to $14.6 \%$ in the second year. In these two full year periods, 224 and 201 total sessions were provided, respectively. McDuff and colleagues reported that there was not a significant difference in service utilization when comparing male and female student-athletes. Overall rates of help-seeking with the other professionals in the team assistance program were not reported. Though the number of sessions used by each student-athlete varied, McDuff and colleagues reported that most used approximately five sessions. The most common presenting concerns that they observed were (in descending order) performance enhancement, injury-related distress, depression, ADHD, substance use, and eating disorders (substance use and eating disorders were equally common).

The Journal of Clinical Sport Psychology published a special issue on sport psychology in the context of intercollegiate athletics in 2007, which offered the next major contribution to 
the service utilization literature. In this issue, several clinicians provided anecdotal insights to their work and the rates of service use that they observed. For instance, Hack (2007) observed that most student-athletes at the University of North Carolina at Chapel Hill used about four sessions of sport psychology services, adding that it was "unusual" for service use to extend beyond ten sessions. Though some saw higher rates of purely performance-related concerns (e.g., Chamberlain, 2007), others noticed that "only a minority of student-athletes who seek services are appropriate for performance-focused interventions" (Wolanin, 2007, p. 279).

Providing some insight to service use over time, Chamberlain (2007) documented exponential growth in the use of comprehensive sport psychology services at Brigham Young University from 71 sessions provided in 1996-97, to 297 the next year, to a peak of almost 1,300 sessions provided during the 2001-02 academic year. From Chamberlain's perspective, service use had only reached a plateau as all of his available appointment times were filled. He expressed that, "I am confident, however, that the numbers will continue to rise as more contact hours are made available by involving graduate students and interns, and possibly hiring additional staff' (p. 284). During the 2005-06 academic year, he estimated that about $21 \%$ his sessions with athletes were clinical in nature, while the majority his work was performancerelated or consultative in nature. The most common clinical concerns that he saw included depression, anxiety, disordered eating, and issues of transition.

Meanwhile, at the University of California, Davis Flowers (2007) reported that counseling services provided to student-athletes hovered between 161 and 212 hours per year from 2000 to 2005 . In the 2005-2006 academic year, 732 hours of counseling services were provided. Flowers suggested that this leap in service use coincided with the university's transition from competing in Division II athletics to Division I. Female athletes appeared to use 
counseling services roughly two to three times more frequently than their male peers. Flowers recorded performance consultation service hours as distinct from counseling hours. Reflecting a similar but amplified trend relative to counseling services, performance consultation service use hovered around 400 hours for three years before jumping to 601 hours in 2004-2005 and 1,058 hours in 2005-2006.

Serving as a counseling psychologist within the Virginia Tech athletics department, Bennett (2007) saw rates of sport psychology service use increase annually until they had roughly tripled 10 years after the embedded position was created. Reporting that he would see about 20-30 student-athletes on a weekly basis, Bennett estimated that about $20 \%$ of these student-athletes sought support for purely performance-related concerns. Overall, he estimated that at least $15 \%$ of all student-athletes at Virginia Tech would utilize counseling services each year. As service use expanded, Bennett saw his appointment count increase from 20 hours per week to 32 hours per week. He anticipated that a full-time appointment would soon follow to accommodate the demand for services.

Since this series of publications in 2007, rates of mental health service use among college student-athletes has been scarce. However, some inferences about service use can be made in an indirect manner. For example, in McGuire and colleagues' (2017) study of depression among student-athletes, the authors indicated that they removed six student-athletes $(2.5 \%$ of their 240 Division II student-athlete sample) from their analyses since they were currently in treatment and/or taking medication specifically for depression. The authors did not assess for mental health service use in general or for issues other than depression. In a more direct assessment of service use, Sandstrom (2012) found in her thesis study that $8.9 \%$ of 45 Division II student-athletes $\left(n_{\text {female }}=20\right)$ self-reported on-campus mental health service use. Finally, Johnson (2017) 
provided a firsthand account of providing psychological services in a collegiate athletics department, reporting that about $25 \%$ of student-athletes utilized mental health services. He observed that about $10 \%$ of student-athletes who presented for services did so for purely performance related concerns, another $10 \%$ presented for clinical reasons, and about $80 \%$ presented for some combination of performance-based and clinical services.

Providing an additional source of insight on student-athlete utilization of mental health services, the Penn State Center for Collegiate Mental Health (CCMH) studies have incorporated de-identified clinical data (such as presenting concerns, demographics of service users, etc.) from a wide variety of institutions across the United States. During its inaugural pilot study, CCMH (2009) clinical data saw $7.3 \%(n=1,171)$ of mental health service users identify as studentathletes. The following year, 8.0\% $(n=1,182)$ of service users identified as student-athletes (CCMH, 2010). In subsequent years, student-athlete status was cross-tabulated by gender identity (see Table ExtRev1 below). These numbers provide a rough estimate of service utilization, but readers are cautioned that, "Year-to-year changes in the number of students in this report are unrelated to changes in counseling center utilization. These changes are due to the number and type of centers contributing data from one year to the next" (CCMH, 2019, p. 4).

To summarize, rates of sport psychology and mental health service use among studentathletes have been studied from the vantage point of clinical records (e.g., Flowers, 2007; CCMH, 2009 - 2019), counseling and athletic administrator perceptions (Bergandi \& Wittig, 1984), practitioner observations (e.g., Johnson, 2017), and athletes' self-reported use (e.g., Selby et al., 1990; Lubker et al., 2012; Martin, 2005; Sandstrom, 2012; Wrisberg et al., 2009). Whereas some practitioners have seen non-clinical performance-related issues as the most prevalent presenting concerns among student-athletes (McDuff et al., 2005; Chamberlain, 2007), others 
have found clinical issues to be more common (Bennett, 2007; Wolanin, 2007). Likewise, some have observed that more females use psychological services relative to males (Selby et al., 1990;

Flowers, 2007; CCMH, 2009 - 2019), whereas others have seen similar rates of service use when

Table ExtRev1. Percentage of all service users and percentage of service users by gender who identified as varsity student-athletes in CCMH clinical data.

\begin{tabular}{cccccc}
\hline Year & $\begin{array}{c}\text { \% of all } \\
\text { service users } \\
(\boldsymbol{n})\end{array}$ & $\begin{array}{c}\text { \% of all } \\
\text { female service } \\
\text { users }(\boldsymbol{n})\end{array}$ & $\begin{array}{c}\text { \% of all male } \\
\text { service users } \\
(\boldsymbol{n})\end{array}$ & $\begin{array}{c}\text { \% of all } \\
\text { transgender } \\
\text { service users } \\
(\boldsymbol{n})\end{array}$ & $\begin{array}{c}\text { \% of all } \\
\text { service users } \\
\text { who self- } \\
\text { identified } \\
\text { gender }(\boldsymbol{n})\end{array}$ \\
\hline 2011 & $7.4 \%(52,332)$ & $6.5 \%(32,360)$ & $9.0 \%(19,242)$ & - & - \\
2012 & $7.1 \%(64,493)$ & $6.2 \%(40,886)$ & $8.9 \%(23,016)$ & - & - \\
2013 & $7.1 \%(71,129)$ & $6.3 \%(39,679)$ & $8.6 \%(22,753)$ & - & - \\
2014 & $6.9 \%(76,622)$ & $6.1 \%\left(45,577^{*}\right)$ & $8.4 \%\left(6,431^{*}\right)$ & $4.4 \%\left(206^{*}\right)$ & $4.4 \%\left(408^{*}\right)$ \\
2015 & $7.2 \%(70,131)$ & $6.5 \%(44,000)$ & $8.6 \%(25,289)$ & $3.9 \%(257)$ & $3.1 \%(585)$ \\
2016 & $7.2 \%(91,247)$ & $6.6 \%(57,837)$ & $8.6 \%(31,977)$ & $3.8 \%(443)$ & $2.4 \%(990)$ \\
2017 & $7.4 \%(82,018)$ & $6.8 \%(52,704)$ & $8.7 \%(27,771)$ & $3.4 \%(471)$ & $4.1 \%(1,072)$ \\
2018 & $3.5 \%(94,329)$ & $3.5 \%(61,286)$ & $3.7 \%(31,082)$ & $0.9 \%(639)$ & $0.5 \%(1,322)$ \\
\hline
\end{tabular}

* = Numbers provided per gender identity did not add up to overall sum. The discrepancy was not addressed in CCMH report. Data compiled from CCMH (2012, 2013, 2014, 2015, 2016, 2017, 2018, 2019).

comparing males and females (Bergandi \& Wittig, 1984; McDuff et al., 2005; Sandstrom, 2012).

However, there appears to be some consensus among practitioners that student-athletes who present for services will rarely use more than five sessions (Carmen et al., 1968; McDuff et al., 2005; Hack, 2007). Finally, the studies reviewed in this section suggest that larger proportions of student-athletes are using mental health services in recent years relative to previous decades (e.g., Carmen et al., 1968; Selby et al., 1990; McDuff et al., 2005; Johnson, 2017).

So far this review has focused on several aspects of "mental health services for studentathletes" as a broad topic, such as rates of mental health concerns among student-athletes, logistics of mental health services (staffing, location, availability), and rates of service use. Without considering the experiences and perspectives of the practitioners who work to serve this population, however, this remains an incomplete picture. As such the following sections will 
make an effort to attend to what is known at present about the practitioner experience - first in the broader realm of collegiate mental health and then within the unique context of collegiate athletics.

\section{Practitioner experiences in college mental health}

To explore the unique challenges faced by practitioners working on small college campuses, Vespia (2007) polled counseling center directors at institutions with less than 4,000 full-time students to examine clinic demographics, usage, and treatment approaches. The 212 directors who took part in the study (35.1\% response rate to mailed surveys) responded to a modified version of Iowa Counseling Center Survey-Revised, which assessed various aspects of center demographics and clinical protocols. Vespia's (2007) survey also invited participants to respond to two open-ended prompts: "What do you believe are the unique issues faced by counseling centers on small campuses?" and "What is the most pressing issue that your counseling center is facing currently?" (p. 24).

Of the 149 who commented on issues unique to small counseling centers, the most common themes that Vespia (2007) identified across participants' responses included a need for additional staffing (34\%), the potential for multiple roles/relationships on a small campus (24\%), budgetary issues (21\%), high workloads (17\%), concerns related to maintaining client confidentiality (16\%), and the intensity of students' presenting concerns (15\%). Responses to the open-ended prompt about current pressing issues came from 151 directors. Showing thematic overlap with responses to the previous item, the most common issues cited were insufficient staffing (32\%), concerns about finances (21\%), heavy workloads (19\%), the intensity of students' presenting concerns (18\%), and issues related to off-campus referral $(6 \%)$. Vespia ultimately concluded that small college counseling centers were providing high quality care in 
light of unique contextual challenges (e.g., lack of peer consultation, pressure to stretch beyond competency to serve a student in need). Calling for future research, Vespia (2007) underscored that findings from studies on large college counseling centers could not be blindly applied to smaller centers given their unique circumstances. As research cited above has indicated that athletic departments tend to only hire one or a few sport psychology practitioners, future research could explore the extent to which embedded sport psychology practitioners face similar challenges as Vespia's (2007) generalist practitioners who serve small campus communities.

In a more recent study, Jodoin and Ayers (2013) interviewed eight practitioners from private and public institutions to examine how they experienced and responded to managerial directives imposed on their campus counseling centers. Participants included five males and three females, whose experience in higher education ranged from 1.5 to 12 years. The interviews were focused on critical incidents in which these practitioners felt that their professional autonomy was challenged by an administrative impetus.

In general, participants expressed a view of non-clinical campus administrators as outsiders with different sets of ethical standards (Jodoin \& Ayers, 2013). Participants also felt that the reporting structures that were in place at their institutions allowed non-clinical administrators to exert some control over the services provided in campus counseling centers. These organizational structures tended to create role ambiguity, and led one participant to wonder, "who is my actual client here?” (p. 439).

While describing their interactions with students, some participants expressed that session limits imposed by campus administrators did not allow for adequate treatment of the concerns for which students sought services. This, in turn, generated discomfort among participants regarding the quality of care they could provide. In other cases, when administrative 
directives compelled participants to serve large numbers of students, it was not only clinical care that suffered but participants' self-care as well. For instance, one of Jodoin and Ayers' (2013) participants expressed that,

We cannot see eight students a day...we are not providing good enough care, that is not good self-care for ourselves, how do we do our paperwork, that kind of stuff... The end of last year...was to be quite honest a nightmare, and we were worn out, overworked, I mean as most counselors are, but we were just dead. We had nothing left to give. (p. 439)

Jodoin and Ayers (2013) found that their participants responded to administrative pressures in three ways. First, some practitioners simply withdrew from their institutions to seek employment elsewhere. Other practitioners demonstrated accommodation in one of two ways: they would either challenge administrators but eventually submit to their directives, or they "quietly disregarded policies and procedures to offer what they had determined to be appropriate standards of care" (p. 442). Jodoin and Ayers (2013) added that the second of these two types of accommodation often left participants feeling frustrated and unhappy. The third theme among practitioners' responses was labeled as “creative resistance and education" (p. 442). Responses in this category included evading session limits to prioritize client care or using managerial barriers as an impetus to educate campus constituents about practitioners' professional roles.

Moving slightly up the administrative chain and departing somewhat from a traditional "research" article, Grayson and Meilman (2013) provided an artful summary of qualitative survey responses from counseling center directors who had been at the same institution for 20 or more years ( $n=28,80 \%$ response rate). Commenting on why they elected to stay in the same position/institution for so long, several directors cited satisfaction with their work and role. Good 
collegial relationships and supportive campus administration were trends as well. Throughout Grayson and Meilman's report, relationships (with students, with colleagues, with administrators) appeared to be important not only for satisfaction, but also for effective and sustainable service delivery. The biggest changes that directors observed since starting in their current roles included increased severity of students' presenting concerns, increased demand for services, and in some cases, a growth in resources and staffing. Some directors also remarked on decreased stigma and increased counseling center visibility - though the latter of these was sometimes borne out of high profile campus crises. Grayson and Meilman also included responses that spoke to increasingly intrusive campus administrators, over-involved parents, and students who presented as more entitled than in previous years.

Themes in the data from Grayson and Meilman (2013) could also be seen in an earlier study on administrator experiences conducted by Watkins, Hunt, and Eisenberg (2012). Watkins and colleagues (2012) interviewed college counseling center administrators from institutions of varying size and geographic location. These interviews focused on perceived changes in and challenges to providing mental health services to college students. Though administrators seemed to think that the rate of service utilization had remained relatively consistent in recent years, they spoke to an increased severity of presenting concerns. This appeared to include issues such as poly-substance use and suicidality, as well as more chronic neurological and developmental challenges such as Tourette's syndrome. Administrators pointed to a number of factors that may contribute to an increasing trend of student distress, including increased societal pressure (and subsequent anxiety, perfectionism, and obsessive compulsive tendencies), overinvolved parents, and a more prevalent dependence on technology that socializes instant gratification. Participants also remarked on a trend of reduced stigma towards mental health 
coupled with an increased proportion of students who have been exposed to mental health services prior to college.

Administrators interviewed by Watkins and colleagues shed some light on ways in which their counseling centers had tried to adapt to the recent changes in demand for services. Preventative outreach was cited, as were expanded services for specific mental health challenges (e.g., bipolar support group) and increased funding to staff graduate trainees/interns as supervised service providers. Despite these adaptations, persistent challenges were mentioned. Some administrators indicated that their current clinics did not offer the necessary amount of space, and further, they had little power to make requests for new or expanded office spaces. Making referrals and utilizing a collaborative approach to mental healthcare (e.g., with other campus or community providers) helped to alleviate some demand for services, while more prevalent student risk (to self or others) was emphasized as a constraining factor. To illustrate, Watkins and colleagues (2012) quoted an administrator from a large research-intensive institution as saying,

one of the most significant challenges regarding student mental health is this notion of risk. There is almost nobody who can predict the future and yet when it comes to mental health, counseling centers are being increasingly put on the spot to predict what a student is going to do...People's ability to predict human behavior is very poor and that's a huge stressor on counseling centers. (pp. 331332)

Watkins and colleagues concluded from their data that, "many counseling centers appear to be in unsustainable positions" (p. 332). The authors made several suggestions for future research, but in terms of practical recommendations, only left readers with a concise directive: "college 
campuses will have to provide more staffing resources or else redefine the roles of counseling centers and direct students to other resources such as those in the surrounding community" (p. $332)$.

Much of the research on college counseling practitioners has focused on challenges experienced therein. Kadambi, Audet, and Knish (2010) attended to an important gap in the literature by exploring the positive experiences of practitioners working in collegiate mental health. These authors used a concept mapping approach to solicit input from 65 (36\% response rate) mental health practitioners in Canadian colleges and universities. From their analyses, 95 distinct meaning units were identified from practitioners' positive experiences. The importance of each positive factor was rated by practitioners (5-point scale, $1=$ "not important" to $5=$ “extremely important") in follow-up analyses, and multidimensional scaling fit the 95 items into 10 categorical clusters. In descending mean importance of each cluster, Kadambi and colleagues identified,

"Contributing to client change" $(M=4.14)$

"Perceiving work as meaningful and valuable" $(M=4.03)$

"Forming meaningful connections" $(M=3.98)$

"Counselor beliefs and values" $(M=3.82)$

"Witnessing the process of change" $(M=3.82)$

"Feeling hopeful for clients" $(M=3.52)$

"Experiencing competence and growth" $(M=3.50)$

"Types of support" $(M=3.49)$

"Positive client characteristics" $(M=3.18)$ and

"Work-related diversity and resourcefulness" ( $M=2.97$; pp. 221-223).

In distilling the four quadrants of their concept map, Kadambi and colleagues (2010) were interested "by what appeared to be a meaningful and logical progression" from internally to externally situated elements that enrich the experience of working in collegiate mental health (p. 226). From their data, the authors theorized that practitioner fulfillment begins with conditions that satisfy their beliefs and values as helping professionals (e.g., "having hope for the human 
condition," "the desire to help others") and promotes a sense of efficacy as a professional enacting those beliefs and values. Client characteristics (e.g., motivated, open, insightful) that tend to be associated with beneficial counseling outcomes contribute next, followed by counselor support systems (e.g., familial support, support from a supervisor, financial compensation). Also noting that practitioners rated internal factors (satisfaction of values, sense of efficacy) as more important than external factors (client characteristics, support), Kadambi and colleagues suggested that "experiences deemed as professionally and personally validating might somehow play a more meaningful role for counselors compared to external support factors" (p. 226) when promoting work-related fulfillment. The authors suggested that efforts to promote counselor fulfillment in the collegiate setting could holistically attend to both the internal factors and external factors identified in their study. This could include identifying practitioners' values and priorities, and to the extent possible, designing organizational policies and individual roles/ responsibilities in such a way as to promote the satisfaction of intrinsic interests and values. When counselor priorities and values get challenged (e.g., as a result of an administrative impetus), making support available could help to alleviate negative effects on the practitioner's overall sense of fulfillment.

As depicted in the publications reviewed in this section, as well as in sections above, there are myriad challenges that mental healthcare professionals face on college campuses. Though they may seem distant at times, there are also meaningful and enriching aspects of the job that reward practitioners who work in this context. If not by choice, then by necessity, college counseling centers have adapted to provide high quality services in an age of limited resources. Perhaps at risk for developing a "mild inferiority complex," Schwartz (2013, p. 96) reminded college mental health professionals that their adaptability has actually placed them at 
the "cutting edge" of mental healthcare service delivery. Further, Eells and colleagues (2005) described how soulful administrative leadership can move practitioners to enjoy the "roller coaster ride" of providing mental health services on college campuses in an inspired and purpose-driven manner. In terms of both challenges and sources of enrichment, some trends from the college counseling literature can apply to mental health practitioners who work within (or as liaisons to) collegiate athletic departments. Just as student-athletes face unique challenges relative to their non-athlete peers, it may also be the case that practitioners embedded within athletic departments face many of the same challenges but also several unique challenges relative to clinicians working with the student body at large. This will be the focus of the following section.

\section{Practitioner experiences with student-athletes and in athletics}

Though the literature on mental health practitioner perspectives appears to be heavily outweighed by research on the clientele served by those practitioners, this appears to be especially true of literature detailing the experiences of mental health practitioners working with collegiate student-athletes or in collegiate athletic departments. Though there have been some studies (e.g., Cropley, Baldock, Mellalieu, Neil, Wagstaff, \& Wadey, 2016) and reviews (e.g., Fortin-Guichard, Boudreault, Gagnon, \& Trottier, 2018) focused on the field experiences of applied sport psychology consultants, there has only been one study to-date that specifically explored the perspectives and experiences of mental health practitioners working with collegiate student-athletes (Schlimmer \& Chin, 2018). Additional detail in the literature that offers a glimpse into the joys, challenges, and day-to-day experiences of these practitioners comes from a handful of insightful firsthand accounts and published program evaluations. Below, the existing 
study by Schlimmer and Chin (2018) will be reviewed, followed by an effort to outline and integrate additional detail from published firsthand accounts and program evaluations.

Pointing to the absence of research in this area, Schlimmer and Chin (2018) used semistructured interviews to examine "the nature of psychological treatment" (p. 54) provided to Division I student-athletes from the vantage point of practitioners. The authors did not explain the questions or areas of inquiry used in their interview guide. Participants included four licensed psychologists and two psychiatrists who worked within or as external referral sources for Division I institutions. Each participant had at least seven years of experience practicing in this context. The authors' analysis placed meaning units into three tiers of exhaustive and mutually exclusive categorization. Only higher-order themes were reported in their manuscript. As a contextual note, one participant's response suggested that Schlimmer and Chin's data collection included interviews from as early as 2014.

The first theme identified by Schlimmer and Chin was communication. One participant spoke to the various constituents who expect communication from a mental health provider, and the authors underscored the "delicate balance" (p. 54) of maintaining client confidentiality therein. Information about how practitioners maneuvered this delicate balance could have been helpful, but was not mentioned by the authors.

The next two themes shed light on practitioners' perspectives on the prevalence and comorbidity of presenting concerns among Division I student-athletes. As one participant put it, the presenting concerns that practitioners saw included "a little bit of everything" (p. 55). Practitioners did not see any particular presenting concerns as more prevalent among studentathletes relative to non-athletes. While some participants cited low coping or social skills and transitional issues (e.g., small fish in a big pond relative to high school) as comorbid concerns for 
student-athletes, Schlimmer and Chin reported that each practitioner had seen instances of comorbid substance abuse.

In the theme of referral, participants spoke to challenges associated with mandated or strongly encouraged referrals, such as student-athletes' resistance to counseling or denial of difficulty. Participants did not appear to elaborate on how they addressed this resistance or denial with student-athletes. Also within this theme, practitioners spoke to the time demands that student-athletes face. Here too, it would have been insightful to learn about how the practitioners experienced student-athletes' time demands, and whether scheduling practices varied between the on- and off-campus providers who Schlimmer and Chin interviewed.

Though not reported as defusing student-athlete resistance, the theme of rapport was well supported with practitioner quotations. Schlimmer and Chin detailed how practitioners sought to develop rapport by involving student-athletes in the practitioner's treatment plan, emphasizing confidentiality, speaking student-athletes' language, and when appropriate, incorporating knowledge of sports or mental skills training. Mental skills training was reported as a distinct theme and four participants endorsed some degree of prior experience with it (specific details were not included). From extended participant quotations, it appeared that practitioners were highly frustrated by the dichotomy of sport psychology practitioners with and without clinical training and the "infighting" (participant quotation, p. 58) that occurs between the two camps. One practitioner called for more cooperation within the field when it comes to marketing sport psychology to universities. From this sentiment, it would have been interesting to hear how participants' employers and clients responded to the professional titles that they used.

Linked to mental skills training, Schlimmer and Chin labeled another theme as "multimodal mental health sport doctors". This captured a sentiment expressed by several 
participants who saw the ideal training for mental health practitioners working with studentathletes as including both clinical and mental skills components. Offering one reason for this, a participant anecdotally remarked that, although $95 \%$ of student-athletes present with a performance issue, only $30 \%$ remain as strictly performance-based consulting. Schlimmer and Chin elaborated that "the multimodal doctor would be able to treat the whole athlete without referral or the chance of any information potentially being lost in translation from one practitioner to the other" (p. 60). From their data, it was not clear if any practitioners had experienced difficulty with referral or information getting lost in the process.

In their final theme, labeled "NCAA," Schlimmer and Chin detailed how participants saw recent efforts from the NCAA as drawing more awareness to the topic of student-athlete mental health. One practitioner saw student-athletes as "a really underserved population" (p. 61), and Schlimmer and Chin reported that all participants saw Division I student-athletes as "a population that needs increased attention" (p. 61). This attention, they suggested, could come in the way of clinical training for practitioners, making services more readily available, and integrating services into athletic departments. The authors did not mention why Division II and III student-athletes were not included as populations in need of more clinical attention.

At present, Schlimmer and Chin (2018) were the first authors to specifically study the perspectives of mental health practitioners working with student-athletes or within collegiate athletic departments. They identified a number of issues that were important to the participants in their sample, namely building rapport and working with resistance, dual competencies to address clinical and performance-based issues, increasing the accessibility of mental health services for student-athletes, and prudently managing multiple channels of communication in the sporting context. From their report, the extent to which these topics emerged organically from the 
interviews was unclear. Reflecting on their study, Schlimmer and Chin indicated that they would have found it interesting to see if more similarity in clinical diagnoses or if contextual challenges would have emerged if their participants all had a similar professional background and location of practice (i.e., on-campus versus off-campus). As a critique, the authors could have actually done more to explicate the nuanced differences that they observed across these contextual factors. For instance, in advocating for more accessible mental health services that are embedded within athletic departments, what challenges did their off-campus providers face that would support this suggestion? Likewise, while promoting clinical training in a general sense for sport psychology professionals, what advantages or disadvantages did the authors find to be associated with the varied backgrounds of their participants? Put differently, what advantages did participants see to their training in psychiatry relative to psychology, and vice versa? This information could be valuable for stakeholders seeking to create or enhance multidisciplinary mental health services for student-athletes. Ultimately, Schlimmer and Chin (2018) made an important and descriptive first contribution to the professional practice literature by exploring the perspectives of mental health practitioners working with collegiate student-athletes. Additional insights from practitioners in this setting can be gleaned from a series of firsthand accounts and program evaluations that have been published. The next sections will attempt to integrate these additional sources.

Emergency services and crisis response. As some collegiate mental health practitioners have commented on the visibility that follows from campus tragedies (e.g., Grayson \& Meilman, 2013) and the increasing emphasis that is being placed on crisis intervention services (e.g., Kitzrow, 2009; Gallagher, 2012), one could be led to wonder if a similar vigilance is required of practitioners working with student-athletes or within athletic departments. For instance, Flowers 
(2007) served as a liaison to intercollegiate athletics from his university's counseling center, and although not necessarily linked to his work with student-athletes, commented that he had at least two crisis intervention or urgent care hours built into his weekly schedule. Additional crisis intervention hours were shared among senior staff at the counseling center. Hack (2007) has noted that the provision of emergency mental health services could also depend on certain contextual factors. If a practitioner working within an athletics department is employed on a parttime basis, it may not be feasible for them to provide emergency intervention and a continuity of care (Hack, 2007). Further, if an institution has standardized emergency protocols that are centralized at the campus clinic, a crisis situation could be outside of a practitioner's role regardless of their availability (Hack, 2007).

In addition to crises such as a student-athletes' imminent risk to self or others, trauma, or other acute mental health concerns, crisis response efforts for mental health providers working within intercollegiate athletic departments could also include incidents of serious behavioral misconduct. Bennett (2007), for instance, commented on the media attention that followed after several student-athletes at his institution were arrested with charges of public intoxication and sexual assault. With the administration's intent to "minimize future problems" (p. 262), Bennett said, his position as a sport psychologist was initially developed "to help student-athletes cope with problems and issues affecting their performance, both on and off the field" (p. 262). Not long after his position was established, Flowers (2007) shared about a similar experience in which he was called upon to fill a remedial role:

Yet before I even had my bearings on campus, let alone a definitive title or an office, I was presented with a crisis involving two prominent student-athletes. I was asked by the director of athletics and the senior associate athletic director to 
schedule individual appointments with each student-athlete and address issues related to NCAA, [my institution], and ICA [intercollegiate athletics] drug and alcohol policies and codes of conduct as well as university and ICA suspensions, drug and alcohol treatment, and individual or group counseling. (p. 225)

While these experiences from Bennett (2007) and Flowers (2007) carry a reactionary tone, others have shed light on a more preemptive, wellness-oriented approach to prevent misconduct. For example, Zillmer and Gigli (2007) noted that, "In response to increasing demands on today's student-athletes and the negative media associated with student-athlete misconduct, there has been a commitment to the psychological care and overall well-being of student-athletes" (p. 210). Elaborating on the role of providing mental health services within collegiate athletics, Zillmer and Gigli (2007) shared that promoting health and wellness can sometimes go hand-in-hand with avoiding risks and problems:

High-risk student-athlete behaviors, including substance abuse, eating disorders, hazing, violence, self-defeating relationships, gambling, and sexual misconduct can become a major problem not only for the athletic department but also for the university's image as a whole. Thus, sport psychologists may have a special entrée within this context of reducing the risk of negative publicity, while adding important life skills lessons to student-athletes. (p. 220)

Beyond these accounts, there is only limited evidence to suggest that athletic or institutional administration might expect mental health providers to prevent or "fix" issues related to risk and misconduct. In their survey of athletic directors, Kornspan and Duve (2006) reported that one director supported the need to hire a sport psychology practitioner at their institution because, they "could assist our department with social/behavior problems that some 
athletes have" (p. 23). While findings in the college counseling literature have shed light on the tension stemming from student risk (Watkins et al., 2012) and administrative directives (Jodoin \& Ayers, 2013), there is little data about if or how mental health practitioners experience similar tensions related specifically to crisis management and risk reduction in their work with studentathletes.

Screening. One aspect of prevention efforts could entail pre-season (NCAA, 2016) or longitudinal (McGuire et al., 2017) mental health screening. Some practitioners have shared hindsight reflections on their design and implementation of mental health screening within collegiate athletics. Shortly after McDuff and colleagues (2005) assembled their interdisciplinary Team Assistance Program for mental health service delivery within a collegiate athletic department, these practitioners indicated that they attached a pre-season mental health screener to a letter introducing the program. Introductory letters and screeners were then distributed to all student-athletes. These authors did not include detail about how data obtained through screening was utilized.

More recently, Tomalski, Clevinger, Albert, Jackson, Wartalowicz, and Petrie (2019) detailed their experiences of developing, implementing, and evaluating a mental health screening initiative within their athletic department. The authors cited buy-in from athletic administration as critical to the successful implementation of screening, but added that securing this buy-in was a two-year process. Part of their preparatory efforts included logistical planning, such as identifying referral sources for student-athletes who endorsed mental health concerns and intervention protocols that would be implemented if student-athletes endorsed self-harm or suicidal ideation. To this point, Tomalski and colleagues cautioned practitioners to consider feasibility and available personnel when developing a mental health screening initiative. 
Importantly, Tomalski and colleagues also commented on the informed consent provided to student-athletes prior to screening, which detailed how the data would be stored (data would not be available to coaches or non-medical staff) and ways in which sport psychology staff would follow-up with student-athletes.

While practitioner perspectives on maintaining confidentiality within an athletics department will be detailed below, this topic warrants brief mention here as well. Wolanin (2007) shared about the use of structured assessments in the doctoral training clinic that services student-athletes on his campus. When student-athletes complete the Sport Performance Questionnaire during intake assessment, Wolanin indicated that they can choose if they would like their coach to complete the inventory as well for the sake of triangulation. While some student-athletes will be comfortable with this, Wolanin indicated many will not be. In such instances, he said, their wishes for confidentiality must be upheld. When appropriate, Bennett (2007) also commented on the potential benefit of triangulating assessment data during athlete observation - an opportunity that appears to be unique for sport psychology personnel relative to other mental health practitioners on campus:

[Observing student-athletes] in competitive environments...is an advantage fairly unique to a clinical sport psychologist. I am able to directly observe - with the permission of the athlete - how effectively strategies generated in the therapy setting prove to be as the athlete attempts to translate them to an actual performance. This immediate feedback on the effectiveness of therapeutic strategies allows for more rapid progress and the fine-tuning of therapeutic interventions. (pp. 266-267) 
Taken together, the practitioner perspectives outlined in this section shed some light on the benefits and challenges associated with mental health screening for student-athletes. However, Tomalski and colleagues (2019) pointed to a gap that still exists in the professional practice literature:

the NCAA has suggested that screening, whenever it occurs, be overseen by licensed mental health practitioners who can either provide services themselves or make referrals to other appropriate professionals. Yet, these screening recommendations are relatively new and there is limited empirical or practical information regarding their application. (p. 123)

As such, future research could explore if or how practitioner perspectives on mental health screening vary across contexts. For instance, screening efforts could be compared by some level of resources or personnel that practitioners have access to. It could also be helpful to know more about the ethical dilemmas that practitioners encounter with mental health screening, as well as how they have been handled.

Service availability. Given that screening efforts, referrals, and service availability go hand-in-hand, it may be helpful to revisit the topic of service availability here. Though this topic was outlined above, that outline was mostly numerical in nature. Here, an effort will be made to focus specifically on practitioner perspectives and experiences pertaining to service availability, and to include examples in their words with direct quotations. That said, before reviewing anecdotes directly from practitioners, Connole and colleagues' (2014) survey of athletic directors will be revisited as it provides pertinent contextual detail.

Recall from above that Connole and colleagues surveyed athletic administrators about their preferences for a sport psychology professional taking into account several variables such 
as services rendered, salary, and so forth. The authors found that the most preferred profile was for a practitioner who was employed on a part-time basis by the athletics department (versus an academic department, counseling center, or private practice) with an annual salary (relative to a fee for service arrangement or one that billed team budgets), who could provide both mental health and performance enhancement services (versus one service or the other), and could serve athletes, teams, and staff (as opposed to just athletes or just teams and staff). Connole and colleagues drew attention to the fact that, relative to other potential profiles, this preferred profile was comprised "of the least number of hours and the most possible clients and services" (p. 214). "This combination," the authors continued, "suggests [athletic administrators] are either overly idealistic with respect to what they expect from [sport psychology professionals] or they assume [sport psychology professionals] are capable of delivering such services within these constraints" (p. 214).

There may be some reason to believe that mental health practitioners working in collegiate athletics do indeed experience heavy expectations. In addition to generally full schedules (e.g., as observed by McDuff et al., 2005), there may be a tug for both additional and more flexible service availability. For example, Bennett (2007) remarked that, Whereas CCC [Cook Counseling Center] psychologists and counselors may take responsibility for "on-call” coverage 1 to 2 weeks per semester and rarely remain in the office past 5:00 p.m., the expectations for the sport psychologist position are radically different. To be effective, the sport psychologist needs to be available when the need for services arises, including evenings and weekends. (p. 264) 
Complicating matters further, Hack (2007) observed that student-athletes and coaches may expect the same rapid response from mental health providers that they tend to receive from athletic trainers and other sports medicine personnel. "Delays," Hack (2007) said, "are typically not well tolerated because of what it can mean in terms of the team's performance" (p. 249). Subsequently,

If the sport psychologist consistently tells the physicians, coaches, and administrators that he or she cannot get an athlete in for an appointment for another week or two, the referrals will eventually stop coming. Instead, coaches and physicians may seek out others who can respond more quickly. Whether these other providers are properly trained can be another matter. (Hack, 2007, p. 249)

Likewise, with the tight and highly regimented schedules that student-athletes maintain, there may be an expectation that practitioners add or adjust clinic hours to accommodate studentathletes (Bennett, 2007; Watson, 2003). In this regard, Chamberlain (2007) shared that, "I have to...be prepared to teach with little notice, and meet with athletes and teams at their convenience" (p. 292). In light of suggestions that collegiate athletic departments create more jobs for sport psychology providers to promote additional staff-hours (e.g., Carr, 2007), barriers can include funding (Zillmer \& Gigli, 2007) and "administrative red tape" (Hack, 2007, p. 250).

Presence, outreach, and program evaluation. Apart from clinicians' availability to provide direct services to student-athletes, mental health practitioners working with studentathletes often remark on the importance of indirect services such as maintaining visibility within the athletic department, conducting outreach, and using program evaluation to assess and enhance models of service delivery. In firsthand accounts that are available, practitioners have remarked on the benefits and challenges associated with each of these endeavors. For example, it 
has been observed that practitioner presence can build credibility (Chamberlain, 2007), promote awareness and trust (Flowers, 2007), decrease the stigma of seeking services (Carr, 2007), and ultimately promote mental health service use (McDuff et al., 2005). However, this often comes at a price. Chamberlain (2007) remarked that maintaining a visible presence at practices and competitions requires “constant effort” (p. 292). Similarly, Wolanin (2007) added that "maintaining a presence within the culture of the Athletics Department requires persistent effort" (Wolanin, 2007, p. 279). From these practitioners' perspectives, it seemed that maintaining a presence came in addition to (rather than as part of, or balanced with) clinical loads and other role-related responsibilities.

In addition to attending practices or competitions, maintaining visibility within an athletics department can also entail educational outreach. For some practitioners, methods of outreach have included formal programs or presentations, brochures, newsletters, and websites (Leffingwell et al., 2001; McDuff, 2005; Flowers, 2007; Wolanin, 2007) that discuss popular sport psychology topics and explain what services are available. Others have observed that teaching a formal for-credit class on sport psychology can also be helpful to normalize helpseeking behavior (Chamberlain, 2007; Wolanin, 2007).

There may be costs, benefits, and opportunities for mental health practitioners that are associated with such outreach. As a potential benefit, outreach could promote wellness in a preventative fashion. Flowers (2007) observed that a year of relatively lower sport psychology service use among student-athletes at his institution coincided with a year in which relatively more energy was devoted to outreach. Whether outreach had a preventative effect or there was simply less time for one-on-one service delivery remains unknown, however. The time required to develop and implement new and relevant outreach programs can be an inherent cost. Flowers 
(2007) spoke briefly to the level of intentionality needed to set aside time for such planning. Opportunities may present in collaborative efforts with other branches of student affairs. Zillmer and Gigli (2007) noted that, "Through creative programming designs, athletics departments can work in conjunction with sport psychologists and other campus partners, such as residential living and Greek life, to maximize the impact of the educational messages being sent" (p. 216).

With the mental health services and programs that practitioners offer to student-athletes, program evaluation can be another aspect of the practitioner experience. Insights gleaned from such evaluation can be beneficial for refining and enhancing services/programs, and when shared as publishable research, can be instructive for other practitioners at different institutions. That said, Bergandi and Wittig (1984) commented that institutions that offer mental health services specifically tailored to student-athletes "do so in something of a vacuum - that is, not knowing what other schools are attempting" (p. 558). Some 30 years later now, the new publication Case Studies in Applied Sport and Exercise Psychology may be generating some momentum in this regard (e.g., Gabana, 2017).

Beyond its importance for refining services, data collection and program evaluation may also be necessary amid pressures to demonstrate the value and impact of mental health services at a college or university (Keeling \& Heitzmann, 2003). This may be especially true for mental health practitioners whose salary comes from the athletic department. Zillmer and Gigli (2007) indicated that

Sport psychologists must understand that athletics departments have full-time business managers and are very cost conscientious...The sport psychologists should receive fair reimbursement for their time, while demonstrating to the intercollegiate athletics department that their services are either an added value to 
the mission of the department or actually provide cost-effectiveness to the department (e.g., concussion assessment, prevention of injuries, increased success, or early detection of clinical issues). (p. 220)

In addition to demonstrating the institutional impact of services, research and program evaluation can contribute to professional knowledge within the field and enhance the effectiveness of services/programs (Lefingwell et al., 2001). Carr (2007) spoke to his scientist-practitioner approach to providing psychological services, adding that

the field has so much more to contribute from the academic/research viewpoint; I am hopeful that I am able to create opportunities for research into the "hows" and "whys" of our interventions, both from a performance-enhancement and psychotherapeutic standpoint (these are not as separate as some may believe). (p. 303)

Having acknowledged these benefits, mental health practitioners have also commented on barriers to collecting, analyzing, and reporting data from their work with student-athletes. For instance, Carr (2007) observed that, as there tend to be relatively few mental health practitioners who are employed within collegiate athletic departments,

We do not have the professional energy to recommend and guide the relevant research. The increase in positions (jobs within athletic systems, such as psychologists for collegiate athletic departments) will also increase the viability of research with this unique population...But without jobs, we have no one to drive the system of change. (p. 299) 
Johnson (2017) also mentioned the "scarcity" of jobs for mental health providers within collegiate athletic departments (p. 57), and reflected on the tone with which his enthusiasm for academic writing was met:

It was clearly communicated to me that I was interviewing for an applied position and there would not be time to write. The current article was first drafted during my university's winter break, and then revised over summer break, during which time my workload is lighter than in the fall and spring. My current position is a one-person office. (p. 64)

Barriers can also exist even in contexts where formal program evaluation is encouraged. Within the doctoral training clinic at his institution, Wolanin (2007) pointed out that an "important component of our model for providing clinical and sport psychology interventions is continual assessment of effectiveness through the use of structured outcome measures" (p.273). Although using a battery of inventories provided helpful data for both clinical practice and applied research, Wolanin (2007) added that "it takes time to administer and complete, which adds time to meetings with athletes and could potentially decrease an athlete's motivation to seek services" (pp. 273-274). If structured "data" is not a priority, some practitioners have remarked on their use of informal methods of program evaluation to sidestep these challenges. For example, feedback can be obtained through word-of-mouth, through exit interviews with graduating student-athletes, and through discussion with coaches (Bennett, 2007; Chamberlain, 2007).

From the available literature, it appears that some mental health practitioners value and will exert considerable effort to maintain a visible presence, conduct educational outreach, and evaluate the programs and services that they deliver to student-athletes. Just as research “doesn't fit in a 50-min hour" for clinicians who work with the student body at large (Bartholomew, 
Pérez-Rojas, Lockard, \& Locke, 2017, p. 265), clinical sport psychologists often spoke about their presence, outreach, and program evaluation as supplementary to their provision of direct clinical services. Future research on practitioner perspectives could shed light on additional factors that facilitate and constrain these efforts for practitioners working with student-athletes. More broadly, questions remain as to how sport psychology practitioners experience these rolerelated activities. For instance, how much time gets allotted to these activities and to what expense? What do practitioners think about the quality of their outreach? To what degree have practitioners used institutional or other data to refine their efforts? To the extent that clinicians see visibility, outreach, and program evaluation as enhancing the services they can provide to student-athletes, additional information in these areas could be of benefit for the institutions, athletic conferences, and governing bodies that shape and support the clinical roles of sport psychology professionals in collegiate settings.

Other practitioner experiences. As practitioners balance expectations for direct service provision and crisis intervention with other indirect services like screening, outreach, and program evaluation it may be helpful to know how additional aspects of their experience impact these role-related activities. One pertinent area revolves around expectations about confidentiality. Koocher and Keith-Spiegel (1998) famously referred to confidentiality as “a cornerstone of the helping relationship" (p. 115). In the context of collegiate athletics, coaches often have access to student-athlete medical records and may be led to expect similar transparency regarding student-athletes' mental health (Loughran, Etzel, \& Hankes, 2014). This presumed "right to know" can be amplified when the athletic department is paying a practitioner's salary (Etzel \& Watson II, 2007). 
Citing others, Hack (2007) concurred that mental health practitioners working with student-athletes "must be aware that the culture of athletics requires greater flexibility and comfort with collateral communication than is typically required in other settings" (p. 251). Likewise, prior to establishing their Team Assistance Program within the university's athletic training room, McDuff and colleagues (2005) noted that sports medicine staff had expressed frustration with "restrictions on feedback" from the campus counseling center (p. 945), presumably with regard to student-athletes' attendance or treatment. Others have also spoken to tugs on the confidentiality of their work. As Bennett (2007) put it, "one of the challenges I routinely face...is continuing to nurture...close professional bonds with administrators and coaches while maintaining confidential relationships with the student-athletes" (p. 263). Chamberlain (2007) also referred to maintaining confidentiality amid multiple role relationships as "a constant challenge" (p. 292). Beyond the culture of athletics, there can be more concrete challenges that practitioners encounter as well. This could include situations in which the practitioner's office is located in the same hallway as the coaching staff (Flowers, 2007; Johnson, 2017) or impromptu consultations with student-athletes while at practice or competition venues (Etzel \& Watson II, 2007). In an effort to overcome these challenges, Chamberlain (2007) remarked on the importance of assertiveness and firm boundaries. Practitioners have also commented that clarifying the limits of confidentiality, educating student-athletes and coaches about these limits, and reiterating this information can help to destigmatize mental health services (Carr, 2007), increase the comfort with which student-athletes seek services (Johnson, 2017), and facilitate student-athletes' self-disclosure when they use services (Watson, 2003). 
Extending beyond the issue of maintaining client confidentiality, practitioners have also shared about other experiences in which it was challenging to maintain student-athlete clientele as the priority. Although such instances can be infrequent, Hack (2007) remarked that

there can exist subtle as well as overt pressures from various sources to do what may be in the best interest of the coach, team, administration, or family and not necessarily what is in the best interest of the student-athlete. (p. 251)

He elaborated on examples like pressures to clear a student-athlete for competition before they are ready (e.g., in the presence of PTSD symptomology following a severe injury) or furnishing psychological reason for a medical disqualification so that a scholarship could be retained after a student-athlete quit the team. With a similar tone, Chamberlain (2007) shared that "my role...in the athletic department has been one where I have had to learn through experience. I have learned to ask myself regularly, 'who is my client?"” (p. 289).

An interesting juxtaposition can be noted at this point. Whereas counseling center clinicians interviewed by Jodoin and Ayers (2013) saw non-clinical campus administrators as outsiders, some have remarked that mental health practitioners working in collegiate athletics "must realize that they are visitors in this athletic culture" (Zillmer \& Gigli, 2007, p. 218). Regardless of who the "outsiders" or "visitors" may be, it appears that similar tensions can exist between practitioners and administrators across contexts. Similar to counseling center clinicians who felt at odds with the ethics and priorities of campus administrators (Jodoin \& Ayers, 2013), Johnson (2017) has remarked on a disconnect that can occur between sport psychology staff and athletic administration:

My observations lead me to believe that there is a less-than-optimal fit between the business- and outcome-minded culture of intercollegiate athletics and the 
principles of counseling with its process orientation...Many times I have found that the person who writes up my annual performance review knows nothing about counseling skills or psychological theory, and may not have a graduate degree. (p. 63)

Disconnects in understanding between clinical sport psychology practitioners and athletic administration can also surface in matters pertaining to competency. From their review, Moreland and colleagues (2018) concluded that "some administrators believe community or general counseling, already offered at the university, is sufficient for sport-related mental health concerns" (p. 65). Pointing to the relative lack of practitioners who could address both clinical mental health issues and performance-related mental skills, Hack (2007) offered some insight as to why this may be less than ideal:

The psychologists at the counseling center were licensed and trained to treat clinical issues but typically had little or no formal education, training, or supervision in sport psychology...Some of the athletes reported that they did not feel completely understood when seeing general psychologists and hence would not return for treatment...Likewise, athletes did not always receive the clinical services they needed because some mental skills coaches did not have the training to routinely assess for psychological disorders. (p. 248)

As practitioners working in other niche contexts have emphasized a need for more domainspecific knowledge and training in their areas of practice (Ren et al., 2017; Khawaja \& Stein, 2016; Hall et al., 2014; Castillo et al., 2016; Leigh, Powers, Vash, \& Nettles, 2004), so too have clinicians providing comprehensive sport psychology services to student-athletes. Carr (2007) voiced his concerns as follows: 
I am truly concerned with the apparent lack of respect that many licensed clinical/counseling psychologists have with the "culture" of sport/athletics. In my opinion, for any licensed psychologist to enter the athletic arena (at any level, from youth sport to professional sport and in-between) without at least coursework/continuing education in sport psychology theory/techniques and sociological aspects of sport is to practice with limited competency. (p. 296)

Carr would also appear to agree with practitioners in other niche contexts about the current lack and dire need for ongoing supervision in the realm of providing comprehensive sport psychology services to student-athletes:

[supervision and case consultation] is often woefully absent in our development of proficiency for psychologists that desire to work in athletic systems... It is important (if psychologists are to enhance athletic systems) that we create "mechanics" to create our skills and develop collaborative dialogue, while at the same time maintaining the confidentiality of care and unique proficiencies of our work. (pp. 300-301)

Perhaps due in part to the many role-related responsibilities that get filled by mental health practitioners working with student-athletes, some have speculated that these professionals can be "stretched too thin" (Moreland et al., 2018, p. 59). In the absence of broader data on practitioner experiences, there is only limited anecdotal evidence to support this. For instance, Chamberlain (2007) acknowledged that, "the hours are long, and during the school year, it is hard to find balance in my own life" (p. 292). Stressors acknowledged, and in a similar tone to Kadambi and colleagues' (2010) exploration of positive experiences for counseling center clinicians, mental health practitioners have also commented on sources of enrichment and 
enjoyment found in their work with student-athletes. Some have remarked on the thrill of working with student-athletes in a competitive environment (Chamberlain, 2007; Zillmer \& Gigli, 2007), the variety and spontaneity of role-related responsibilities that they fill (Chamberlain, 2007; Flowers, 2007; Wolanin, 2007), the enjoyment of developing trusting relationships with athletes and staff (Chamberlain, 2007), and the opportunity to play a small role in student-athletes' growth and success (Chamberlain, 2007; Wolanin, 2007). In sum, mental health practitioners working with student-athletes and within collegiate athletic departments balance a variety of role-related activities, and appear do so while facing a host of contextual challenges.

\section{References (for extended review of literature)}

Armstrong, S., Oomen-Early, J. (2009). Social connectedness, self-esteem, and depression symptomatology among collegiate athletes versus nonathletes. Journal of American College Health, 57(5), 521-526. doi: 10.3200/JACH.57.5.521-526

Back, S. E., \& Brady, K. T. (2008). Anxiety disorders with comorbid substance use disorders: Diagnostic and treatment considerations. Psychiatric Annals, 38(11), 724-729. doi: $10.3928 / 00485713-20081101-01$

Bär, K., \& Markser, V. Z. (2013). Sport specificity of mental disorders: The issue of sport psychiatry. European Archives of Psychiatry and Clinical Neuroscience, 263(Suppl 2), S205-S210. doi: 10.1007/s00406-013-0458-4

Barnard, J. D. (2016). Student-athletes' perceptions of mental illness and attitudes toward helpseeking. Journal of College Student Psychotherapy, 30(3), 161-175. https://doi.org/10.1080/87568225.2016.1177421 
Bartholomew, T. T., Pérez-Rojas, A. E., Lockard, A. J., \& Locke, B. D. (2017). “Research doesn't fit in a 50-minute hour': The phenomenology of therapists' involvement in research at a university counseling center. Counselling Psychology Quarterly, 30(3), 255273. https://doi.org/10.1080/09515070.2016.1275525

Bauman, J. N. (2016). The stigma of mental health in athletes: Are mental toughness and mental health seen as contradictory in elite sport? British Journal of Sports Medicine, 50, 135136. doi:10.1136/bjsports-2015-095570

Beamish, P. M. (2005). Introduction to the special section - Severe and persistent mental illness on college campuses: Considerations for service provision. Journal of College Counseling, 8(2), 138-139. https://doi.org/10.1002/j.2161-1882.2005.tb00080.x

Bennett, G. (2007). The role of a clinical sport psychologist in a division I athletics program. Journal of Clinical Sport Psychology, 1(3), 261-269. https://doi.org/10.1123/jcsp.1.3.261

Benton, S. A., Robertson, J. M., Tseng, W. C., Newton, F. B., \& Benton, S. L. (2003). Changes in counseling center client problems across 13 years. Professional Psychology: Research and Practice, 34(1), 66-72. doi: 10.1037/0735-7028.34.1.66

Bergandi, T. A., \& Wittig, A. F. (1984). Availability of and attitudes toward counseling services for the college athlete. Journal of College Student Personnel, 25(6), 557-558.

Bianchi, R., Schonfeld, I. S., \& Laurent, E. (2015). Burnout-depression overlap: A review. Clinical Psychology Review, 36, 28-41. http://dx.doi.org/10.1016/j.cpr.2015.01.004

Brown, G. T., Hainline, B., Kroshus, E., \& Wilfert, M. (Eds.). (2014). Mind, body and sport: Understanding and supporting student-athlete mental wellness. Indianapolis, IN: National Collegiate Athletic Association. 
Brutlag Hosick, M. (January 24, 2019). Access to mental health services guaranteed by autonomy conferences. Obtained from http://www.ncaa.org/about/resources

Buckman, J. F., Yusko, D. A., Farris, S. G., White, H. R., \& Pandina, R. J. (2011). Risk of marijuana use in male and female college student athletes and nonathletes. Journal of Studies on Alcohol and Drugs, 72(4), 586-591. doi: 10.15288/jsad.2011.72.586

Cameron, O. G. (2007). Understanding comorbid depression and anxiety. Psychiatric Times, 24(14), 51.

Carmen, L. R., Zerman, J. L., \& Blaine, G. B. (1968). Use of the Harvard psychiatric service by athletes and non-athletes. Mental Hygiene, 52(1), 134-137.

Carr, C. M. (2007). A psychologist in the world of intercollegiate sports: Professional development issues. Journal of Clinical Sport Psychology, 1(3), 293-303. https://doi.org/10.1123/jcsp.1.3.293

Castillo, J. M., Wolgemuth, J. R., Barclay, C., Mattison, A., Yin Tan, S., Sabnis, S., ... Marshall, L. (2016). A qualitative study of facilitators and barriers related to comprehensive and integrated school psychological services. Psychology in the Schools, 53(6), 641-658. doi: 10.1002/pits.21932

Center for Collegiate Mental Health (2009, April). 2009 pilot study: Executive summary (Publication No. STA 09-160 MPC105808). Retrieved from https://ccmh.psu.edu/publications/

Center for Collegiate Mental Health (2010, March). 2010 Annual Report (Publication No. STA 11-000). Retrieved from https://ccmh.psu.edu/publications/

Center for Collegiate Mental Health (2012, January). 2011 Annual Report (Publication No. STA 12-59). Retrieved from https://ccmh.psu.edu/publications/ 
Center for Collegiate Mental Health (2013, January). 2012 Annual Report (Publication No. STA 13-68). Retrieved from https://ccmh.psu.edu/publications/

Center for Collegiate Mental Health (2014, January). 2013 Annual Report (Publication No. STA 14-43). Retrieved from https://ccmh.psu.edu/publications/

Center for Collegiate Mental Health (2015, January). 2014 Annual Report (Publication No. STA 15-30). Retrieved from https://ccmh.psu.edu/publications/

Center for Collegiate Mental Health (2016, January). 2015 Annual Report (Publication No. STA 15-108). Retrieved from https://ccmh.psu.edu/publications/

Center for Collegiate Mental Health (2017, January). 2016 Annual Report (Publication No. STA 17-74). Retrieved from https://ccmh.psu.edu/publications/

Center for Collegiate Mental Health (2018, January). 2017 Annual Report (Publication No. STA 18-166). Retrieved from https://ccmh.psu.edu/publications/

Center for Collegiate Mental Health (2019, January). 2018 Annual Report (Publication No. STA 19-180). Retrieved from https://ccmh.psu.edu/publications/

Chamberlain, R. B. (2007). Sport psychology in a collegiate athletic department setting. Journal of Clinical Sport Psychology, 1(3), 281-292. https://doi.org/10.1123/jcsp.1.3.281

Chatterton, J. M., \& Petrie, T. A. (2013). Prevalence of disordered eating and pathogenic weight control behaviors among male collegiate athletes. Eating Disorders, 21(4), 328-341. doi: $10.1080 / 10640266.2013 .797822$

Chow, G. M., Gabana, N. T., \& Swanbrow Becker, M. A. (2019). Tackling stigma: A pilot program to promote mental health literacy and help-seeking in student-athletes. $N C A A$ Innovations in Research and Practice Grant Program. Retrieved from http://www.ncaa. org/about/resources/research 
Connole, I. J., Shannon, V. R., Watson II, J. C., Wrisberg, C., Etzel E., \& Schimmel, C. (2014). NCAA athletic administrators' preferred characteristics for sport psychology positions: A consumer market analysis. The Sport Psychologist, 28(4), 406-417. http://dx.doi.org/10.1123/tsp.2013-0096

Cox, C. E., Ross-Stewart, L., \& Foltz, B. D. (2017). Investigating the prevalence and risk factors of depression symptoms among NCAA division I collegiate athletes. Journal of Sports Science, 5, 14-28. doi: 10.17265/2332-7839/2017.01.002

Cropley, B., Baldock, L., Mellalieu, S. D., Neil, R., Wagstaff, C. R., \& Wadey, R. (2016). Coping with the demands of professional practice: Sport psychology consultants' perspectives. The Sport Psychologist, 30(3), 290-302. http://dx.doi.org/10.1123/tsp.20150125

Douce, L. A., \& Keeling, R. P. (2014). A strategic primer on college student mental health. Washington, DC: American Council on Education.

Eaton, W. W., Smith, C., Ybarra, M., Muntaner, C., \& Tien, A. (2004). Center for epidemiologic studies depression scale: Review and revision (CESD and CESD-R). In M. E. Maruish (Ed.), The use of psychological testing for treatment planning and outcomes assessment (3rd ed., pp. 363-377). Mahwah, NJ: Lawrence Erlbaum.

Eells, G. T., Seals, T., Rockett, J., \& Hayes, D. (2005). Enjoying the roller coaster ride: Directors' perspectives on fostering staff morale in university counseling centers. Journal of College Student Psychotherapy, 20(2), 17-28. doi: 10.1300/J035v20n02_03

Eisenberg, D. (2014). 2014 NCAA innovations grant final report: Developing and evaluating a model program for supporting the mental health of student athletes. Retrieved from http://athletesconnected.umich.edu/research-and-data/ 
Elreda, D. (2014). Examining how the ratio of students on campus to counseling center staff relates to dosage and counseling center treatment effectiveness. Retrieved from ProQuest Dissertations \& Theses Full Text. https://search.proquest.com/docview/1639700764? accountid $=2837$

Esfandiari, A., Broshek, D. K., \& Freeman, J. R. (2011). Psychiatric and neuropsychological issues in sports medicine. Clinics in Sports Medicine, 30(3), 611-627. doi: 10.1016/j.csm.2011.03.002

Etzel, E. F., \& Watson II, J. C. (2007). Ethical challenges for psychological consultations in intercollegiate athletics. Journal of Clinical Sport Psychology, 1(3), 304-317. https://doi.org/10.1123/jcsp.1.3.304

Etzel, E. F., Watson, J. C., Visek, A. J., \& Maniar, S. D. (2006). Understanding and promoting college student-athlete health: Essential issues for student affairs professionals. NASPA Journal, 43(3), 518-546. doi: 10.2202/0027-6014.1682

Flowers, R. (2007). Psychologist-sport psychologist liaison between counseling and psychological services and intercollegiate athletics. Journal of Clinical Sport Psychology, 1(3), 223-246. https://doi.org/10.1123/jcsp.1.3.223

Fortin-Guichard, D., Boudreault, V., Gagnon, S., \& Trottier, C. (2018) Experience, effectiveness, and perceptions toward sport psychology consultants: A critical review of peer-reviewed articles. Journal of Applied Sport Psychology, 30(1), 3-22, doi:

$10.1080 / 10413200.2017 .1318416$

Frank, R., Nixdorf, I., \& Beckmann, J. (2017). Analyzing the relationship between burnout and depression in junior elite athletes. Journal of Clinical Sport Psychology, 11(4), 287-303. https://doi.org/10.1123/JCSP.2017-0008 
Gabana, N. (2017). A strengths-based cognitive behavioral approach to treating depression and building resilience in collegiate athletics: The individuation of an identical twin. Case Studies in Sport and Exercise Psychology, 1(1), 4-15. https://doi.org/10.1123/cssep.20160005

Gallagher, R. P. (2012). National Survey of College Counseling 2012. Retrieved from http://dscholarship.pitt.edu/28175/1/NSCCD_Survey_2012.pdf

Gorczynski, P. F., Coyle, M., \& Gibson, K. (2017). Depressive symptoms in high-performance athletes and non-athletes: A comparative meta-analysis. British Journal of Sports Medicine, 51(18), 1348-1354. doi:10.1136/bjsports-2016-096455

Grayson, P., \& Meilman, P. (2013). Longevity speaks: Observations from long-serving counseling center directors. Journal of College Student Psychotherapy, 27(3), 185-199. doi: $10.1080 / 87568225.2013 .798219$

Greenleaf, C., Petrie, T. A., Carter, J., \& Reel, J. J. (2009). Female collegiate athletes: Prevalence of eating disorders and disordered eating behaviors. Journal of American College Health, 57(5), 489-496. doi: 10.3200/JACH.57.5.489-496

Gross, M. B., Wolanin, A. T., Pess, R. A., \& Hong, E. S. (2017). Socially desirable responding by student-athletes in the context of depressive symptom evaluation. Journal of Clinical Sport Psychology, 11(2), 148-157. https://doi.org/10.1123/jcsp.2017-0020

Gulliver, A., Griffiths, K. M., \& Christensen, H. (2012). Barriers and facilitators to mental health help-seeking for young elite athletes: A qualitative study. BMC Psychiatry, 12, 157-170. doi: $10.1186 / 1471-244 X-12-157$ 
Hack, B. (2007). The development and delivery of sport psychology services within a university sports medicine department. Journal of Clinical Sport Psychology, 1(3), 247-260. https://doi.org/10.1123/jcsp.1.3.247

Hall, J., d'Ardenne, P., Nsereko, J., Kasujja, R., Baillie, D., Mpango, R., ... Hunter, E. (2014). Mental health practitioners' reflections on psychological work in Uganda: Exploring perspectives from different professions. British Journal of Guidance \& Counselling, 42(4), 423-435. doi: 10.1080/03069885.2014.886672

Haines, M., Haubenreiser, J., Dollinger, R., Frazier, L., Gordon, K., Havasi, A. ... Leino, V. (2008). American College Health Association National College Health Assessment: Reference group executive summary. Retrieved from https://www.acha.org/ncha Hainline, B., Bell, L., \& Wilfert, M. (2014). Substance use and abuse. In G. T. Brown, B. Hainline, E. Kroshus, \& M. Wilfert (Eds.), Mind, body and sport: Understanding and supporting student-athlete mental wellness (pp. 40-45). Indianapolis, IN: National Collegiate Athletic Association.

Harris, S. A., \& Kranz, P. (1991). Small college counseling centers: Changing trends for a new decade, Journal of College Student Psychotherapy, 5(3), 81-89. https://doi.org/10.1300/J035v05n03_06

Hayden, E. W., Kornspan, A. S., Bruback, Z. T., Parent, M. C., \& Rodgers, M. (2013). The existence of sport psychology services among NCAA Division I FBS university athletic departments and counseling centers. The Sport Psychologist, 27(3), 296-304. https://doi.org/10.1123/tsp.27.3.296 
Hill, K., Burch-Ragan, K. M., \& Yates, D. Y. (2001). Current and future issues and trends facing student athletes and athletic programs. New Directions for Student Services, 93, 65-80. https://doi.org/10.1002/ss.6

Hodges, S. (2001). University counseling centers at the twenty first century: Looking forward, looking back. Journal of College Counseling, 4(2), 161-173. https://doi.org/10.1002/j.2161-1882.2001.tb00196.x

Hodges, S. J. (2017). College counseling: Past, present, and future. In S. J. Hodges, K. Sheton, \& M. M. King Lyn (Eds.), The college and university counseling manual: Integrating essential services across the campus (pp. 1-12). New York, NY: Springer.

Howard-Hamilton, M. F., \& Sina, J. A. (2001). How college affects student athletes. New Directions for Student Services, 93, 35-45. https://doi.org/10.1002/ss.3

International Accreditation of Counseling Services (2019). IACS standards for university and college counseling services. Retrieved from https://iacsinc.org/iacs-standards/\#v-c

Jodoin, E. C., \& Ayers, D. F. (2013). Professional norms versus managerialism in campus mental health centers: The experiences of eight clinicians. Journal of Student Affairs Research and Practice, 50(4), 432-449. doi:10.1515/jsarp-2013-0030

Jodoin, E. C., \& Ayers, D. F. (2017). Communication conflict styles, perception of ethical environment, and job satisfaction among college and university counselors. Journal of College Counseling, 20(2), 139-153. doi: 10.1002/jocc.12066

Johnson, C., Powers, P. S., \& Dick, R. (1999). Athletes and eating disorders: The National Collegiate Athletic Association study. International Journal of Eating Disorders, 26(2), 179-188. https://doi.org/10.1002/(SICI)1098-108X(199909)26:2<179::AIDEAT7>3.0.CO;2-Z 
Johnson, M. B. (2017). Becoming a sport psychologist employed by a university athletic department. Journal of Clinical Sport Psychology, 11(1), 53-66. https://doi.org/10.1123/ jcsp.2016-0001

Joy, E., Kussman, A., \& Nattiv, A. (2016). 2016 update on eating disorders in athletes: A comprehensive narrative review with a focus on clinical assessment and management. British Journal of Sports Medicine, 50(3), 154-162. doi:10.1136/bjsports-2015-095735

Kadambi, M., Audet, C. T., \& Knish, S. (2010). Counseling higher education students: Counselors' positive Experiences. Journal of College Student Psychotherapy, 24(3), 213232. doi: $10.1080 / 87568225.2010 .486296$

Kaier, E., DeMarni Cromer, L., Johnson, M. D., Strunk, K, \& Davis, J. L. (2015). Perceptions of mental illness stigma: Comparisons of athletes to nonathlete peers. Journal of College Student Development, 56(7), 735-739. https://doi.org/10.1353/csd.2015.0079

Keeling, R. P., \& Heitzmann, D. (2003). Financing health and counseling services. New Directions for Student Services, 103, 39-58. doi: 10.1002/jocc.12066

Kern, A., Heininger, W., Klueh, E., Salazar, S., Hansen, B., Meyer, T., \& Eisenberg, D. (2017). Athletes connected: Results from a pilot project to address knowledge and attitudes about mental health among college student-athletes. Journal of Clinical Sport Psychology, 11(4), 324-336. https://doi.org/10.1123/JCSP.2016-0028

Khawaja, N. G., \& Stein, G. (2016). Psychological services for asylum seekers in the community: Challenges and solutions. Australian Psychologist, 51(6), 463-471. doi:10.1111/ap.12149 
King Lyn, M. M. (2017). Professional issues in college counseling center staffing. In S. J. Hodges, K. Sheton, \& M. M. King Lyn (Eds.), The college and university counseling manual: Integrating essential services across the campus (pp. 89-107). New York, NY: Springer.

Kitzrow, M. A. (2009). The mental health needs of today's college students: Challenges and recommandations. NASPA Journal, 46(4), 646-660. doi: 10.2202/1949-6605.5037

Koocher, G. P., \& Keith-Spiegel, P. (1998). Ethics in psychology: Professional standards and cases (2nd ed.). New York: Oxford University Press.

Kornspan, A. S., \& Duve, M. A. (2006). A niche and a need: A summary of the need for sport psychology consultants in collegiate sports. Annals of American Psychotherapy, 9(1), 1925.

Kroshus, E. (2017). Stigma, coping skills, and psychological help seeking among collegiate athletes. Athletic Training \& Sports Health Care, 9(6), 254-262. doi: 10.3928/1942586420171010-02

Leffingwell, T. R., Wiechman, S. A., Smith, R. E., Smoll, F. L., \& Christensen, D. S. (2001). Sport psychology training within a clinical psychology program and a department of intercollegiate athletics. Professional Psychology: Research and Practice, 32(5), 531536. doi: 10.1037/0735-7028.32.5.531

Leigh, I. W., Powers, L., Vash, C., \& Nettles, R. (2004). Survey of psychological services to clients with disabilities: The need for awareness. Rehabilitation Psychology, 49(1), 4854. doi: 10.1037/0090-5550.49.1.48 
LeViness, P., Bershad, C., Gorman, K., Braun, L., \& Murray, T. (2018). The Association for University and College Counseling Center Directors annual survey - public version 2018. Obtained from https://www.aucccd.org/director-surveys-public

Li, H., Moreland, J. J., Peek-Asa, C., \& Yang, J. (2017). Preseason anxiety and depressive symptoms and prospective injury risk in collegiate athletes. The American Journal of Sports Medicine, 45(9), 2148-2155. doi: 10.1177/0363546517702847

López, R. L., \& Levy, J. J. (2013). Student athletes' perceived barriers to and preferences for seeking counseling. Journal of College Counseling, 16(1), 19-31. https://doi.org/10.1002/j.2161-1882.2013.00024.X

Loughran, M., Etzel, E. F., \& Hankes, D. (2014). Ethical issues in work with collegiate studentathletes. In E. F. Etzel \& J. C. Watson II (Eds.), Ethical issues in sport, exercise, and performance psychology (pp. 37-48). Morgantown, WV: FiT Publishing.

Lubker, J. R., Visek, A. J., Watson, J. C., \& Singpurwalla, D. (2012). Athletes' preferred characteristics and qualifications of sport psychology practitioners: A consumer market analysis. Journal of Applied Sport Psychology, 24(4), 465-480. doi:

$10.1080 / 10413200.2012 .694968$

Marcia, J. E. (1966). Development and validation of ego identity status. Journal of Personality and Social Psychology, 3(5), 551-558. doi: 10.1037/h0023281

Martens, M. P., Kilmer, J. R., \& Beck, N. C. (2009). Alcohol and drug use among college athletes. In E. F. Etzel (Ed.), Counseling and psychological services for college studentathletes (pp. 451-475). Morgantown, WV: Fitness Information Technology. 
Martin, S. B. (2005). High school and college athletes' attitudes toward sport psychology consulting. Journal of Applied Sport Psychology, 17(2), 127-139. https://doi.org/10.1080/10413200590932434

Martin, S. B., \& Andersen, M. B. (2014). Helping intercollegiate athletes in and out of sport. In J. L. Van Raalte \& B. W. Brewer (Eds.), Exploring sport and exercise psychology (3rd ed., pp. 379-400). Washington, DC: American Psychological Association.

McAllister, M., Wynaden, D., Happell, B., Flynn, T., Walters, V., Duggan, R. ... \& Gaskin, C. (2014). Staff experiences of providing support to students who are managing mental health challenges: A qualitative study from two Australian universities. Advances in Mental Health, 12(3), 192-201. https://doi.org/10.1080/18374905.2014.11081897

McDuff, D. R., Morse, E. D., \& White, R. K. (2005). Professional and collegiate team assistance programs: Services and utilization patterns. Clinics in Sports Medicine, 24(4), 943-958. doi:10.1016/j.csm.2005.02.001

McGuire, L. C., Ingram, Y. M., Sachs, M. L., \& Tierney, R. T. (2017). Temporal changes in depression symptoms in male and female collegiate student-athletes. Journal of Clinical Sport Psychology, 11(4), 337-351. https://doi.org/10.1123/JCSP.2016-0035

Miller, S., Ringeisen, H., Munoz, B., Hedden, S. L., Colpe, L. J., Rohloff, H., \& Embry, V. (2016). Correlates of mental health service use among young adults with mental illness: Results from the national survey on drug use and health. Psychiatric Services, 67(6), 642649. https://doi.org/10.1176/appi.ps.201400486

Moore, M. (2016). Do psychosocial services make the starting lineup? Providing services to student-athletes. Journal of Amateur Sport, 2(2), 50-74. https://doi.org/10.17161/jas.v0i0.5046 
Moore, M. (2017). Stepping outside of their comfort zone: Perceptions of seeking behavioral health services amongst college athletes. Journal of Issues in Intercollegiate Athletics, 2017(Special Issue), 130-144.

Moreland, J. J., Coxe, K. A., \& Yang, J. (2018). Collegiate athletes' mental health services utilization: A systematic review of conceptualizations, operationalizations, facilitators, and barriers. Journal of Sport and Health Science, 7(1), 58-69. https://doi.org/10.1016/j.jshs.2017.04.009

Mowbray, C. T., Megivern, D., Mandiberg, J. M., Strauss, S., Stein, C. H., Collins, K. ... \& Lett, R. (2006). Campus mental health services: Recommendations for change. American Journal of Orthopsychiatry, 76(2), 226-237. doi: 10.1037/0002-9432.76.2.226

Much, K., Wagener, A. M., \& Hellenbrand, M. (2010). Practicing in the 21 st century college counseling center. Journal of College Student Psychotherapy, 24(1), 32-38. doi: $10.1080 / 87568220903400138$

National Collegiate Athletic Association (2016). Interassociation consensus document: Mental health best practices. Indianapolis, IN: National Collegiate Athletic Association.

Neal, T. L., Diamond, A. B., Goldman, S., Klossner, D., Morse, E. D., Pajak, D. E. ... Welzant, V. (2013). Inter-association recommendations for developing a plan to recognize and refer student-athletes with psychological concerns at the collegiate level: An executive summary of a consensus statement. Journal of Athletic Training, 48(5), 716-720. doi: $10.4085 / 1062-6050-48.4 .13$

Nelson, T. F., \& Wechsler, H. (2001). Alcohol and college athletes. Medicine \& Science in Sports \& Exercise, 33(1), 43-47. 
Pérez-Rojas, A. E., Lockard, A. J., Bartholomew, T. T., Janis, R. A., Carney, D. M., Xiao, H., ... Hayes, J. A. (2017). Presenting concerns in counseling centers: The view from clinicians on the ground. Psychological Services, 14(4), 416-427. http://dx.doi.org/10.1037/ser0000122

Petitpas, A. J., \& Tinsley, T. M. (2014). Counseling interventions in applied sport psychology. In J. L. Van Raalte \& B. W. Brewer (Eds.), Exploring sport and exercise psychology $\left(3^{\text {rd }}\right.$ ed., pp. 241-259). Washington, DC: American Psychological Association.

Pierce, R. A. (1969). Athletes in psychotherapy: How many, how come? Journal of the American College Health Association, 17(3), 244-249.

Pinkerton, R., Hinz, L., \& Barrow, J. (1989).The college student-athlete: Psychological considerations and interventions. Journal of American College Health, 37(5), 218-226. https://doi.org/10.1080/07448481.1989.9939063

Proctor, S. L., \& Boan-Lenzo, C. (2010). Prevalence of depressive symptoms in male intercollegiate student-athletes and nonathletes. Journal of Clinical Sport Psychology, 4(3), 204-220. https://doi.org/10.1123/jcsp.4.3.204

Radloff, L. S. (1977). The CES-D scale: A self-report depression scale for research in the general population. Applied Psychological Measurement, 1, 385-401. https://doi.org/10.1177/014662167700100306

Ren, Z., Wang, H., \& Zhang, W. (2017). Experiences in disaster-related mental health relief work: An exploratory model for the interprofessional training of psychological relief workers. Journal of Interprofessional Care, 31(1), 35-42. http://dx.doi.org/10.1080/13561820.2016.1233097 
Rexroat, M., \& Hollomon, N. (2014). NCAA student-athlete substance use study: Executive summary August 2014. Obtained from http://www.ncaa.org/about/resources/research

Roberts, C. M., Faull, A. L., \& Tod, D. (2017). Blurred lines: Performance enhancement, common mental disorders and referral in the U.K. athletic population. Frontiers in Psychology, 7, 1-13. doi: 10.3389/fpsyg.2016.01067

Rogers, C. R. (1961). On becoming a person. Boston, MA: Houghton Mifflin.

Sandstrom, A. (2012). Student athlete perception of mental health support at Division II institutions. Masters thesis obtained from https://d-commons.d.umn.edu:8443/bitstream/ 10792/350/1/Sandstrom,\%20Amy.pdf

Schlimmer, E., \& Chin, J. W. (2018). Addressing psychiatric disorders among student-athletes: Challenges facing mental health professionals in NCAA Division I athletics. The International Journal of Sport and Society, 10(1), 49-66. http://doi.org/10.18848/21527857/CGP/v10i01/49-66

Schuch, F. B. (2015). Depression in athletes or increased depressive symptoms in athletes? Current Sports Medicine Reports, 14(3), 244. doi: 10.1249/JSR.0000000000000151

Schwartz, V. (2013). College mental health at the cutting edge? Journal of College Student Psychotherapy, 27(2), 96-98. doi: 10.1080/87568225.2013.766094

Schwartz, V., \& Kay, J. (2009). The crisis in college and university mental health. Psychiatric Times, 26(10), 32-34.

Selby, R., Weinstein, H. M., \& Bird, T. S. (1990). The health of university athletes: Attitudes, behaviors, and stressors. Journal of American College Health, 39(1), 11-18. https://doi.org/10.1080/07448481.1990.9936208 
Sharkin, B. S. (2004). Assessing changes in categories but not severity of counseling center clients' problems across 13 years: Comment on Benton, Robertson, Tseng, Newton, and Benton (2003). Professional Psychology: Research and Practice, 35(3), 313-315. https://doi.org/10.1037/0735-7028.35.3.313

Stone, G. L., Vespia, K. M., \& Kanz, J. E. (2000). How good is mental health care on college campuses? Journal of Counseling Psychology, 47(4), 498-510. doi: 10.1037//00220167.47.4.498

Storch, E. A., Storch, J. B, Killiany, E. M., \& Roberti, J. W. (2005). Self-reported psychopathology in athletes: A comparison of intercollegiate student-athletes and nonathletes. Journal of Sport Behavior, 28(1), 86-98.

Stukenberg, K. W., Dacey, C. M., \& Nagy, M. S. (2006). Psychotherapy services provided by a college counseling center: Continuity through change over 37 years. Journal of College Student Psychotherapy, 20(4), 53-70. doi:10.1300/J035v20n04_06

Sudano, L. E., Collins, G., \& Miles, C. M. (2017). Reducing barriers to mental health care for student-athletes: An integrated care model. Families, Systems, \& Health, 35(1), 77-84. http://dx.doi.org/10.1037/fsh0000242

Sudano, L. E., \& Miles, C. M. (2017). Mental health services in NCAA Division I athletics: A survey of head ATCs. Sports Health: A Multidisciplinary Approach, 9(3), 262-267. doi: $10.1177 / 1941738116679127$

Tomalski, J., Clevinger, K., Albert, E., Jackson, R., Wartalowicz, K., \& Petrie, T. A. (2019). Mental health screening for athletes: Program development, implementation, and evaluation. Journal of Sport Psychology in Action, 10(2), 121-135. doi:

$10.1080 / 21520704.2019 .1604589$ 
Vespia, K. M. (2007). A national survey of small college counseling centers: Successes, issues, and challenges. Journal of College Student Psychotherapy, 22(1), 17-40. doi: 10.1300/J035v22n01_03

Watkins, D. C., Hunt, J. B., \& Eisenberg, D. (2012). Increased demand for mental health services on college campuses: Perspectives from administrators. Qualitative Social Work, 11(3), 319-337. doi: 10.1177/1473325011401468

Watson, J. C. (2003). Overcoming the challenges of counseling college student athletes. ERIC Digest, No. EDO-CG-03-01. Obtained from https://www.counseling.org/resources/ library/ERIC\%20Digests/2003-01.pdf

Watson, J. C. (2005). College student-athletes' attitudes toward help-seeking behavior and expectations of counseling services. Journal of College Student Development, 46(4), 442449. doi: $10.1353 / \mathrm{csd} .2005 .0044$

Way, W. C., Coker-Cranney, A. M., \& Watson II, J. C. (2020). "So many mental health issues go unsaid": Implications for best practice guidelines from student-athletes' perspectives about service availability. Journal of Clinical Sport Psychology, 14(3), 305-324. https://doi.org/10.1123/jcsp.2019-0051

Williamson, E. G. (1939). How to counsel students: A manual of techniques for clinical counselors. New York, NY: McGraw-Hill.

Wolanin, A. T. (2007). Clinical sport psychology services based in a doctoral training clinic. Journal of Clinical Sport Psychology, 1(3), 270-280. https://doi.org/10.1123/jcsp.1.3.270 Wolanin, A., Hong, E., Marks, D., Panchoo, K., \& Gross, M. (2016). Prevalence of clinically elevated depressive symptoms in college athletes and differences by gender and sport. British Journal of Sports Medicine, 50(3), 167-171. doi: 10.1136/bjsports-2015-095756 
Wrisberg, C. A., Simpson, D., Loberg, L. A., Withycombe, J. L., \& Reed, A. (2009). NCAA Division-I student-athletes' receptivity to mental skills training by sport psychology consultants. The Sport Psychologist, 23(4), 470-486. https://doi.org/10.1123/tsp.23.4.470

Yang, J., Peek-Asa, C., Corlette, J. D., Cheng, G., Foster, D. T., \& Albright, J. (2007). Prevalence of and risk factors associated with symptoms of depression in competitive collegiate student athletes. Clinical Journal of Sport Medicine, 17(6), 481-487. doi: 10.1097/JSM.0b013e31815aed6b

Yusko, D. A., Buckman, J. F., White, H. R., \& Pandina, R. J. (2008). Alcohol, tobacco, illicit drugs, and performance enhancers: A comparison of use by college student athletes and nonathletes. Journal of American College Health, 57(3), 281-290. doi:

10.3200/JACH.57.3.281-290

Zillmer, E. A. \& Gigli, R. W. (2007). Clinical sport psychology in intercollegiate athletics. Journal of Clinical Sport Psychology, 1(3), 210-222. https://doi.org/10.1123/jcsp.1.3.210 